\title{
Characterization of ENTH domain proteins and their interaction with SNAREs in S. cerevisiae
}

\author{
Dissertation \\ zur Erlangung des Doktorgrades \\ der Mathematisch-Naturwissenschaftlichen Fakultäten \\ der Georg-August-Universität zu Göttingen
}

vorgelegt von

Subbulakshmi Chidambaram

aus Dharmapuri (Indien)

Göttingen 2005 
D7

Referent:

Prof. Dr. Dr. h. c. Kurt von Figura

Korreferent:

PD Dr. Stefan Irniger

Tag der mündlichen Prüfung:

08.07.2005 


\section{Contents}

\section{Abbreviations}

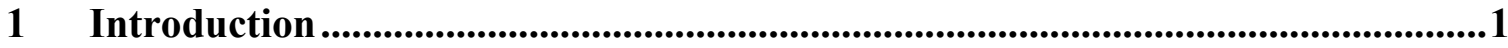

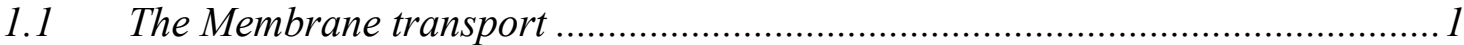

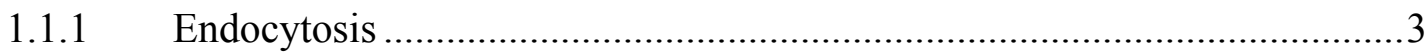

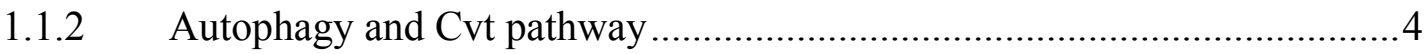

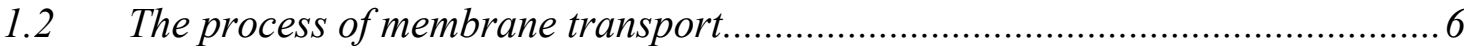

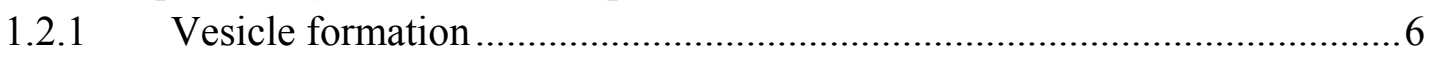

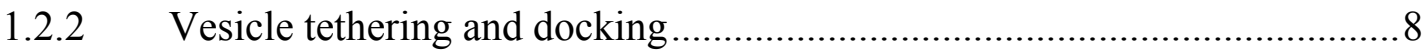

1.3 Molecular mechanism of membrane fusion .................................................... 9

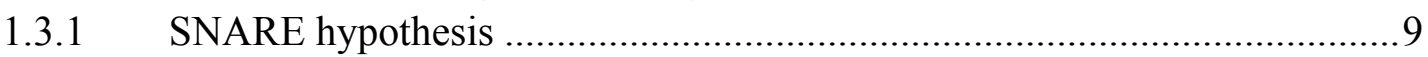

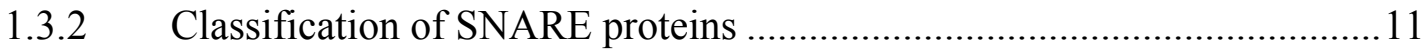

1.3.3 Function of N-terminal domains of SNAREs ......................................... 12

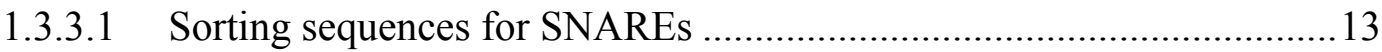

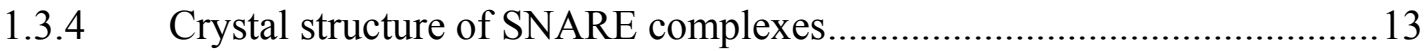

1.3.5 Mechanics of membrane fusion .............................................................. 15

1.4 Biosynthetic transport to the yeast vacuole ......................................................... 16

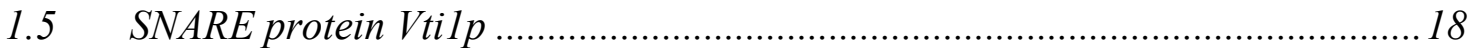

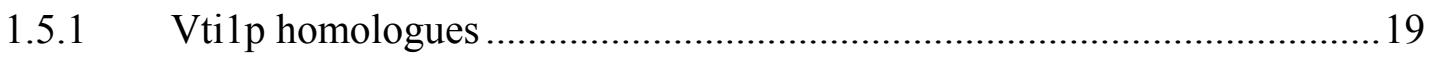

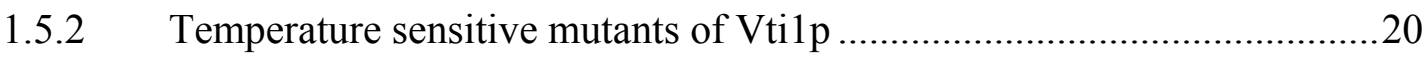

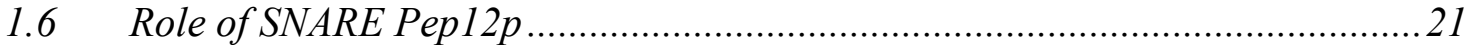

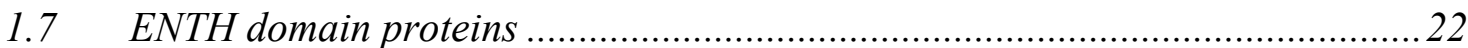

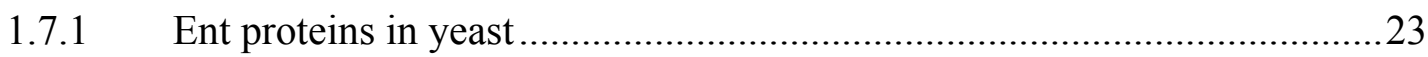

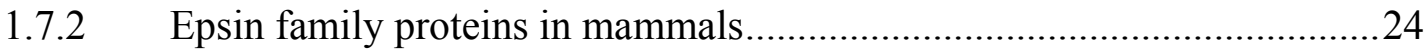

1.7.3 Membrane curvature by ENTH domain....................................................26

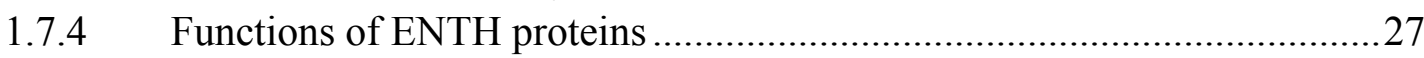

1.7.5 ENTH domains interact with SNARE proteins .....................................27

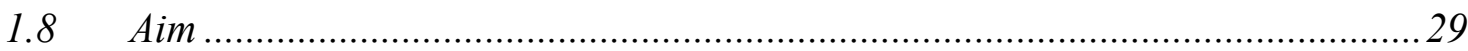

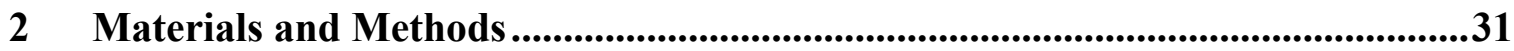

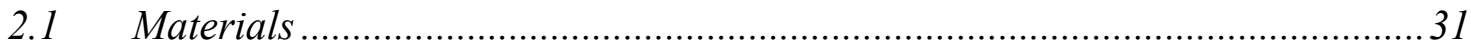

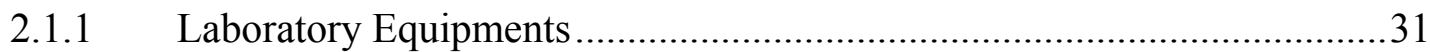

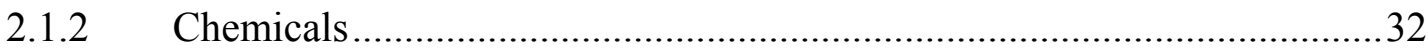

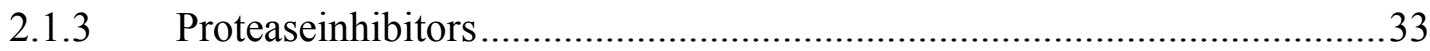

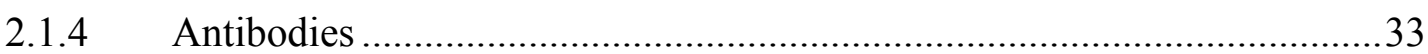

2.1.5 Enzymes, Nucleotides and Standards ........................................................ 34

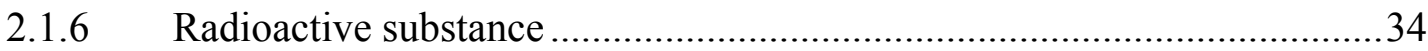




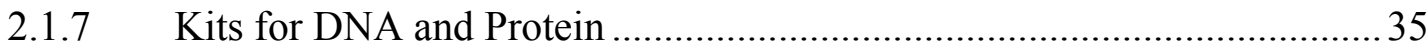

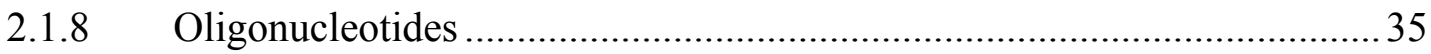

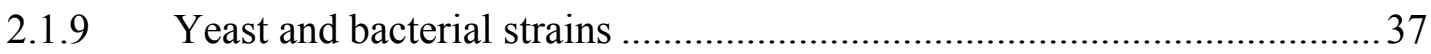

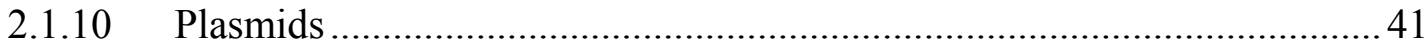

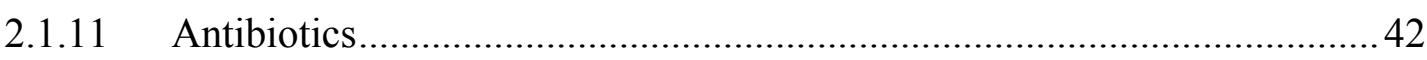

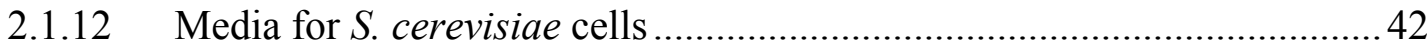

2.1.13 Media for Escherichia coli .................................................................. 44

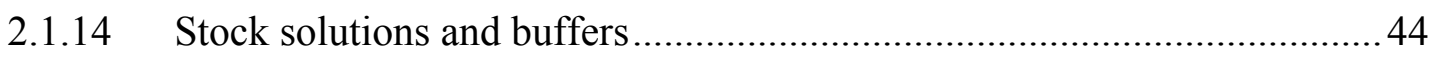

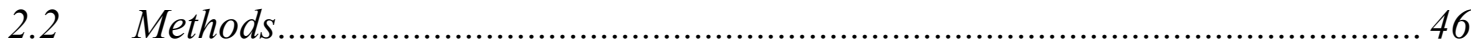

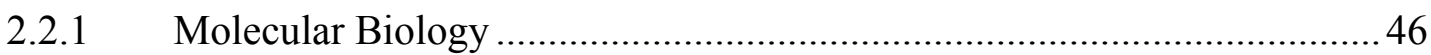

2.2.1.1 Preparation of electrocompetent $E$. coli.......................................... 46

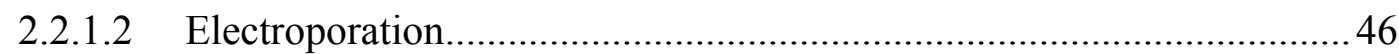

2.2.1.3 Isolation of DNA from $E$. coli ......................................................... 46

2.2.1.4 Determination of the concentration of DNA …................................. 47

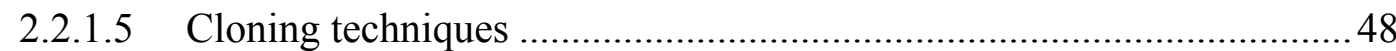

2.2.1.5.1 Polymerase Chain Reaction (PCR) .............................................. 48

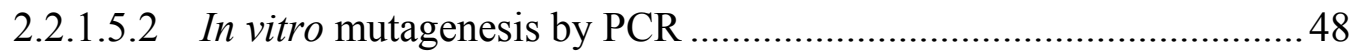

2.2.1.5.3 Phenol Extraction and Ethanol precipitation .................................. 50

2.2.1.5.4 Restriction endonuclease (RE) digestion of DNA .........................5 50

2.2.1.5.5 Agarose gel electrophoresis of DNA ............................................... 51

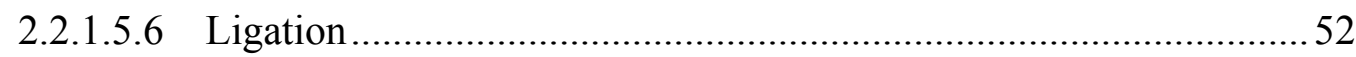

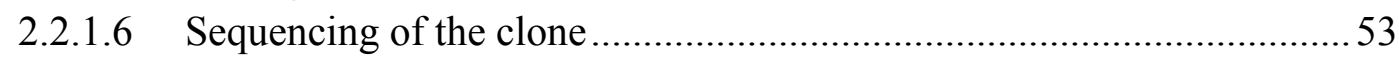

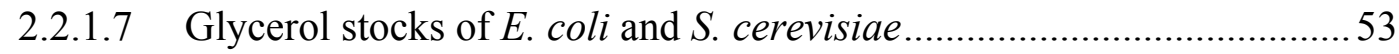

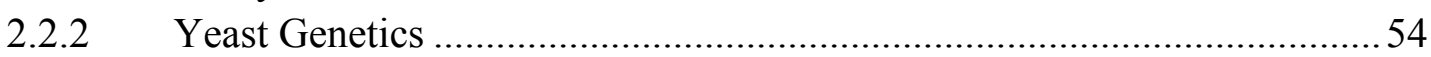

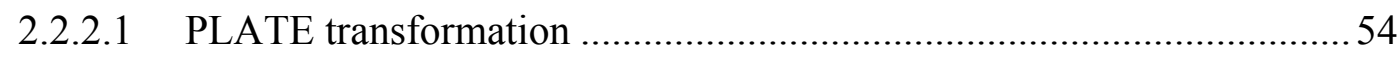

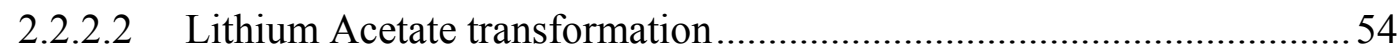

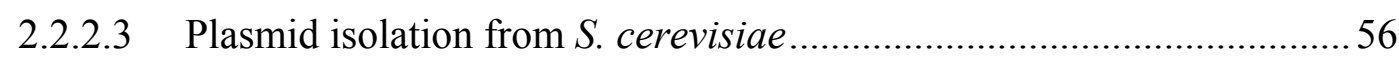

2.2.2.4 Isolation of yeast genomic DNA ......................................................56

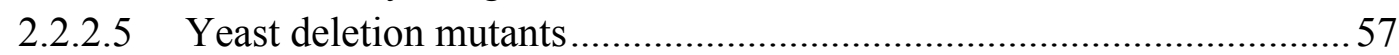

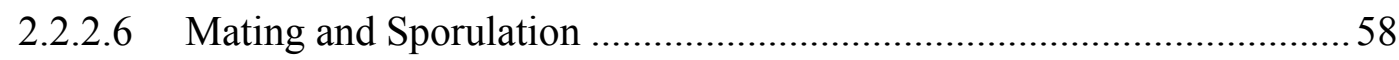

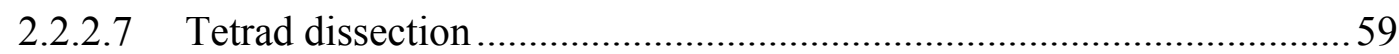

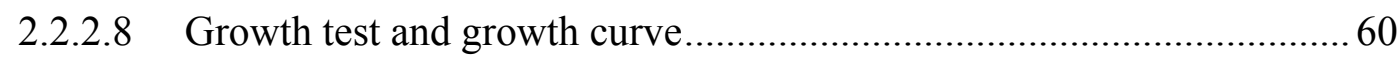

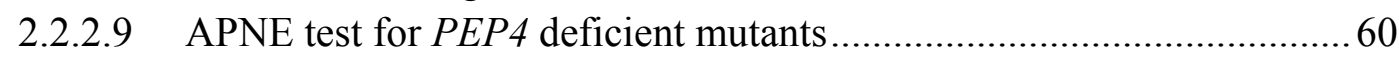

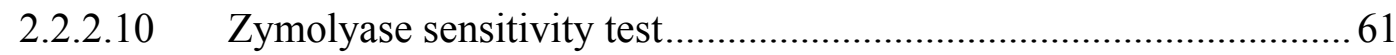

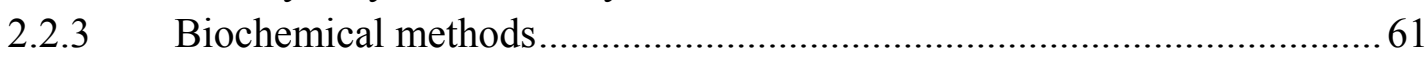

2.2.3.1 Preparation of protein extract from yeast cells ...................................... 61

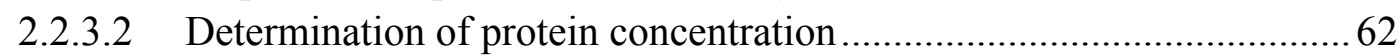

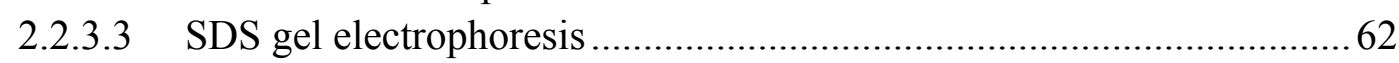

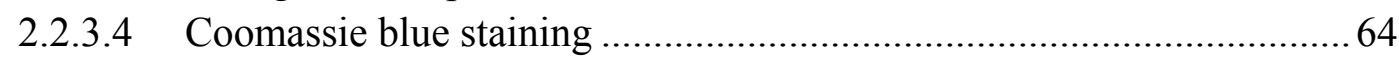

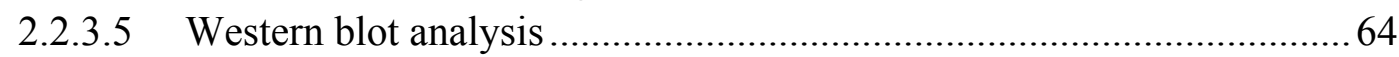

2.2.3.6 Kar2p/BiP secretion test (TCA precipitation) .....................................66 66

2.2.3.7 Cross linking of antisera to Protein A/G Sepharose beads .....................67 67

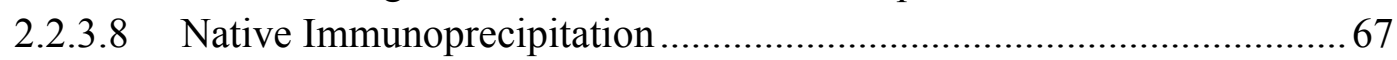


2.2.3.9 "Pulse-Chase" Immunoprecipitaion.....................................................69

2.2.3.10 Purification of Ent3p-Strep tag fusion protein .................................. 72

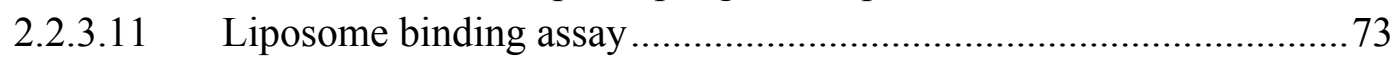

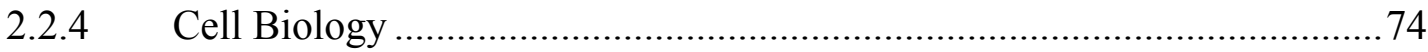

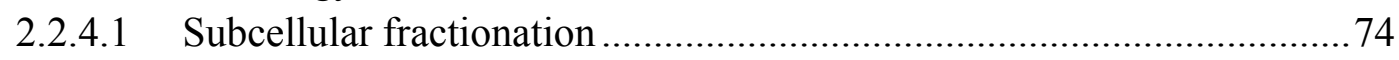

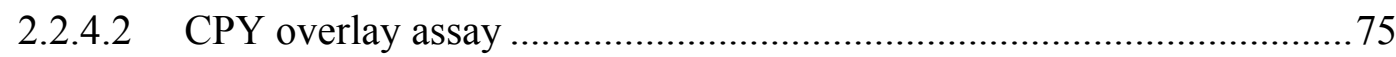

2.2.4.3 Aminopeptidase I maturation test ....................................................... 75

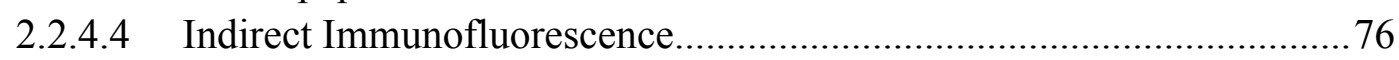

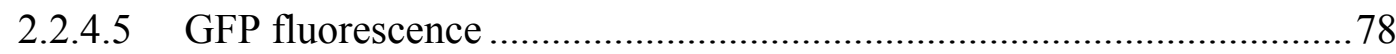

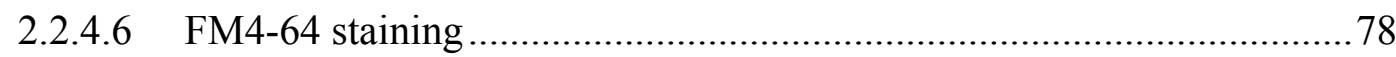

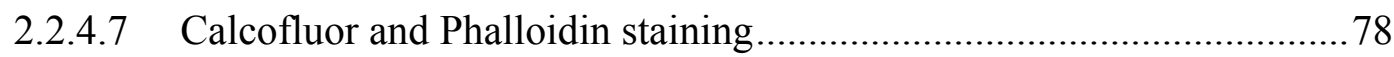

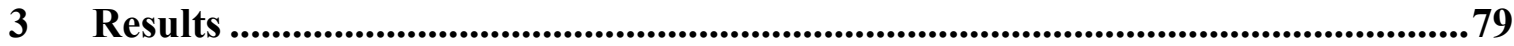

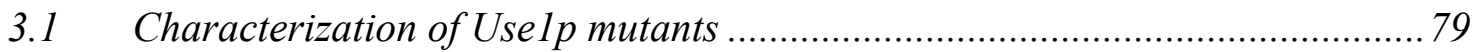

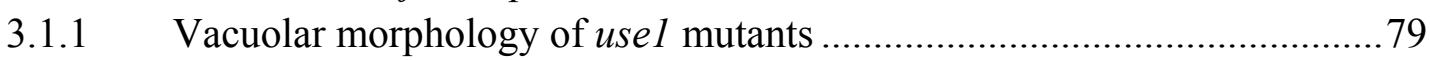

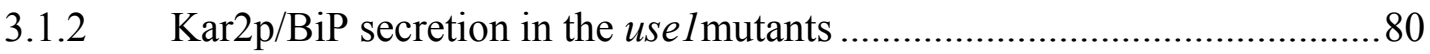

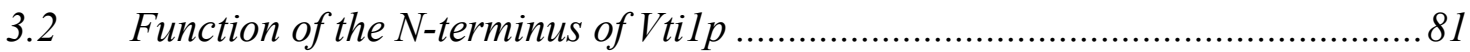

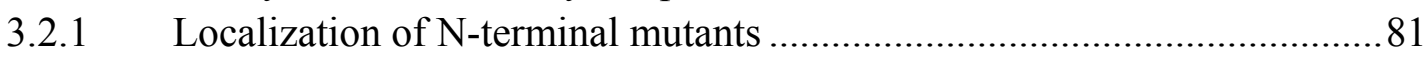

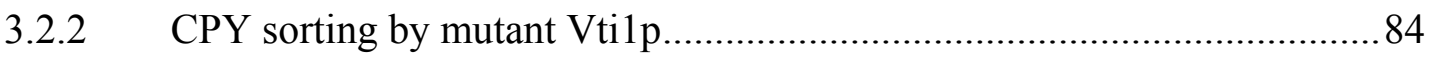

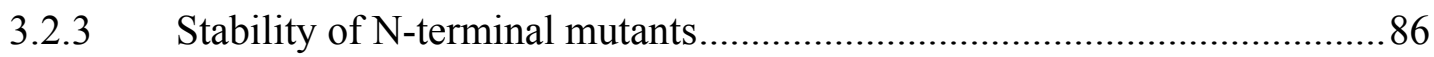

3.2.4 vtiQ29RW79Rp is not degraded by Vacuolar proteases............................87

3.2.5 Polyubiquitination is required for $v t i Q 29 R W 79 R p$ degradation ..................87

3.3 Characterization of Ent proteins in S.cerevisiae ............................................. 89

3.3.1 Role of Ent proteins in the trafficking of CPY and ALP ..........................89

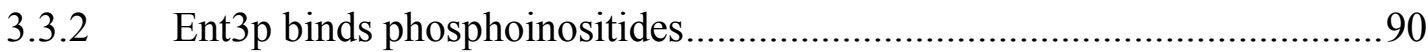

3.3.3 Localization of Ent3p and Ent5p in wildtype and in mutant cell..............91

3.3.3.1 Localization of endogenous Ent3p using antibody against Ent3p ........91

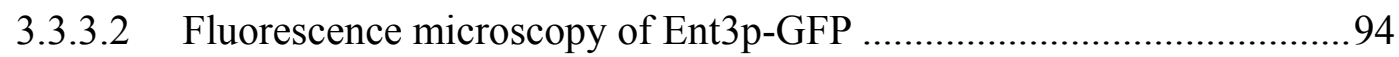

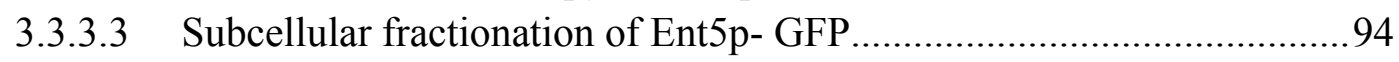

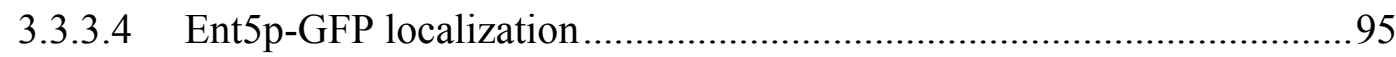

3.3.4 Overexpression of Ent3p C-terminus and Ent3p in vtil mutants...............97

3.3.5 Vacuolar morphology of ent mutants by FM4-64 staining ........................98

3.3.6 Genetic interaction of Ent proteins with Vtilp .........................................99

3.3.6.1 CPY pathway in vtil mutants with ent deletion....................................99

3.3.6.2 ALP pathway in $v t i 1$ mutants with ent deletions ................................ 100

3.3.6.3 Synthetic growth defects of ent deletions in vtil-2 .............................101

3.3.7 Cell wall defects in ent3 $\Delta$ ent $5 \Delta$ mutants ............................................... 102

3.3.7.1 Abnormal cell shapes in ent $3 \Delta$ ent $5 \Delta$............................................. 102

3.3.7.2 Irregular distribution of Chitin and Actin assembly in ent $3 \Delta e n t 5 \Delta . . . .103$

3.3.7.3 Localization of Chs3p-GFP in ent mutants......................................... 105

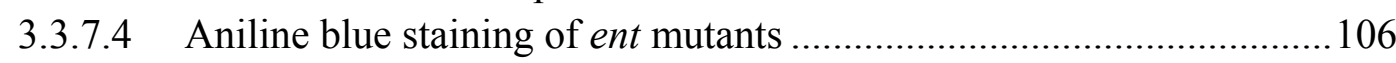

3.3.7.5 Growth defects caused by cell wall perturbing agents ........................107 


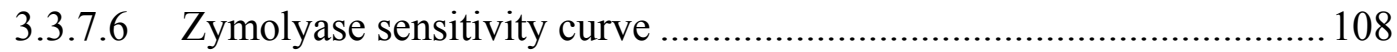

3.3.8 Interaction of Ent3p with Pep12p and Syn8p ........................................ 109

3.3.8.1 Two hybrid interactions of Ent3p .................................................... 109

3.3.8.2 Pep12p and vti1-2p are stabilized in ent $3 \Delta$ cells ............................... 110

3.3.8.3 Localization of Pep12p in ent deletion cells ....................................... 111

3.3.8.4 Synthetic growth defect of pep12 deletion in ent mutants................... 112

3.3.8.5 vti1-2p was destabilized in ent $5 \Delta$.................................................. 112

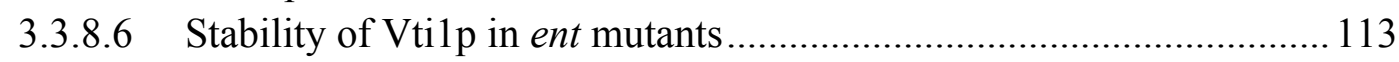

3.3.8.7 Subcellular distribution of Vtilp in ent mutants................................ 114

3.3.8.8 Vti1p Immunofluorescence in ent mutants ......................................... 114

3.3.9 The composition of endosomal SNARE complex in ent $3 \Delta$ ent $5 \Delta$............ 115

3.3.10 Retrograde transport of A-ALP and Vps10p ........................................ 116

3.3.11 Role of Ent proteins in pApe1p processing ........................................ 117

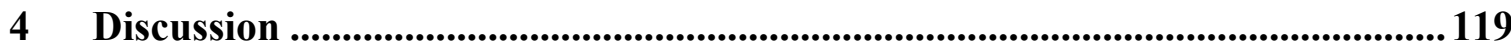

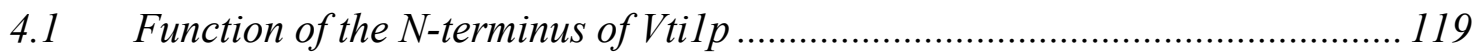

4.2 Interaction of ENTH domain with SNARE proteins .................................... 121

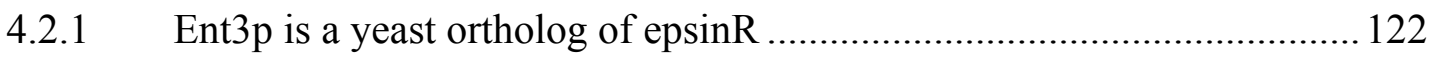

4.2.2 Role of Ent proteins in the TGN-endosome trafficking ........................ 123

4.2.3 Consequences of the interaction between ENTH domains and SNAREs 124

4.2.4 Characterization of ent mutants ........................................................ 126

4.2.5 Ent3p is required for the anterograde transport of Pep12p and vti1-2p... 128

4.2.6 Role of Ent proteins in processing of pApe1p ...................................... 130

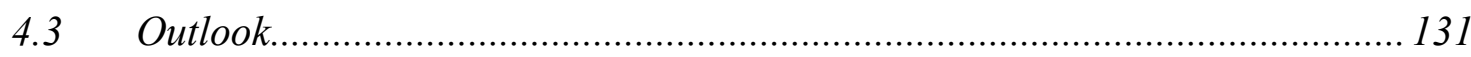

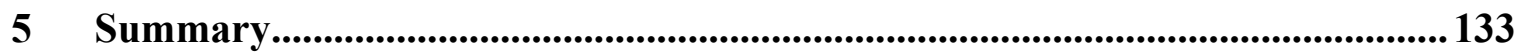

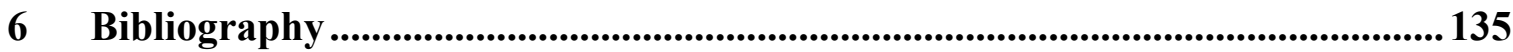




\section{Abbreviations}

$\begin{array}{ll}\text { AA } & \text { Amino acid } \\ \text { ALP } & \text { Alkaline Phosphatase } \\ \text { Amp } & \text { Ampicillin } \\ \text { API } & \text { Aminopeptidase I } \\ \text { APNE } & \text { N-Acetyl-phenylalanin- } \beta \text {-naphtylester } \\ \text { APS } & \text { Ammonium peroxodi sulphate } \\ \text { ATP } & \text { Adenosine -Triphosphate } \\ \text { bp } & \text { Base pairs } \\ \text { BSA } & \text { Bovine Serum Albumin } \\ \text { cDNA } & \text { Complenmentary DNA } \\ \text { CPY } & \text { Carboxypeptidase Y } \\ \text { DAPI } & \text { 4'-6-Diamino-2-phenylindol-dihydrochloride } \\ \text { ddH }{ }_{2} \mathrm{O} & \text { Double distilled water } \\ \text { DMP } & \text { Dimethyl-pimelinediimidat-dihydrochloride } \\ \text { DMSO } & \text { Dimethylsulfoxide } \\ \text { DNA } & \text { Deoxyribonucleicacid } \\ \text { dNTPs } & \text { Deoxynucleosidetriphosphate (dATP, dGTP, dCTP, dTTP) } \\ \text { ds } & \text { Double strand } \\ \text { DTT } & \text { Dithiothreitol } \\ \text { E. coli } & \text { Escherichia coli } \\ \text { EDTA } & \text { Ethylenediamintetraacetate-Disodium salt } \\ \text { ER } & \text { Endoplasmic Reticulum } \\ \text { EtOH } & \text { Ethanol } \\ \text { Fig } & \text { Figure } \\ \text { GFP } & \text { Green fluorescent protein } \\ \text { GST } & \text { Glutathione-S-Transferase } \\ \text { HA } & \text { hours } \\ & \end{array}$


HEPES N-2-Hydroxyethylpiperazin-N'-2-ethanesulfonic acid

HPLC High performance liquid chromatogryphy

HRP Horseradish-Peroxidase

IgG Immunglobulin $\mathrm{G}$

IP Immuno-precipitation

IPTG Isopropyl- $\alpha$-D-Thiogalactopyranoside

Kan Kanamycin

$\mathrm{kb} \quad$ Kilobase

kDA Kilodalton

1 Liter

LB Luria Bertani

M molar

$\mathrm{mA} \quad$ Milliampere

mg Milligram

min Minute

$\mathrm{ml} \quad$ Milliliter

$\mathrm{mM}$ millimolar

MW Molecular weight

nm Nanometer

NSF N-Ethylmaleimid-Sensitive-Factor

nt Nucleotide

$\mathrm{OD}_{600} \quad$ Optical density at $600 \mathrm{~nm}$

PAGE Poly-acrylamide gel electrophoresis

pApe1 Precursor aminopeptidase I

PCR Polymerase chain reaction

PEP4 A gene, which codes for vacuolar proteinase 1

$\mathrm{Pfu} \quad$ Pyrococcus furiosus

$\mathrm{pH} \quad$ Negative logrithm of Hydrogen ion concentration

PMSF Phenylmethylsulfonylfluoride

RNA Ribonucleic acid

rpm revolutions per minute

RT Room temperature 


\begin{tabular}{|c|c|}
\hline Abbreviations & \\
\hline S. cerevisiae & Saccharomyces cerevisiae \\
\hline SDS & Sodium Dodecyl Sulphate/Lauryl Sulphzate \\
\hline $\sec$ & Seconds \\
\hline SNAP & Soluble-NSF-Attachment-Protein \\
\hline SNARE & $\begin{array}{l}\text { Soluble N-ethylmalimide Sensitive factor Attachment protein } \\
\text { receptor }\end{array}$ \\
\hline ss & Single strand \\
\hline Tab. & Table \\
\hline TAE & Tris-Acetat-EDTA-buffer \\
\hline Taq & Thermus aquaticus \\
\hline TCA & Trichloroaceticacid \\
\hline $\mathrm{TE}$ & Tris-EDTA-buffer \\
\hline TEMED & N,N,N',N'-Tetramethylethylendiamine \\
\hline TGN & Trans-Golgi network \\
\hline Tm & Melting temperature \\
\hline Tris & Tris-(hydroxymethyl)-aminomethane \\
\hline ts & temperatursensitive \\
\hline $\mathrm{U}$ & Unit \\
\hline $\mathrm{ON}$ & Overnight \\
\hline UV & Ultraviolet \\
\hline V & Volt \\
\hline $\mathrm{v} / \mathrm{v}$ & volume/volume \\
\hline $\mathrm{w} / \mathrm{v}$ & weight/volume \\
\hline WT & Wildtype \\
\hline$\mu$ & Micro- \\
\hline
\end{tabular}





\section{Introduction}

\subsection{The Membrane transport}

All eukaryotic cells have within them functionally interrelated cellular membranes called "Endomembrane System". The various membranes involved, though interrelated, differ in structure and function. The endomembrane system consists of seven major compartments: the endoplasmic reticulum (ER), the Golgi complex, the trans-Golgi network (TGN), the vacuole (or lysosome in mammals), the plasma membrane (PM), the prevacuolar compartment (PVC), and the endosome (Fig.1) (Sanderfoot and Raikhel, 1999). The endomembrane system plays a very important role in moving materials around the cell, notably proteins and membranes with high fidelity. The movement of the cargo between different compartments is mediated primarily by coated vesicles that are detached from the donor membrane by a process commonly called "budding" and incorporated to the target membrane by docking and fusion. For every compartment, an organelle-specific mechanism exists to recruit and package a correct set of proteins and lipids into vesicles that are destined for transport to an acceptor membrane (Lippincott-Schwartz et al., 2000; Schekman and Orci, 1996). The transport from the ER to either the cell surface or the vacuole is referred to as the 'anterograde pathway'. Some vesicles also carry proteins in the reverse direction which is called as the 'retrograde pathway', is essential for the recovery of proteins that may have escaped from other endomembrane compartments and also for the recycling of the machinery involved in anterograde transport. There are two major pathways for membrane or protein exchange, namely, the Secretory pathway and the Endocytic pathway. 


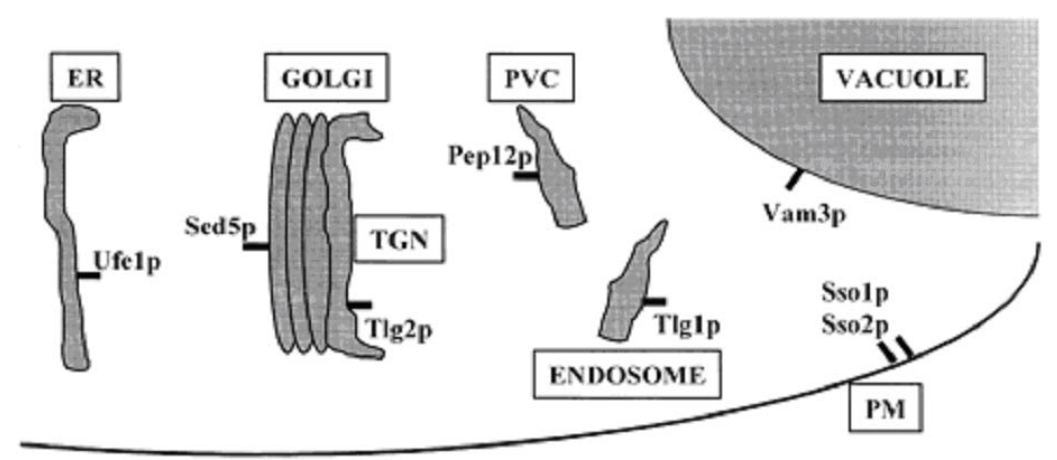

Fig.1. The Endomembrane System of Yeast Secretory pathway (Sanderfoot and Raikhel, 1999)

The secretory pathway is the biosynthetic path for the endomembrane system, which delivers the cargo to various compartments by anterograde pathway. This pathway was originally described in pancreatic exocrine cells (Palade, 1975). Secretion can be of two types, 'constitutive and regulated secretion'. In the constitutive secretion, the cargo is discharged to the cell exterior continuously and in unregulated manner. Most of the cells do it, to form the extracellular matrix and plasma membrane. But in the regulated secretion, the material to be secreted is held within secretory granules and released upon appropriate stimulation, for example, cells producing hormones, digestive enzymes and neurotransmitters (Traub and Kornfeld, 1997). The early secretory system consists of ER and the Golgi complex. Most of the proteins destined for secretion first enter at the ER. The sorting of proteins into specific vesicles are controlled by molecular markings such as signal sequences and glycosylation (Blobel, 1980). The ER-resident proteins carry a signal sequence called 'KDEL', the KDEL proteins which have escaped the ER, are recycled back from the Golgi to ER by COPI vesicles (Lippincott-Schwartz et al., 2000). On the way through the Golgi, newly synthesized glycoproteins are subjected to several post-translational modifications such as ordered remodeling of their N-linked oligosaccharide side chains and biosynthesis of O-linked glycans.

The late secretory system starts at TGN, where the cellular sorting machineries and specific sorting signals in the cargo molecules are responsible for directing the cargo to the plasma membrane (PM), to regulated secretory granules, or to the endosomal/lysosomal system (Le Borgne and Hoflack, 1998). In higher eukaryotes, the proteins glycosylated with mannose-6-phosphate are targeted to the lysosome by the mannose-6-phosphate receptors present in the TGN through the late endosome (Kornfeld 
and Mellman, 1989). In yeast, the Pre-vacuolar compartment (PVC) is the immediate target for the cargoes from the TGN though some proteins bypass the PVC and reach vacuole directly. Integral membrane proteins and secretory proteins are targeted to the plasma membrane and secreted out by exocytosis. In general, the secretory pathway links organelles together to provide a framework by which proteins undergo a series of posttranslational modifications including proteolytic processing, folding and glycosylation (Storrie et al., 2000).

\subsubsection{Endocytosis}

The endocytic pathway moves cargo or membrane surface into cell from outside to cytoplasmic compartments (endosomes, lysosomes etc.). Many critical functions of a cell are mediated by endocytic mechanisms, including the uptake of extra cellular nutrients, maintenance of cell polarity, regulation of cell-surface receptor expression and antigen presentation. Additionally, pathogens such as viruses, toxins and different microorganisms utilize endocytic pathway to get inside the cell (Mukherjee et al., 1997). In mammalian cells, at least five different pathways for endocytic internalization are known: the clathrin-dependent pathway, macropinocytosis, the caveolar pathway, a clathrin- and caveolin-independent pathway, and phagocytosis (Riezman et al., 1997). The most common and best characterized endocytic pathway is receptor dependent clathrinmediated endocytosis.

The pinched off vesicles rapidly lose their coats which leave them unstable, which in turn facilitate fusion of the vesicles with the sorting or early endosomes (EE), the first station of the endocytic pathway (Kornfeld and Mellman, 1989; Mellman, 1996). Early Endosomes are structurally seen as a network of tubules and vesicles throughout the cytoplasm, and their basic function includes the sorting of received molecules (Mellman, 1996). From the EEs the membrane-bound receptors are recycled efficiently back to the PM and the free ligands are further transported for degradation to the late endosomes (LE) or to the lysosomes (Mukherjee et al., 1997). Late endosomes (LE) are responsible for the accumulation and concentration of the cargo after receiving it from the EEs. LEs contain hydrolytically active lysosomal hydrolases and they are considered to be a starting point for the degradative process of foreign material. Mannose 6-Phosphate Receptors (MPRs) concentrate in the LEs from there, they are recycled back to the TGN 
(Mukherjee et al., 1997). Delivery of endocytosed material from the LEs to the lysosomes is thought to occur by fusion of the LEs with the lysosomes, resulting in the digestion of cargo in the lysosomes by low $\mathrm{pH}$ and the lysosomal enzymes (Gruenberg and Howell, 1989; Mellman, 1996). The resulting degradation products are transferred out from the lysosomes to cytosol, where they can be utilized by the cell or alternatively transported out of the cell (Mellman, 1996). Clathrin-independent phagocytosis ("cell eating") refers to the internalization of large $(>0.5 \mu \mathrm{m}$ diameter) particles. Micro-organisms are also internalised by phagocytosis (Mellman, 1996). In mammals, phagocytosis is seen preferentially in cells with specialized roles, such as e.g. macrophages and neutrophils (Mukherjee et al., 1997). In contrast to phagocytosis, pinocytosis ("cell drinking") mediated by clathrin-coated pits is commonly seen in eukaryotic cells. It refers to a constitutive formation of smaller vesicles $(<0.2 \mu \mathrm{m})$ through which extracellular fluid and macromolecules bound to plasma membrane are internalized for further processing. The best characterized type of pinocytosis is receptor-mediated endocytosis which provides a selective uptake of specific macromolecules (Mellman, 1996).

\subsubsection{Autophagy and Cvt pathway}

Auto-phagy (self-eating) is an inducible, catabolic membrane transport pathway which transports bulk cytoplasm and sometimes entire organelles to the lysosome/vacuole for recycling in response to nutrient starvation or during specific physiological conditions (Klionsky and Emr, 2000). There are two major types of autophagy, viz, macroautophagy and microautophagy. The primary morphological difference between these pathways has to do with the site of sequestration and the origin of the sequestering membrane. In macroautophagy, a sequestering double membrane vesicle called 'autophagosome' is formed, de novo from the cytosol (Noda et al., 2002). The outer membrane of the autophagosome fuse with the membrane of vacuole and releases the inner membrane bound 'autophagic body' in the lumen of the vacuole where the hydrolases digest the membrane and process the cargo. But in microautophagy, portions of cytosol or whole organelles are sequestered directly at the surface of the degradative organelle by invagination of the limiting membrane or by septation or protrusion of arm like structures and there is no intermediate transport vesicle.

Cytoplasmic to vacuole targeting (Cvt) pathway is an alternative biosynthetic pathway to the vacuole from the cytoplasm. This process has only been demonstrated in 
Sacchromyces cerevisiae. Most of the vacuolar hydrolases in yeast, reach the vacuole by the secretory pathway except $\alpha$-mannosidase and Aminopeptidase 1 (AP1) which uses the Cvt pathway. Autophagy and Cvt pathways share many components in common localized to a punctuate perivacuolar site, called the pre-autophagosomal structure (PAS), but they are two different distinct processes (Fig.2). Autophagy is catabolic, nonselective and is induced under various starvation conditions whereas Cvt pathway is biosynthetic, constitutive and active under growing conditions. The kinetics of the two pathways is also different. In 1992, studies on the transport process of Aminopeptidase I (AP1) by Klinsky et.al, confirmed the existence of Cvt pathway. The $61 \mathrm{kDa}$ Aminopeptidase precursor (pApe1p) is synthesized in the cytosol and rapid oligomerization leads to homododecameric units as the major cytosolic form of pApelp (Kim et al., 1997). Multiple pApe1p dodecamers unite and form a 'Cvt complex' which finally matures into a double-membranous 'Cvt vesicel'. The Cvt vesicles are targeted to the vacuole where the outer membrane fuses with the vacuole and releases inner membrane bound ' $\mathrm{Cvt}$ body' inside the lumen of vacuole. The vacuolar hydrolases degrade the inner membrane and process the $61 \mathrm{kDa}$ pApe1p into $51 \mathrm{kDa}$ mature Ape $1 \mathrm{p}$ (mApe $1 \mathrm{p}$ ). The maturation of pApe1p is a two step process where a $55 \mathrm{kDa}$ intermediate form appears followed by a 51 kDa mApelp by sequential action of two vacuolar proteinases PrA and PrB (Segui-Real et al., 1995) coded by PEP4 gene. Under starvation conditions, the Cvt complex containing pApelp was found in the autophagosomes (Baba et al., 1997) which showed that Ape $1 \mathrm{p}$ is transported by two distinct (autophagy and Cvt) pathways, controlled by the nutrient conditions. Tor protein and phosphoinositide lipid mediated signaling are known to regulate the switch between the Cvt pathway and autophagy (Kamada et al., 2000; Kihara et al., 2001; Nice et al., 2002). The processing of pApe1p is used as the best marker to study Cvt pathway.

Ape1p is recruited onto Cvt membranes and the Cvt vesicle is formed by homotypic membrane fusion which depends on the SNARE Tlg2p and Vps45p (Abeliovich et al., 1999). For docking and fusion of Cvt vesicles with the vacuole, Vam3p (Darsow et al., 1997) and Vps18p (Rieder and Emr, 1997) are thought to be required. The SNARE complex involved in the vacuolar fusion step is: Ykt6p, Nyv1p, Vtilp, Vam3p and Vamp7p along with the class C Vps protein complex also known as HOPS (Homotypic fusion and vacuole protein sorting) and a Rab family GTPase Ypt7p (Huang and 
Klionsky, 2002). A protein called Cczlp which is an interacting partner of Ypt7p is also required for the homotypic vacuolar fusion and conventional vacuolar hydrolase transport (Kucharczyk et al., 2000).

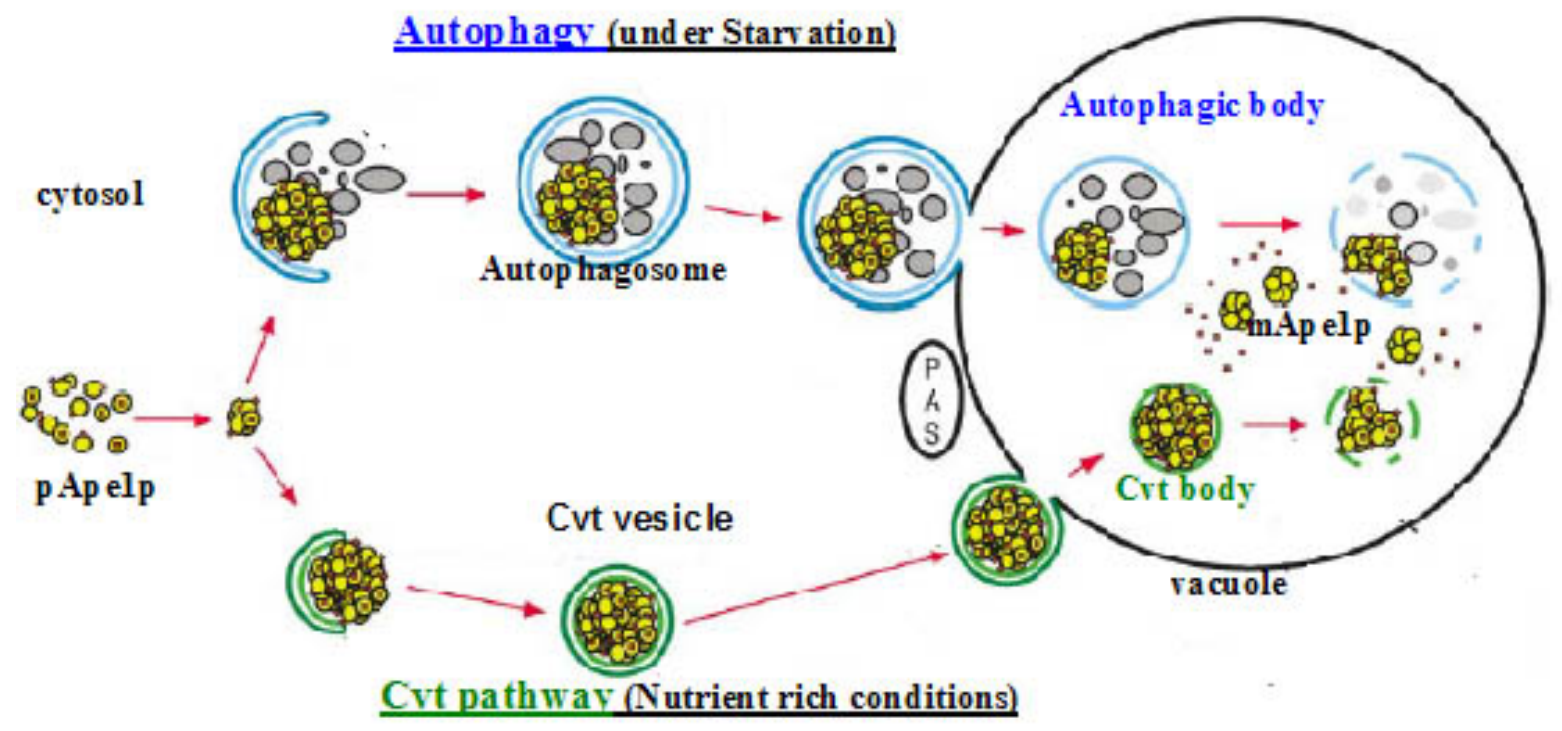

Fig.2. Autophagy and the Cvt pathway in yeast (Levine and Klionsky, 2004)

\subsection{The process of membrane transport}

The vesicle mediated transport is a multi-step process, consists of vesicle formation (budding), targeting, tethering and fusion. The vesicles, with their accompanying protein cargo, are released from the donor organelle in a process called budding (Rothman and Orci, 1996). After budding, interactions of v- and t-SNARE (SNAP receptor) proteins on the surface of the vesicle and acceptor organelle play a role in targeting the vesicle to the appropriate organelle (Rothman, 1994). Upon fusion, vesicle cargo is delivered to the target organelle (Fig.3).

\subsubsection{Vesicle formation}

Vesicle formation requires interaction of many proteins. Small GTPases of ARF (ADPribosylation factor) and Sar (Secretion-associated and Ras-related) families in their GTP bound form, recruit coat proteins like clathrin onto the membrane. Cargo proteins are concentrated at a specialized region called coated pits on the donor membrane and packed into a nascent vesicle. Clathrin assembles into a cage like lattice on membranes, even in the absence of vesicles, which during the process of vesicle formation, polymerizes into a 
basket made out of hexagons and pentagons on vesicles. Vesicular transport within the early secretory pathway is mediated by two types of non-clathrin coated vesicles: COPIand COPII-coated vesicles. COPII is a coat complex which forms a main structure of transport vesicles responsible for forward transport of cargo from the ER to the Golgi complex (Barlowe et al., 1994). COPI vesicles in their turn carry cargo retrograde from the Golgi to the ER and are also involved in the intra-Golgi transport (Letourneur et al., 1994; Orci et al., 1997). Adaptor proteins are required to recruit cargo into coated vesicles. A group of cytosolic heterotetrameric adapter complexes (AP) is involved in the formation of clathrin coated vesicles both in the late secretory and the endocytic pathways. They recognize three distinct sorting signals, two tyrosine based signals (NPXY and YXXØ) and a dileucine sorting signal, for the selection of cargo into clathrincoated vesicles. So far 4 Adaptor Proteins (APs) were identified in mammalian system (Boehm and Bonifacino, 2001; 2002; Kirchhausen, 1999; Robinson and Bonifacino, 2001). Yeast has only three adaptor complexes and lacks AP-4. In mammals, AP-1 is involved in the assortment and the clathrin dependent export of lysosomal enzymes and proteins bound to Mannose-6-Phosphate-Receptor (MPR) from the TGN to the lysosomes (Le Borgne and Hoflack, 1998). Now, AP1 is thought to be involved in the anterograde and retrograde transport between the TGN and the endosome and in traffic to the cell surface (Hinners and Tooze, 2003). In yeast, AP-1 seems to be involved in transport from the TGN to the early Endosome (Stepp et al., 1995). The AP-2 is localized to PM and mediates clathrin dependent endocytosis (Schmid, 1997). AP-3 is involved in the clathrin independent transport from the TGN to the vacuole in yeast (Robinson and Bonifacino, 2001). In contrast to yeast, AP-3 in mammals binds clathrin (Dell'Angelica et al., 1998) and transports proteins to the lysosomes, to some specialized compartments like the melanosomes and to the platlet granules. AP-4 also functions at the TGN and is involved in the basolateral sorting of proteins from the TGN (Dell'Angelica et al., 1999; Simmen et al., 2002).

There are three homologous monomeric clathrin adaptor proteins in yeast and in mammalian cells, GGA-1,-2,-3 (Golgi-localized, $\gamma$-adaptin homologue and ARF-binding) proteins (Boman et al., 2000). They share functional similarities with APs. They are located in TGN and are involved in export of MPRs from TGN to endosome (Puertollano, 2001). In yeast, the double deletion of GGA1/GGA2 showed a defect in transport and 
processing of Carboxypeptidase Y (CPY) (Dell'Angelica et al., 2000; Hirst et al., 2000). In addition, GGA proteins are also required for the sorting of the pre-vacuolar syntaxin Pep12p (Black and Pelham, 2000). AP-1 and GGA proteins co-operate in anterograde transport from the TGN to the vacuole (Costaguta et al., 2001; Hirst et al., 2001).

Thus, Clathrin Coated Vesicles (CCVs) with selected cargo are formed. A protein called dynamin, in its GTP-bound form, assembles into a collar around the neck of deeply invaginated pits. Hydrolysis of GTP bound to dynamin drives the closing of the collar's neck, resulting in the dissociation of dynamin and pinching off of an isolated clathrincoated vesicle (Hinshaw and Schmid, 1995). Amphiphysin recuits dynamin onto the membrane (Owen et al., 1998) and endophillin helps in the final stages of vesicle budding. Synaptojanins and auxilins help in the uncoating of clathrin vesicles. COPI and COPII coats are removed after GTP hydrolysis of ARF and Sar1 respectively.

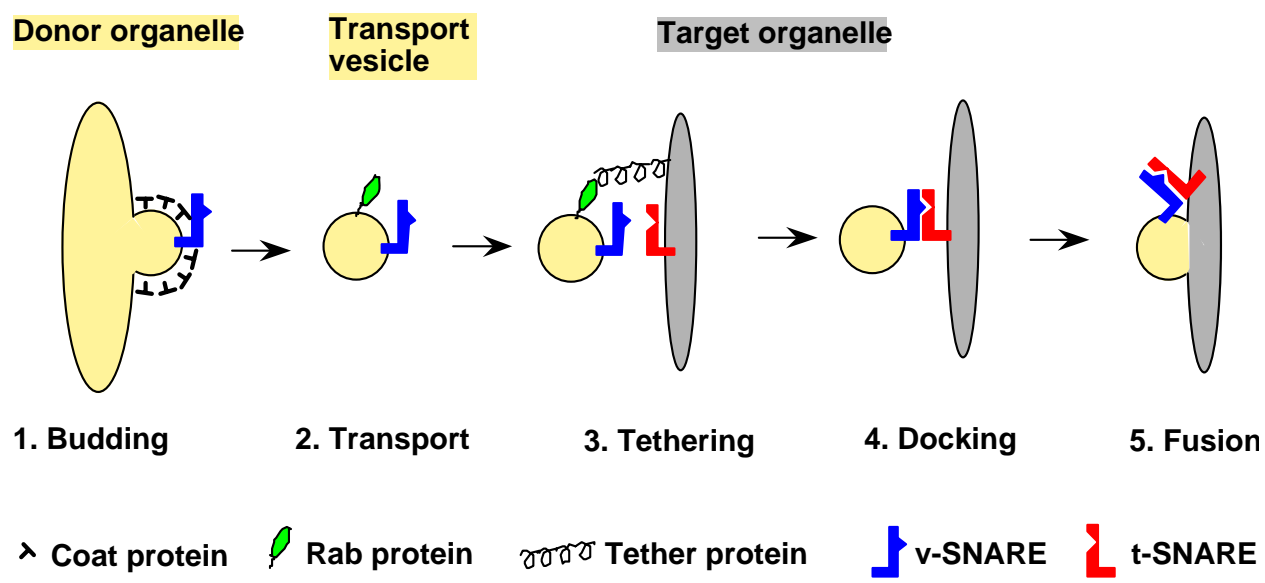

Fig.3. Molecular mechanisms of membrane trafficking

\subsubsection{Vesicle tethering and docking}

The uncoated vesicles may reach their destination by simple diffusion (e.g intra Golgi transport) but for long distances, the movement can be aided by cytoskeletal fibres or by motor proteins. As soon as the vesicle reaches the target membrane, a loose connection (physical contact) between the vesicle and the membrane is formed, which is called as 'Tethering'. Two broad classes of tethering proteins are proposed. A group of 'long coiled-coil proteins' like, Uso1p which is important for tethering ER-derived vesicles (Barlowe, 1997), endosomal EEA1/Vac1p protein (Dumas et al., 2001) and Golgins may be attached to membrane by one end of the coil, using the other end it searches for the 
vesicles passing by and may make a loose attachment with the membrane. Another group consists of 'multisubunit tethering complexes' like COG complex, the exocyst complex, GARP complex, TRAPP I and II, Class C Vps complex and Dsl 1p complex (Whyte and Munro, 2002). The small GTPase Ypt/Rab family proteins, present on the vesicle interacts with the tethering protein in a short time frame and further GTP hydrolysis dissociates the interaction (Cao et al., 1998; Lazar et al., 1997; Stahl et al., 1996). Ypt/Rab proteins seem to be involved in all aspects of vesicle trafficking, localized to specific compartments and are key regulators of membrane trafficking. There are $11 \mathrm{Ypt}$ proteins in yeast (Lazar et al., 1997) and around 60 different Rab proteins in mammalian cells (Bock et al., 2001). During the tethering process, the SNARE proteins (see chapter: 1.3.1) present both on the vesicle and the target membranes bind and form a firm link between the vesicle and the target membrane which is called as 'docking'. The time for the cognate-SNARE interaction is limited by the GTP hydrolysis rate of the Rab proteins (Clague, 1999). The interaction of tether proteins and rabs contributes to specificity.

\subsection{Molecular mechanism of membrane fusion}

\subsubsection{SNARE hypothesis}

In vesicular transport, the very fundamental question is how the vesicles recognize the correct target membrane. The SNARE hypothesis confers a widely accepted explanation of the mechanism of specificity in vesicle targeting (Söllner et al., 1993). SNAREs (Soluble N-Ethylmaleimide-Sensitive factor Attachement Protein Receptors) are a superfamily of small membrane proteins found on both transport vesicles (v-SNARE) and target organelles (t-SNARE). The specific interactions between t- and v-SNAREs ensure that vesicles are targeted to the correct compartment and lead to membrane fusion. SNARE proteins were first implicated in membrane fusion by Rothman group in 1993, when they identified three previously known proteins (synaptobrevin, syntaxin and SNAP-25) as SNAP-receptors from bovine brain extract which are involved in $\mathrm{Ca}^{2+}$ mediated exocytosis of neurotransmitter at the nerve terminal (Söllner et al., 1993). The role of SNAREs in membrane fusion was further confirmed by proteolysis of SNAREs with tetanus and botulinum toxin which blocked neurotransmission (Jahn and Niemann, 1994; Montecucco and Schiavo, 1995). SNARE proteins are type II integral membrane proteins of around $15-40 \mathrm{kDa}$ in size. The original SNARE hypothesis postulates that 
each target membrane contains t-SNAREs that interact with complementary v-SNAREs on the in-coming vesicle membrane, thus each fusion step would be mediated by a unique set of (cognate) SNAREs. This set of SNAREs would function only in one fusion step and the specificity for the interaction was offered by the intrinsic affinity of SNAREs (Rothman, 1994). But, later it has become very clear that at least some SNAREs can function in multiple trafficking steps such as the yeast proteins Sed5p which is involved in 3 different complexes by binding 7 different SNAREs (Nichols and Pelham, 1998) and Vtilp interacts with four different syntaxins (Fischer von Mollard et al., 1997; Fischer von Mollard and Stevens, 1999; Holthuis et al., 1998; Lupashin et al., 1997). These proteins can pair with more than one set of partners and thus participate in the formation of several different SNARE complexes. In 1999, Reinhard Jahn's group showed that noncognate SNARE complexes can be formed in vitro and are very similar to cognate SNARE complexes with respect to biophysical properties, assembly and disassembly. This disproved one of the aspects of original SNARE hypothesis, suggesting that the specificity of membrane fusion is not due to intrinsic specificity of SNARE pairing and (Fasshauer et al., 1999). Studies on Ykt6p or Ykt6p and Vtilp on the transport vesicle showed that they are not sufficient to ensure specificity in membrane traffic (Dilcher et al., 2001). This would support participation of additional proteins in vesicular targeting (Dilcher et al., 2001; Fischer von Mollard et al., 1997; Lazar et al., 1997; Lupashin et al., 1997).

SNAREs are distinguished by a functionally important, conserved stretch of approximately 60 amino acids near their membrane binding region, referred to as SNARE motif (Terrian and White, 1997; Weimbs et al., 1997). Most of the SNAREs have only one SNARE motif with an N-terminal sequence followed by a C-terminal transmembrane domain which anchors it on the membrane. SNARE motives contain sequences capable of forming $\alpha$-helical coiled-coils near the C-terminus (Chapman et al., 1994; Gerst, 1997). These putative coiled-coils are involved in interaction between various SNARE proteins. When the cognate sets of SNARE motives are mixed, a conformational change of the SNARE-motif from an unstructured form towards an $\alpha$ helical bundle occurs spontaneously in a stoichiometric fashion which is a prerequisite for fusion (Sutton et al., 1998). This mechanism docks vesicles to target membranes and the assembly is known as 'SNAREpins' (or trans-SNARE complex). Some SNARE motives 
are constitutively active due to a binding of the N-terminus to the SNARE motif. Some SNAREs, for example SNAP-25 (Synaptosome associated protein of $25 \mathrm{kDa}$ ) have two SNARE motives, without a transmembrane domain. This SNARE is attached to membrane by palmytyl residues (by post translational modifications) present in the cyteine rich region which separates the two SNARE motives (Hess et al., 1992). Others have two conformation, if the SNARE-motif is competent to bind with other SNARE proteins, the conformation is called as 'open conformation', if it is not able to interact, then it is named as 'closed conformation'.

\subsubsection{Classification of SNARE proteins}

In $S$. cerevisiae, so far, 24 SNARE proteins have been identified. In mammalian cells, more than 40 SNAREs were identified. By classical classification, SNAREs are classified on the basis of their localization either on a vesicle ( $\mathrm{v}$-SNARE) or on a target membrane (t-SNARE) (Söllner et al., 1993). t-SNAREs were divided into Syntaxin- and SNAP-25families and Synaptobrevins/VAMPs belonged to the v-SNAREs (Terrian and White, 1997; Weimbs et al., 1997). But, the main disadvantage of this classification is that based on this it would be difficult to assign a function for a SNARE (Jahn and Sudhof, 1999). Also in the case of homotypic vacuolar fusion, there is no difference between the target and vesicle membrane and a single SNARE may be present on several membranes. So, vand t-SNARE classification is incomplete. A further classification was done on the basis of the amino acid sequence similarity between different SNARE motives. When the four SNARE proteins form the complex, the amino acid side chains interact in 16 different layers. The amino acid composition of the 0-layer (ionic layer) at the centre of the SNARE complex is highly conserved with one arginine and three glutamines (Weimbs et al., 1998). One arginine-residue (R) and three glutamine residues (Qa,b,c) form the central layer of each SNARE complex and contribute to the stability. Based on this, SNAREs were reclassified. R-SNAREs contribute Arginine to the ionic layer and QSNAREs contribute Glutamine to the 0-layer. The yeast SNARE, Bet1p, is an exception for this rule which provides serine to the 0-layer (Fasshauer et al., 1998). Also the mouse and rat Vtila has an aspartate residue in the 0-layer but it was shown that aspartate can functionally replace glutamine (Antonin et al., 2000a). All t-SNAREs (syntaxins and SNAP-25) are Q-SNAREs and most of the v-SNAREs are R-SNAREs. Three families of Q-SNAREs can be distinguished due to sequence similarities. Among Q-SNAREs, the 
conserved -3 layer has either a big amino acid like phenylalanine (Qa) or small amino acid residues like glycine or alanine (Qb or Qc). Syntaxin 1 related SNAREs are QaSNAREs, related to the N-terminal helix of SNAP-25 are Qb-SNAREs and Qc-SNAREs are similar to the C-terminal helix of SNAP-25 (Bock et al., 2001). S. cerevisiae contains five R-SNAREs, seven Qa-SNAREs, Six Qb-SNAREs and seven Qc-SNAREs (Pelham, 2001).

\subsubsection{Function of N-terminal domains of SNAREs}

The N-terminal domains of many SNAREs have some independently folded domains which are not conserved and highly divergent in their amino acid sequences. The Nterminal domains of Qa-SNAREs and some Qb and Qc SNAREs such as vtilb and syntaxin 8 consist of a three-helix bundle whereas the R-SNAREs Sec22p and Ykt6p form a mixed $\alpha$-helical $/ \beta$-sheet profilin-like fold. The $N$-terminal domains of SNAREs belonging to syntaxins or to Qa-SNAREs can bind proteins that regulate SNARE complex formation. Some R-SNAREs or Qa-SNAREs are recruited into budding vesicles by the binding partners of their N-terminal domain. The N-terminus of Vam7p contains a Phox domain which helps in membrane attachment (Cheever et al., 2001; Lu et al., 2002). The yeast syntaxins, Sed5p and Ufe1p bind to Sly1p (Sec1/Munc18 family protein which organizes membrane fusion) by a short peptide motif from the $\mathrm{N}$-terminus (Yamaguchi et $a l ., 2002)$. In the same way, Munc-18 can bind to Syntaxin 1 in the closed comformation and is a negative regulator of SNARE complex formation (Dulubova et al., 1999; Misura et al., 2000). Sec20p through its N-terminus recruits Tip20 which is required for the retrograde transport to ER (Sweet and Pelham, 1993). The N-terminal domain of neuronal syntaxin 1 and its yeast plasma membrane homologue Ssolp, consists of a three-helix bundle which interacts with its own SNARE motif and can down regulate the capability to form SNARE complexes (Dulubova et al., 1999; Munson et al., 2000). But when the N-terminal domain of Ssolp was removed, formation of the SNARE complex assembly was accelerated (Nicholson et al., 1998). VAMP-4 (Vaculor associated membrane protein) has a di-leucine motif in the cytoplasmic domain which interacts with AP-1 at the TGN (Peden et al., 2001). The N-terminal extension of VAMP-4 contains a target signal for the TGN (Zeng et al., 2003). From our lab, recently we showed that the N-terminus of vtilb interacts with the Epsin N-terminal homology domain (ENTH-domain) of Enthoprotin/CLINT/epsinR, and Vtilp with the ENTH-domain of Ent3p in yeast 
(Chidambaram et al., 2004). The ENTH domain proteins are needed for the formation of CCVs. The N-term of retrograde SNARE Use1p interacts with Frq1, which is a Ca2+ binding protein (Burri and Lithgow, 2004). It is believed that through Frq1p, Use1p might support Pik1p to dock and modify the phosophoinositide composition of membranes for retrograde transport. Syn8p, through its N-terminus interacts with Glc7p, a protein phosphatase which regulates vacuolar traffic by controlling final stages of vacuolar fusion (Burri and Lithgow, 2004). Thus, the N-terminal domains of SNAREs may serve as inhibitors of the adjacent SNARE motif and have regulatory functions.

\subsubsection{Sorting sequences for SNAREs}

The cytosolic domain of SNAREs can assist them to target and localize to some extent. But this is not well defined. For some SNAREs, the sorting sequences seem to be located within the region of the SNARE motif, ex. Bos1p, Bet1p and Sec22 and Vamp2p (Burri and Lithgow, 2004). In some SNAREs, sorting signal is present outside of the SNARE motif; for example, Ykt6p has a profilin-like domain proximal to the SNARE motif which is necessary and sufficient for sorting (Hasegawa et al., 2003). In SNAP-25, the palmitoylated interhelical domain targets the protein to the PM (Gonzalo et al., 1999; Loranger and Linder, 2002). For some SNAREs the N-terminal domain helps in the targeting and localization like Vamp4, as mentioned in chapter 1.3.3.

\subsubsection{Crystal structure of SNARE complexes}

So far only two SNARE complexes have been crystallized and the best characterized one is the exocytotic SNARE complex in synapses which releases neurotransmitter into the synaptic cleft. The crystal structure of this complex showed that one helix from Syntaxin1 and Synaptobrevin and two helices of SNAP-25 assembled to a parallel four helix bundle (Sutton et al., 1998) (Fig.4a). When the SNARE motives of these SNAREs interact they form 16 layers, each layer containing four amino acids. The central 0-layer of this complex contains an arginine from Synaptobrevin and three glutamines one from syntaxin and two from SNAP-25. The stabilizing interaction is mainly mediated by hydrophobic interactions. The ionic interactions are shielded from the aqueous environment by neighboring leucin-zipper-motives and the peptide-backbone, which contribute to the stability of the complex. Apart from the ionic 0-layer, the amino acids which form the additional 15 layers in the centre of the bundle are hightly conserved. These other layers 
were numbered positively towards the $\mathrm{C}$-terminus and negatively towards the $\mathrm{N}$-terminus (Fig.4b). An additional well characterized late endosomal SNARE-complex consists of the 4 SNAREs vtilb, Syntaxin 8, Syntaxin 7 and Endobrevin. Crystal structures as well as functional data supported the hypothesis, that all SNARE-complexes are similar in structure, despite of limited sequence homology (Antonin et al., 2002b; Antonin et al., 2000a). In yeast, a SNARE-complex which is involved in exocytosis and consists of the proteins Sec9p, Snc1/2p and Ssp1/2p shows a lot of similarities to the neuronal SNAREcomplex (Gerst, 1997; Rice et al., 1997). Therefore it seems that some features are common for all SNARE-complexes, for example, SNARE core complexes are extremely stable, most of them are resistant to SDS denaturation, heat stable, resistant to cleavage by toxins and for proteases digestion (Chen and Scheller, 2001). In contrary to the four helix bundle model of SNARE complexes, pentameric complexes was suggested to be formed by the SNAREs involved in homotypic vaculor fusion, Vti1p, Nyv1p, Ykt6p, Vam3p and Vam7p (Ungermann et al., 1999). However, another group has disproven this by demonstrating that Nyv1p and Ykt6p compete for the same binding site in a complex with Vam3p, Vam7p and Vtilp and can form two different quarternary complexes (Fukuda et al., 2000).

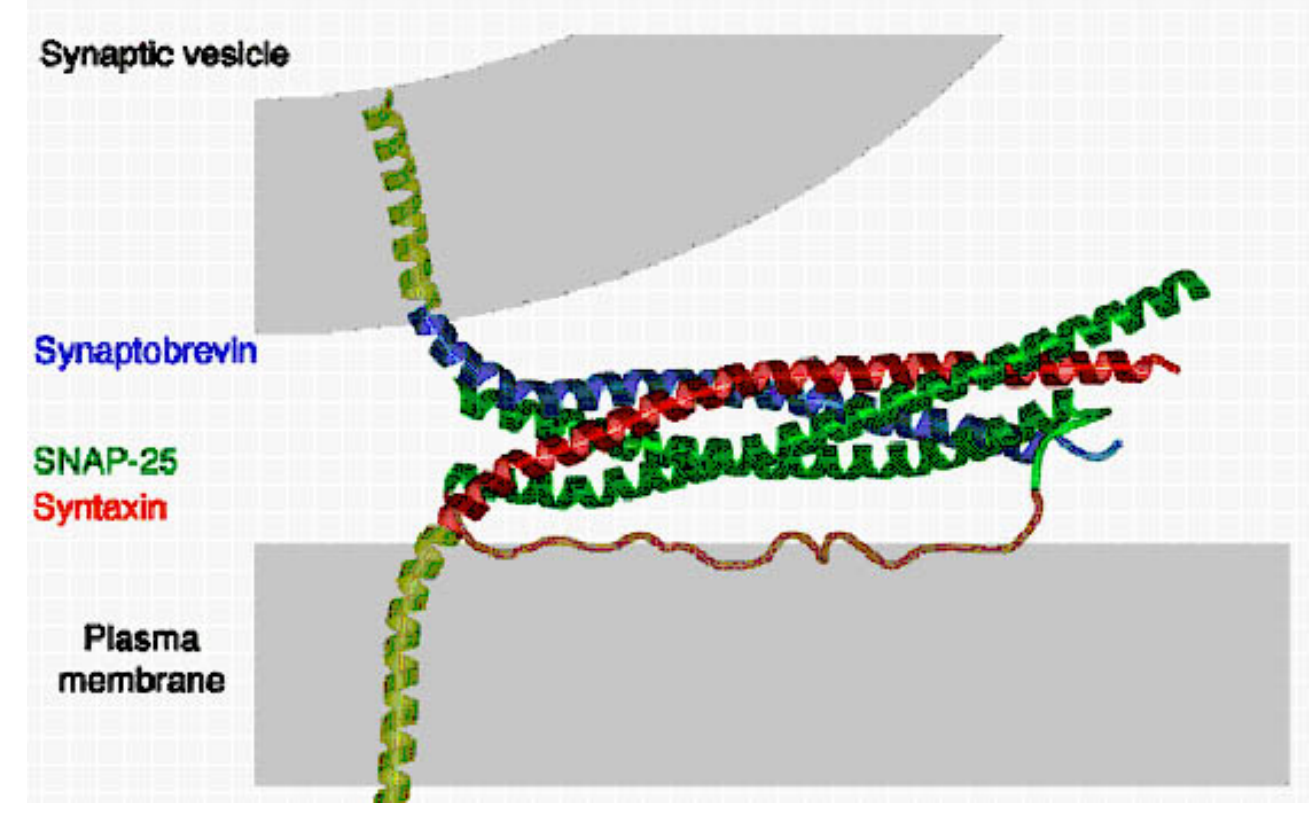

Fig.4a. Crytal structure of synaptic SNARE complex (Sutton et al., 1998) 


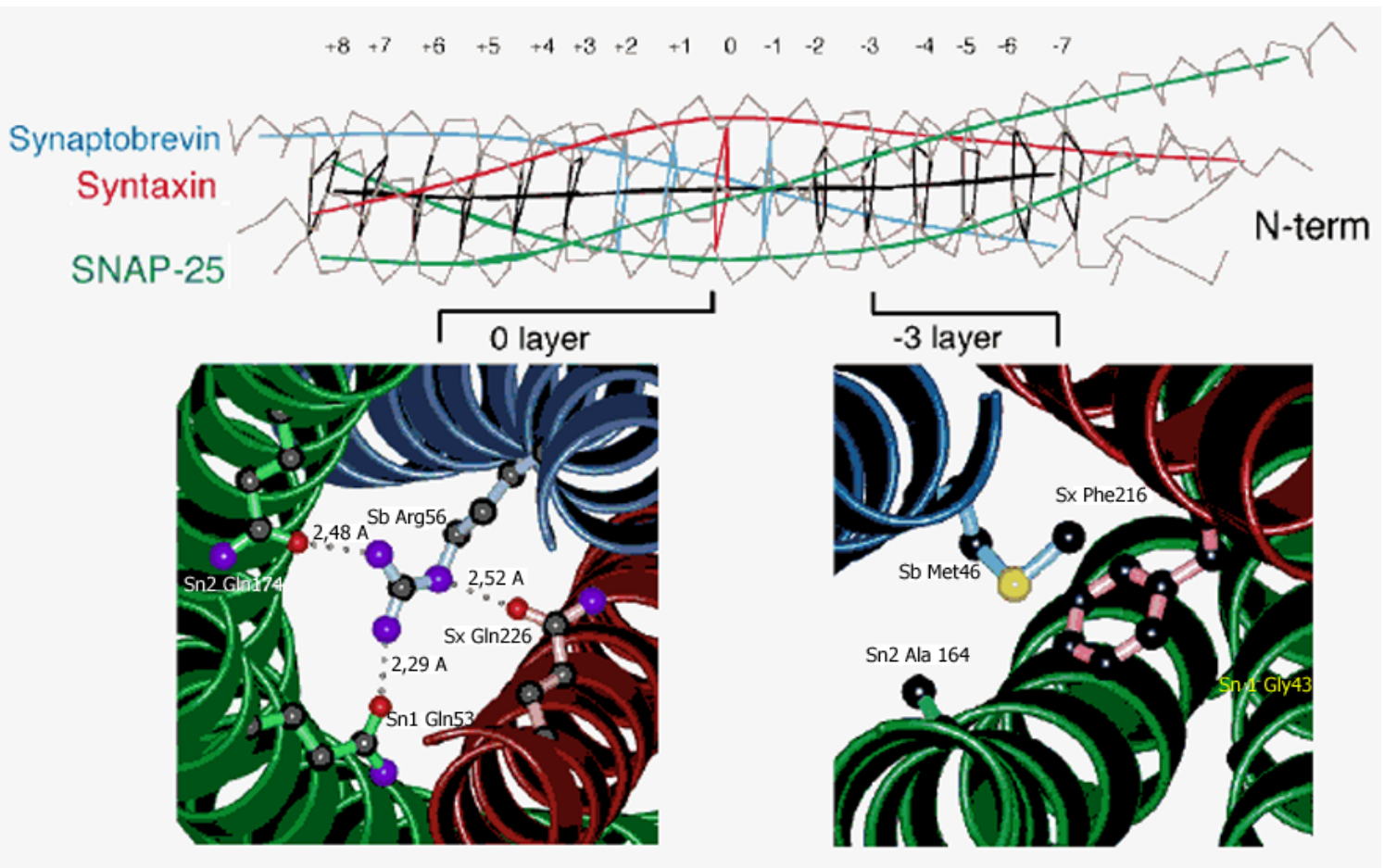

Fig.4b. Ionic layers of SNARE complexes (Sutton et al., 1998)

\subsubsection{Mechanics of membrane fusion}

SNARE proteins are present in all intracellular compartments and mediate specific fusion reaction. A trans-SNARE complex is formed by the action of SM (Sec1/Munc18)proteins which might link the Ypt/Rab effectors and tethering complexes to the SNARE complex (Jahn et al., 2003). The SNARE complex formation is associated with release of energy which drives off the energy barrier and all the four SNARE proteins align on the same membrane, now it is called as cis-SNARE complex. After fusion, the SNARE complex is dissociated into individual SNARE proteins on the membranes, a step known as 'Priming' by the action of Sec17p and Sec18p by hydrolyzing ATP (Novick et al., 1981) or by the mammalian chaperone-like ATPase NSF in conjunction with cofactors, thus re-activating the SNAREs for another round of membrane fusion (Hanson et al., 1997). So, the SNARE proteins are ready for the next round of fusion. According to 'zipper' model of membrane fusion, once the amino termini of the SNARE motifs have found each other, they may 'zip' from the membrane-distal amino termini towards the membrane-proximal carboxyl termini of the SNARE motifs and the formation of the stable SNARE complex overcomes the energy barrier to drive fusion of the lipid bilayers (Hanson et al., 1997; Lin and Scheller, 1997). SNARE proteins may partially zipper to 
transfer the vesicle into a readily releasable state leading to 'hemi-fusion' or 'preassembled pore' between both membranes. In synaptic vesicle exocytosis, $\mathrm{Ca}^{2+}$ triggers the full zipping of the coiled-coil complex, which results in membrane fusion and release of vesicle contents. Further recruitment of NSF and $\alpha$-SNAP dissociates the SNARE complex and free SNARE proteins are ready for next round of fusion. In viral protein mediated membrane fusion, coiled-coil helical bundles are the main structural component of the fusion protein, and a conformational change of the protein promotes fusion (Jahn and Sudhof, 1999; Skehel and Wiley, 1998). In viral fusions, a helix bundle bends and brings two membranes together, which is called as 'jack-knife' mechanism (Hughson, 1997). Studies on yeast homotypic vacuolar fusion, showed that membrane fusion is promoted by a proteinaceous pore (Peters et al., 1999). It was proposed that V0subunits, the membrane integral sector of the H+-ATPase, is a target of calmodulin in yeast and assemble into gap-junction-like channels that connect the fusing membranes.

Various SNARE (SNAP receptor) proteins critical to intracellular membrane fusion is believed to operate by similar mechanisms in eukaryotic organelles (Götte and von Mollard, 1998; Rossi et al., 1997; Rothman and Wieland, 1996). Operation by a similar mechanism would imply structural similarity, regardless of a lack of sequence conservation among evolutionarily distant members of the SNARE family. This structural similarity has been observed between mammalian SNARE proteins and some yeast homologues. Structural similarity between yeast v-SNARE Vtilp and its human homologue is suggested by the recent result that the human homologue can functionally replace Vtilp in two vesicle transport pathways (Fischer von Mollard and Stevens, 1998).

\subsection{Biosynthetic transport to the yeast vacuole}

At the trans-Golgi Network, the vacuolar proteins are sorted due to the presence of vacuolar sorting signals (Bryant and Stevens, 1998). Different routes have been identified from the TGN to the vacuole. They are the carboxypeptidase Y (CPY) pathway, the alkaline phosphatase (ALP) pathway and the multivesicular body (CPS-1) pathway. Vacuolar proteins are usually synthesized as precursors, modified during the transport in different ways, processed into the mature form in the vacuole by proteinase A encoded by PEP4 and thus used as marker proteins to study the different pathways. After translocation into the ER and transport through the Golgi-complex most of the soluble 
proteins and integral membrane proteins of the yeast vacuole are transported in the biosynthetic-secretory pathway through the pre-vacuolar compartment (late endosome) towards the vacuole. The soluble vacuolar hydrolase carboxypeptidase Y (CPY) serves as a marker protein for this transport route. Therefore this pathway is also called as the CPYpathway (Bryant and Stevens, 1998; Conibear and Stevens, 1998). The inactive precursor-form of CPY (prepro-CPY) is transported into the lumen of the ER after synthesis. After removal of the signal sequence, the proteins receive a core-glycosylation by which the $67 \mathrm{kDa}$ p1CPY-form is generated. This is then transported to the Golgiapparatus, where further oligosaccharide-modifications take place which leads to the 69 $\mathrm{kDa}$ p2CPY-form. In the TGN p2CPY binds the CPY-transport receptor Vps10p (Marcusson et al., 1994). This complex is then transported in transport vesicles towards the pre-vacuolar compartment. Here the complex dissociates. p2CPY is further transported to the vacuole and Vps10p recycles back to the Golgi-apparatus (Cereghino et al., 1995; Cooper and Stevens, 1996; Piper et al., 1995). In the vacuole p2CPY is processed to the mature $61 \mathrm{kDa} \mathrm{mCPY}$-form by the action of proteinase A. These different forms of CPY can be analyzed by separating them on a SDS-gel.

Apart from the CPY-pathway there exists a second, direct transport pathway from the TGN to the vacuole, without the detour through the pre-vacuolar compartment. This pathway is called as ALP-pathway, the vacuolar membrane protein alkaline phosphatase (ALP) serves as a marker protein (Piper et al., 1997). After translocation into the ER ALP is glycosylated to the $76 \mathrm{kDa}$ proform (pALP), which does not change in size through out the transport within the Golgi-apparatus. It was shown that the adapter-complex AP-3 is involved in the transport of ALP from the TGN to the vacuole. In addition pALP accumulates in AP-3 deficient strains (Cowles et al., 1997a). In the TGN pALP is sorted into transport vesicles via interaction of its $\mathrm{N}$-terminal dileucine-signal with AP-3. In the vacuole pALP is processed to the mature $72 \mathrm{kDa}$ mALP-form. Apart from ALP, the vacuolar SNAREs Vam3p and Nyv1p are also transported via this direct pathway (Cowles et al., 1997b; Reggiori et al., 2000). The specific marker of multivesicular body (MVB) pathway is CPS1, a type II integral membrane protein, is synthesized as an inactive precursor (proCPS) that is transported through the secretory pathway to the TGN and delivered to the prevacuolar compartment (PVC). In the PVC, proCPS is sorted to the forming internal vesicles of the multivesicular bodies (MVB), and these vesicles are then 
delivered to the vacuole where the vesicles are degraded and CPS1 proteolytic maturation yields the active mature form of CPS1 (mCPS) (Cowles et al., 1997b). The fourth biosynthetic pathway to the yeast vacuole is used by the soluble vacuolar hydrolase aminopeptidase I (API) (Klionsky et al., 1992). This route is called as the API-pathway or the Cvt-pathway (cytoplasm-to-vacuole-targeting) and described in chapter 1.1.3.

\subsection{SNARE protein Vti1p}

The yeast-v-SNARE-protein Vtilp ( $\underline{\mathrm{V} p s} \underline{10}$ - tail-interacting) was discovered in a 2-hybridscreen in search for binding partners of the cytosolic domain of Vps10p (CPY-transport receptor) (Fischer von Mollard et al., 1997). But a specific biochemical interaction between Vtilp and Vps10p could not be shown. The VTII-gene encodes a 217-amino acid protein with a C-terminal transmembrane domain, which is followd by a luminal part of 4 amino acids. VTII is an essential gene and Vtilp was shown to be localized to Golgi and pre-vacuolar membrane by sub cellular fractionation and immunofluorescence microscopy (Fischer von Mollard et al., 1997; Fischer von Mollard and Stevens, 1999). The SNARE-motif is located next to the transmembrane domain which contains a glutamine in the 0-layer. Therefore Vtilp belongs to the Q-SNARE-family and sequence comparisons showed that the SNARE-motif of Vtilp is related to the N-terminal helix of SNAP-25 (Qb-SNARE). Functional studies showed that Vtilp is involved in several transport steps, from Golgi to late endosomes, retrograde transport to the cis-Golgi, biosynthetic transport to the vacuole and in TGN homotypic fusion (Fig.5). Vtilp interacts with the Syntaxin (Qa-SNARE) Sed5p in the retrograde transport to the cisGolgi, (Lupashin et al., 1997) with the Qa-SNARE Pep12 in the transport from the Golgi to the prevacuole (Fischer von Mollard et al., 1997) and with the vacuolar Syntaxin Vam3p in the biosynthetic transport of CPY, ALP and API to the vacuole (Fischer von Mollard and Stevens, 1999). In addition Vtilp is involved in the homotypic vacuolar fusion by interaction with Vam3p (Ungermann et al., 1999). It was also shown, that Vti1p interacts biochemically with the Syntaxin Tlg2p (TGN) (Holthuis et al., 1998). Snc1/2, Tlg2p, Tlg1p and Vtilp are involved in the homotypic TGN fusion and the retrograde transport from the early endosome to the TGN transport (Brickner et al., 2001). The Nterminus of Vtilp interacts with ENTH domain of Ent3p which is involved in endocytosis (Chidambaram et al., 2004). 


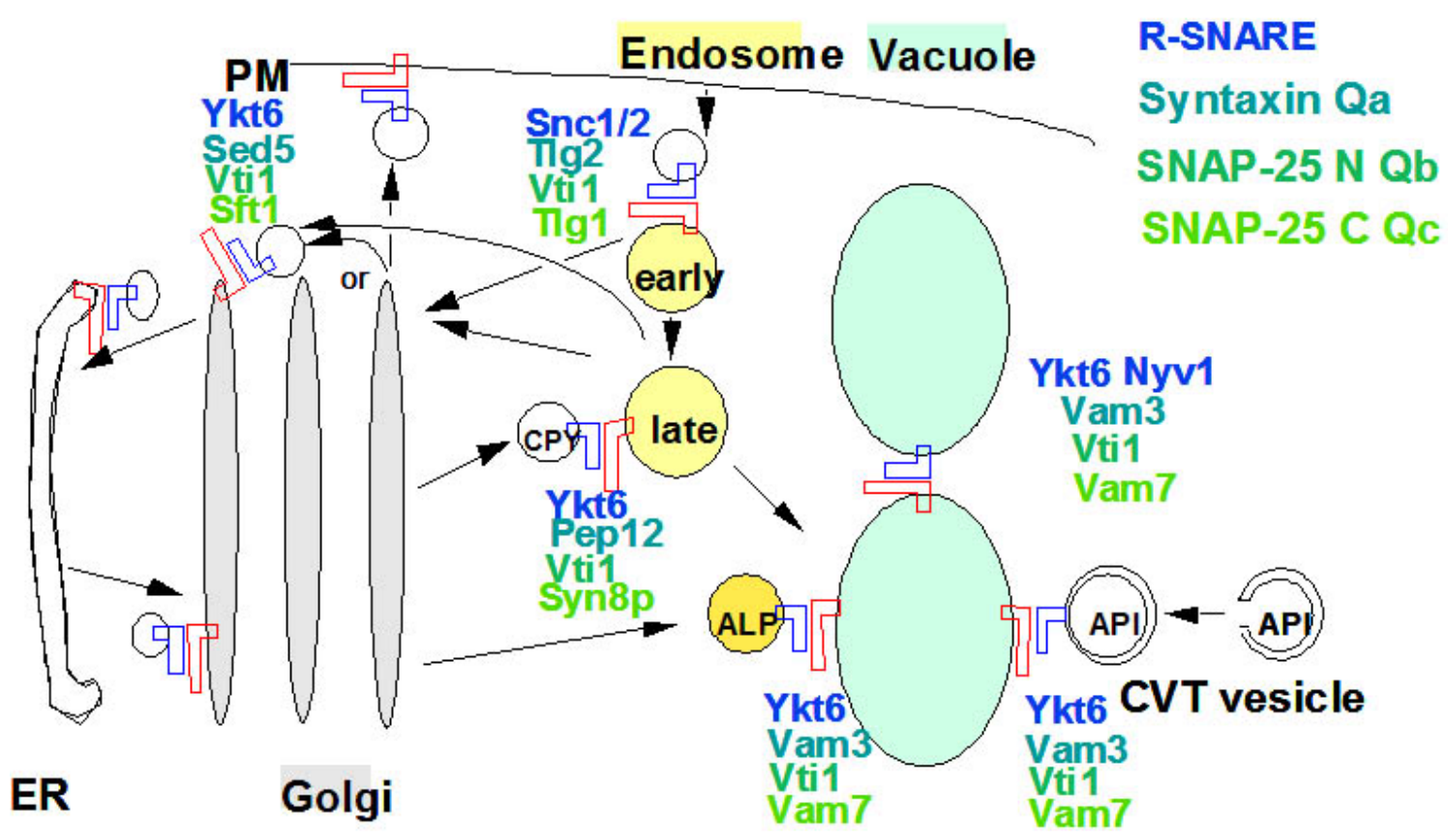

Fig.5. SNARE complexes with Vtilp

\subsubsection{Vti1p homologues}

Vtilp-homologuous proteins were found in C. elegans, Drosophila, Arabidopsis and mammals. In Arabidopsis so far 3 Vti1-homologues were identified (Sanderfoot et al., 2000; Zheng et al., 1999). In mammals two Vtil-proteins exist, Vtila (27 kDa) which shares $33 \%$ identity with Vtilp and Vtilb (29 kDa), which only shares $27 \%$ identity (Fischer von Mollard and Stevens, 1998; Lupashin et al., 1997). Mouse Vtila and Vti1b share only $30 \%$ amino acid identity. In addition a brain specific splice-variant of Vtila, Vtila-ß $(29 \mathrm{kDa})$ was identified, which contains an insertion of 7 amino acids (Antonin et $a l ., 2000 \mathrm{c})$. As already mentioned, mouse-, rat- and human-Vtila contain an aspartate instead of the glutamine in the 0-layer-position (Antonin et al., 2000c). It seems that the two mammalian and the 3 plant-homologues of Vtilp do not possess redundant functions, but that they are specialized to different transport-pathways, which is also supported by their different subcellular localization. In the indirect immunofluorescence Vtila was localized to Golgi and TGN-structure, whereas Vtilb seems to be associated to early and late endosomes (Kreykenbohm et al., 2002). During homotypic fusion of late endosomes, Vtilb forms a complex with the SNARE-proteins Syntaxin 7, Syntaxin 8 and Endobrevin/Vamp-8 of which the crystal-structure has been solved (Antonin et al., 2000a; 
Antonin et al., 2000b). Vtilb-knock-out-mice are viable, but show phenotypic heterogeneity. The protein level of the SNARE partner Syntaxin 8 is decreased in these mice. Hepatocytes of small knock-out-mice show a decreased level of the lysosomal degradation of endocytosed material (Atlashkin et al., 2003). The N-terminus of Vti1b interacted with ENTH domain of Epsin-R, a protein involved in transport between the TGN and the endosomes (reference: chapter 1.7) (Chidambaram et al., 2004) and Epsin-R is an adaptor for Vtilb (Hirst et al., 2004). Vtila forms a SNARE-complex with VAMP4, Syntaxin 6 and Syntaxin 16, which is involved in the fusion of early endosomes and in the retrograde transport from the early endosome to the TGN (Kreykenbohm et al., 2002; Mallard et al., 2002). Vtila-ß functions in a SNARE complex during recycling or biogenesis of synaptic vesicles but not in exocytosis (Antonin et al., 2000c). It has been shown, that human Vtilb could functionally replace the yeast-Vtilp in the transport to the cis-Golgi as well as in the transport from the Golgi to the prevacuolar compartment, but not in the ALP-pathway (Fischer von Mollard and Stevens, 1998). In activated macrophages, Vtilb and syntaxin 6 forms a novel SNARE complex which is up regulated to secrete increased level of cytokines (Murray et al., 2005).

\subsubsection{Temperature sensitive mutants of Vti1p}

Since VTII is an essential gene, temperature sensitive vtil mutants were generated to study the function of Vtilp. Different temperature sensitive alleles of vtil cause blocks at different stages in the secretory pathway. Via random mutagenesis of the VTII gene and analysis of cells, which showed an impaired growth at higher temperatures, or defects in the protein transport, 3 different temperature-sensitive (ts) VTI1-mutants were identified: vti1-1, vti1-2 and vti1-11 (Fischer von Mollard et al., 1997) (Fig.6). vti1-1 mutants were obtained by shuttle mutagenesis with hydroxylamine treated VTII on a CEN-based plasmid. The other two alleles, vtil-2 and vtil-11 were generated by PCR mutagenesis. It turned out, that the mutations in all vtil-ts-mutants affected amino acids in the SNAREmotif, especially conserved amino acids in the interaction points (layers) with which Vtilp forms SNARE-complexes with other SNARE-proteins. The mutants vtil-1, vtil-2 and vtil-11 all show defects in CPY-transport from the Golgi to the prevacuolar compartment after temperature shift. vtil-11 cells display in addition a block in the retrograde transport to the cis-Golgi, which leads to an acculumation of the ER-modified p1CPY-form because of an indirect effect on the ER to Golgi transport. vtil-2 cells are 
defective both in CPY and ALP pathway whereas vtil-1 cells are defective only in CPY pathway (Fischer von Mollard and Stevens, 1999). vtil-1 cells show slight defects in APItransport to the vacuole, whereas this pathway is completely blocked in vtil-11 cells after temperature-shift. Also vtil-2 cells show a partial defect in API transport step. vtil-1 and vtil-2 mutants also cause a defect in homotypic vacuolar fusion in vitro (Ungermann et al., 1999). vtil-1 cells grow at $37^{\circ} \mathrm{C}$ nearly like wild type cells, whereas vtil-2 and vtil11-cells exhibit a growth defect at $37^{\circ} \mathrm{C}$ (Fischer von Mollard et al., 1997). Apart from these SNARE motif mutants, few N-terminal mutants of Vtilp were also obtained by random mutagenesis (unpublished data, Fishcer von Mollard). vtiQ29RW79Rp is an interesting N-terminus mutant with two point mutations, replacing glutamine (at 29) and tryptophan (at 79) by arginine.

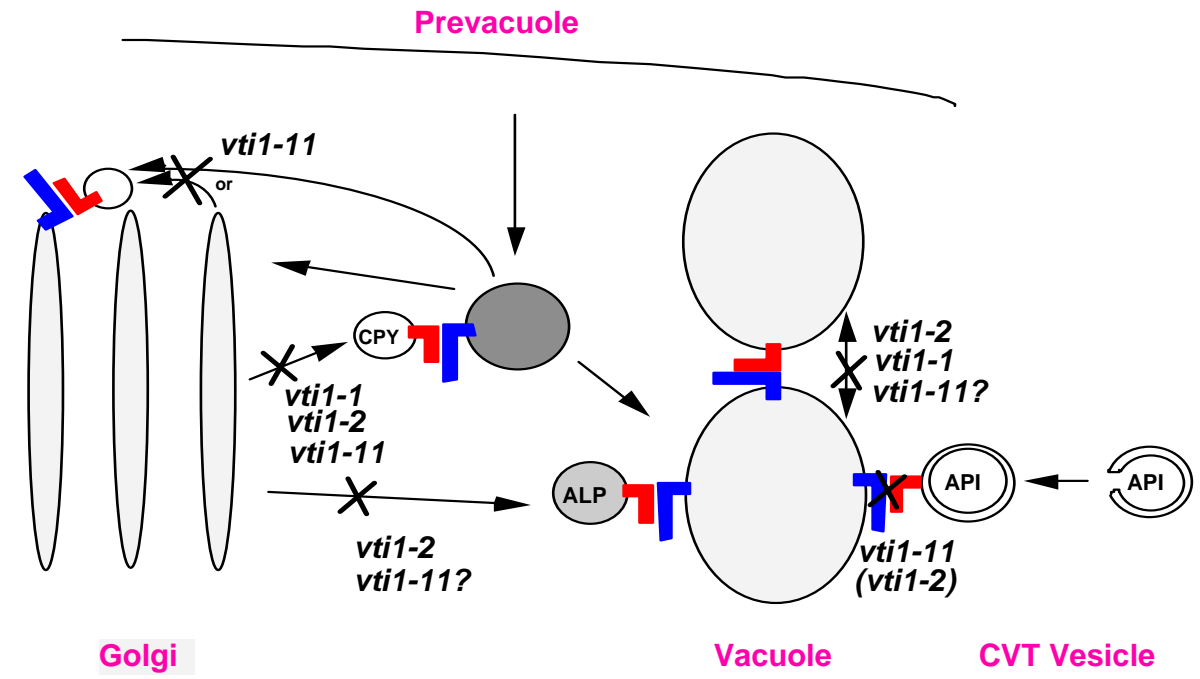

Fig.6. Temperature sensitive mutants of Vtilp

\subsection{Role of SNARE Pep12p}

The endosomal syntaxin, Pep $12 p$ is required for the delivery of proteins to the vacuole of the $S$. cerevisiae. It is a multifunctional SNARE which controls all the known membrane fusion events in pre-vacuolar endosomes (PVC) since the deletion of Pep12p results in the block of all the trafficking pathways to PVC (Gerrard et al., 2000a). Pep12p forms SNARE complexes with Vtilp (Fischer von Mollard et al., 1997), Ykt6p and Syn8p. Pep12p is localized to pre-vacuolar (late) endosomes. Syntaxin 7 is the mammalian homolog of Pep12p (Becherer et al., 1996). In the absence of Tlg1p, Syn8p is required for Pep12p function. But when Tlg1p is present, Syn8p can be removed without loss of 
function of Pep12p (Lewis and Pelham, 2002). Pep12p localization requires clathrin and GGA coat proteins and also it contains a FSD motif which directs it to the late endosome (Black and Pelham, 2000). The TMDs from SNAREs on each membrane is needed to transfer the 'zipping' force to form the core complex. In the vacuole only Vtilp and Vam3p contribute the TMDs. In the PVC, Syn8p, Vtilp and Pep12p provide the TMDs. Pep12p requires its transmembrane domain (TMD) for its proper localization but not for its role in vesicle fusion. Overexpression of Pep12p can compensate for loss of Vam3p and vice versa which indicates that Vam3p and Pep12p are interchangeable in the endosomal as well as the vacuolar SNARE complexes. But the TMD of Pep12p is required for participation in this complex. Thus the TMD of Pep12p plays different role in the pre-vacuolar and the vacuolar SNARE complexes (Darsow et al., 1997; Gerrard et al., $2000 \mathrm{~b}$ ). Vtilp uses the retrograde transport to achieve its proper steady-state localization. Loss of Pep12p may alter the localization of Vti1p but it could not be shown clearly because of the diffuse and punctuate localization of Vtilp (Gerrard et al., 2000a).

\subsection{ENTH domain proteins}

Membrane recruitment of cytosolic proteins is mediated by a growing number of modular membrane targeting modules like, PH, FYVE, PX, ENTH, ANTH, BAR and FERM domains that recognize specific lipid molecules in the membrane. Epsin N-terminal homology domain (ENTH) is a highly conserved domain of around 140 amino acids shared by variety of proteins implicated in the regulation of endocytosis or cytoskeletal machinery in budding and fission yeast, in nematodes, rat, mouse, oat and man (Kay et al., 1999). There is a homologous domain for ENTH domain which is called as ANTH domain (AP180 N-terminal homology) present in AP180/CALM and HIP1/HIP1R protein families. Both ANTH and ENTH domains bind $\mathrm{PI}(4,5) \mathrm{P}_{2}$ with high specificity which is essential for endocytosis, mediated by clathrin-coated pits (Itoh et al., 2001). ENTH proteins have binding sites for adaptor proteins, clathrin and some multidomain proteins like Eps15. Phylogenetic analysis of ENTH domains suggested two ENTH domain families, namely the epsin family (contains epsins 1-3, Ent1p and Ent2p), which interacts through NPF motifs with EH domains and functions at the cell surface; and the enthoprotin family (contains enthoprotin/clint/EpsinR and Ent3p), which contains sequences for binding to GGAs and $\gamma$-adaptin and functions on internal membranes 
(Legendre-Guillemin et al., 2004). The ENTH and ANTH domain proteins in mammals and yeast are summarized in the Fig.7.

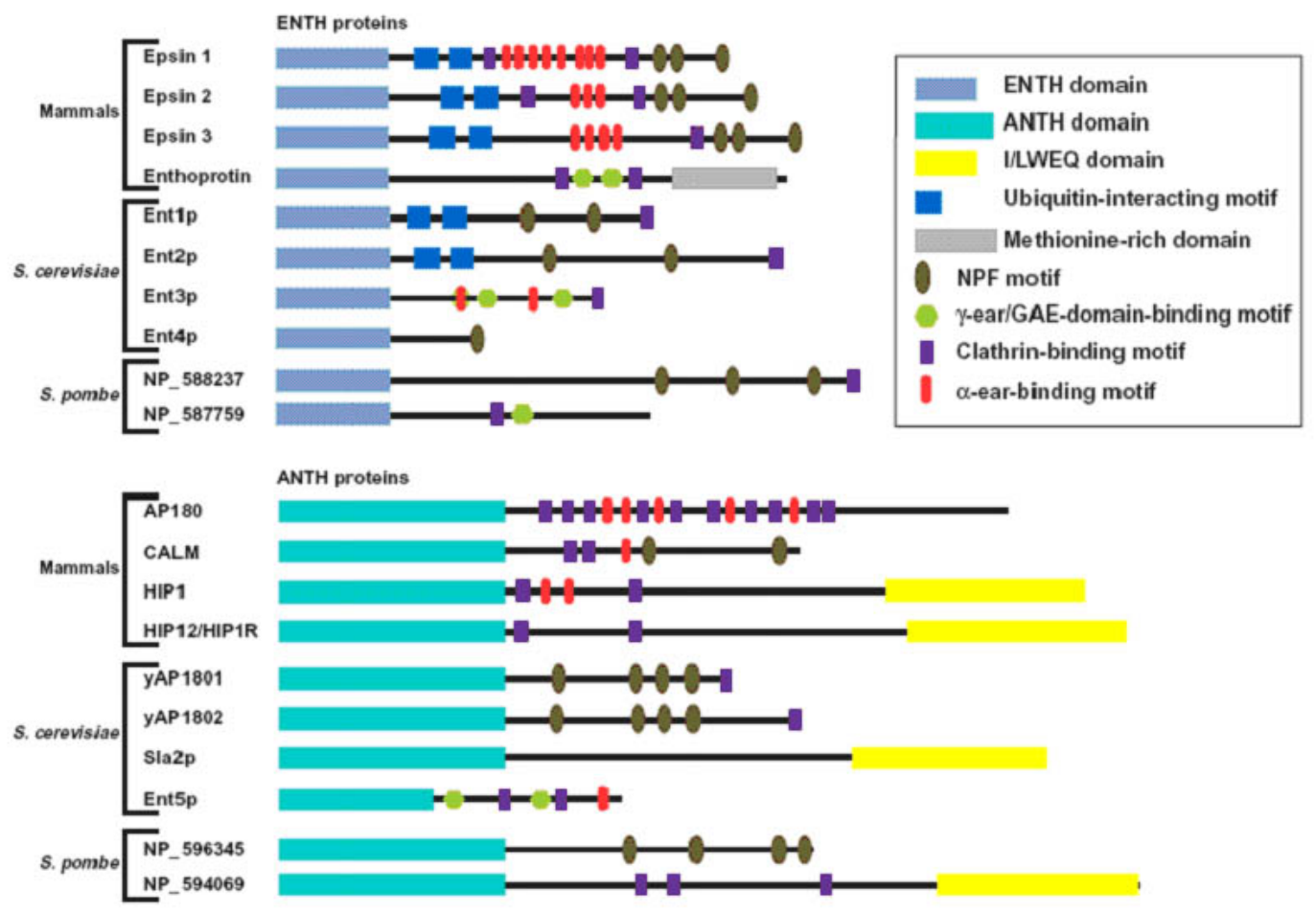

Fig.7. A/ENTH domain proteins in yeast and mammals (Legendre-Guillemin, 2004)

\subsubsection{Ent proteins in yeast}

There are five Ent proteins in $S$. cerevisiae, from Ent1p through Ent5p. Ent1p and Ent2p were identified by a two hybrid screen in a search for interacting factors for EH domains of Pan1p (Wendland et al., 1999). ENTH domains of Ent1p and Ent2p are 76.9\% identical, while their identities with the ENTH domains of Ent3p and Ent4p range from 24 to $34 \%$. The ENTH domain is required for the essential functions of Entlp and Ent $2 p$ and single deletions of these two proteins did not show any phenotype but the double mutant was inviable, suggesting that Ent1p and Ent2p are redundant in function. At least one ENTH domain was required for the viability. Ent1p is localized to the cell periphery and internal compartments and both the proteins are required for endocytosis and organization of actin cytoskeleton. The ENTH domain of Entlp interacts with phospholipids, whereas the ubiquitin-interaction motifs (UIMs) in the C-terminal region bind to ubiquitylated proteins at the membrane (Wendland et al., 1999). These events promote interactions between NPF motifs in Entlp and EH-domain proteins (Aguilar et 
al., 2003). Ent3p and Ent $4 p$ are functionally non redundant with Ent1p or Ent2p. Ent3p and Ent5p localized to TGN and early endosomes (Duncan et al., 2003). ENTH domain of Ent5p resembles lysine-rich ANTH domain, so the ENTH domains of Ent3p and Ent5p may be functionally different and Ent5p is unlikely to promote membrane curvature. Ent3p and Ent5p interact with Gga2p and localized to clathrin coats at the TGN and endosomes. Ent5p binds with AP1 and clathrin. Ent3p and Ent5p are required together for clathrin recruitment but they differ in clathrin-binding properties. Single deletions of ENT3 and ENT5 did not lead to defects in clathrin-mediated protein transport but the double mutant caused a defect in clathrin localization, but Ent3p lacks a clathrin binding motif. All these points provide evidence for overlapping functions of ENTH and ANTH domains in clathrin assembly and CCV mediated transport in the yeast. Ent3p and Ent5p seem to be functional accessory factors for $\mathrm{CCV}$ formation and function at TGN/endosomes (Duncan et al., 2003). Ent3p has been shown as a specific effector of $\mathrm{PI}(3,5) \mathrm{P}_{2}$ localized to endosomes and is required for protein sorting into the MVB (Friant et al., 2003). Ent5p binds $\mathrm{PI}(3,5) \mathrm{P}_{2}$ specifically, associates with $\mathrm{Vps} 27 \mathrm{p}$ and together with Ent3p is required for ubiquitin-dependent protein sorting into the multivesicular body (Eugster et al., 2004). In Schizosaccharomyces pombe, Ent1p is an essential component of endocytosis, required for actin organization and cell morphology. PI(4,5) $\mathrm{P}_{2}$ may not be needed for the proper localization of Ent1p to endocytic sites (Sakamoto et al., 2004).

\subsubsection{Epsin family proteins in mammals}

The best characterized among the epsin proteins is epsin 1 which consists of an ENTH domain in the N-terminus which is highly conserved in yeast, plant, frogs and human (Kay et al., 1999; Rosenthal et al., 1999) and the C-terminus contains multiple short peptide motifs that mediate interaction with endocytic proteins. These short peptides are eight copies of DPW tripeptide that mediate binding to $\alpha$-ear of AP-2 (Owen, 1999; Traub et al., 1999), two distinct clathrin binding motifs (Drake and Traub, 2001; Hussain et al., 1999; Rosenthal et al., 1999), three NPF motifs which bind to the EH domain of Eps15 and intersectin (Chen et al., 1998; Hussain et al., 1999). Epsin1 is localized to clathrin coated pits and participates in clathrin-dependent endocytosis, including endocytosis at synapses (Chen et al., 1998). Itoh et al showed that in cultured mammalian cells, overexpression of epsin 1 containing a mutation in the ENTH domain prevented epsin 1 from binding to PIP2 which blocked clathrin dependent endocytosis (Itoh et al., 2001). 
Epsin1 interacts with promyelocytic leukemia zinc finger protein (PLZF), a transcription factor which can target epsin 1 to the nucleus (Hyman et al., 2000). Enthoprotin was independently discovered (Wasiak et al., 2002) and referred also as Clint (Kalthoff et al., 2002) and epsinR (Hirst et al., 2003). It contains two clathrin binding domains in its Cterminal region and binds directly to clathrin. It also binds to AP-1 and GGA2 through its C-terminal domain at the TGN. The $\gamma$-ear (of AP1) and GAE domain (of GGA2) both bind to two conserved motifs in the C-term of enthoprotin (Duncan and Payne, 2003; Miller et al., 2003; Mills et al., 2003; Wasiak et al., 2003). Enthoprotin is localized primarily to the TGN and in endosomal membranes (Wasiak et al., 2003). Constructs of enthoprotin lacking ENTH domain concentrate on clathrin-enriched membrane fractions (Wasiak et al., 2002) thus C-terminal domain of the protein seems to contain membranetargeting sequences. However, ENTH-domain mutants unable to bind phospholipids relocalize from the TGN to large perinuclear puncta (Mills et al., 2003) which suggested that ENTH domain contributes to the specificity of membrane localization. Enthoprotin/EpsinR specifically binds to PI4P (Hirst et al., 2003; Mills et al., 2003). EpsinR is functionally equivalent to epsin 1 in $\mathrm{CCV}$ budding but in a different transport step, namely in budding from the TGN/endosomes rather than from the plasma membrane (Fig.8) (Mills et al., 2003). Drosophila epsin, Liquid facets (Lqf), was shown to be important for internalization of the Delta (D1) transmembrane ligand in the developing eye. Also, when Lqf was divided into two pieces, one with ENTH domain and one without ENTH, surprisingly each part retain significant ability in D1 internalization and eye patterning (Overstreet et al., 2003).

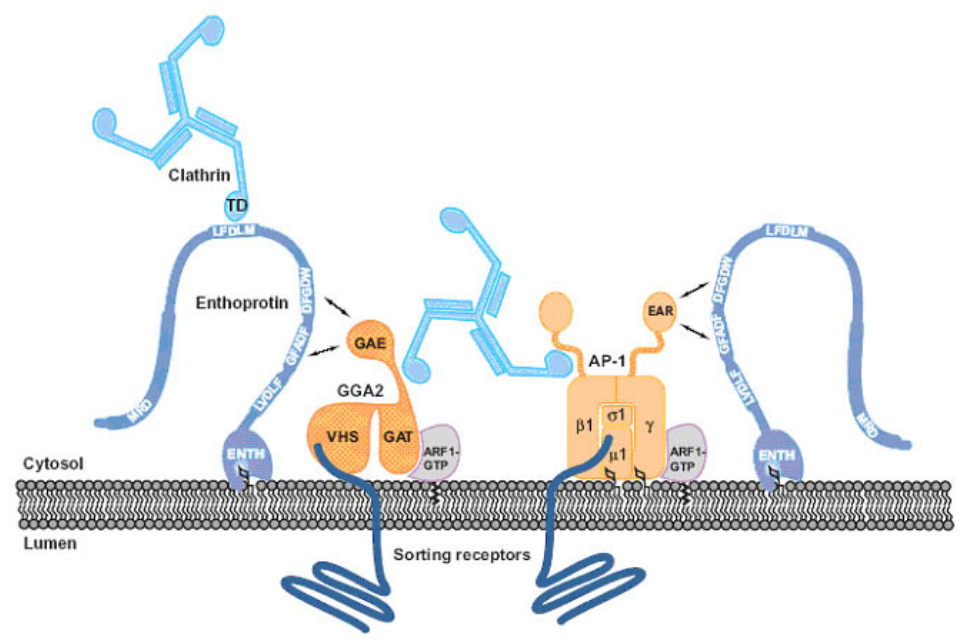

Fig.8. Enthoprotin interaction at the TGN (Legendre-Guillemin, 2004) 


\subsubsection{Membrane curvature by ENTH domain}

ENTH proteins are anchored to the membrane by $\mathrm{PI}(4,5) \mathrm{P}_{2}$ through ENTH domain, leaving their C-terminal region available to recruit coat components and catalyze clathrin assembly (Kalthoff et al., 2002). Epsins are recruited to biological membranes by multiple independent interactions instead of being targeted to the membrane by the ENTH domain alone. The ENTH domain is made up of a superhelix of $8 \alpha$-helices (Lohi et al., 2002) whereas ANTH domain is extended by one or more $\alpha$-helices compared to ENTH domain, which has in total nine $\alpha$-helices (Ford et al., 2001). When the ENTH domain binds $\mathrm{PI}(4,5) \mathrm{P}_{2}$, the structure shifts from eight $\alpha$-helices to nine, the additional helix termed as 'helix 0' (Ford et al., 2001). Structurally the ENTH domain is similar to another N-terminal domain called, VHS [Vps27p, Hrs (hepatocyte growth-regulated tyrosine kinase substrate), STAM (signal-transducing adaptor molecule)] domain, (Hyman et al., 2000) present in the proteins involved in membrane trafficking. The binding site for $\mathrm{PI}(4,5) \mathrm{P}_{2}$ in ENTH consists of a pocket of basic amino acids conserved in all ENTH domains (Ford et al., 2002) and that in ANTH domain consists of a cluster of lysine amino acids (Ford et al., 2001). Though both domains bind $\mathrm{PI}(4,5) \mathrm{P}_{2}$, they have different modes of membrane interaction (Stahelin et al., 2003b). The ENTH domain of epsin by itself caused liposome tubulation while the ANTH domain could not do it (Ford et al., 2002). In the monolayer analysis, $\mathrm{PI}(4,5) \mathrm{P}_{2}$ specifically triggers the penetration of the ENTH domain but not the ANTH domain (Stahelin et al., 2003b) which is similar to specific membrane penetration of FYVE domains and PX domain by PI3P (Stahelin et al., 2003a; Stahelin et al., 2002). The ENTH domain lacks a well-defined ligand binding pocket, but when $\mathrm{PI}(4,5) \mathrm{P}_{2}$ binds, it triggers the formation of the binding pocket, also aligns the hydrophobic residues toward the membrane surface and inserts the residues (helix 0, an amphipathic helix) into the cytoplasmic leaflet of the membrane by electrostatic switch mechanism. This membrane insertion initiates the membrane deformation by pushing surrounding lipids aside, producing a more curved surface. The energy cost for this process could be obtained by increasing the surface pressure on one side of the membrane, creating an imbalance and lowering the curvation energy. If epsin is only involved in the initial budding process, dozens of epsin molecules might be enough to shift the balance to favor the curved state (Hurley and Wendland, 2002). There are two possible models for the formation of the curvature. Insertion of the ENTH domain 
could function synergistically with the clathrin assembly to drive the membrane curvature or ENTH domain itself is enough to bend the membrane with the assembled clathrin stabilizing the deformed membrane (reviewed in: Legendre-Guillemin et al., 2004).

Since $\mathrm{PI}(4,5) \mathrm{P}_{2}$ is a central player in the formation of membrane curvature, regulation of its synthesis and turnover are great importance for endocytic vesicle trafficking. Synaptojanin dephosphorylates $\mathrm{PI}(4,5) \mathrm{P}_{2}$, converting it into PI4P which could weaken the association of ENTH proteins and other coat components with the membrane, resulting in the uncoating of clathrin-coated vesicles (Cremona, 1999).

\subsubsection{Functions of ENTH proteins}

Apart from the membrane attachment of proteins by phsopholipid binding, ENTH domain proteins stimulate clathrin assembly (Kalthoff et al., 2002; Morgan et al., 2000). In addition to recruiting coat components to membranes, ENTH proteins contribute to the formation of ordered clathrin coats. Also ENTH proteins act as cargo specific adaptors, for example, EpsinR acts as a cargo adaptor for Vtilb (Hirst et al., 2004). Mammalian and yeast epsins carry UIMs and are likely to accumulate ubiquitylated membrane proteins (Aguilar et al., 2003; Polo et al., 2002) thus act as adaptors for a wide range of ubiquitylated cargo. Epsin 1 may function as a transcriptional regulator by binding PLZF (Legendre-Guillemin et al., 2004). E/ANTH domains, isolated from various species bind tubulin and microtubules (de Camili et al., 2002; Hussain et al., 2003). So, ENTH domain proteins may link clathrin-coated membranes to microtubules. Two ANTH domain containing proteins HIP1 and HIP1R were shown to localize to clathrin coated pits, also contains a putative actin binding motif (ILWEQ) in the C-terminus shows evidence for the elusive link between the actin cytoskeleton and endocytosis (Senetar et al., 2004). A/ENTH domains play multiple roles as lipid and protein binding modules.

\subsubsection{ENTH domains interact with SNARE proteins}

To identify interacting partners for the N-terminal domain of Vtilb, a two hybrid screen was done in our lab. Interestingly, an ENTH domain containing protein, EpsinR/enthoprotin/Clint was identified as a binding partner (Fig. 9(i) a). To check whether this interaction was conserved in yeast also, two hybrid interactions were done with N-terminal domain of Vtilp and yeast A/ENTH domains (Fig. 9(ii) a). A specific interaction between ENTH domain of Ent3p and Vti1p was observed. These interactions 
were confirmed further by in vitro binding assays with bacterially expressed Strep tagged ENTH domains of Ent3p/EpsinR and His-Vti1p/Vtilb (Fig. 9(i) and (ii) b).

(i)

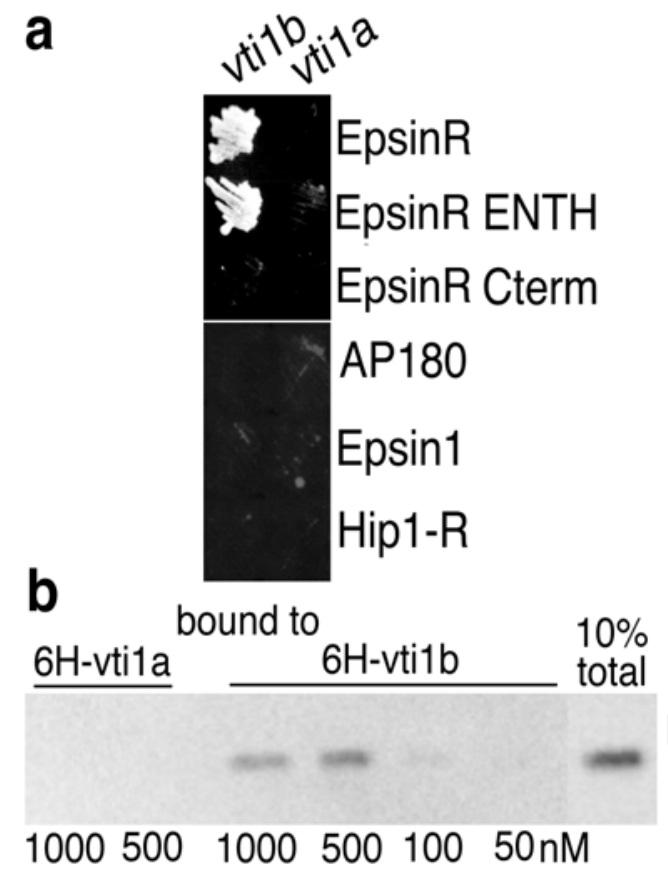

(ii)

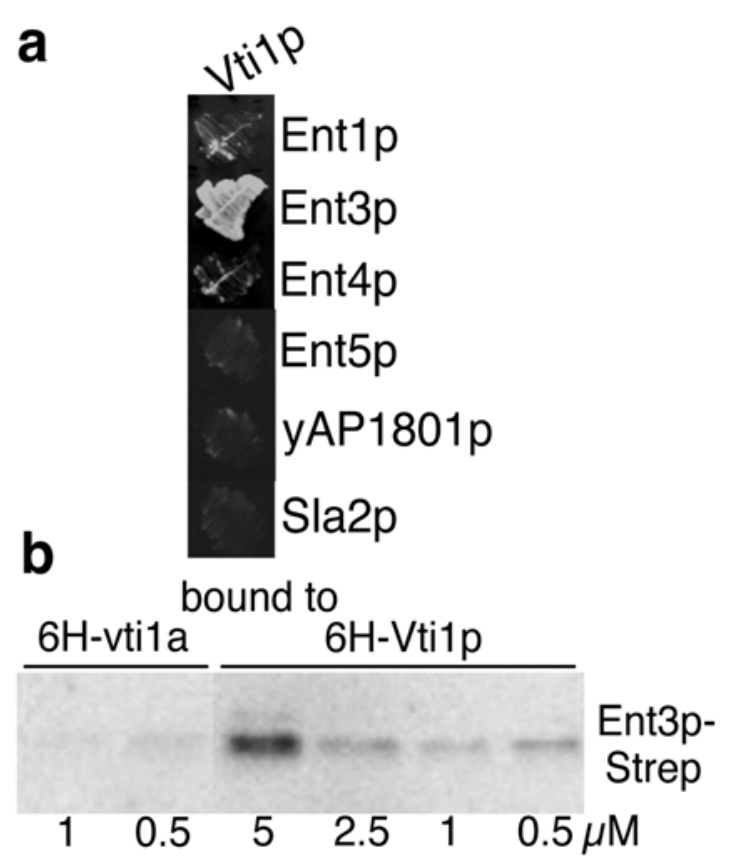

Fig.9. Two hybrid (a) and in vitro binding assay (b) for the interaction of vtilb/EpsinR (i) and Vtilp/Ent3p (ii) 


\subsection{Aim}

\section{Project 1: Function of the N-terminus of Vtilp}

The precise function of the SNARE complex, its individual components, and of its accessory proteins remains to be characterized. The extent to which SNAREs are responsible for the initial recognition and specificity of interactions between vesicles has, however, been controversial. Many questions have arisen because some SNAREs, can act at more than one transport step (Clague, 1999). Some individual SNAREs are promiscuous in their partnerships, for example the yeast v-SNARE Vtilp has been shown to pair with four of the seven yeast syntaxin related t-SNAREs. The ability of Vtilp to mediate multiple fusion steps requires additional proteins to ensure specificity in membrane traffic. In addition, the activity of Vtilp has to be tightly regulated and it has to be transported to the correct organelles. While interaction with SNAREs, requires the SNARE motif, the function of the N-terminus is poorly understood. It is proposed that the N-terminal domains of SNAREs may have some regulatory functions. So, we would like to unravel the functions of the N-terminus of Vtilp, a versatile SNARE protein which deserves intensive investigation. Using an N-terminal mutant vtiQ29RW79R, the stability, localization, function and the turn over of mutant Vtilp should be studied to get further insight.

\section{Project 2: Characterization of Ent proteins in yeast}

The preliminary data from our lab showed that ENTH domain proteins EpsinR/Ent3p interacted with the N-term domain of SNARE proteins Vtilb/Vtilp. Further studies should be conducted to investigate the functional interaction between Vtilp and Ent proteins. Also, the function of Ent3p and Ent5p should be studied by generation and characterization of deletion mutants. 



\section{Materials and Methods}

\subsection{Materials}

\subsubsection{Laboratory Equipments}

All Glasswares

Autoclave bags

Autoclave type Tecnoclav 50

Bottle top filters

Corex ${ }^{\circledR}$ tubes $15 \mathrm{ml}$

Cuvetts for Electroporation

DNA-Sequencer Type 310

Electroporator 1000

Eppendorf- Tabletop centrifuge 5415C

Fluorescence microscope IX50

French ${ }^{\circledR}$ Pressure Cell Press, SLM-Minco ${ }^{\circledR}$

Gene quant II, RNA/DNA calculator

Ice machine

Incubators Innova 4230 and 4330

Intelligent Dark Box II, LAS-1000

Phosphoimager Fujix BAS1000

Ultra turrax T8

Supersignal Chemiluminiscent Substrate

Syringes

Tabletop Ultracentrifuge TLA-100.3

Thermocycler GeneAmp PCR system 9600

Mastercycler gradient

JA-10 and JA-20 Polypropylene tube

Culture flasks for bacteria

Glass pipettes
Schütt, Göttingen

Sarstedt, Nümbrecht

Tecnomara, Zürich

Sarstedt Inc., Newton, USA

Corning Inc., NY

Invitrogen, Leek

ABI, PE Biosystems

Stratagene, USA

Schütt, Göttingen

Olympus, Hamburg

Spectronic Instruments

Pharmacia Biotech, UK

Ziegra, Isernhagen

New Brunswick Scintific, Edison

Fuji, Japan

Fuji, Japan

IKA Labortechnik, Staufen

Pierce, Illinois/ USA

Sarstedt, Braunschweig

Beckmann, Münich

Perkin-Elmer Cetus, Norwalk

Eppendorf, Hamburg

Nalgene, München

Schott, Mainz

Schütt, Göttingen 
Microscope slides

Needles for syringes

Liquid Scintillation counter 1900R

Parafilm

Pasteur pipettes

Pipette tips

Plastic tubes 10, 15 and $50 \mathrm{ml}$

Nitrocellulose membrane $0.2 \mu \mathrm{M}$

Whatman GB002 paper

Whatman GB003 paper extra thick

X-ray films XAR-5

$\mathrm{X}$-ray film developing machine

\subsubsection{Chemicals}

All the chemicals are of Analysis grade.

Aminoacids

APNE (N-Acetyl-Phenylalanin- $\beta$-Naphtylester)
Bacto-Agar
Bacto-Pepton
Bacto-Trypton
Coomassie Brilliant Blue

Coomassie Brilliant Blue

DAPI (4'-6-Diamino-2-phenylindoldihydrochlorid)

Dimethyl-pimelinediimidat-dihydrochlorid (DMP)

dNTPs

Fast Carnet GBC Salt

Liquid Scintillation Lumasafe Plus

Yeast Extract

Isopropyl- $\alpha$-D-Thiogalactopyranosid (IPTG)

Pansorbin ${ }^{\circledR}$ Cells, Standardised

Phenol:Chloroform:Isoamylalkohol (25:24:1)

Poly-L-Lysin Hydrobromide

Ponceau-S

Protein-A-Sepharose / Protein-G-Sepharose

Bovine Serum Albumin

(Albumin bovine Fraction V, BSA)

Triton X-100
Menzel-Glaser

B.Braun Melsungen AG,

Melsungen

Packard, Frankfurt

American National Can ${ }^{\mathrm{TM}}$

Chicago

Schütt, Göttingen

Sarstedt, Nümbrecht

Sarstedt, Nümbrecht

Schleicher and Schüll, Dassel

Schleicher and Schüll, Dassel

Schleicher and Schüll, Dassel

Kodak, Stuttgart

Agfa-Gevaert, Leverkusen

Biomol, Hamburg, Heidelberg,

Serva, München,

Sigma, ICN Meckenheim

Sigma Münich

DIFCO Detroid (USA)

DIFCO Detroid (USA)

DIFCO Detroid (USA)

Serva Heidelberg

Sigma Münich

Fluka Buchs

Amersham Braunschweig

Sigma Münich

Packard Groningen

DIFCO Detroid (USA)

BTS St. Leon-Rot

Calbiochem Bad Soden

Fluka Buchs (Schweiz)

Sigma Münich

Serva Heidelberg

Pharmacia Freiburg

Serva Heidelberg

Serva Heidelberg 
Tween-20

Water, HPLC-purified

Yeast-Nitrogene-Base

$30 \%(\mathrm{w} / \mathrm{v})$ Acrylamid $/ 0.8 \%(\mathrm{w} / \mathrm{v})$ Bisacrylamid
Serva

Baker

DIFCO

Roth
Heidelberg

Deventer

Detroid (USA)

Karlsruhe

\subsubsection{Proteaseinhibitors}

Leupeptin

Pepstatin A

Phenylmethylsulfonylfluorid (PMSF)

$100 \mu \mathrm{l} 100 \mathrm{x}$ Proteaseinhibitor-Mix

$50 \mu 1100 \mathrm{mM}$ PMSF $(17.4 \mathrm{mg} / \mathrm{ml}$ in Ethanol)

$10 \mu \mathrm{l}$ Pepstatin $(1 \mathrm{mg} / \mathrm{ml}$ in Methanol)

$39 \mu 1$ Methanol

$1 \mu \mathrm{l}$ Leupeptin $\left(10 \mathrm{mg} / \mathrm{ml}\right.$ in $\left.\mathrm{H}_{2} \mathrm{O}\right)$
Biomol, Hamburg

Biomol, Hamburg

Serva, Heidelberg

\subsubsection{Antibodies}

\begin{tabular}{|c|c|c|c|c|c|}
\hline $\begin{array}{l}\text { Primary } \\
\text { Antibody }\end{array}$ & $\begin{array}{l}\text { Molecular } \\
\text { weight } \\
(\mathrm{kDa})\end{array}$ & $\begin{array}{l}\text { Immunized } \\
\text { species }\end{array}$ & $\begin{array}{l}\text { Dilution } \\
\text { for } \\
\text { western } \\
\text { blot }\end{array}$ & $\begin{array}{l}\text { Dilution for } \\
\text { Immunofluorecence }\end{array}$ & Source \\
\hline Vtilp & 29 & Rabbit & $1: 3000$ & $1: 50$ & FvMollard \\
\hline Apelp & $60(p), 51(M)$ & Rabbit & $1: 5000$ & & Thumm \\
\hline Vph1p & 100 & Mouse & $1: 100$ & & T. Stevens \\
\hline Vps10p & 190 & Rabbit & $1: 1000$ & & T. Stevens \\
\hline Pep12p & 33 & Rabbit & $1: 1000$ & $1: 50$ & $\begin{array}{l}\text { FvMollard } \\
\text { Molecular } \\
\text { probes }\end{array}$ \\
\hline GFP & 45 & Mouse & $1: 2000$ & & MBL \\
\hline Use1p & 33 & Rabbit & $1: 1000$ & & FvMollard \\
\hline ALP & 72 & Mouse & $1: 100$ & & T. Stevens \\
\hline Bip/Kar2p & 75 & Rabbit & $1: 1000$ & & $\begin{array}{l}\text { H.D. } \\
\text { Schmitt }\end{array}$ \\
\hline ENT3p & 48 & Rabbit & $1: 500$ & & FvMollard \\
\hline
\end{tabular}




\begin{tabular}{|l|l|l|l|l|l|}
\hline HA & - & Mouse & $1: 1000$ & & $\begin{array}{l}\text { BabCo, } \\
\text { Richmond }\end{array}$ \\
\hline CPY & 69 & Mouse & $1: 100$ & & T. Stevens \\
\hline $\begin{array}{l}\text { Secondary } \\
\text { antibodies }\end{array}$ & & & & & \\
\hline Cy2 & & anti Mouse & & $1: 100$ & Dianova \\
\hline Cy2 & & anti Rabbit & & $1: 100$ & Dianova \\
\hline Cy3 & & anti Mouse & & $1: 100$ & Dianova \\
\hline Cy3 & & anti Rabbit & & $1: 100$ & Dianova \\
\hline Goat anti-mouse Horseradish peroxidase & $1: 10000$ & & Sigma \\
\hline Goat anti-rabbit Horseradish peroxidase & $1: 10000$ & & Sigma \\
\hline
\end{tabular}

\subsubsection{Enzymes, Nucleotides and Standards}

1 kb-DNA-Ladder

Alkaline Phosphatase (Calf Intestine)

Prestained Protein Standard

Restriction Endonucleases

RNAse A

T4-DNA-Ligase

T4-Polynucleotide-Kinase

Taq-DNA-Polymerase

$P f u$-DNA-Polymerase

TITANIUM ${ }^{\text {TM }}$ Taq-DNA-Polymerase

Ultrapure dNTP Set

Zymolyase $^{\circledR}-20 \mathrm{~T}$
Gibco BRL, Eggenstein

Roche, Mannheim

Bio-Rad, Münich

New England Biolabs, Bad Schwalbach

Boehringer, Mannheim

New England Biolabs, Bad Schwalbach

New England Biolabs, Bad Schwalbach

Pharmacia, Freiburg

Stratagene, Heidelberg

Clonetech, Palo Alto, CA

Pharmacia, Freiburg

Seikagaku, Tokyo (Japan)

\subsubsection{Radioactive substance}

L- $\left[{ }^{35} \mathrm{~S}\right]-$ Methionin/Cystein, $10 \mathrm{mCi} / \mathrm{mmol}$ from Hartmann-Analytik, Braunschweig 


\subsubsection{Kits for DNA and Protein}

ABI PRISM Dye Terminator Cycle

Sequencing Ready Reaction Premix

Perkin Elmer Cetus, Norwalk (USA)

BioRad Protein Assay

Bio-Rad, Munich

QIAEX $^{\circledR}$ II Agarose Gel Extraction Kit

Qiagen, Hilden

QIAprep Spin Miniprep Kit

Qiagen, Hilden

SuperSignal ${ }^{\circledR}$ West Pico

Chemiluminescent Substrate

PIERCE, Rockford (USA)

\subsubsection{Oligonucleotides}

\begin{tabular}{|c|c|c|}
\hline Name & Oligonucleotide & Purpose \\
\hline ENT3HA f & $\begin{array}{l}\text { TAACCATACATCATCCAAAGAAATCGATTTACTTTCCTTT } \\
\text { CGG ATC CCC GGG TTA ATT AA }\end{array}$ & $\begin{array}{l}\text { For genomic } \\
\text { integration of } \\
\text { HA tag to ENT3 }\end{array}$ \\
\hline ENT3HA r & $\begin{array}{l}\text { TTATAAAACATTTACATATTGTGTAAACCAATAATATCAC } \\
\text { GAA TTC GAG CTC GTT TAA AC }\end{array}$ & $\begin{array}{l}\text { For genomic } \\
\text { integration of } \\
\text { HA tag to ENT3 }\end{array}$ \\
\hline ENT3UT5 & CG GGA TCC ATT TTG CTA AGC CAA TTC & $\begin{array}{l}\text { To amplify } \\
\text { ENT3 and also to } \\
\text { delete ENT3 }\end{array}$ \\
\hline ENT3UT3 & GC TCT AGA AGG GCA CTT CAA CTC TC & $\begin{array}{l}\text { To amplify } \\
\text { ENT3 and also to } \\
\text { delete ENT3 }\end{array}$ \\
\hline $\begin{array}{l}\text { ENT3- } \\
\text { Aux3 }\end{array}$ & $\begin{array}{l}\text { TTATAAAACATTTACATATTGTGTAAACCAATAATATCAC } \\
\text { GGTATTTCACACCGCATA }\end{array}$ & To delete ENT3 \\
\hline $\begin{array}{l}\text { ENT3- } \\
\text { Aux5 }\end{array}$ & $\begin{array}{l}\text { CGTCGATAGGAGATCACATCGTTAATTAGTGTTAGGAAGA } \\
\text { TTGTACTGAGAGTGCACCAT }\end{array}$ & To delete ENT3 \\
\hline 6HENT3f & GCAT AT GAG TTT AGA GGA TAC ATTAG & $\begin{array}{l}\text { To tag ENTH } \\
\text { domain of ENT3 } \\
\text { with 6xHIS }\end{array}$ \\
\hline
\end{tabular}




\begin{tabular}{|c|c|c|}
\hline $6 \mathrm{HENT3 \textrm {r }}$ & CGGATCC TCA AAA GGA AAG TAA ATC GAT TTC & $\begin{array}{l}\text { To tag ENTH } \\
\text { domain of ENT3 } \\
\text { with 6xHIS }\end{array}$ \\
\hline ENT3 5 & CGG GAT CCG AAT GAG TTT AGA GGA TAC ATT & $\begin{array}{l}\text { To amplify and } \\
\text { tag GFP to the } \\
\text { C-term of ENT3 }\end{array}$ \\
\hline ENT3cfo & CGG GAT CCA AAG GCA AGA GAA ACG GCA AAG & $\begin{array}{l}\text { To amplify C- } \\
\text { term of ENT3 } \\
\text { (AA158-408) }\end{array}$ \\
\hline ENT3cre & GCC CAA GCT TCA AAA GGA AAG TAA ATC GAT TTC & $\begin{array}{l}\text { To amplify } \\
\text { C-term of ENT3 } \\
\text { (AA158-408) }\end{array}$ \\
\hline ENT3 GFP & TCC CCC GGG AAA GGA AAG TAA ATC GAT TTC & $\begin{array}{l}\text { To amplify and } \\
\text { tag GFP to the } \\
\text { C-term of ENT3 }\end{array}$ \\
\hline ENT5 5 & CGGG ATC CAA ATG GAC TCA TTA TCA AAA AAG & $\begin{array}{l}\text { To amplify and } \\
\text { tag GFP to the } \\
\text { C-term of ENT5 }\end{array}$ \\
\hline Ent5 GFP & CCCC AAG CTTG ACC AAC GACT TGG AGT AAG & $\begin{array}{l}\text { To amplify and } \\
\text { tag GFP to the } \\
\text { C-term of ENT5 }\end{array}$ \\
\hline ENT5 delf & CAA TCTAGA TTT TAG TTTT CGG & To delete ENT5 \\
\hline ENT5 delr & TTT CTT CTG CAT GGA TAA TGAC & To delete ENT5 \\
\hline Ent5au5 & $\begin{array}{l}\text { ATTAAACGTTCCAATTGCATAAATACCAACACCATACAAA } \\
\text { TTGTACTGAGAGTGCACCAT }\end{array}$ & To delete ENT5 \\
\hline Ent5au3 & $\begin{array}{l}\text { CTGTATTGAATGTATTGGGAGATGAAGGGGTATTTGGTGA } \\
\text { GGTATTTCACACCGCATA }\end{array}$ & To delete ENT5 \\
\hline Pep12 5' & AATGCAGCGCAGAGGCTATC & To delete Pep12 \\
\hline
\end{tabular}




\begin{tabular}{|l|l|l|}
\hline Pep12 3' & CACTCTTCATTAGGGTATGATG & To delete Pep12 \\
\hline ubc7 f & AATAGTGTAATTTGGAAGGGC & To delete Ubc7 \\
\hline ubc7 r & ATCATTAACCTGCTACCTGC & To delete Ubc7 \\
\hline cue1 f & CATTACAATCTACGATCGCGC & To delete Cue1 \\
\hline cue1 r & TCCCGACAAGCACTTAAGCG & To delete Cue1 \\
\hline
\end{tabular}

\subsubsection{Yeast and bacterial strains}

\section{Yeast strains}

\begin{tabular}{|c|c|c|}
\hline Strain & Genotype & Reference \\
\hline SEY6210 & $\begin{array}{l}\text { MAT } \alpha \text { leu2-3,112 ura3-52 his3- } \Delta 200 \\
\text { trp1- } \Delta 901 \text { lys2-801 suc2- } \Delta 9 \text { mel- }\end{array}$ & (Robinson et al., 1988) \\
\hline SEY6211 & $\begin{array}{l}\text { MATa leu2-3,112 ura3-52 his3- } \Delta 200 \\
\text { ade2-101 trp } 1-\Delta 901 \text { suc2- } \Delta 9 \text { mel- }\end{array}$ & (Robinson et al., 1988) \\
\hline FvMY7 & $\begin{array}{l}\text { MATa leu2-3,112 ura3-52 his3- } \Delta 200 \\
\text { ade2-101trp1- } \Delta 901 \text { suc2- } \Delta 9 \text { mel- } v t i 1-1\end{array}$ & G. Fischer von Mollard \\
\hline FvMY24 & $\begin{array}{l}\text { MATa leu2-3,112 ura3-52 his3- } \Delta 200 \\
\text { ade2-101trp1- } \Delta 901 \text { suc2- } \Delta 9 \text { mel- } v t i 1-2\end{array}$ & G. Fischer von Mollard \\
\hline FvMY29 & $\begin{array}{l}\text { MATa leu2-3,112 ura3-52 his3- } \Delta 200 \\
\text { ade2-101trp1- } \Delta 901 \text { suc2- } \Delta 9 \text { mel- vti1- } \\
\text { lpho8s }\end{array}$ & G. Fischer von Mollard \\
\hline FvMY6pBK117 & $\begin{array}{l}\text { MATa leu2-3,112 ura3-52 his3- } \Delta 200 \\
\text { ade2-101trp1- } \Delta 901 \text { suc2- } \Delta 9 \\
\text { mel } \Delta \text { vti1 }:: H I S 3 \text { vtilQ116-217 }\end{array}$ & G. Fischer von Mollard \\
\hline FvMY6pBK119 & $\begin{array}{l}\text { MATa leu2-3,112 ura3-52 his3- } \Delta 200 \\
\text { ade2-101trp1- } \Delta 901 \text { suc2- } \Delta 9 \\
\text { mel } \Delta \text { vti1 }:: H I S 3 \text { vtilM55-217 }\end{array}$ & G. Fischer von Mollard \\
\hline FvMY6pBK120 & $\begin{array}{l}\text { MATa leu2-3,112 ura3-52 his3- } \Delta 200 \\
\text { ade2-101trp1- } \Delta 901 \text { suc2- } \Delta 9 \\
\text { mel } \Delta \text { vtil }:: H I S 3 \text { vtilQ29R } W 79 R\end{array}$ & G. Fischer von Mollard \\
\hline FvMY6pBK123 & $\begin{array}{l}\text { MATa leu2-3,112 ura3-52 his3- } \Delta 200 \\
\text { ade2-101trp1- } \Delta 901 \text { suc2- } \Delta 9 \\
\text { mel } \Delta \text { vti1 }:: H I S 3 \text { vtilQ29R }\end{array}$ & G. Fischer von Mollard \\
\hline FvMY6pBK128 & $\begin{array}{l}\text { MATa leu2-3,112 ura3-52 his3- } \Delta 200 \\
\text { ade2-101trp1- } \Delta 901 \text { suc2- } \Delta 9 \\
\text { mel } \Delta \text { vti1 }: \because H I S 3 \text { vtil W79R }\end{array}$ & G. Fischer von Mollard \\
\hline BKY12 & $\begin{array}{l}\text { MAT } \alpha \text { leu2-3,112 ura3-52 his } 3-\Delta 200 \\
\text { trp1- } \triangle 901 \text { lys } 2-801 \text { suc2- } \Delta 9 \text { mel- } \\
\text { pep } 4 \Delta:: U R A 3\end{array}$ & Beate Veith \\
\hline BKY13 & $\begin{array}{l}\text { MATahis } 3 \Delta 1 \text { leu } 2 \Delta 0 l y s 2 \Delta 0 u r a 3 \Delta 0 \\
\text { ent } 5 \Delta:: \text { kanMX4 ent } 3 \Delta:: L E U 2\end{array}$ & Beate Veith \\
\hline
\end{tabular}




\begin{tabular}{|c|c|c|}
\hline Strain & Genotype & Reference \\
\hline BKY15 & $\begin{array}{l}\text { MATa leu2-3,112 ura3-52 his3- } \Delta 200 \\
\text { ade2-101 trp } 1-\Delta 901 \text { suc2- } \Delta 9 \text { mel-vtil-1 } \\
\text { ent5 } \Delta:: \text { kanMX4 }\end{array}$ & Beate Veith \\
\hline BKY16 & $\begin{array}{l}\text { MATa leu2-3,112 ura3-52 his3- } \Delta 200 \\
\text { ade2-101 trp1- } \triangle 901 \text { suc2- } \Delta 9 \text { mel- vtil-2 } \\
\text { ent } 5 \Delta:: \text { kanMX4 }\end{array}$ & Beate Veith \\
\hline BKY17 & $\begin{array}{l}\text { MATa his } 3 \Delta 1 \text { leu } 2 \Delta 0 \text { lys } 2 \Delta 0 \text { ura } 3 \Delta 0 \\
\text { ent } 4 \Delta:: \text { kanMX4 ent } 5 \Delta:: U R A 3\end{array}$ & Beate Veith \\
\hline BKY18 & $\begin{array}{l}\text { MAT } \boldsymbol{a} \text { ura3-52 his } 3-\triangle 200 \text { ent } 3 \Delta:: L E U 2 \\
\text { ent } 4 \Delta:: \text { kanMX4 ent } 5 \Delta:: U R A 3\end{array}$ & Beate Veith \\
\hline BKY19 & 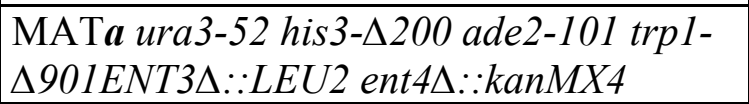 & Beate Veith \\
\hline BKY20 & $\begin{array}{l}\text { MAT } \boldsymbol{a} \text { ura3-52 his3- } \triangle 200 \text { ade2-101 trp1- } \\
\Delta 901 \text { ent } 3 \Delta:: L E U 2 \text { ent } 5 \Delta:: U R A 3\end{array}$ & Beate Veith \\
\hline BKY21 & $\begin{array}{l}\text { MAT } \alpha \text { ura3-52 his3- } 200 \text { ade2-101 trp1- } \\
\Delta 901 \text { ent } 4 \Delta:: \text { kanMX4 ent } 5 \Delta:: U R A 3\end{array}$ & Beate Veith \\
\hline BKY22 & $\begin{array}{l}\text { MAT } \alpha \text { ura3-52 his3- } \Delta 200 \text { trp } 1-\Delta 901 \\
\text { ent3 } \Delta:: L E U 2\end{array}$ & Beate Veith \\
\hline BKY23 & $\begin{array}{l}\text { MATa ura3-52 his3- } 200 \text { ade2-101 trpl- } \\
\Delta 901 \text { ent } 4 \Delta:: k a n M X 4\end{array}$ & Beate Veith \\
\hline BKY24 & 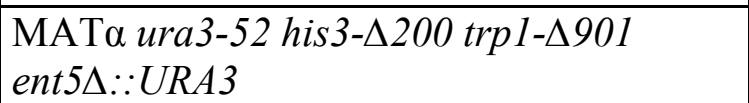 & Beate Veith \\
\hline BKY25 & $\begin{array}{l}\text { MATa leu2-3,112 ura3-52 his3- } \triangle 200 \\
\text { ade2-101 trp1- } \triangle 901 \text { suc2- } \Delta 9 \text { mel- } \\
\text { ent } 3 \Delta:: \text { kanMX4 pho } 8 \Delta:: A D E 2\end{array}$ & Beate Veith \\
\hline BKY26 & 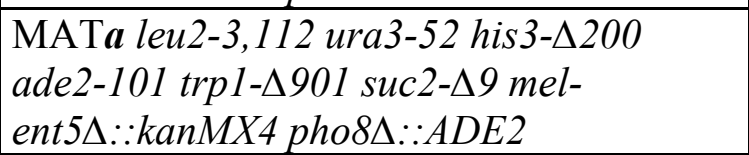 & Beate Veith \\
\hline SNY18 & $\begin{array}{l}\text { MATa leu2-3,112 ura3-52 his3- } \Delta 200 \\
\text { ade2-101 trp1- } \triangle 901 \text { suc2- } \Delta 9 \text { mel- } \\
\text { pho8 }:: A D E 2\end{array}$ & Steve Nothwehr \\
\hline MDY7 & $\begin{array}{l}\text { MATa leu2-3,112 ura3-52 his3- } \Delta 200 \\
\text { ade2-101 trp1- } \triangle 901 \text { suc2- } \Delta 9 \text { mel- vtil-2 } \\
\text { pep } 4 \Delta:: \text { URA3 }\end{array}$ & Meik Dilcher \\
\hline BY4742 & MATa his $3 \Delta 1$ leu $2 \Delta 0$ lys $2 \Delta 0$ ura $3 \Delta 0$ & Euroscarf \\
\hline ent $3 \Delta$ & 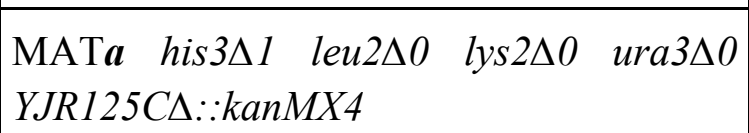 & Euroscarf \\
\hline ent $4 \Delta$ & $\begin{array}{l}\text { MATa his } 3 \Delta 1 \text { leu2 } 2 \Delta 0 \text { lys } 2 \Delta 0 \text { ura3 } \Delta 0 \\
Y L L 038 c \Delta:: k a n M X 4\end{array}$ & Euroscarf \\
\hline ent5 $\Delta$ & $\begin{array}{l}\text { MATa his } 3 \Delta 1 \text { leu2 } \Delta 0 \text { lys } 2 \Delta 0 \text { ura3 } \Delta 0 \\
Y D R 153 c \Delta:: \text { kanMX4 }\end{array}$ & Euroscarf \\
\hline SCY1 & $\begin{array}{l}\text { MATa leu2-3,112 ura3-52 his3- } \Delta 200 \\
\text { ade2-101 trp1- } \Delta 901 \text { suc2- } \Delta 9 \text { mel- } \\
\text { ent } 3 \Delta:: \text { kanMX4 vtil-2 }\end{array}$ & This study \\
\hline
\end{tabular}




\begin{tabular}{|c|c|c|}
\hline Strain & Genotype & Reference \\
\hline SCY2 & $\begin{array}{l}\text { MAT } \alpha \text { leu2-3,112 ura3-52 his3- } \Delta 200 \\
\text { trp1- } \Delta 901 \text { lys2-801suc2- } \Delta 9 \text { mel- } \\
\text { ent } 3 \Delta:: \text { kanMX4 }\end{array}$ & This study \\
\hline SCY3 & $\begin{array}{l}\text { MATa leu2-3,112 ura3-52 his3- } \Delta 200 \\
\text { ade2-101 trp1- } \Delta 901 \text { suc2- } \Delta 9 \text { mel- } \\
\text { ent } 3 \Delta:: \text { kanMX4 vtil-1 }\end{array}$ & This study \\
\hline SCY4 & 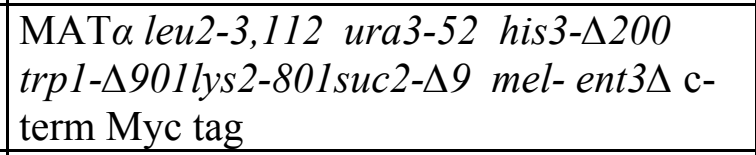 & This study \\
\hline SCY5 & $\begin{array}{l}\text { MATa his } 3 \Delta 1 \text { leu } 2 \Delta 0 \text { lys } 2 \Delta 0 \text { ura } 3 \Delta 0 \\
\text { ent } 3 \Delta:: L E U 2 \text { ent } 4 \Delta:: \text { kanMX } 4\end{array}$ & This study \\
\hline SCY6 & $\begin{array}{l}\text { MAT } \alpha \text { leu2-3,112 ura3-52 his } 3-\Delta 200 \\
\text { ade2-101 trp } 1-\Delta 901 \text { suc2- } \Delta 9 \text { mel- } \\
\Delta v t i 1:: H I S 3 \text { vtil Q29R W79 } \\
\text { ent } 3 \Delta:: \text { kanMX4 }\end{array}$ & This study \\
\hline SCY7 & $\begin{array}{l}\text { MAT } \alpha \text { leu2-3,112 ura3-52 his3- } \Delta 200 \\
\text { trp1- } \triangle 901 \text { lys2-801suc2- } \Delta 9 \text { mel- } \\
\text { ENT3HA::TRP2 }\end{array}$ & This study \\
\hline SCY8 & $\begin{array}{lr}\text { MAT } \alpha \text { leu2-3,112 ura3-52 } & \text { his3- } \Delta 200 \\
\text { trp } 1-\Delta 901 \text { lys } 2-801 \text { suc2- } \Delta 9 & \text { mel- } \\
\Delta v t i 1: \therefore H I S 3 \text { vtil Q29R } & \\
\end{array}$ & This study \\
\hline SCY9 & 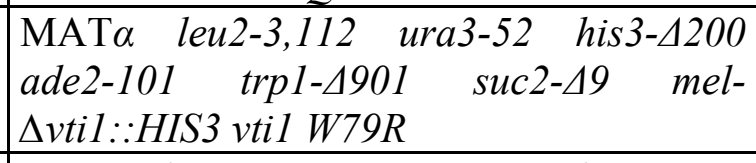 & This study \\
\hline SCY10 & 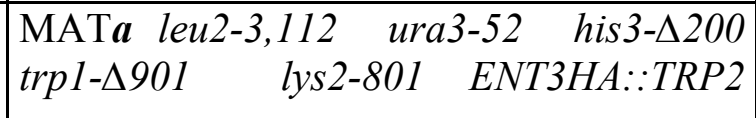 & This study \\
\hline SCY11 & $\begin{array}{lr}\text { MATa leu2-3,112 } & \text { ura3-52 his3- } \triangle 200 \\
\text { trp 1- } \triangle 901 \text { lys2-801 } & \text { fab1 }:: L E U 2 \\
\text { ENT3HA::TRP2 } & \\
\end{array}$ & This study \\
\hline SCY12 & $\begin{array}{l}\text { MATa leu2-3,112 ura3-52 his3- } \Delta 200 \\
\text { ade2-101trp1- } \triangle 901 \text { suc2- } \Delta 9 \text { mel- } \\
\text { ENT3HA::TRP2 vtil-2 }\end{array}$ & This study \\
\hline SCY13 & 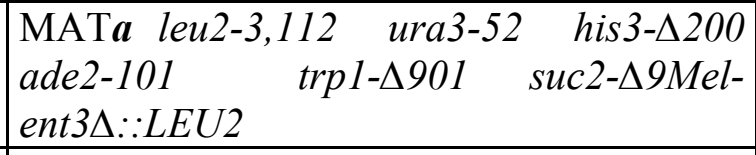 & This study \\
\hline SCY14 & $\begin{array}{l}\text { ATa leu2-3,112 ura3-52 his3- } \Delta 200 \text { ade2- } \\
1 \text { trp1- }-901 \text { suc2- } \Delta 9 \text { Mel-:: vtil-Q29R } \\
79 R\end{array}$ & This study \\
\hline SCY15 & 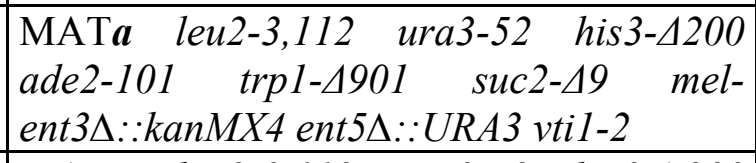 & This study \\
\hline SCY16 & 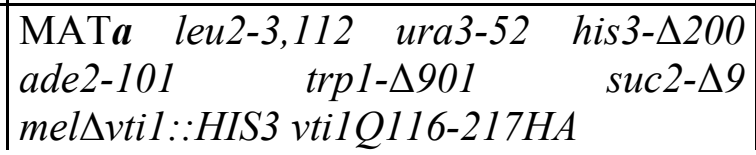 & This study \\
\hline
\end{tabular}




\begin{tabular}{|c|c|c|}
\hline Strain & Genotype & Reference \\
\hline SCY17 & $\begin{array}{|lr|}\text { MATa leu2-3,112 ura3-52 } & \text { his } 3-\Delta 200 \\
\text { ade2-101 trp } 1-\Delta 901 & \text { suc2- } \Delta 9 \\
\text { melsvtil::HIS3vtilM55-217HA } & \\
\end{array}$ & This study \\
\hline SCY18 & 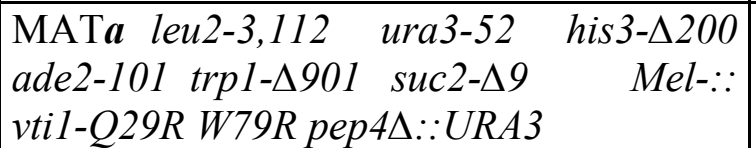 & This study \\
\hline SCY19 & 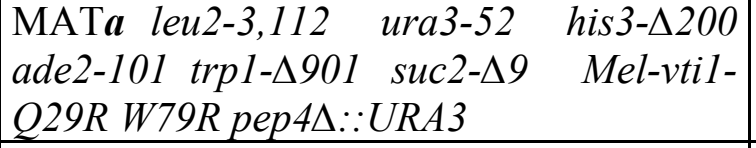 & This study \\
\hline SCY20 & $\begin{array}{l}\text { MAT } \alpha \text { his } 3 \Delta 1 \text { leu } 2 \Delta 0 \text { lys } 2 \Delta 0 \text { ura3 } \Delta 0 \\
\text { ent } 5 \Delta:: \text { kanMX4 pep } 4 \Delta:: U R A 3\end{array}$ & This study \\
\hline SCY21 & 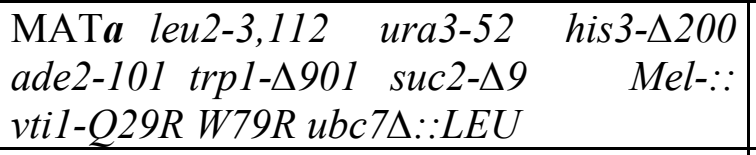 & This study \\
\hline SCY22 & 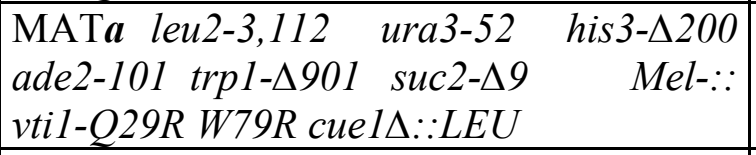 & This study \\
\hline SCY23 & 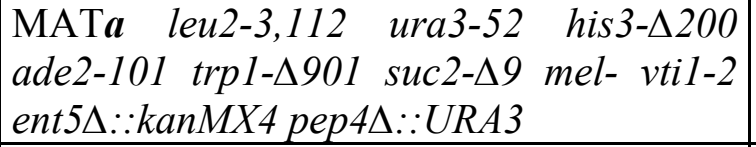 & This study \\
\hline SCY24 & 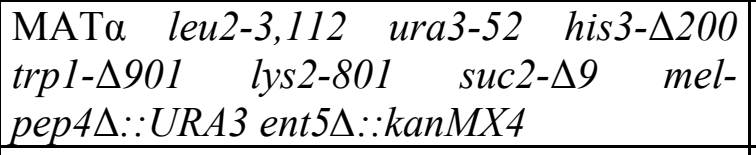 & This study \\
\hline SCY25 & 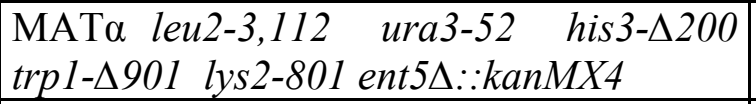 & This study \\
\hline SCY26 & 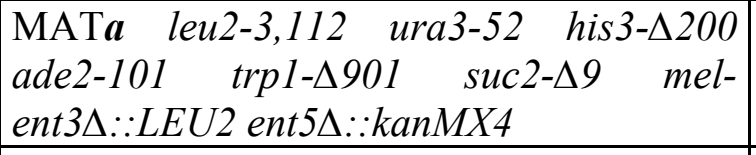 & This study \\
\hline SCY27 & 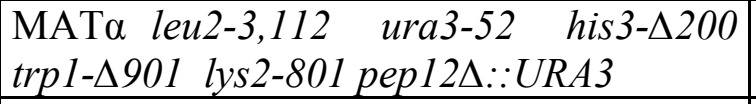 & This study \\
\hline SCY28 & $\begin{array}{lc}\text { MAT } \alpha \text { leu2-3,112 } & \text { ura3-52 } \\
\text { trp } 1-\triangle 901 & \text { lys2-801ent } 3 \Delta:: L \text { LEU2 } \\
\text { pep } 4 \Delta:: U \text { URA3 } & \end{array}$ & This study \\
\hline SSY1 & 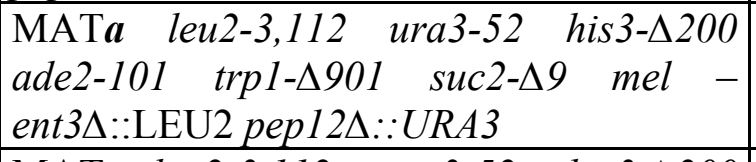 & Sarah Schulz \\
\hline SSY2 & 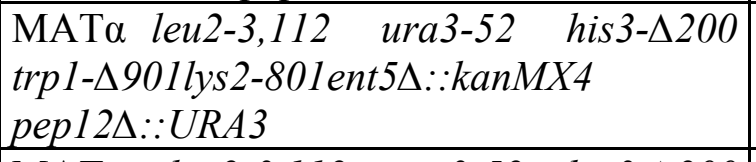 & Sarah Schulz \\
\hline SSY3 & 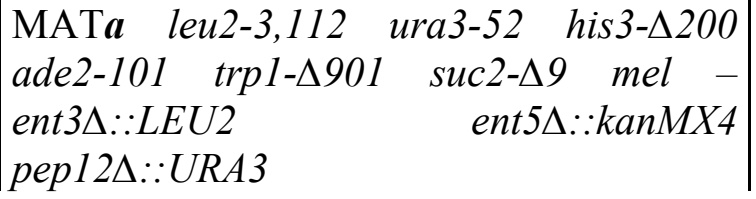 & Sarah Schulz \\
\hline
\end{tabular}




\section{Bacterial strains}

\begin{tabular}{|c|c|c|}
\hline Strain & Genotype & Reference \\
\hline DH5a & 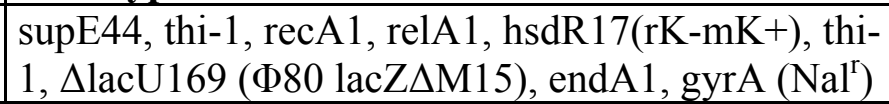 & Gibco BRL, Eggenstein \\
\hline XL1-Blue & $\begin{array}{l}\text { recA1, endA1, gyrA96, thi-1, hsdR17, supE44, } \\
\text { relA1, lac }\left[F^{\prime}, \text { proAB, lacl }{ }^{\mathrm{A}} \mathrm{Z} \Delta \mathrm{M} 15, \mathrm{Tn} 10\left(\mathrm{Tet}^{\mathrm{r}}\right)\right]^{\mathrm{c}}\end{array}$ & Stratagene, Heidelberg \\
\hline $\begin{array}{l}\text { BL21- } \\
\text { (D3)-RIL }\end{array}$ & $\begin{array}{l}\text { E. coli } \mathrm{B} \mathrm{F}^{-} \text {ompT hsdS }\left(\mathrm{r}_{\mathrm{B}}{ }^{-} \mathrm{m}_{\mathrm{B}}{ }^{-}\right) \mathrm{dcm}^{+} \mathrm{Tet}^{\mathrm{r}} \text { gal } \\
\left.\lambda(\mathrm{DE} 3) \text { endA Hte [argU ileY leuW Cam}{ }^{\mathrm{r}}\right]\end{array}$ & Stratagene, Heidelberg \\
\hline
\end{tabular}

\subsubsection{Plasmids}

\begin{tabular}{|c|c|c|}
\hline Plasmid & Details & Reference \\
\hline $\mathrm{pSC} 2$ & $\begin{array}{l}\text { C-terminus of ENT3 (AA158-408 end, PCR) } \\
\text { overexpressed under TPI promotor from } \\
\text { pYX242 }(2 \mu) \text {, cloned in BamH1-HindIII site. }\end{array}$ & This study \\
\hline $\mathrm{pSC} 4$ & $\begin{array}{l}\text { 1,7 kb PCR-amplified ENT3 cloned in YEp351 } \\
\text { by XbaI-BamH1 }\end{array}$ & This study \\
\hline pSC5 & $\begin{array}{l}1.7 \mathrm{~kb} \text { PCR-amplified ENT3 cloned in pRS315 } \\
\text { by PvuII }\end{array}$ & This study \\
\hline pSC6 & $\begin{array}{l}1.7 \mathrm{~kb} \text { ENT3-3xHA -TRP1 (C-term) by, in vivo } \\
\text { recombination with pFA6a-3HA-TRP1 }\end{array}$ & This study \\
\hline pSC8 & $\begin{array}{l}\text { PCR amplified mvtilb from AA105524 cloned } \\
\text { in pCDNA3.1 by BamH1-Xho1 }\end{array}$ & This study \\
\hline pSC9 & $\begin{array}{l}2 \mathrm{~kb} \text { vti1Q29RW79R from pBK120 in pRS306 } \\
\text { by PvuII }\end{array}$ & This study \\
\hline pSC10 & $\begin{array}{l}\text { PCR amplified EpsinR from pZ1 in pGEM- } \\
\text { Teasy }\end{array}$ & This study \\
\hline pSC11 & $\begin{array}{l}\text { EpsinR from pSC10 was subcloned in pcDNA3.1 } \\
\text { by BamH1-Not1 }\end{array}$ & This study \\
\hline pSC14 & $\begin{array}{l}\text { 2kb vtilQ29RW79R from pBK120 cloned in } \\
\text { YEp351 }(2 \mu) \text { by PvuII }\end{array}$ & This study \\
\hline pSC19 & $\begin{array}{l}1.15 \mathrm{~kb} \text { PCR-amplified SYN8 with } 3 \times \mathrm{xHA} \text { after } \\
\text { ATG in pRS315 by PvuII }\end{array}$ & This study \\
\hline pSC20 & $\begin{array}{l}\text { PCR-amplified ENT3 ENTH domain (AA1-160) } \\
\text { into pGEM-Teasy }\end{array}$ & This study \\
\hline pSC21 & $\begin{array}{l}\text { Nde1-EcoR1 fragment from pSC20 cloned into } \\
\text { pET } 28\end{array}$ & This study \\
\hline pSC22 & $\begin{array}{l}\text { PCR amplified ENT3 in C-terminal pGFP vector } \\
\text { in BamH1-Smal site }\end{array}$ & This study \\
\hline pSC23 & CHS7 subcloned from RSB2312 into pRS314 & This study \\
\hline pSC24 & $\begin{array}{l}\text { PCR amplified ENT5 in C-terminal pGFP vector } \\
\text { in BamH1-HindIII }\end{array}$ & This study \\
\hline pKW5 & $\begin{array}{l}\text { ENTH-domain ENT3 (aa1-172) with C-terminal } \\
\text { Strep tag in pASK-IBA3 }\end{array}$ & Katrin Wiederhold \\
\hline
\end{tabular}




\begin{tabular}{l|l|l} 
Plasmid & Details & Reference \\
\hline PTS15 & $\begin{array}{l}\text { PEP4 }:: U R A 3 \text { in pBR322. Cut with EcoR1- } \\
\text { Xho1 to distrupt pep4 }\end{array}$ & Tom Stevens \\
\hline pSN55 & Eag1-EcoR1 fragment of A-ALP in pRS316 & Steve Nothwehr \\
\hline RSB2310 & CHS3GFP in pRS313 & Schekman
\end{tabular}

2.1.11 Antibiotics

Ampicillin Trihydrate

Geneticin G418

Kanamycin A Monosulfate
Serva, Heidelberg

Sigma-Aldrich, Munich

Sigma, Munich

\subsubsection{Media for $S$. cerevisiae cells}

$\underline{\text { YEPD Medium (1L) }}$

$20 \mathrm{~g} \quad$ Peptone

$10 \mathrm{~g} \quad$ Yeast extract

were dissolved in $960 \mathrm{ml}$ of $\mathrm{ddH}_{2} \mathrm{O}$ and autoclaved. Then added,

$40 \mathrm{ml} \quad 50 \%$ Glucose (final conc. $2 \%$ )

For preparing YEPD plates, $1.5 \%$ of agar was added to the YEPD medium, before autoclaving and poured in $20 \mathrm{~cm}$ petridishes. For YEPD-G418 plates, Geneticin was added to the final concentration of $200 \mathrm{mg} / \mathrm{L}$.

$\underline{\text { Synthetic minimal medium (SD) (1L) }}$

$6.7 \mathrm{~g} \quad$ Yeast nitrogen base w/o aminoacids

was dissolved in $860 \mathrm{ml}$ of $\mathrm{ddH}_{2} \mathrm{O}$, autoclaved and cooled down.

$40 \mathrm{ml} \quad 50 \%$ Glucose (final conc. $2 \%$ )

$100 \mathrm{ml} \quad$ 10X Aminoacid mix

The composition of $10 \mathrm{X}$ aminoacid mix is listed below. The mix was prepared without Methionine for the purpose of pulse chase labeling of yeast cells. The desired auxotrophic 10X mix was prepared by not adding the particular aminoacid in the mix. The mix was autoclaved and stored at $4^{\circ} \mathrm{C}$. 


\begin{tabular}{|l|c|}
\hline \multicolumn{1}{|c|}{ Supplements } & Concentration $(\mathrm{g} / \mathrm{L})$ \\
\hline Adenine & 0.20 \\
\hline L-Tyrosine & 0.30 \\
\hline L-Phenylalanine & 0.50 \\
\hline L-Arginine & 0.20 \\
\hline L-Lysine-HCl & 0.60 \\
\hline L-Threonine & 2.00 \\
\hline Uracil & 0.20 \\
\hline L-Leucine & 1.20 \\
\hline L.Typtophan & 0.20 \\
\hline L-Histidine & 0.20 \\
\hline
\end{tabular}

\section{$\underline{\text { Nitrogen starvation medium }}$}

$6.7 \mathrm{~g} \quad$ Yeast nitrogen base w/o aminoacids and Ammonium Sulphate was dissolved in $1000 \mathrm{ml}$ of $\mathrm{ddH}_{2} \mathrm{O}$ and autoclaved.

\section{$\underline{\text { Sporulation plate }}$}

$10 \mathrm{~g} \quad$ Potassium acetate (final conc. 1\%)

$1 \mathrm{~g} \quad$ Yeast Extract (final conc. 0.1\%)

$15 \mathrm{~g} \quad$ Agar (final conc. $1.5 \%$ )

dissolved in $974 \mathrm{ml}$ of $\mathrm{ddH}_{2} \mathrm{O}$ and autoclaved, then added

$1 \mathrm{ml} \quad 50 \%$ Glucose (final conc. $0.05 \%$ )

$25 \mathrm{ml}$ 10X Aminoacid mix (final conc. $0.25 \mathrm{X}$ ) 


\subsubsection{Media for Escherichia coli}

\section{$\underline{\text { Luria Bertani (LB) medium (1L) }}$}

$1 \mathrm{~g} \quad$ Glucose

$5 \mathrm{~g} \quad$ Bacto-yeast extract

$5 \mathrm{~g} \quad \mathrm{NaCl}$

$10 \mathrm{~g} \quad$ Bacto-Tryptone

The medium was autoclaved and stored at room temperature.

$\underline{\text { LB Agar Plates }}$

$1.5 \%$ of Agar was added to the LB medium, autoclaved and the medium was let to cool down to around $50{ }^{\circ} \mathrm{C} .100 \mu \mathrm{g} / \mathrm{ml}$ Ampicillin or $50 \mu \mathrm{g} / \mathrm{ml}$ of Kanamycin was added to the medium and poured into Petri dishes.

For Blue/white screen, $100 \mu \mathrm{IPTG}\left(25 \mathrm{mg} / \mathrm{ml}\right.$ in water, stored at $\left.-20^{\circ} \mathrm{C}\right)$ and $50 \mu 1 \mathrm{X}-\mathrm{Gal}$ $\left(50 \mathrm{mg} / \mathrm{ml}\right.$ in DMF, stored at $-20^{\circ} \mathrm{C}$ ) was spreaded evenly on the LB-Amp plate.

\section{$\underline{2 \mathrm{xYT} \text { medium }(1 \mathrm{~L})}$}

$10 \mathrm{~g} \quad$ Bacto-yeast extract

$5 \mathrm{~g} \quad \mathrm{NaCl}$

$16 \mathrm{~g} \quad$ Bacto-Tryptone

$\underline{\text { SOC medium (1L) }}$

$5 \mathrm{~g} \quad$ Bacto-yeast extract

$0.6 \mathrm{~g} \quad \mathrm{NaCl}$

$0.19 \mathrm{~g} \quad \mathrm{KCl}$

$2 \mathrm{~g} \quad \mathrm{MgCl}_{2} 6 \mathrm{H}_{2} \mathrm{O}$

$20 \mathrm{~g} \quad$ Bacto-Tryptone

\subsubsection{Stock solutions and buffers}

10x PBS (1L)

$87.70 \mathrm{~g} \mathrm{NaCl}$

$28.48 \mathrm{~g} \quad \mathrm{Na}_{2} \mathrm{HPO}_{4}$

$5.52 \mathrm{~g} \quad \mathrm{NaH}_{2} \mathrm{PO}_{4}$ $\underline{\text { Final Concentration }}$

\section{$1.5 \mathrm{M}$}

$160 \mathrm{mM}$

$40 \mathrm{mM}$ 
dissolve in $\mathrm{ddH}_{2} \mathrm{O}$, Adjust the $\mathrm{pH}$ to 7.4 with $\mathrm{NaOH}$, make up the volume to $1000 \mathrm{ml}$.

\section{$\underline{50 x \operatorname{TAE}(1 \mathrm{~L})}$}

$242 \mathrm{~g}$ Tris

$37 \mathrm{~g} \quad \mathrm{Na}_{2}$ EDTA (Titriplex III)

$57 \mathrm{ml}$ Acetic acid

Make up the volume to $1000 \mathrm{ml}$.

$\underline{\mathrm{TE}(100 \mathrm{ml})}$

$1 \mathrm{ml} 1 \mathrm{M}$ Tris-HCl, $\mathrm{pH} 7.5$

$20 \mu 1 \quad 0.5 \mathrm{M}$ EDTA

$\underline{\mathrm{TE}} \beta(10 \mathrm{ml})$

$1 \mathrm{ml} 1 \mathrm{M}$ Tris-HCl, $\mathrm{pH} 8.0$

$200 \mu 1 \quad 0.5$ M EDTA

$50 \mu \mathrm{l} \quad \beta$-Mercaptoethanol
Final Concentration

\section{$\underline{\text { Final Concentration }}$}

$2 \mathrm{M}$

$0.1 \mathrm{M}$

$10 \mathrm{mM}$

$0.1 \mathrm{mM}$

Final Concentration

$200 \mathrm{mM}$

$20 \mathrm{ml}$

$1 \%$

Sphereoblast-buffer $(10 \mathrm{ml}): \quad$ Final Concentration

$\begin{array}{rlr}6 \mathrm{ml} & 2 \mathrm{M} \text { Sorbitol } & 1.2 \mathrm{M} \\ 500 \mu \mathrm{l} & 1 \mathrm{M} \mathrm{KPO}_{4}, \mathrm{pH} 7.3 & 50 \mathrm{mM} \\ 100 \mu \mathrm{l} & 0.1 \mathrm{M} \mathrm{MgCl}_{2} & 1 \mathrm{mM}\end{array}$

$10 \% \mathrm{SDS}$ :

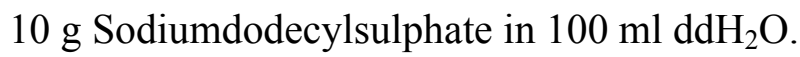

$\underline{0.5 \mathrm{M} \text { EDTA: }}$

Dissolve $14.61 \mathrm{~g}$ Ethylene-diamine-tetra-acetate (Titriplex II) in $100 \mathrm{ml}$ of $\mathrm{ddH}_{2} \mathrm{O}$ and adjust the $\mathrm{pH}$ with $10 \mathrm{~N} \mathrm{NaOH}$ to $\mathrm{pH} 8.0$.

1 M Tris-HCl:

Dissolve $12.11 \mathrm{~g}$ Tris in $80 \mathrm{ml}$ of $\mathrm{ddH}_{2} \mathrm{O}$ and adjust to the desired $\mathrm{pH}$ with conc.HCL and make up the volume to $100 \mathrm{ml}$.

$1 \mathrm{M} \mathrm{DTT}(20 \mathrm{ml})$ :

$3.08 \mathrm{~g}$ DTT, dissolved in $20 \mathrm{ml}$ of $0.01 \mathrm{M}$ Sodium Acetate (pH 5.2). Filter sterilized and stored at $-20^{\circ} \mathrm{C}$. 


\subsection{Methods}

\subsubsection{Molecular Biology}

\subsubsection{Preparation of electrocompetent $E$. coli}

A single $E$. coli colony was inoculated into $10 \mathrm{ml}$ of LB media and allowed to grow overnight at $37^{\circ} \mathrm{C}$ in a shaking incubator. This pre-culture was inoculated in $11 \mathrm{LB}$ media and allowed to grow at $37{ }^{\circ} \mathrm{C}$ to an $\mathrm{OD}_{600}$ of 0.4-0.6. Cells were pre-chilled on ice for 15 min and then pelleted in JA-10 rotor at $5000 \mathrm{rpm}$ for $15 \mathrm{~min}$ at $4{ }^{\circ} \mathrm{C}$. Pellet was washed twice with 11 of ice cold water and centrifuged as mentioned above. Pellet was resuspended in $20 \mathrm{ml}$ ice cold sterile $10 \%$ glycerol and centrifuged in JA-20 rotor at 6000 rpm for $15 \mathrm{~min}$ at $4{ }^{\circ} \mathrm{C}$. Pellet was resuspended in $2 \mathrm{ml}$ ice cold, $10 \%$ glycerol, and aliquots of $40 \mu \mathrm{l}, 80 \mu \mathrm{l}$ and $160 \mu \mathrm{l}$ in sterile eppendorfs were stored at $-80^{\circ} \mathrm{C}$.

\subsubsection{Electroporation}

The electroporation cuvette was washed thoroughly with $70 \%$ alcohol, followed by sterile water and chilled on ice for $5 \mathrm{~min}$. The $40 \mu \mathrm{l}$ or $80 \mu \mathrm{l}$ aliquot of the electro competent cells was used for each transformation. $1.2 \mu 1$ or $2.5 \mu \mathrm{l}$ of DNA was added to the cells and the contents were transferred into the pre-chilled, sterile electroporation cuvette. The cuvette was placed in the electroporater and a pulse of $1800 \mathrm{~V}$ was given. Immediately after the pulse, SOC medium was added to the cells and were allowed to recover in sterile tubes for $30 \mathrm{~min}$ at $37{ }^{\circ} \mathrm{C}$ in a water bath. Then, the cells were plated on LB plates containing appropriate antibiotic and incubated overnight at $37^{\circ} \mathrm{C}$.

\subsubsection{Isolation of DNA from $E$. coli}

A single E. coli colony was inoculated into $2 \mathrm{ml}$ of LB medium or $2 \mathrm{xYT}$ medium containing appropriate antibiotic and grown overnight at $37{ }^{\circ} \mathrm{C}$ in a shaking incubator. Cells were pelleted in a table-top centrifuge at 13,000 rpm for $1 \mathrm{~min}$. Cell pellet was resuspended in $100 \mu \mathrm{l}$ Lysozyme solution and $200 \mu \mathrm{l}$ of $\mathrm{NaOH}::$ SDS was added, mixed gently by inverting the tube 3-4 times and incubated at RT for 5 min. To this, $150 \mu 1$ of $3 \mathrm{M}$ NaoAc, $\mathrm{pH} 4.8$ was added gently, mixed and incubated for $5 \mathrm{~min}$ at RT. It was centrifuged for $10 \mathrm{~min}$ at $13000 \mathrm{rpm}$ in a table-top eppendorf centrifuge. The supernatant 
was taken in a new eppendorf cup, $150 \mu$ of Phenol-Chloroform-Isoamylalcohol (25:24:1) was added, mixed and centrifuged for $5 \mathrm{~min}$ at $13000 \mathrm{rpm}$. The upper (aqueous) phase was carefully taken into a new tube and 2.5 volumes of cold $100 \%$ ethanol was added and centrifuged for $15 \mathrm{~min}$ at $13000 \mathrm{rpm}$ at $4{ }^{\circ} \mathrm{C}$. The pellet was washed with $1 \mathrm{ml}$ of $70 \%$ ethanol and was air dried or dried with the help of vacuum. The pellet was resuspended in $20 \mu \mathrm{l}$ of TE with $100 \mu \mathrm{g} / \mathrm{ml}$ RNase.

Lysozyme-solution

$50 \mathrm{mM} \quad$ Glucose

$10 \mathrm{mM} \quad$ EDTA

$25 \mathrm{mM} \quad$ Tris-HCl, $\mathrm{pH} 8,0$. It was stored at $4^{\circ} \mathrm{C}$.

$\underline{\mathrm{NaOH}-\mathrm{SDS}}$

$0.2 \mathrm{M} \quad \mathrm{NaOH}$

$1 \%(\mathrm{w} / \mathrm{v}) \quad \mathrm{SDS} \quad$ Stored at RT. Prepared freshly.

$\underline{\text { RNase A- Solution }(10 \mathrm{mg} / \mathrm{ml})}$

$10 \mathrm{mg}$ RNase A in $1 \mathrm{ml} \mathrm{TE}$ and stored at $-20^{\circ} \mathrm{C}$.

TE/RNase $(100 \mu \mathrm{g} / \mathrm{ml})$

$5 \mu \mathrm{l}$ of $10 \mathrm{mg} / \mathrm{ml} \mathrm{RNase} \mathrm{A}$ in $500 \mu \mathrm{TE}$ and stored at $4^{\circ} \mathrm{C}$.

\subsubsection{Determination of the concentration of DNA}

DNA concentration was determined using a spectrophotometer at $260 \mathrm{~nm}$. DNA was diluted in water and the absorbance was measured at $260 \mathrm{~nm}$.

Absorbance or optical density (OD) of 1 at $260 \mathrm{~nm}$ corresponds to $\sim 50 \mu \mathrm{g} / \mathrm{ml}$ of double stranded DNA or $\sim 40 \mu \mathrm{g} / \mathrm{ml}$ of single stranded DNA and RNA or $\sim 20 \mu \mathrm{g} / \mathrm{ml}$ of oligonucleotides. The ratio of the readings at $260 \mathrm{~nm}$ and $280 \mathrm{~nm}\left(\mathrm{OD}_{260} / \mathrm{OD}_{280}\right)$ provides an estimate of the purity of the nucleic acid. Pure preparations of DNA and RNA have $\mathrm{OD}_{260} / \mathrm{OD}_{280}$ values of 1.8 and 2.0, respectively. Any contamination with proteins or phenol would yield values less than mentioned above. 


\subsubsection{Cloning techniques}

\subsection{Polymerase Chain Reaction (PCR)}

PCR is a rapid and versatile in vitro method for amplifying defined target DNA fragments by DNA polymerase which occurs naturally in living organisms, where it duplicates DNA when cells divide. It is used to amplify a short, well-defined part of a DNA strand. Taq polymerase is widely used but the disadvantage is that it lacks $3^{\prime} \rightarrow 5^{\prime}$ proof reading exonuclease activity, leading to mutations in the sequence. But polymerases such as $P$ wo and $P f u$ have proof reading mechanism, so, combinations of Taq and $P f u$ provide high fidelity and accurate amplification of DNA.

For example

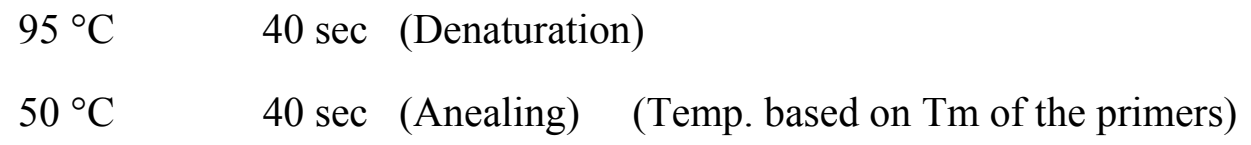

$72{ }^{\circ} \mathrm{C} \quad 1 \mathrm{~min} \quad$ (Extension) (Time depends on the size of the fragment. Taq polymerase amplifies $1 \mathrm{~kb}$ in $1 \mathrm{~min}$ )

30 Cycles

\section{$\underline{\text { PCR Mix }}$}

10X Taq buffer (100 mM Tris/HCl pH 9.0; $500 \mathrm{mM} \mathrm{KCl)} \quad 10 \mu \mathrm{l}$

$2.5 \mathrm{mM}$ dNTPs (Amersham, Stock $100 \mathrm{mM}$ ) $\quad 10 \mu \mathrm{l}$

$25 \mathrm{mM} \mathrm{MgCl}_{2} \quad 5 \mu 1$

5'-primer (Stock $100 \mathrm{pmol} / \mu \mathrm{l}) \quad 2 \mu \mathrm{l}$

3'-primer (Stock $100 \mathrm{pmol} / \mu \mathrm{l}) \quad 2 \mu \mathrm{l}$

Template DNA $\quad 1 \mu 1$

Taq polymerase $+1 / 10 P f u$-Polymerase $\quad 1 \mu \mathrm{l}$

Final volume made upto $100 \mu$ with HPLC water

\subsection{In vitro mutagenesis by PCR}

In vitro mutagenesis results in alteration of a specific amino acid or small component of the gene product in a predetermined way. Also, it is used to introduce restriction sites into 
cloned DNA of interest. Both primers are phosphorylated by T4-PNK to facilitate ligation.

Phosphorylation of the Primer:

$1 \mu \mathrm{l}$ Primer 1

$1 \mu \mathrm{l} \quad$ 10x T4-Polynucleotide Kinase buffer

$1 \mu 1 \quad 10 \mathrm{mM}$ ATP

$6 \mu \mathrm{l} \quad \mathrm{HPLC}-\mathrm{H}_{2} \mathrm{O}$

$1 \mu \mathrm{l} \quad$ T4-Polynukleotide-Kinase $(10 \mathrm{U} / \mu \mathrm{l})$

Incubate for $30 \mathrm{~min}$, at $37^{\circ} \mathrm{C}$.

$\underline{\text { PCR }}$

$1 \mu$ diluted Plasmid (1:10 to 1:50)

$5 \mu \mathrm{l}$ 10x Pfu-buffer

$5 \mu \mathrm{d}$ dNTPs

$1.5 \mu$ phosphorylated Primer 1 (3 $\mu$ f for PfuTurbo ${ }^{\circledR}$-Polymerase)

$1.5 \mu$ phosphorylated Primer 2 (3 $\mu$ l for PfuTurbo ${ }^{\circledR}$-Polymerase)

$35 \mu \mathrm{l}$ HPLC- $\mathrm{H}_{2} \mathrm{O}$ (32 $\mu \mathrm{l}$ for PfuTurbo ${ }^{\circledR}$-Polymerase)

Denaturation for $4 \mathrm{~min}$ at $95^{\circ} \mathrm{C}$

Add $1 \mu \mathrm{l} f u$-Polymerase

For example:

$1 \min$ at $95^{\circ} \mathrm{C}$

1 min at $52^{\circ} \mathrm{C} \quad$ (Temperature based on $\mathrm{T}_{\mathrm{m}}$ of the Primers)

10 min at $72^{\circ} \mathrm{C} \quad(P f u$ amplifies $1 \mathrm{~kb}$ in $2 \mathrm{~min}$ )

10 cycles (maximum 12)

The PCR product was treated with DpnI. The DpnI endonuclease is specific for methylated and hemimethylated DNA and is used to digest the parental DNA template and to select the synthesized mutation containing DNA.

\section{$\underline{D p n I-d i g e s t i o n}$}

PCR product $+1 \mu \mathrm{l} \operatorname{DpnI}(20 \mathrm{U} / \mu \mathrm{l})$

- Incubated for $1 \mathrm{~h}$ in $37^{\circ} \mathrm{Cwater}$ bath.

- Inactivated the enzyme by incubating for $30 \mathrm{~min}$ at $80^{\circ} \mathrm{C}$.

$2 \mu \mathrm{l}$ was checked by an analytical agarose gel. 


\section{$\underline{\text { Ligation }}$}

$12.5 \mu \mathrm{l} \quad$ DpnI-digested PCR product

$1.5 \mu \mathrm{l} \quad$ 10x T4-DNA-Ligase-buffer

$1.0 \mu \mathrm{l} \quad$ T4-DNA-Ligase $(400 \mathrm{U} / \mu \mathrm{l})$

-Incubate for overnight at $16^{\circ} \mathrm{C}$ in a waterbath.

The ligation mix was then transformed to E. coli.

\subsection{Phenol Extraction and Ethanol precipitation}

To $100 \mu \mathrm{l}$ of PCR product, $10 \mu \mathrm{l}$ of Sodium Acetate, $\mathrm{pH} 5.2$ and $30 \mu \mathrm{l}$ of PhenolChloroform-Isoamylalcohol (25:24:1) was added and vortexed. It was centrifuged for 2 min at $13000 \mathrm{rpm}$. The aqueous phase was taken carefully and 2.5 volumes of $100 \%$ ethanol were added. This was incubated for $20 \mathrm{~min}$, at $-70{ }^{\circ} \mathrm{C}$ or $10 \mathrm{~min}$ on dry ice or overnight at $-20^{\circ} \mathrm{C}$. DNA was pelleted at $13000 \mathrm{rpm}$ for $10 \mathrm{~min}$. The pellet was washed with $70 \%$ ethanol. The DNA pellet was dried at $37^{\circ} \mathrm{C}$ and was resuspended in $50 \mu \mathrm{l}$ TE/RNase.

\subsection{Restriction endonuclease (RE) digestion of DNA}

Restriction enzymes cut DNA at internal phosphodiester bonds. Different types of RE exist and the most useful one is Type II restriction enzymes which cleaves at specific sequences. The activity of restriction enzyme is measured in Units (U). One unit of restriction enzyme is the amount of enzyme required to completely digest $1 \mu \mathrm{g}$ substrate DNA in $1 \mathrm{~h}$.

\section{For Analytical digestion}

$6,8 \mu \mathrm{ldd} \mathrm{dH}_{2} \mathrm{O}$

1,0 $\mu 1$ 10x Enzyme buffer

$1,0 \mu 1$ 10x BSA (1 mg/ml) [on requirement]

$0,1 \mu 1 \quad$ Restriction enzyme A

$0,1 \mu 1$ Restriction enzyme B

- Incubated at $37^{\circ} \mathrm{C}$ for one hour and $6 \mu \mathrm{l}$ of $1 \mathrm{x}$ DNA dye was added and $6 \mu \mathrm{l}$ was checked on agarose gel. 
For Preparative digestion:

$41 \mu \mathrm{l} \quad \mathrm{ddH}_{2} \mathrm{O}$

$5 \mu \mathrm{l}$ Plasmid-DNA (or $25 \mu \mathrm{l}$ PCR product)

$6 \mu 1 \quad 10 x$ Enzyme buffer

$6 \mu \mathrm{l} \quad 10 \mathrm{x}$ BSA $(1 \mathrm{mg} / \mathrm{ml})$

$1 \mu \mathrm{l} \quad$ Restriction enzyme A

$1 \mu \mathrm{l} \quad$ Restriction enzyme B

- Incubated for $2-3 \mathrm{~h}$ at $37^{\circ} \mathrm{C}$ or overnight for PCR product and the enzyme was inactivated by incubating at $80^{\circ} \mathrm{C}$ for $20 \mathrm{~min}$ and loaded on a preparative agarose gel. Using QiaexII-DNA-Extraction kit, DNA was purified and ligation was set up.

\subsection{Agarose gel electrophoresis of DNA}

Agarose gel electrophoresis is used to clean and separate specific DNA fragments. The agarose used for analysis is inversely proportional to the size of the DNA of interest, and can be used to differentiate the circular and linear DNA also. Thus the size and purity of DNA is analyzed.

\begin{tabular}{|c|c|}
\hline Agarose concentration (\%) & Resolved DNA size (kb) \\
\hline 0.7 & $12-0.8$ \\
\hline 1.0 & $10-0.5$ \\
\hline 1.2 & $6-0.4$ \\
\hline 1.5 & $3-0.2$ \\
\hline 2.0 & $2-0.05$ \\
\hline
\end{tabular}

6x DNA loading buffer

$0.15 \%(\mathrm{w} / \mathrm{v})$ Bromophenol blue (seen at $400 \mathrm{bp}$ in the gel)

$0.15 \%(\mathrm{w} / \mathrm{v})$ Xylenecyanol FF (seen at $4 \mathrm{~kb}$ in the gel)

$40 \%$ Sucrose in $1 \mathrm{x}$ TAE 


\section{Ethidiumbromide bath}

Added around $20 \mu 1$ Ethidiumbromide in $200 \mathrm{ml}$ of $1 \mathrm{x}$ TAE.

The required amount of Agarose was weighed, dissolved in 1x TAE by boiling and poured into the agarose gel cassette and allowed to solidify completely. The gel was immersed in 1x TAE, then the DNA marker and the sample DNA was mixed with gel loading buffer and loaded into the lanes. The gel electrophoresis was carried out at $70 \mathrm{~V}$ for preparative gel and at $95 \mathrm{~V}$ for analytical gel. When the dye reaches the front, the gel was removed from the tank and incubated in the Ethidium bromide bath for 5-10 min. Ethidium bromide is a fluorescent dye which contains a planar group that intercalates between the stacked bases of the DNA. Three kinds of transilluminators are used to detect DNA fragments, viz., $254 \mathrm{~nm}, 302 \mathrm{~nm}$ and $365 \mathrm{~nm}$. The $302 \mathrm{~nm}$ transilluminator is recommended for easy detection of small amounts of DNA without inducing damage, thus allowing further cloning of the purified fragments. The gel was photographed using a gel documentation system.

\subsection{Ligation}

Joining linear DNA fragments together by a phosphodiester bond between the 3' hydroxyl of one nucleotide and the 5' phosphate of another is called ligation. T4 DNA ligase is used for this purpose which ligates the cohesive ends of the fragments. There are two types of ligation viz., cohesive end or sticky end ligation and blunt end ligation, depending on the restriction digestion of the DNA. For the blunt end ligation and also if digestion was with single sticky end enzyme, the vector should be dephosphorylated by alkaline phosphatase, and the ligation mix should be incubated for overnight.

\section{For example}

$\mathrm{x} \mu \mathrm{l}$ linearised vector DNA

y $\mu 1$ Insert DNA [1(vector DNA):10 (insert DNA)]

$1,5 \mu \mathrm{l}$ 10x Ligase buffer

$1,0 \mu \mathrm{l}$ T4-DNA-Ligase $(400 \mathrm{U} / \mu \mathrm{l})$

Made upto $15 \mu \mathrm{l}$ with $\mathrm{ddH}_{2} \mathrm{O}$, incubated overnight at $16^{\circ} \mathrm{C}$ and transformed into E.coli competent cells. 


\subsubsection{Sequencing of the clone}

DNA sequencing was done by Sanger's method using a DNA sequencer. The plasmid DNA to be sequenced was supplied with a mixture of all four nucleotides plus four ddNTPs, each labeled with a tag that fluoresces different color. For sequencing reaction, clean DNA should be used (prepared by QIAprep-Spin-Miniprep-Kit).

\section{For example:}

$\underline{\text { PCR mix }}$

$\mathrm{x} \mu \mathrm{l}$ Plasmid-DNA $(0.2-0.5 \mu \mathrm{g})$

$3.2 \mu \mathrm{l}$ Forward primer or reverse primer $(1 \mathrm{pmol} / \mu \mathrm{l})$

$2.0 \mu \mathrm{l}$ ABI PRISM Dye Terminator Cycle Sequencing Ready Reaction Premix x $\mu \mathrm{l}$ HPLC- $\mathrm{H}_{2} \mathrm{O}$ (Make it upto $\left.10 \mu \mathrm{l}\right)$

\section{$\underline{\text { Programme }}$}

$$
\begin{array}{llr}
96^{\circ} \mathrm{C} & --- & 10 \mathrm{sec} \\
50^{\circ} \mathrm{C} & --- & 5 \mathrm{sec} \\
60^{\circ} \mathrm{C} & --- & 4 \mathrm{~min}
\end{array}
$$

25 cycles

The PCR product for sequencing should be cleaned thoroughly to remove fluorecently labeled free ddNTPs to avoid background. To the PCR product $2 \mu \mathrm{l}$ of $3 \mathrm{M}$ Sodium aceteate ( $\mathrm{pH}$ 5.2) and $50 \mu \mathrm{l} 95 \% \mathrm{EtOH}$ (room temperature) was added, incubated at RT for $10 \mathrm{~min}$ and centrifuged for $20 \mathrm{~min}$ at $13000 \mathrm{rpm}$. The pellet was washed with $250 \mu \mathrm{l}$ of $70 \%$ ethanol for $10 \mathrm{~min}$ at $13000 \mathrm{rpm}$, dried and resuspended in $25 \mu \mathrm{l}$ of HPLC water and given for sequencing.

\subsubsection{Glycerol stocks of $E$. coli and $S$. cerevisiae}

The Bacteria was streaked on a LB plate and the yeast strain was streaked on a YEPD plate and incubated overnight at $37^{\circ} \mathrm{C}$ and $30^{\circ} \mathrm{C}$ respectively. A small scrape of cells were resuspended well in $7 \%$ sterile DMSO and was frozen immediately at $-80^{\circ} \mathrm{C}$. 


\subsubsection{Yeast Genetics}

\subsubsection{PLATE transformation}

It is an easy method to transform plasmids into yeast cells. PLATE medium contains Lithium acetate which makes the cell wall permeable for DNA and PEG acts as a volume excluder and causes stronger proximation of DNA and yeast cells.

Yeast cells from fresh plates were scraped and resuspended in $500 \mu 1$ of PLATE medium or overnight cultures were pelleted and resuspended in $500 \mu \mathrm{l}$ of PLATE and 1-2 $\mu 1$ of plasmid DNA was added. The mix was incubated at $42^{\circ} \mathrm{C}$ for $30 \mathrm{~min}$ or $1-2$ days at RT with slow shaking and centrifuged for $15 \mathrm{sec}$ at $6500 \mathrm{rpm}$. The pellet was resuspended in $200 \mu \mathrm{l}$ of SOS, incubated for $20-30 \mathrm{~min}$ at $30^{\circ} \mathrm{C}$ and plated on the respective SD-selection plate.

PLATE-Medium (100 ml):

$\begin{array}{rl}40 \mathrm{~g} & \text { PEG } 4000 \\ 10 \mathrm{ml} & 1 \mathrm{M} \text { Lithiumacetate } \\ 1 \mathrm{ml} & 1 \mathrm{M} \text { Tris/HCl, pH } 7.5 \\ 0.2 \mathrm{ml} & 0.5 \mathrm{M} \text { EDTA }\end{array}$

Autoclave the mix.

$\underline{\text { SOS-Medium (Prepared freshly): }}$

$\begin{array}{ll}500 \mu \mathrm{l} & \text { YEPD } \\ 500 \mu \mathrm{l} & 2 \mathrm{M} \text { Sorbitol } \\ 6.5 \mu \mathrm{l} & 1 \mathrm{M} \mathrm{CaCl}_{2}\end{array}$

\subsubsection{Lithium Acetate transformation}

This method is extremely efficient to transform PCR products, plasmids and libraries. The yeast cells are made competent freshly before the transformation. All materials used for this procedure should be sterilized well.

\section{Preparation of competent yeast cells:}

$100 \mathrm{ml}$ of overnight yeast culture was grown till $\mathrm{OD}_{600}$ 0.5-1.0. Cells were pelleted in a JA20 rotor for $5 \mathrm{~min}$ at $5000 \mathrm{rpm}$ and were washed with $50 \mathrm{ml}$ of sterilized water. The pellet was resuspended in $25 \mathrm{ml}$ of Lisorb, incubated for $15-30 \mathrm{~min}$ at $30^{\circ} \mathrm{C}$ and pelleted 
at $5000 \mathrm{rpm}$ for $5 \mathrm{~min}$. The competent cells were resuspended in $300 \mu \mathrm{l}$ of Lisorb and kept on ice.

Transformation

DNA mix for library:

$100 \mu \mathrm{l}$ of Salmon Sperm (SS) DNA was boiled for 7-10 min, $400 \mu \mathrm{l}$ of Lisorb was added and mixed by pipetting up and down. The mix was let to cool to RT and $10 \mu$ of library DNA was added to it.

DNA mix for genomic integration:

$10 \mu \mathrm{l}$ of SS DNA was boiled and $100 \mu \mathrm{l}$ of PCR product or $10 \mu \mathrm{l}$ of digested plasmid was added and mixed well.

$100 \mu \mathrm{l}$ of competent yeast cells and $100 \mu \mathrm{l}$ of DNA-mix were mixed well. $900 \mu \mathrm{l}$ of $40 \%$ PEG3350 in LiAc/TE was added and mixed well by pipetting up and down. The transformation mix was incubated at $30^{\circ} \mathrm{C}$ for $30 \mathrm{~min}$ and shifted to $42^{\circ} \mathrm{C}$ for $15 \mathrm{~min}$. The heat shock should not be given for more than $15 \mathrm{~min}$, otherwise the cells would die. The transformation mix was pelleted down, resuspended in $300 \mu \mathrm{l}$ of SOS medium and incubated at $30^{\circ} \mathrm{C}$ water bath for 30 min (except for Kanamycin selection which needs around 2-3 h of incubation). The mix was spreaded on an appropriate selection plate.

$\underline{\text { LiSorb }(100 \mathrm{ml})}$

$18.2 \mathrm{~g}$ Sorbitol

$10 \mathrm{ml} 1 \mathrm{M}$ Lithiumacetate

$1 \mathrm{ml} 1 \mathrm{M}$ Tris/HCl, $\mathrm{pH} 8.0$

$200 \mu \mathrm{l} \quad 0.5 \mathrm{M}$ EDTA

- Autoclave the mix

$\underline{40 \%(\mathrm{w} / \mathrm{v}) \text { PEG } 3350 \text { in } \mathrm{LiAc} / \mathrm{TE}(50 \mathrm{ml})}$

$20 \mathrm{~g}$ Polyethylene glycol MW 3350

$5 \mathrm{ml} 1 \mathrm{M}$ Lithiumacetate

$0.5 \mathrm{ml} 1 \mathrm{M}$ Tris/HCl, $\mathrm{pH} 8.0$

$100 \mu \mathrm{l} \quad 0.5 \mathrm{M}$ EDTA

- Autoclave the mix

\section{Final conc.:}

\section{$1 \mathrm{M}$}

$100 \mathrm{mM}$

$10 \mathrm{mM}$

$1 \mathrm{mM}$

Final conc.:

$$
\begin{array}{r}
40 \%(\mathrm{w} / \mathrm{v}) \\
100 \mathrm{mM} \\
10 \mathrm{mM} \\
1 \mathrm{mM}
\end{array}
$$




\subsubsection{Plasmid isolation from $S$. cerevisiae}

$2 \mathrm{ml}$ liquid culture of Yeast in SD medium was used for the isolation of plasmid DNA. Cells were taken in a micro centrifuge tube and centrifuged for $30 \mathrm{sec}$ at $13000 \mathrm{rpm}$. Pellet was resuspended in $200 \mu \mathrm{l}$ of Lysis buffer. Around $100 \mu \mathrm{l}$ of glass beads and $200 \mu \mathrm{l}$ of Phenol-Chloroform was added to remove the proteins. This was vortexed for $2 \mathrm{~min}$ and centrifuged for $5 \mathrm{~min}$ at $13000 \mathrm{rpm}$ at $4{ }^{\circ} \mathrm{C}$. The aqueous phase was carefully transferred into a new microfuge tube without taking any phenol. To this, $20 \mu \mathrm{l}$ of $3 \mathrm{M}$ Sodium acetate $\mathrm{pH} 5.2$ and $550 \mu \mathrm{l}$ of $100 \%$ Ethanol (cold) was added and centrifuged for $10 \mathrm{~min}$ at $13000 \mathrm{rpm}$ at $4{ }^{\circ} \mathrm{C}$. The pellet was washed with $70 \%$ Ehanol (cold) and centrifuged again for $1 \mathrm{~min}$. Pellet was dried at $37^{\circ} \mathrm{C}$. DNA pellet was resuspended in $20 \mu \mathrm{l}$ of TE.

\section{$\underline{\text { Lysis Buffer }}$}

$1 \% \quad$ SDS

$2 \% \quad$ Triton $\mathrm{X} 100$

$1 \quad \mathrm{mM} \quad$ EDTA $\mathrm{pH} 8.0$

$10 \mathrm{mM} \quad$ Tris/HCL $\mathrm{pH} 8.0$

$100 \mathrm{mM} \quad \mathrm{NaCl}$

\subsubsection{Isolation of yeast genomic DNA}

Yeast cells were grown in $10 \mathrm{ml}$ YEPD till an $\mathrm{OD}_{600}$ 0.5-1.0. Cells were pelleted at 3000 rpm for $3 \mathrm{~min}$ in a $15 \mathrm{ml}$ falcon tube and washed with $5 \mathrm{ml}$ of $1 \mathrm{M}$ Sorbitol, $0.1 \mathrm{M}$ EDTA pH7.5. Pellet was resuspended in $400 \mu$ of 1M Sorbitol, 0.1 M EDTA pH7.5 with $100 \mu \mathrm{l}$ of freshly prepared Zymolyase from $2 \mathrm{mg} / \mathrm{ml}$ stock and incubated for $30-40 \mathrm{~min}$ at $37^{\circ} \mathrm{C}$. Spheroplasts were pelleted at $6500 \mathrm{rpm}$ for $30 \mathrm{sec}$ and resuspended in $500 \mu \mathrm{TE}$. $90 \mu \mathrm{l}$ of freshly prepared Lysis buffer was added and incubated at $65^{\circ} \mathrm{C}$ for $30 \mathrm{~min} .80 \mu \mathrm{l}$ of $5 \mathrm{M}$ Potassium acetate $\mathrm{pH} 5.0$ was directly added to the lysis mix, incubated for $2 \mathrm{~h}$ on ice and centrifuged for $15 \mathrm{~min}$ at $13000 \mathrm{rpm}$ at $4{ }^{\circ} \mathrm{C}$. Supernatant was collected into a new eppendorf tube and $1 \mathrm{ml}$ of $100 \%$ ethanol (room temperature) was added. It was centrifuged for $1 \mathrm{~min}$ at high rpm and the pellet was washed with $70 \%$ ethanol. The pellet was dried, resuspended in $300 \mu \mathrm{l}$ of TE and phenol extraction was done three times with $200 \mu$ of Phenol-Chloroform-Isoamylalcohol (25:24:1). To the clear aqueous phase, 
$30 \mu \mathrm{l} 3 \mathrm{M}$ Sodium acetate $\mathrm{pH} 5.2$ and $750 \mu \mathrm{l}$ of $100 \%$ ethanol was added, centrifuged for $10 \mathrm{~min}$ at $13000 \mathrm{rpm}$. The pellet was dried and resuspended in $100 \mu \mathrm{l} \mathrm{TE}$.

\section{$\underline{\text { Lysis Buffer }}$}

$2 \% \quad$ SDS

$0.1 \mathrm{M} \quad$ Tris/HCL $\mathrm{pH} 8.0$

$10 \mathrm{mM} \quad$ EDTA $\mathrm{pH} 8.0$

\subsubsection{Yeast deletion mutants}

Genetic manipulations are very easy in yeast which makes it one of the best tools for research. The very high efficiency of homologous recombination in yeast is used to make the gene deletions and to introduce specific mutations. There are different methods to disrupt a yeast gene. The most commonly used methods are PCR based one-step gene disruption and two step gene replacement or allele replacement.

\section{One step gene disruption:}

This method is useful for gene deletions and to insert PCR products. PCR primers were designed such that they consist of around 40 nucleotides as a complementary sequence to the 5'- or 3' flanking region of the gene of interest, followed by approximately 20 nucleotides complementary to the selectable marker. Using these primers, a gene disruption cassette was amplified from a vector that consisted of a selectable marker (URA3, HIS3, LYS2, LEU2, TRP1 and MET15) flanked by sequences derived from the 5' and 3' ends of the target gene to be detected. The PCR mix was transformed into yeast cells and initial screening was done using the selection marker. Genomic DNA was isolated from the probable clones and again PCR was done to confirm the gene disruption.

\section{Two step gene disruption:}

By this method all kind of mutations can be inserted into the chromosome at any location. The desired mutations with flanking sequences are cloned into a conventional plasmid that also contains a marker that can be selected both for and against URA3. Then the plasmid was digested with a restriction enzyme that cuts once within the yeast sequences flanking the mutation and is introduced into yeast by transformation. The DNA break 
stimulates recombination within the flanking sequences, leading to integration of all the vector sequences and the mutated yeast sequences into the chromosome of the yeast cell. The successfully transformed cells are selected by growth in medium lacking the uracil. Some of the cells are then subjected to medium containing Uracil and 5'-fluororatic acid (FOA). The 5-FOA is only toxic to cells expressing the URA3 gene. The 5-FOA resistant colonies are the possible positive clones and further screening was done by looking for the desired mutant phenotype.

\subsubsection{Mating and Sporulation}

In heterothallic yeast strains, sex is determined by the alleles of mating-type present in a given cell. The mating-type $\boldsymbol{a}$ cells mate with the cells of mating-type $\boldsymbol{\alpha}$ and vice versa. Cells containing both mating-types, $\boldsymbol{a} \boldsymbol{\alpha}$ diploids, do not mate but they are able to undergo meiosis and sporulation. Yeast can exist stably in either haploid or diploid states. A diploid cell grows indefinitely, but under starving conditions, it undergoes meiosis forming 4 haploid spores enclosed in a structure called ascus.

\section{Mating of MATa or MATa}

MAT $\boldsymbol{\alpha}$ and MATa were streaked heavily on a YEPD plate, like a cross. The plate was incubated at $30^{\circ} \mathrm{C}$ for $14-16 \mathrm{~h}$. Then the possible diploid cells were checked on an appropriate selection plate. If there was no selection marker, the mating was allowed only up to 4-6 h on a YEPD plate, the zygotes were picked up using a micro manipulator and spotted on a YEPD plate to grow further. The mating types of the zygotes were checked and the diploids were selected.

\section{Sporulation}

When the diploid cells are exposed to nitrogen starvation conditions, they undergo meiosis. The four meiotic products from a diploid cell are contained together as four spores in an ascus sac, commonly called as a tetrad. Using a micro manipulator, the four spores were separated and grown as haploid cells separately. Then the mating-type of each spore was tested. 


\section{Procedure}

The diploid strain was streaked freshly on a SD-minimal plate and was grown overnight at $30^{\circ} \mathrm{C}$. Then, a heavy streak was made on a sporulation plate and incubated at $30^{\circ} \mathrm{C}$ for 3-5 days. The tetrads were analyzed and dissected using a micromanipulator.

\subsubsection{Tetrad dissection}

From the sporulation plate, cells were scraped and resuspended in $50 \mu \mathrm{l}$ of $1 \mathrm{M}$ sorbitol with $2.5 \mu \mathrm{l}$ of $10 \mathrm{mg} / \mathrm{ml}$ zymolyase. Cells were incubated for $7 \mathrm{~min}$ at $30^{\circ} \mathrm{C}$ in a water bath when the thick cell wall surrounding the ascus was digested. $25 \mu l$ was taken out for further incubation at $30^{\circ} \mathrm{C}$ for $7 \mathrm{~min}$ and $200 \mu \mathrm{l}$ of $1 \mathrm{M}$ sorbitol was added to the rest and kept on ice. After the incubation, $200 \mu \mathrm{l}$ of $1 \mathrm{M}$ sorbitol was added to it and kept on ice. From each solution, $10 \mu \mathrm{l}$ was taken on a YEPD plate as a line in the middle. Under an optical microscope, the four spores of an ascus were isolated using a fine needle of a micro manipulator and spotted individually in a line on the YEPD plate. The plate was incubated at $30^{\circ} \mathrm{C}$ or at $24^{\circ} \mathrm{C}$ for ts-mutants, until the spores grew up to a big colony. The spores were analyzed for deletions, on the selection plates for auxotrophic genes and the mating-type was tested. For the identification of ts-mutants, the growth was examined at different temperatures.

\section{Halo test to identify the mating type}

The strains to be tested and the control a (SEY6210) and $\alpha$ (SEY6211) strains were patched on a YEPD plate with at least $2 \mathrm{~cm}$ distance between each patch and grown overnight at $30^{\circ} \mathrm{C}$. The tester strains $[\mathrm{RC} 828$ (a) and/or $\operatorname{sst}(\alpha)]$ were grown overnight in YEPD liquid medium till an $\mathrm{OD}_{600} 0.1-0.5$ and were diluted to $0.01 \mathrm{OD} / \mathrm{ml} .1 .5 \%$ sterile agar was dissolved in water by microwave and let to cool till $55^{\circ} \mathrm{C} .1 .5 \mathrm{ml}$ of agar and 1.5 $\mathrm{ml}$ of diluted tester strains were mixed well and poured on a YEPD plate. After 20 min, the strains to be tested were replica plated onto the agar poured plate and incubated at $30^{\circ} \mathrm{C}$ for 1-2 days to get a lawn like growth of the tester strains. The growth would be inhibited by the opposing mating type which resulted in a clear halo around the patch whereas the growth was not inhibited by the same mating type. 


\subsubsection{Growth test and growth curve}

The growth patterns of wild type and mutants are compared by growth test. The yeast strains were inoculated in $8 \mathrm{ml}$ of YEPD or SD-medium and grown overnight at $24^{\circ} \mathrm{C}$ till $\mathrm{OD}_{600}$ 0.2-1.0. The plates were pre-warmed at respective temperatures. For each strain, two dilutions were prepared in sterile water viz., $0.01 \mathrm{OD} / \mathrm{ml}$ and $0.05 \mathrm{OD} / \mathrm{ml} .10 \mu 1$ from each dilution is spotted onto the pre-warmed plates using a pattern. The spots were allowed to dry and the plates were incubated at the corresponding temperatures (usually $24^{\circ} \mathrm{C}, 30^{\circ} \mathrm{C}, 33^{\circ} \mathrm{C}$ and $37^{\circ} \mathrm{C}$ ). The growth was scored after $24 \mathrm{~h}$.

For growth curves, the $\log$ phase yeast cultures were diluted to $0.1 \mathrm{OD} / \mathrm{ml}$ in $5 \mathrm{ml}$ medium and allowed to grow at desired temperatures. Every two hours, the $\mathrm{OD}_{600}$ was measured at least for $10 \mathrm{~h}$ and the growth curve was drawn.

\subsubsection{APNE test for PEP4 deficient mutants}

This test is very fast and easy way to identify the PEP4, which codes for vacuolar Proteinase A, deletion strains. The strains to be tested, the PEP4-positive (wildtype) strain and the PEP4-deficient strains were streaked on a YEPD or SD plate and incubated overnight at $30^{\circ} \mathrm{C}$. Next day, APNE mix was prepared as follows:

\section{For $25 \mathrm{ml}$ APNE-Mix}

$$
\begin{array}{ll}
0.175 \mathrm{~g} & \text { Agar } \\
17.5 \mathrm{ml} & \mathrm{ddH}_{2} \mathrm{O} \\
5.0 \mathrm{ml} & 1 \mathrm{M} \text { Tris-HCl, } \mathrm{pH} 7.4
\end{array}
$$

Were taken in a $50 \mathrm{ml}$ flask and boiled in the microwave and cooled down to $55^{\circ} \mathrm{C} .20 \mathrm{mg}$ of Fast Garnet GBC salt and $2.5 \mathrm{ml}$ freshly prepared APNE solution (2 $\mathrm{mg} / \mathrm{ml}$ in DMF) were added to the flask, mixed well and poured onto the overnight grown YEPD plate. After few minutes, strains would develop colors. The PEP4-deficient strain would be white in color whereas the PEP4-positive strain (wild type) would be red in color. Further confirmation of PEP4-deficient strain was done by checking the protein extract for the maturation of CPY by western blotting using anti-CPY antibodies. Since Proteinase A is needed for the processing of the p2CPY into mature CPY, only in the PEP4-deficient strains p2CPY would be present whereas in the PEP4- positive strain, only mCPY would be found. 


\subsubsection{Zymolyase sensitivity test}

Zymolyase is an $\beta-1,3$-Glucanse enzyme which hydrolyses the glucose residues from the cell wall of yeast cells by cleaving the $\beta$-1, 3-glucosidic linkages. If there are any changes in the composition of the cell wall, the sensitivity towards zymolyase would be altered. So, this test is used to screen cell wall defective mutants.

Yeast cells were grown in YEPD medium at $24^{\circ} \mathrm{C}$ and $2 \mathrm{OD}$ of cells were pelleted in a 15 $\mathrm{ml}$ falcon tube at 3000rpm for $3 \mathrm{~min}$ and washed once with $4 \mathrm{ml}$ of $10 \mathrm{mM}$ Tris pH7.4. The pellet was resuspended in $5 \mathrm{ml}$ of $10 \mathrm{mM}$ Tris pH7.4. Zymolyase-20T (Seikagaku, Tokyo, Japan) was added to the cells to the final concentration of $5 \mu \mathrm{g} / \mathrm{ml}$ and incubated at $37^{\circ} \mathrm{C}$ with slow shaking. Every one hour the OD was measured for up to $3 \mathrm{~h}$ and graph was drawn by setting the initial OD to $100 \%$.

\subsubsection{Biochemical methods}

\subsubsection{Preparation of protein extract from yeast cells}

$10 \mathrm{ml}$ of yeast culture was grown overnight till an $\mathrm{OD}_{600}$ of maximum 1.0 and 1-10 OD of cells were pelleted at $3000 \mathrm{rpm}$ for $3 \mathrm{~min}$. The pellet was washed with $1 \mathrm{ml}$ of water in an eppendorf at $6500 \mathrm{rpm}$ for $30 \mathrm{sec}$. The supernatant was discarded and $50 \mu \mathrm{l}$ of glass beads were added to the pellet. For 1 OD of cells, $40 \mu \mathrm{l}$ of Thorner buffer was taken. The required volume of Thorner buffer $+5 \% \beta$-Mercaptoethanol was heated at $70^{\circ} \mathrm{C}$ for 5 min. 1x Protease inhibitors was added to the Thorner buffer and the appropriate volume of buffer was added to the pellet. It was vortexed well, incubated at $70^{\circ} \mathrm{C}$ for $10 \mathrm{~min}$ and kept in the automatic vortexer for $2 \mathrm{~min}$. Then the extract was collected at $13000 \mathrm{rpm}$ for $5 \mathrm{~min}$ at $4{ }^{\circ} \mathrm{C} .10 \mu \mathrm{l}$ of the protein extract $+10 \mu \mathrm{l}$ of $2 \mathrm{x}$ stop buffer was boiled at $95^{\circ} \mathrm{C}$ for $5 \mathrm{~min}$ and $15 \mu \mathrm{l}$ was loaded onto the SDS-gel.

Thorner-buffer

$\begin{array}{ll}8 \mathrm{M} & \text { Urea } \\ 5 \% & \text { SDS } \\ 50 \mathrm{mM} & \text { Tris-HCl, pH } 6.8\end{array}$




\subsubsection{Determination of protein concentration}

Protein estimation was done using Coomassie-G-250 coloring agent (Bradford reagent), which after binding to protein absorbs light at $595 \mathrm{~nm}$. The absorption is directly proportional to the amount of protein bound to the coloring agent. A standard curve was made using BSA in the range of $5-20 \mu \mathrm{g}$. $2 \mu \mathrm{l}$ or $5 \mu \mathrm{l}$ of the sample was used for the protein estimation. The volume was made up to $200 \mu 1$ with water. One part of Bradford reagent and three parts of water was mixed, $800 \mu \mathrm{l}$ was added to the samples and were incubated for $20 \mathrm{~min}$ at room temperature. The optical density was measured at $595 \mathrm{~nm}$ in the Spectrophotometer.

Bovine Serum Albumin (BSA) stock solution $\quad 1 \mathrm{mg} / \mathrm{ml}$

\subsubsection{SDS gel electrophoresis}

Proteins can be separated on the basis of mass by electrophoresis in a polyacrylamide gel under denaturing conditions. To the protein samples, sodium dodecyl sulphate was added to disrupt the noncovalent interactions and $\beta$-mercaptoethanol was added to reduce the disulfide bonds. Now, the SDS-protein complex has a net negative charge and moves under electric field. Thus, proteins are separated on the basis of mass from $200 \mathrm{kDa}$ to 10 $\mathrm{kDa}$ by adjusting the pore size of the SDS gel.

\begin{tabular}{|c|c|}
\hline Acrylamide concnetration & Molecular weight \\
\hline $8 \%$ & $200-40 \mathrm{kDa}$ \\
\hline $11 \%$ & $100-20 \mathrm{kDa}$ \\
\hline $12.5 \%$ & $40-10 \mathrm{kDa}$ \\
\hline
\end{tabular}

SDS gel comprises of a stacking gel which is present on top of the resolving gel. Two clean glass plates (for small gel: $16 \times 16 \mathrm{~cm}$; big gel: $18 \times 17.5$ ) were fixed together with a spacer of $1 \mathrm{~mm}$, using clips. $1 \%$ agarose was used to seal the sides. The required percentage of resolving gel was prepared and poured in between the glass plates. On top of resolving gel, a small amount of water was added immediately. The gel was allowed to polymerize for about $30 \mathrm{~min}$. The stacking gel was poured on top of the resolving gel and a comb with 16 wells was placed in the stacking gel and left undisturbed for about 15 min. After polymerization of the stacking gel, the combs were removed and the wells were cleaned with double distilled water to wash off any unpolymerized acrylamide. The 
glass plates were fixed onto an electrophoretic apparatus with 1x Running buffer. The samples were denatured at $95^{\circ} \mathrm{C}$ for $5 \mathrm{~min}$ and loaded into the wells and $5 \mu \mathrm{l}$ of molecular weight marker was also loaded. The small gel was run at $200 \mathrm{~mA}$ for $1 \mathrm{~h}$ and the big gel was run at $30 \mathrm{~mA}$ for $2 \mathrm{~h}$.

Then the gels were stained with Coomasie-blue or with Ponseau-S stain or transferred to a nitrocellulose membrane by western blotting. For Pulse-chase immunoprecipitaion (radioactive) samples, the bigger gel was run at $15 \mathrm{~mA}$ for 5-6 h, dried and exposed to a phosphor imager screen for further analysis.

$\underline{3 x \text { stop buffer }(45 \mathrm{ml})}$

1 Spatula Bromo phenol blue

$15 \mathrm{~g} \quad$ Sucrose

$4.5 \mathrm{~g} \quad \mathrm{SDS}$

$18.8 \mathrm{ml} \quad 1 \mathrm{M}$ Tris- $\mathrm{HCl}, \mathrm{pH} 6.8$

$26.2 \mathrm{ml} \quad \mathrm{ddH}_{2} \mathrm{O}$

$900 \mu \mathrm{l} 3 \mathrm{x}$ stop buffer and $100 \mu \mathrm{l} \beta$-Mercaptoethanol was mixed before use.

10x Running buffer

$\begin{aligned} 10 \mathrm{~g} / \mathrm{L} & \text { SDS } \\ 30.2 \mathrm{~g} / \mathrm{L} & \text { Tris } \\ 144 \mathrm{~g} / \mathrm{L} & \text { Glycin }\end{aligned}$

$\underline{\text { Acrylamide solution }}$

$30 \%(w / v)$ Acrylamide

$0.8 \%$ (w/v) Bisacrylamide

Ammonium persulphate (APS)

$10 \%(\mathrm{w} / \mathrm{v})$ Ammonium persulphate in $\mathrm{ddH}_{2} \mathrm{O}$

\begin{tabular}{|l|c|c|c|}
\hline \multicolumn{4}{|c|}{ Resolving gel (15 ml) } \\
\hline $\begin{array}{l}\text { Acrylamide } \\
\text { concentration }\end{array}$ & $8 \%$ & $11 \%$ & $12.5 \%$ \\
\hline $1.5 \mathrm{M}$ Tris-HCl, $\mathrm{pH} 8.8$ & & $3.75 \mathrm{ml}$ \\
\hline Acrylamide solution & $4.0 \mathrm{ml}$ & $5.5 \mathrm{ml}$ & $6.25 \mathrm{ml}$ \\
\hline $\mathrm{ddH}_{2} \mathrm{O}$ & $6.9 \mathrm{ml}$ & $5.45 \mathrm{ml}$ & $4.65 \mathrm{ml}$ \\
\hline $10 \%(\mathrm{w} / \mathrm{v}) \mathrm{SDS}$ & \multicolumn{3}{|c|}{$150 \mu \mathrm{l}$} \\
\hline $10 \%(\mathrm{w} / \mathrm{v}) \mathrm{APS}$ & $150 \mu \mathrm{l}$ \\
\hline TEMED & $7.5 \mu \mathrm{l}$ \\
\hline
\end{tabular}




\begin{tabular}{|l|c|}
\hline \multicolumn{2}{|c|}{ Stacking gel (7.5 ml) } \\
\hline Acrylamide concentration & $5.6 \%$ \\
\hline $1 \mathrm{M}$ Tris-HCl, $\mathrm{pH} 6.8$ & $936 \mu \mathrm{l}$ \\
\hline Acrylamide solution & $1.39 \mathrm{ml}$ \\
\hline $\mathrm{ddH}_{2} \mathrm{O}$ & $4.95 \mathrm{ml}$ \\
\hline $10 \%(\mathrm{w} / \mathrm{v}) \mathrm{SDS}$ & $75 \mu \mathrm{l}$ \\
\hline $10 \%(\mathrm{w} / \mathrm{v}) \mathrm{APS}$ & $150 \mu \mathrm{l}$ \\
\hline TEMED & $7.5 \mu \mathrm{l}$ \\
\hline
\end{tabular}

\subsubsection{Coomassie blue staining}

This is the most commonly used staining procedure for the detection of proteins for a range of 0.5 to $20 \mu \mathrm{g}$ of protein and is both qualitative and quantitative. The SDS gel was incubated in Coomassie blue solution at RT for 1-2 hours with slow shaking to spread the dye evenly and the gel was destained for few hours with several changes of destaining solution until the background is clear. The gel was placed in double distilled water for few minutes and then dried in a gel drier.

$\underline{\text { Coomassie-blue stain }}$

$0.1 \%(\mathrm{w} / \mathrm{v}) \quad$ Serva blue R (Coomassie brilliant blue R-250)

$25 \%(\mathrm{v} / \mathrm{v}) \quad$ Isopropanol

$10 \%(\mathrm{v} / \mathrm{v}) \quad$ Acetic acid

$65 \%(\mathrm{v} / \mathrm{v}) \quad \mathrm{ddH}_{2} \mathrm{O}$

Destain

$$
\begin{array}{ll}
50 \%(\mathrm{v} / \mathrm{v}) & \text { Methanol } \\
10 \%(\mathrm{v} / \mathrm{v}) & \text { Acetic acid } \\
40 \%(\mathrm{v} / \mathrm{v}) & \mathrm{ddH}_{2} \mathrm{O}
\end{array}
$$

\subsubsection{Western blot analysis}

For further immunological analysis, the proteins separated by SDS-PAGE were transferred onto a nitrocellulose membrane, by "semi dry" western blot procedure. The nitrocellulose membrane $(0,2 \mu \mathrm{m})$ and 6 pieces of filter paper (Whatman, $3 \mathrm{~mm}$ ) were cut 
into shape according to the gel size and soaked in the Semi Dry blot buffer. The transfer was set as follows without any bubbles in a special blotting apparatus,

3x whatman paper
Nitrocellulose membrane
SDS-acrylamide gel
$\underline{3 \times \text { whatman paper }}$

$(+)$

Transfer of proteins

$(-)$

The transfer took place for $1 \mathrm{~h}$ with constant amperage from $1.0 \mathrm{~mA} / \mathrm{cm} 2$. After the transfer, the membrane was stained with Ponceau-S (0,2 \% in $3 \%$ TCA, Serva) for 5 - 10 min to detect the proteins, the membrane was now cut into shape, washed with water for complete decolorization and stored up or continued with immunodetection.

On nitrocellulose membrane, the immobilized proteins (antigens) can be detected with very high sensitivity by specific primary anti-bodies and the corresponding secondary anti-bodies. By the enzyme Horse Radish Peroxidase (HRP), coupled to the secondary anti-body, the protein can be detected by "Enhanced Chemiluminescence" (ECL system, Amersham). Under alkaline conditions peroxidase catalyzes the oxidation of Luminol by $\mathrm{H}_{2} \mathrm{O}_{2}$, when Luminol emits the light. This reaction is strengthened by phenol derivatives such as p-coumaric acid. The chemiluminescent half-life of the reaction lasts to approximately $1 \mathrm{~h}$.

After the transfer, membrane was blocked with 2\% Milk powder (Blotto) in PBS-T for 30 min at room temperature to block all non-specific interaction sites on the membrane. The primary antibody (polyclonal from rabbits and/or monoclonal from mouse) was diluted in Blotto at required concentration, was packed in a plastic foil with the membrane and incubated for $1-2 \mathrm{~h}$ at room temperature, on a rocker. If the signal is weak, the incubation was done in the cold room for overnight. The membrane was washed at least $3 \mathrm{x}$, each 5 min with PBS-T, the incubation with the secondary anti-body diluted in PBS-T (goat antirabbit HRP and/or goat anti- mouse HRP) was followed for $1 \mathrm{~h}$. The membrane was washed for $5 \mathrm{x}$, each wash lasting for 5 min with PBS-T and washed finally with 1x PBS. Then, the membrane was treated with a 1:1 mix of the two ECL solutions for approx. 2 min. For detection and quantification, a CCD camera of the company Fuji with the soft wares AIDA image reader and AIDA image Analyzer was used. 
$\underline{\text { Semi-Dry-Blot buffer }}$

$5.80 \mathrm{~g} / \mathrm{L} \quad$ Tris

$2.92 \mathrm{~g} / \mathrm{L} \quad$ Glycin

$3.7 \mathrm{ml} / \mathrm{L} \quad 10 \%(\mathrm{w} / \mathrm{v}) \mathrm{SDS}$

Made upto 1 litre with $\mathrm{ddH}_{2} \mathrm{O}$

$\mathrm{pH} \quad 9.2$ (adjusted with $\mathrm{NaOH}$ )

$200 \mathrm{ml} / \mathrm{L} \quad$ Methanol (added freshly)

\section{$\underline{\text { PBS-T }}$}

$0.1 \%(\mathrm{w} / \mathrm{v})$ Tween $-20^{\circledR}$ in PBS

Blotto

$2 \%(\mathrm{w} / \mathrm{v})$ Milk powder in PBS-T

ECL-solution:

SuperSignal $^{\circledR}$ West Pico Chemiluminescent Substrate (PIERCE) package containing, Stable-Peroxide-solution and Luminol/Enhancer-solution was used.

\subsubsection{Kar2p/BiP secretion test (TCA precipitation)}

$\mathrm{Kar} 2 \mathrm{p} / \mathrm{BiP}$ is one of the molecular chaperones present in ER lumen to translocate proteins into ER and recycles between cis Golgi and ER. If there is any defect in the retrograde transport from the cis Golgi to ER, BiP would be secreted into the medium. This method was used in order to determine whether the usel mutants secrete Kar2p/BiP into the medium. The yeast strains were grown in $20 \mathrm{ml}$ of YEPD medium or in the appropriate selection medium up to a density of $\mathrm{OD}_{600}$ of 0.3 to $0.5 \mathrm{OD} / \mathrm{ml}, 15 \mathrm{ml}$ was pelleted down for $5 \mathrm{~min}$ at $3000 \mathrm{rpm}$ and resuspended in $15 \mathrm{ml}$ of medium. Afterwards the cultures were incubated for $2 \mathrm{~h}$ at the appropriate temperature. The density of the cultures was again determined and the cells were centrifuged at $3000 \mathrm{rpm}$ for $5 \mathrm{~min}$. The pellet was processed as described in 2.2.3.1 and the supernatant (medium) was transferred into Corex ${ }^{\circledR}$ tubes cooled on ice and 1/10 volume $100 \%(\mathrm{w} / \mathrm{v})$ of TCA (Final conc.: $10 \%$ ) was added, well mixed and incubated on ice for $10 \mathrm{~min}$ to precipitate the proteins secreted into the medium. The corex tubes were centrifuged for $15 \mathrm{~min}$ at $10000 \mathrm{rpm}$ at $4{ }^{\circ} \mathrm{C}$ in the JA20-Rotor. The pellet was loosened with $1 \mathrm{ml}$ of $-20^{\circ} \mathrm{C}$ cold acetone and transferred to an eppendorf tube. The tubes were sonicated for 20 seconds and centrifuged for $5 \mathrm{~min}$ at $13000 \mathrm{rpm}$ at $4^{\circ} \mathrm{C}$. The pellet was washed again with $1 \mathrm{ml}$ of $-20^{\circ} \mathrm{C}$ cold acetone and 
dried. Subsequently, the pellet was resuspended in $8.3 \mu 12 \mathrm{x}$ sample buffer per 1 OD of cells and was neutralized with $5 \mu \mathrm{l}$ of $1 \mathrm{M}$ Tris, $\mathrm{pH} 9.5$ per $100 \mu \mathrm{l}$ sample buffer. The pellet was resuspended completely by 20 seconds sonication.

A 1:2 dilution was made from the protein extracts of the cell pellets with $2 \mathrm{x}$ stop buffer. The protein extracts from pellet and the supernatant was boiled at $95^{\circ} \mathrm{C}$ for 5 min and 30 $\mu \mathrm{l}$ was loaded on $8 \%$ SDS PAGE and analyzed by Immunoblot with anti-Kar2p-antibody.

\subsubsection{Cross linking of antisera to Protein A/G Sepharose beads}

In an eppendorf tube, $100 \mu \mathrm{l}$ bed volumes of protein $\mathrm{A} / \mathrm{G}$ Sepharose beads were washed for $3 \mathrm{x}$ with $1 \mathrm{ml} \mathrm{KPi}$ buffer ( $5 \mathrm{~min}$ on the turning wheel, thereafter 15 seconds of centrifugation at $4000 \mathrm{rpm}$ ). The protein A/G Sepharose pellets were resuspended into $100 \mu 1 \mathrm{KPi}$ buffer.

$50 \mu 1$ washed protein A Sepharose beads $+25 \mu 1$ Antibody $+200 \mu 1 \mathrm{KPi}$

$50 \mu 1$ washed protein A Sepharose beads $+25 \mu 1$ preimmune serum $+200 \mu 1 \mathrm{KPi}$

The binding of the anti-body to the protein A Sepharose took place for $1 \mathrm{~h}$ at room temperature on the turning wheel. The Beads were washed $2 \mathrm{x}$ each for 3 min incubation with $0.5 \mathrm{ml} 0.1 \mathrm{M}$ Sodium borate buffer $\mathrm{pH}$ 7.5. For cross linking, $300 \mu \mathrm{l}$ of freshly prepared 0.1 M Sodium borate buffer with Dimethyl pimelinediimidate dihydrochloride (DMP) to a final concentration of $4.5 \mathrm{mg} / \mathrm{ml}$ was added to the tubes and incubated at room temperature for $30 \mathrm{~min}$ in the wheel. The beads were centrifuged for 20 seconds at $3000 \mathrm{rpm}$. After washing with $1 \mathrm{ml}$ of $1 \mathrm{M}$ Tris $\mathrm{HCl}, \mathrm{pH} 7.5$ the Beads were incubated in the same for $2 \mathrm{~h}$ at $4^{\circ} \mathrm{C}$ on the turning wheel. The Beads were resuspended in $100 \mu 1 \mathrm{PBS}$, and sodium azide was added to a final concentration of $10 \mathrm{mM}$ and stored at $4{ }^{\circ} \mathrm{C}$.

\subsubsection{Native Immunoprecipitation}

The yeast strain was grown in $40 \mathrm{ml}$ YEPD medium, overnight at $24^{\circ} \mathrm{C}$ up to an $\mathrm{OD}_{600}$ of 0.5 to 1.0. Now $20 \mathrm{OD}$ of cells were harvested by 5 min centrifugation at $3000 \mathrm{rpm}$, the pellet was resuspended in $2 \mathrm{ml}$ TE $\beta$ and incubated for 10 min under slow shaking at $24^{\circ} \mathrm{C}$. The cells were centrifuged thereafter for $3 \mathrm{~min}$ at $3000 \mathrm{rpm}$. The pellet was resuspended in $2 \mathrm{ml}$ Sphereoplast buffer with $60 \mu 110 \mathrm{mg} / \mathrm{ml}$ Zymolyase (Final conc. 300 $\mu \mathrm{g} / \mathrm{ml}$ ) and sphereoplasted for $1 \mathrm{~h}$ at $24^{\circ} \mathrm{C}$ under slow shaking. The sphereoplasts were washed with $1 \mathrm{ml} \mathrm{YEPD/Sorbitol,} \mathrm{for} 2$ times (centrifuged for 30 seconds at $6500 \mathrm{rpm}$ ). 
If the mutants are temperature sensitive, then the cells were divided into $10 \mathrm{ml}$ each into two falcon tubes. One tube was incubated at $24^{\circ} \mathrm{C}$ or permissive temperature and another at $37^{\circ} \mathrm{C}$ or restrictive temperature for $1 \mathrm{~h}$ under slow shaking. The cells were centrifuged for $2 \mathrm{~min}$ at $2000 \mathrm{rpm}$. The pellets were resuspended in $1 \mathrm{ml}$ cold Lysis buffer + Proteaseinhibitors and were homogenized in each case 20 times in the ice-cold Potter ("loose"). The homogenized cells were incubated at $4^{\circ} \mathrm{C}$ for $15 \mathrm{~min}$ on the turning wheel. A centrifugation for $20 \mathrm{~min}$ at $50000 \mathrm{rpm}$ at $4^{\circ} \mathrm{C}$ was done and the supernatant was collected. $40 \mu \mathrm{l}$ of the supernantant was saved for the gel (Homogenate fraction), each $450 \mu 1$ of the supernatant was transferred into two new eppendorf tubes:
A) $450 \mu 1$ Homogenate $+48 \mu 1$ antibody-Beads (see chapter 2.2.3.7)
B) $450 \mu 1$ Homogenate $+48 \mu 1$ Preimmune-Beads (see chapter 2.2.3.7)

Overnight incubation was done at $4{ }^{\circ} \mathrm{C}$ on the turning wheel. On the next day they were centrifuged for 20 seconds at $6500 \mathrm{rpm}$. The Unbound fraction was saved for the gel. The Beads were washed, $3 \mathrm{x}$ each for $5 \mathrm{~min}$ at $4^{\circ} \mathrm{C}$ with $1 \mathrm{ml}$ Lysis buffer and resuspended afterwards in $50 \mu 1$ 1x sample buffer without $\beta$-Mercaptoethanol.

For the Gel: $25 \mu 1$ was taken from the Homogenate and the Unbound fractions, with 12.5 $\mu 13 x$ sample buffers and the bead fractions were boiled at $95{ }^{\circ} \mathrm{C}$ for $5 \mathrm{~min}$. On an $11 \%$ gel, $30 \mu \mathrm{l}$ from each sample was loaded followed by western analysis.

$\underline{\text { YEPD/Sorbitol }}$

$\begin{aligned} 10 \mathrm{~g} / \mathrm{L} & \text { Yeast extract } \\ 20 \mathrm{~g} / \mathrm{L} & \text { Bacto-Peptone } \\ 182.2 \mathrm{~g} / \mathrm{L} & \text { Sorbitol (final conc.: } 1 \mathrm{M} \text { ) }\end{aligned}$

after autoclaving, added

$40 \mathrm{ml} / \mathrm{L} \quad 50 \%$ Glucose (final conc.: $2 \%(\mathrm{w} / \mathrm{v})$ )

Lysis-buffer $(50 \mathrm{ml})$ :

final conc.:

$1 \mathrm{ml} 1 \mathrm{M}$ HEPES-KOH, $\mathrm{pH} 7.0$

$20 \mathrm{mM}$

$5 \mathrm{ml} \quad 1 \mathrm{M} \mathrm{KCl}$

$100 \mathrm{mM}$

$0.2 \mathrm{ml} \quad 0.5 \mathrm{M}$ EDTA

$2 \mathrm{mM}$

$1 \mathrm{ml} 25 \%$ Triton X-100

$0.5 \%(\mathrm{w} / \mathrm{v})$ 


\subsubsection{9 "Pulse-Chase" Immunoprecipitaion}

Pulse-chase experiment is used to study the fate of a protein inside a cell. To analyze the transport and the specific processing, the yeast cells were grown in Methionine and Cysteine free medium, then marked with radioactive $\left[{ }^{35} \mathrm{~S}\right]$-Methionine and $\left[{ }^{35} \mathrm{~S}\right]$-Cysteine ("Pulse"). Non radioactive Methionine and Cysteine was added to the cells to stop the pulse and the samples were taken at different time points ("Chase"). Finally, immunoprecipitation was done to analyze the fate of the protein. In this study, the pulse chase immunoprecipitations were done for Carboxypeptidase Y (CPY), Alkaline Phosphatase (ALP), Vacuolar Sorting Protein 10 (Vps10p), A-ALP, Vti1p, Use1p and Pep12p.

\section{CPY and ALP-IP:}

The yeast cells were grown 2 days before the experiment and diluted evening before the experiment in a manner that the $\mathrm{OD}_{600}$ would be 0.1-1.1 in the next morning. 0.5 OD of cells were taken in $13 \mathrm{ml}$ tubes and pelleted down at $3000 \mathrm{rpm}$ for $3 \mathrm{~min}$. The cells were resuspended in $500 \mu \mathrm{l}$ SD-Met $+50 \mathrm{mM} \mathrm{KPO} 4 \mathrm{pH} 5.7+2 \mathrm{mg} / \mathrm{ml}$ BSA and incubated at $24^{\circ} \mathrm{C}$ for $15 \mathrm{~min}$.

Pulse-Chase labeling:

For ts-experiment, cells were again preinucbated at $37^{\circ} \mathrm{C}$ or at desired temperature for 15 min. $10 \mu \mathrm{l}$ (for CPY) or $15 \mu \mathrm{l}$ (for ALP) of radioactive L- $\left[{ }^{35} \mathrm{~S}\right]$-label ([ $\left.{ }^{35} \mathrm{~S}\right]$-Methionine and $\left[{ }^{35} \mathrm{~S}\right]$-Cystein, $\left.14 \mu \mathrm{Ci} / \mu \mathrm{l}\right)$ was added to the cells and pulsed for $10 \mathrm{~min}$. $50 \mu \mathrm{l}$ of cold Met + Cys (equal volumes of $10 \mathrm{mg} / \mathrm{ml}$ stocks were mixed) was added and chased for 30 min. $5 \mu \mathrm{l} \mathrm{Na-Azide} \mathrm{was} \mathrm{added} \mathrm{to} \mathrm{stop} \mathrm{the} \mathrm{chase} \mathrm{and} \mathrm{the} \mathrm{contents} \mathrm{were} \mathrm{transferred} \mathrm{into}$ screw cap eppendorf tubes. Cells were pelleted for $20 \mathrm{sec}$ at 13,000 rpm and both the pellet and the supernatant fractions were processed for CPY-IP whereas only the pellet fraction was analyzed for ALP-IP.

Spheroplasting the yeast cells:

For spheroplasting the pellet fraction, the cells were pretreated with $1 \mathrm{ml}$ of $50 \mathrm{mM}$ Tris $\mathrm{pH} 9.5,10 \mathrm{mM}$ DTT and $10 \mathrm{mM} \mathrm{NaAzide}$ for $5 \mathrm{~min}$ at $30^{\circ} \mathrm{C}$ and centrifuged. To the pellet, $150 \mu \mathrm{l}$ of Spheroplast-Mix with $250 \mu \mathrm{g} / \mathrm{ml}$ Zymolyase was added and incubated at $30{ }^{\circ} \mathrm{C}$ for $30-45 \mathrm{~min}$. The spheroplasts were collected by centrifuging at $6500 \mathrm{rpm}$ for 30 sec. 
Lysis and Pre-absorption:

For CPY-IP:

To the cell pellet (I), $780 \mu 1$ lysis mix was added which contained $100 \mu 1$ 10x IP-buffer, $670 \mu \mathrm{l}$ water and $10 \mu \mathrm{l} 100 \mathrm{x}$ Protease inhibitors. To the Supernatant (E) with protease

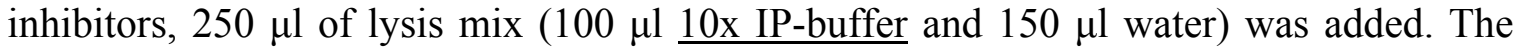
samples were boiled at $95^{\circ} \mathrm{C}$ for $5 \mathrm{~min}$ and cooled for several min on ice. $270 \mu \mathrm{l}$ of Preabsorption mix (containing $50 \mu \mathrm{l}$ washed Pansorbin and $220 \mu \mathrm{l}$ water) was added to the cells and incubated on ice for $15 \mathrm{~min}$.

\section{For ALP-IP:}

The cell pellet was resuspended in $50 \mu \mathrm{l}$ lysis mix with $1 \%$ SDS, 8 M Urea and $1 \mathrm{x}$ Protease inhibitors. The samples were boiled at $95^{\circ} \mathrm{C}$ for $5 \mathrm{~min}$ and cooled for several min at room temperature. $1 \mathrm{ml}$ of Pre-absorption mix (containing $100 \mu 1$ 10x IP-buffer without $\underline{\text { SDS }}, 50 \mu \mathrm{l}$ washed Pansorbin, $10 \mu \mathrm{l}$ Protease inhibitors and $850 \mu \mathrm{l}$ water) was added to the cells and incubated on ice for $15 \mathrm{~min}$.

\section{Immunoprecipitation:}

The pre-absorbed cells were pelleted at $13000 \mathrm{rpm}$ for $5 \mathrm{~min} .5 \mu \mathrm{l}$ of the supernatant was taken for counting at liquid scintillation counter and the rest was transferred to the new eppendorf tubes with $1 \mu \mathrm{l}$ of anti-CPY or with $2 \mu \mathrm{l}$ of anti-ALP antiserum. The cells were incubated on ice for $1 \mathrm{~h} 30 \mathrm{~min}$ with frequent mixing. After the incubation, $50 \mu \mathrm{l}$ Pansorbin was added to the cells and again incubated on ice for $1 \mathrm{~h} 30 \mathrm{~min}$ with frequent mixing. The eppendorf tubes were centrifuged at $12000 \mathrm{rpm}$ for $30 \mathrm{sec}$ and the pellet was washed three times with $1 \mathrm{ml}$ ALP + CPY wash buffer. Finally the pellet was resuspended in $40 \mu 1$ of $2 x$ Stop buffer and frozen at $-20^{\circ} \mathrm{C}$.

\section{A-ALP and Pep12p-IP}

The pulse chase immunoprecipitaion of A-ALP and Pep12p was done as mentioned for CPY and ALP-IP, except that 1.6 OD of cells were taken in $3.1 \mathrm{ml}$ of SD-met and labeled with $35 \mu$ of radioactive L- $\left[{ }^{35} \mathrm{~S}\right]$-label and pulsed for $25 \mathrm{~min}$. $150 \mu \mathrm{l}$ of cold Met $+\mathrm{Cys}$ was added and chased for $5 \mathrm{~min}, 60 \mathrm{~min}$ and $120 \mathrm{~min}$ for A-ALP and $10 \mathrm{~min}, 3 \mathrm{hr}$ and 5 $\mathrm{hr}$ for Pep12p. For each chase point, $1 \mathrm{ml}$ of cells was taken out and $10 \mu \mathrm{l}$ of Na-Azide was added and kept on ice. The immunoprecipitation was continued as mentioned for $\underline{\text { ALP-IP }}$ and $2 \mu \mathrm{l}$ of anti-ALP antibody was used for A-ALP-IP and $2 \mu 1$ of anti-Pep12p antibody was used for Pep12p IP. 


\section{Vps10p-IP:}

Vps10p IP was done as mentioned in CPY and ALP-IP with few modifications. 0.825 OD cells were taken in $3 \mathrm{ml}$ of SD-met, labeled with $35 \mu \mathrm{l}$ of radioactive L- $\left[{ }^{35} \mathrm{~S}\right]$-label and pulsed for $25 \mathrm{~min}$. $150 \mu \mathrm{l}$ of cold Met + Cys was added and chased for $10 \mathrm{~min}, 3 \mathrm{hr}$ and 5

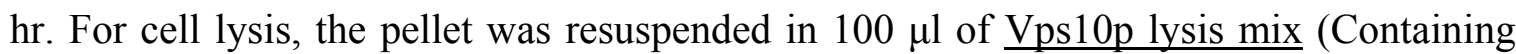
$1 \%$ SDS, 50mM Tris-HCL pH7.4, $2 \mathrm{mM} \mathrm{MgCl}_{2}$ and $3 \mu \mathrm{l} / \mathrm{ml} \beta$-Mercaptoethanol), continued as in ALP-IP and $2.5 \mu \mathrm{l}$ of anti-Pep1 (Vps10) antibody was used for IP.

\section{Vti1p and Use1p-IP:}

This IP was done exactly like Pep12p-IP, except that the cells were lysed with $50 \mu 1$ of $0.5 \%$ SDS with $1 \mathrm{X}$ Protease inhibitors and heated at $65^{\circ} \mathrm{C}$ for $5 \mathrm{~min} .2 \mu \mathrm{l}$ of anti-Vtilp antiserum was used for Vtilp-IP and $4 \mu \mathrm{l}$ anti-Use1p antiserum was used for Use1p-IP.

Spheroplast-Mix:

$$
\begin{aligned}
1.2 \mathrm{M} & \text { Sorbitol } \\
50 \mathrm{mM} & \mathrm{KPO}_{4}, \mathrm{pH} 7.3 \\
10 \mathrm{mM} & \text { Sodiuim Azide }
\end{aligned}
$$

10x IP-buffer:

\begin{tabular}{cl}
$0.9 \mathrm{M}$ & Tris-HCl, pH 8.0 \\
$1 \%$ & SDS \\
$1 \%$ & Triton X-100 \\
$20 \mathrm{mM}$ & EDTA \\
$10 \mathrm{x} \mathrm{IP-buffer}$ (without SDS): \\
\hline $0.9 \mathrm{M}$ & Tris-HCl, pH 8.0 \\
$1 \%$ & Triton X-100 \\
$20 \mathrm{mM}$ & EDTA \\
CPY+ALP-Wash buffer: \\
\hline $10 \mathrm{mM}$ & Tris, pH 8.0 \\
$0.1 \%$ & SDS \\
$0.1 \%$ & Triton X-100 \\
$2 \mathrm{mM}$ & EDTA
\end{tabular}




\section{Washig of Pansorbin:}

Pansorbin cells were washed $3 \mathrm{x}$ with $20 \mathrm{mM}$ Tris, $\mathrm{pH} 7.5+100 \mathrm{mM} \mathrm{NaCl}$ (centrifugation for $30 \mathrm{sec}$ at $11000 \mathrm{rpm}$ ) and made up to the start volume with $20 \mathrm{mM}$ Tris, $\mathrm{pH} 7.5+100 \mathrm{mM} \mathrm{NaCl}$.

\section{For the SDS-gel:}

The samples were boiled at $95^{\circ} \mathrm{C}$ for $5 \mathrm{~min}, 20 \mu \mathrm{l}$ was loaded onto $8 \% \mathrm{SDS}$ gel for CPY, ALP, A-ALP and Vps10p-IP and 11\% SDS gel was used for Pep12p, Vti1p and Use1p. The gel was run at $15 \mathrm{~mA}$ for 5-6 hr, destained for $30 \mathrm{~min}$, washed with water and dried for $2 \mathrm{hr}$. Then the gel was exposed to a phosphor-imager screen, scanned and analyzed by BAS1000 (Fuji).

\subsubsection{Purification of Ent3p-Strep tag fusion protein}

$10 \mathrm{ml}$ of pKW5 (Strep-tag Ent3p-ENTH) culture was grown overnight in 2xYT-Amp medium. The next day, the $10 \mathrm{ml}$ culture was added to $250 \mathrm{ml}$ of fresh $2 x Y T$-Amp, grown at $30^{\circ} \mathrm{C}$ for $1 \mathrm{~h} 30 \mathrm{~min}$ till an $\mathrm{OD}_{600}$ of 0.5 . The cells were induced with $12.5 \mu \mathrm{l}$ of AHT ( $2 \mathrm{mg} / \mathrm{ml}$ anhydrotetracycline) for $4 \mathrm{~h}$ at $30^{\circ} \mathrm{C}$. The cells were pelleted at $10000 \mathrm{rpm}$ for $10 \mathrm{~min}$ at $4^{\circ} \mathrm{C}$ in JA20 rotor. The pellet was resuspended in $4 \mathrm{ml}$ of buffer $\mathrm{W}$ and was frozen in $-20^{\circ} \mathrm{C}$. The next day, the pellet was thawed and $40 \mu \mathrm{l}$ of protease inhibitors was added immediately before French Press lysis with 900 psi at medium for 3 times in the small cell. The cells were centrifuged for $10 \mathrm{~min}$ at $13000 \mathrm{rpm}$ at $4^{\circ} \mathrm{C}$. The supernatant was collected and filtered through $0.2 \mu \mathrm{m}$ filter for the purification. $2 \mu \mathrm{l}$ of the supernatant and the pellet (resuspended it in the same volume) was saved for SDS-gel.

IBA-Strep-Tactin Superflow column was equilibrated two times at $4^{\circ} \mathrm{C}$ with $4 \mathrm{ml}$ bufferW. The supernatant was loaded on the column, the unbound fraction was collected and saved for the gel. The column was washed five times with $1 \mathrm{ml}$ buffer $\mathrm{W}$ and eluted five times with $0.5 \mathrm{ml}$ buffer E. $0.5 \mathrm{ml}$ fractions were collected and the fractions 3 and 4 were aliquoted and frozen immediately on dry ice. Protein concentrations of the fractions were analyzed. The column was regenerated by washing three time with $5 \mathrm{ml}$ buffer $\mathrm{R}$ and stored in it. 


\section{Buffer W:}

$100 \mathrm{mM} \quad$ Tris, $\mathrm{pH} 8.0$

$150 \mathrm{mM} \quad \mathrm{NaCl}$

$1 \mathrm{mM} \quad$ EDTA

Buffer E:

Buffer $\mathrm{W}+2.5 \mathrm{mM}$ desthiobiotin

Buffer R:

Buffer W + 1mM 2-[4'-hydroxy-benzeneazo] benzoic acid (HABA)

\subsubsection{Liposome binding assay}

Preparation of liposomes:

Liposomes are lipid-bilayer bounded vesicles. They are prepared by hydrating lipids (from Sigma) in aqueous solutions. $1 \mathrm{mg}$ of lipids consisting of $70 \%$ phosphatidylcholine (PC), $20 \%$ phosphatidylethanolamine (PE) and $10 \%$ variable lipids were dried under nitrogen to form a thin lipid film. It should not be dried too fast. The thin lipid film was rehydrated by adding $150 \mu \mathrm{l}$ of $0.3 \mathrm{M}$ sucrose, incubated at room temperature for $1 \mathrm{hr}$ and vortexed occasionally. $850 \mu \mathrm{l}$ of water was added and centrifuged for $1 \mathrm{hr}$ at $4^{\circ} \mathrm{C}$ at $20,000 \mathrm{rpm}$ in a Beckmann table top ultracentrifuge with TLA-100.3 rotor. The pellet was resuspended in $500 \mu \mathrm{l}$ of $20 \mathrm{mM}$ Hepes pH7.4 and passed 15 times through a pre-wet extruder with 100 or $400 \mathrm{~nm}$ membrane. The liposomes were stored at $4^{\circ} \mathrm{C}$ and used within one week.

Liposome binding assay:

Bacterially expressed strep-tagged ENTH domain of Ent3p was diluted with buffer-L to required concentration. For each reaction, $6 \mu \mathrm{g}$ of Ent3p in $100 \mu \mathrm{l}$ of buffer-L and $100 \mu \mathrm{g}$ of liposomes were used. The purified Ent $3 p$ protein concentration used in this experiment was $1.1 \mu \mathrm{g} / \mu \mathrm{l}$. So, $5.5 \mu \mathrm{l}$ of Ent3p in $94.5 \mu \mathrm{l}$ of buffer-L was taken for each reaction. Totally, for $7(6+1)$ reactions, (PC, PE, PI3P, PI4P, PI3,5P and a negative control (only protein)), $38.2 \mu \mathrm{l}$ of protein in $661.5 \mu \mathrm{l}$ of buffer-L was pre-incubated on ice for $10 \mathrm{~min}$ and pre-cleared at 50,000 rpm for $20 \mathrm{~min}$ in a Beckman table top centrifuge using TLA100.3 rotor. The final salt concentration of buffer-L with protein was $55 \mathrm{mM} \mathrm{NaCl}$. $100 \mu \mathrm{l}$ of the pre-cleared supernatant was incubated with $50 \mu \mathrm{l}(100 \mu \mathrm{g})$ of liposomes on ice for $15 \mathrm{~min}$ and re-isolated at $25000 \mathrm{rpm}$ for $20 \mathrm{~min}$ using TLA100.3 rotor. The pellet 
was rinsed twice with $150 \mu \mathrm{l}$ of buffer-L at $25000 \mathrm{rpm}$ for $20 \mathrm{~min}$. The pellet was resuspended in $20 \mu \mathrm{l}$ of $2 \mathrm{x}$ stop buffer and analyzed by SDS-PAGE followed by Coomassie blue staining. $30 \%(1.64 \mu \mathrm{l}$ of Strep-Ent3p) of the starting material was loaded as a standard.

\section{Buffer-L:}

$20 \mathrm{mM}$ Hepes $\mathrm{pH} 8.0$

$50 \mathrm{mM} \mathrm{NaCl}$

\subsubsection{Cell Biology}

\subsubsection{Subcellular fractionation}

The yeast cells were grown overnight to an $\mathrm{OD}_{600}$ of $0.5-1.0$. And $20 \mathrm{OD}$ of cells were pelleted at $3000 \mathrm{rpm}$ for $3 \mathrm{~min}$. The pellet was resuspended in $2 \mathrm{ml}$ of TE $\beta$ and incubated at $30^{\circ} \mathrm{C}$ for $10 \mathrm{~min}$ under slow shaking. Cells were pelleted down at $3000 \mathrm{rpm}$ for $3 \mathrm{~min}$ and spheroplasted with $60 \mu \mathrm{l}$ of $10 \mathrm{mg} / \mathrm{ml}$ zymolyase in $2 \mathrm{ml}$ spheroplast buffer for $1 \mathrm{~h}$ at $30^{\circ} \mathrm{C}$. Spheroplasts were pelleted at $6500 \mathrm{rpm}$ for $30 \mathrm{sec}$ and washed 3 times with spheroplast buffer. Spheroplasts were resuspended in $1 \mathrm{ml}$ of lysis buffer in the presence of protease inhibitors. Cells were homogenized 5 times in a tight glass potter. For some, experiments in which glass beads were used, the cells were washed once with $5 \mathrm{ml}$ of ice cold lysis buffer containing $20 \mathrm{mM}$ HEPES (pH6.8), $0.15 \mathrm{M}$ potassium acetate, $10 \mathrm{mM}$ $\mathrm{MgCl}_{2}$ and $0.25 \mathrm{M}$ Sorbitol with protease inhibitors, resuspended in $1 \mathrm{ml}$ of the same buffer and transferred to prechilled $15 \mathrm{ml}$ corex tube with $1.6 \mathrm{~g}$ glass beads. At $4^{\circ} \mathrm{C}$, the cells were vortexed vigorously for $30 \mathrm{sec}$ followed by chilling on ice for $30 \mathrm{sec}$ which was repeated 10 times. The supernatant was transferred to an eppendorf cup. The homogenates from the gentle method (homogeneization) and the harsh method (with glass beads) were centrifuged at $2000 \mathrm{rpm}$ for $5 \mathrm{~min}$ at $4^{\circ} \mathrm{C}$, to remove the broken cells. The supernatant was transferred carefully to a new eppendorf cup, $400 \mu \mathrm{l}$ was saved as $\mathbf{H}$ fraction and $500 \mu \mathrm{l}$ was centrifuged at $13000 \mathrm{rpm}$ for $10 \mathrm{~min}$ at $4{ }^{\circ} \mathrm{C}$ to obtain the $\mathrm{S} 13$ and P13 fractions. S13 fraction was then centrifuged at $50000 \mathrm{rpm}$ for $20 \mathrm{~min}$ at $4^{\circ} \mathrm{C}$ in a Beckman table top centrifuge using TLA100.3 rotor to obtain the S200 (cytosolic proteins) and the P200 fraction (membrane proteins). P13 and P200 fractions were resuspended in $500 \mu \mathrm{l}$ and $400 \mu \mathrm{l}$ respectively with the lysis buffer containing protease 
inhibitors. For some experiments, the pellet fractions were resuspended in $70 \mu$ of lysis buffer.

\section{Gel:}

To $50 \mu$ fractions of $\mathbf{H}, \mathbf{P 1 3}, \mathbf{P 2 0 0}$ and S200, $25 \mu$ of 3x Stop buffer was added and boiled for $5 \mathrm{~min}$ at $95^{\circ} \mathrm{C}$. From each sample $30 \mu \mathrm{l}$ was loaded onto SDS-PAGE, for equal volume of load. For experiments in which equal amounts of protein were loaded: usually $10 \mu \mathrm{g}$ per well. But it varied depending on the amounts of protein present in the fractions. TE $\beta$ :

$\begin{array}{ll}200 \mathrm{mM} & \text { Tris } \mathrm{pH} 8.0 \\ 20 \mathrm{mM} & \text { EDTA } \\ 1 \% & \beta \text {-Mercaptoethanol }\end{array}$

Lysis-buffer $(10 \mathrm{ml})$ :

$500 \mu \mathrm{l} \quad 1 \mathrm{M}$ Tris, $\mathrm{pH} 7.5$

$1 \mathrm{ml} 2 \mathrm{M}$ Sorbitol

$20 \mu \mathrm{l} \quad 0.5 \mathrm{M}$ EDTA
Final conc.:

$50 \mathrm{mM}$

$0.2 \mathrm{M}$

$1 \mathrm{mM}$

\subsubsection{CPY overlay assay}

This assay was used to detect the mutants which secrete CPY. The strains to be checked were streaked on a YEPD plate with a positive (vtil-1 or vtil-2 cells) and a negative (wild type cells) control and a nitrocellulose membrane was placed on the top of the cells. The plate was incubated at the semi-permissive temperature for overnight. Then the membrane was removed from the plate, washed with water to clear up the adhering cells. The membrane was processed for immuno staining using antiserum against CPY.

\subsubsection{Aminopeptidase I maturation test}

Aminopeptidase I is a vacuolar hydrolase which is transported from the cytosol to the vacuole by the CVT pathway (during logarithmic and early stationary phases) and by the autophagy (during late stationary and starvation conditions). The pro form of the amino peptidase I would appear if the CVT pathway or the autophagy was blocked. The cultures from the log phase, stationary phase and nitrogen starvation were prepared as follows. 
The strains were grown overnight at $30^{\circ} \mathrm{C}$ till $\mathrm{OD}_{600} 0.5$ to 1.2 , for the log phase cells. The stationary cultures were obtained by growing the cells for nearly 24 hours at $30^{\circ} \mathrm{C}$ to an $\mathrm{OD}_{600}$ above 4 . The stationary cultures were pelleted down, resuspended in the nitrogen starvation medium and again grown for $4 \mathrm{~h}$ at $30^{\circ} \mathrm{C}$ to obtain the starved cells. Protein extracts from the log phase, stationary phase and starved cells were prepared as mentioned in 2.2.3.1 and analyzed by western immnuo blotting to check the maturation of aminopeptidase I using antibody against aminopeptidase I.

\subsubsection{Indirect Immunofluorescence}

$5 \mathrm{ml}$ of SD or YEPD medium was inoculated with cells and grown overnight at $30{ }^{\circ} \mathrm{C}$. Next day, cells equal to $2.5 \mathrm{OD}_{600}$ were harvested and was inoculated in $10 \mathrm{ml}$ of YEPD medium and incubated for $4 \mathrm{~h}$ at $30{ }^{\circ} \mathrm{C}$. Cells were then fixed by adding 1-1.2 $\mathrm{ml}$ of $37 \%$ formaldehyde (final concentration 3.7\%), incubated for $30 \mathrm{~min}$ in the shaker. Cells were harvested and resuspended in $2 \mathrm{ml}$ fixative solution and incubated overnight at room temperature on the rocker. Fixed cells were harvested and suspended in $1 \mathrm{ml}$ TE $\beta$ for 10 min. Spheroplasts were obtained by incubating with zymolyase at $30{ }^{\circ} \mathrm{C}$ with gentle shaking. While cells were spheroplasting, slides (8-well multitest slides) were prepared. $20 \mu \mathrm{l}$ of $1 \mathrm{mg} / \mathrm{ml}$ poly-L-Lysine in water was added to each well and allowed to sit for 1 min. Each well was washed with $25 \mu$ of water (6 times). Aspirated and allowed to air dry. Spheroplasted cells were pelleted at $6500 \mathrm{rpm}, 30 \mathrm{sec}$ and washed once with $1 \mathrm{ml}$ of 1.2 $\mathrm{M}$ sorbitol containing $5 \mathrm{mM}$ sodium azide and repelleted. Cells were resuspended in 1.2 M sorbitol containing 1-2 \% SDS, incubated for $2 \mathrm{~min}$ and were pelleted at $6500 \mathrm{rpm}$, $30 \mathrm{sec}$ and washed twice with $1 \mathrm{ml}$ of $1.2 \mathrm{M}$ sorbitol. The cells were resuspended in an appropriate volume of $1.2 \mathrm{M}$ sorbitol depending on the size of the pellet. $40 \mu \mathrm{l}$ of cells per well were added and allowed to settle for $10 \mathrm{~min}$. Remaining cells were aspirated and each well was washed 3 times with 20-25 $\mu$ l of PBS-BSA. The slides were allowed to sit in humid chamber for $15 \mathrm{~min}$ at room temperature. Wells were aspirated and primary antibody was added and incubated for $1 \mathrm{~h}$ at room temperature. Cells were washed with 20-25 $\mu 1$ of PBS-BSA-azide 6 times. Secondary antibody was added and incubated for 1h. Cells were washed 6 times with PBS-BSA-azide. $10 \mu \mathrm{l}$ of DAPI $(1 \mathrm{mg} / \mathrm{ml})$ was added, incubated for 10 min and washed with PBS-BSA-Azide 3 times. $8 \mu$ of mounting media was added in each well, slides were covered with coverslip and allowed to settle. 
After $5 \mathrm{~min}$, ends of the cover slips were sealed with nail polish. Slides were viewed under a fluorescence microscope. DAPI staining was examined at $395 \mathrm{~nm}$.

Fixative: $1 \mathrm{~g}$ of paraformaldehyde was dissolved in $25 \mathrm{ml}$ of water by heating to $60{ }^{\circ} \mathrm{C}$. $187.5 \mu \mathrm{l}$ of $6 \mathrm{~N} \mathrm{NaOH}$ was added and then $0.34 \mathrm{~g}$ of potassium hydrogen phosphate was added. The $\mathrm{pH}$ of the solution was 6.5.

$\underline{\text { TE } \beta \text { buffer }}$

Tris/HCl, pH 8.0 $200 \mathrm{mM}$

EDTA $20 \mathrm{mM}$

$\beta$-mercaptoethanol

$1 \%$

Spheroplasting buffer

Sorbitol $1.2 \mathrm{M}$

Potassium phosphate $\mathrm{pH} 7.3$ $50 \mathrm{mM}$

Magnesium chloride $1 \mathrm{mM}$

$\underline{\text { Sorbitol-Azide }}$

Sorbitol $1.2 \mathrm{M}$

Sodium azide $5 \mathrm{mM}$

Sorbitol-SDS

$10 \% \mathrm{w} / \mathrm{v}$ SDS $2 \%$

Sorbitol $1.2 \mathrm{M}$

Sodiumazide $5 \mathrm{mM}$

$\underline{\text { PBS-BSA-Azide }}$ BSA $5 \mathrm{mg} / \mathrm{ml}$

Sodiumazide $5 \mathrm{mM}$

10X PBS $1 \mathrm{X}$ 


\subsubsection{GFP fluorescence}

Overnight grown yeast cells were washed once with PBS and directly viewed under the fluorescence microscope AxioCAM without fixation. If required, the nuclear staining was done with 1:1000 dilution of DAPI $(1 \mathrm{mg} / \mathrm{ml})$ and incubated at room temperature for 10 min. Cells were washed twice with PBS. 1 or $3 \mu$ of cells were examined under microscope.

\subsubsection{FM4-64 staining}

The cultures were grown overnight at $24^{\circ} \mathrm{C}$ in YEPD. When the cultures reached 0.4 OD to $1.0 \mathrm{OD}$, they were shifted to the restrictive temperatures for 15 minutes. $0.5 \mathrm{OD}$ of the cells were pelleted down and resuspended in $120 \mu \mathrm{l}$ of YEPD. The dye FM4-64 was added to the final concentration of $65 \mu \mathrm{M}$ (from $16 \mathrm{mM}$ stock in DMSO) and inubated at the restrictive temperatures for $15 \mathrm{~min}$. The samples were pelleted at $6500 \mathrm{rpm}$ for $30 \mathrm{sec}$, washed once with YEPD and resuspended in $7 \mu$ of YEPD. The cells were viewed immediately under a fluorescence microscope with texas red-filter.

\subsubsection{Calcofluor and Phalloidin staining}

Chitin in the yeast cell wall was stained using Calcofluor (Fluorescent brightener 28, Sigma-aldrich, Steinheim, Germany) and actin was localized after Phalloidin TRITC (Sigma, Steinheim, Germany) staining as described by Pringle et al. $20 \mathrm{ml}$ Yeast cultures were grown overnight at $24^{\circ} \mathrm{C}$ and the $\log$-phase cultures were shifted to $18^{\circ} \mathrm{C}$ or $30^{\circ} \mathrm{C}$ for $5 \mathrm{~h}$ or $2 \mathrm{~h}$ respectively. $2.2 \mathrm{ml}$ of $37 \%$ Formaldehyde was added to the cells, inucbated at the same temperature for $10 \mathrm{~min}$ and pelleted down at $3000 \mathrm{rpm}$ for $5 \mathrm{~min}$. The pellet was resuspended in $2 \mathrm{ml}$ of PBS / $4 \%$ formaldehyde for $1 \mathrm{~h}$ at RT. Cells were pelleted, washed thoroughly with PBS and resuspended in $500 \mu \mathrm{l}$ of PBS. To $100 \mu \mathrm{l}$ of cells, $10 \mu \mathrm{l}$ of $1 \mathrm{mg} / \mathrm{ml}$ calcofluor in water and $10 \mu \mathrm{l}$ of $6.6 \mu \mathrm{M}$ phalloidin in methanol was added and incubated for $1 \mathrm{~h} 30 \mathrm{~min}$ in the dark. Cells were washed five times with PBS, resuspended in $10 \mu \mathrm{l}$ of mounting medium and $3 \mu \mathrm{l}$ was viewed under a fluorescence microscope. 


\section{Results}

\subsection{Characterization of Use1p mutants}

During the doctoral studies of Dr. Meik Dilcher, he identified an uncharacterized open reading frame, YGL098w which shared the characteristic features of SNARE proteins. He showed that the 245 amino acids product from the ORF is really a SNARE protein and named it Uselp (Unconventional $\underline{S} N A R E$ in the ER), since it was localized in the ER. USE1 is an essential gene, so, Dr. Meik Dilcher created ts mutants by random mutagenesis to analyze its function. A 10 amino acid mutant allele (use1-10AA), which contained 5 amino acid replacements in the SNARE motif, including the mutation D183G in the 0 layer grew more slowly at $24^{\circ} \mathrm{C}$ than WT cells and did not grow at 30 and $37^{\circ} \mathrm{C}$. To determine the importance of the 0 layer, the allele use1-0 layer with the mutation D183G was created which didn't show any growth defect. He showed that usel mutants were defective in the retrograde traffic to the ER and co-immunoprecipitation of Use $1 p$ revealed that it formed a SNARE complex with Ufe1p, Sec20p and Sec22p. When the manuscript was submitted for publication, the reviewers asked for some more experiments. A small part of Use1p project was continued by me, by checking the vacuolar morphology of use1 mutants with FM4-64 staining and repeating Kar2p/BiP secretion assays in usel mutants to support the finding that Use1p is involved in the retrograde trafficking.

\subsubsection{Vacuolar morphology of use1 mutants}

The use1-10AA cells were larger, accumulated ER membranes and nuclei appeared fragmented in some cells. The morphology of vacuoles was studied by FM4-64 staining. Cells grown at $24^{\circ} \mathrm{C}$ were shifted to 30 or $37^{\circ} \mathrm{C}$ for 15 min and incubated with FM4-64 for an additional $15 \mathrm{~min}$ at the same temperature to stain vacuolar membranes. Vacuoles had wild-type morphology in most use 1 mutant cells, but were slightly more fragmented in some use1-10AA cells as showed in the Fig.10. 


\section{WT use1-0layer use1-10AA \\ $37^{\circ} \mathrm{C} \quad 37^{\circ} \mathrm{C} \quad 30^{\circ} \mathrm{C}$}
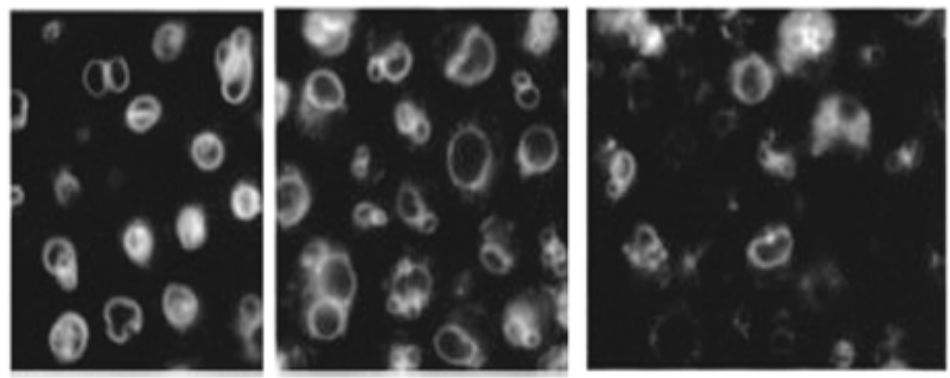

Fig.10. Vacuolar morphology in use1 mutants: WT, use1-0layer and use1-10AA cells were incubated with FM4-64 at $37^{\circ} \mathrm{C}$ or $30^{\circ} \mathrm{C}$ to stain the vacuoles.

\subsubsection{Kar2p/BiP secretion in the use1mutants}

Kar2p/Bip is a soluble ER protein, which is retrieved from the Golgi (Semenza et al., 1990). Kar2p is secreted into the medium if retrograde traffic to the ER is blocked. It is a specific assay to check the block in the retrograde traffic. The amount of Kar2p secreted by use 1 mutants was determined in a period of $2 \mathrm{~h}$ at permissive and restrictive temperatures. use 1-10AA cells secreted some Kar2p at $24^{\circ} \mathrm{C}$ and slightly larger amounts at $30^{\circ} \mathrm{C}$. A shift to $37^{\circ} \mathrm{C}$ increased Kar2p secretion from use 1-Olayer cells to levels clearly above that from wild-type cells. use1-Olayer cells secreted less Kar2p at non-permissive temperature than use1-10AA cells. sec20-1 cells were used for comparison since this defect primarily affects the retrograde traffic to the ER (Fig.11). Wild-type cells secreted $0.37 \%$ (SD 0.2), sec20-1 cells 3.7\% (SD 0.9) and use 1-10AA cells 4.9\% (SD 3.4) of the intracellular Kar2p within $2 \mathrm{~h}$ at $30^{\circ} \mathrm{C}$ in four independent experiments; use 1-Olayer cells secreted $0.8 \%$ in $2 \mathrm{~h}$ at $37^{\circ} \mathrm{C}$. 


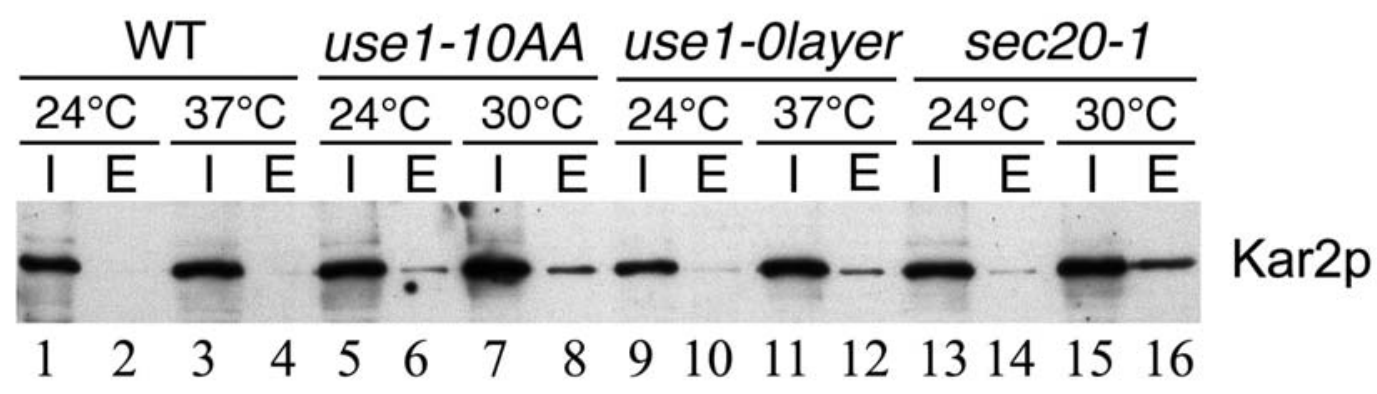

Fig.11. Kar2p/BiP secretion in use1 mutants: Protein extracts from the cell pellet (I) and the TCA precipitated medium (E) were prepared from the WT, use1-10AA, use1-0layer and sec20-1 cells at $24^{\circ} \mathrm{C}$ or $30^{\circ} \mathrm{C}$ or $37^{\circ} \mathrm{C}$. Kar2p was detected by western immunoblotting using antibody against Kar2p/BiP. Load: Equivalents of 0.19 OD for the pellet fractions and 3.6 OD for the external fractions were subjected to SDS PAGE.

\subsection{Function of the N-terminus of Vtilp}

The function of the N-terminus of Vtilp is not known, so far. Using the N-terminal mutants of Vtilp, the function of N-terminus could be studied well. Random mutagenesis of VTI1 gene generated a mutation with no big change in the SNARE motif and 7 amino acid exchanges. The N-terminus with 2 amino acid mutation till AA105 was cloned into wild type Vtilp. This 2 AA mutant allele, vtiQ29RW79R (2 AA mutant) caused phenotype. From the $2 \mathrm{AA}$ allele, the $1 \mathrm{AA}$ alleles $(v t i Q 29 R$ and $v t i W 79 R)$ were cloned separately, to study the effects of 1 AA replacement.

\subsubsection{Localization of N-terminal mutants}

The localization of the mutant Vtilp in FvmY6pBK120 cells (vti1AvtiQ29RW79R on CEN plasmid) was done by immunofluresecence with antibody against Vtilp. At $24^{\circ} \mathrm{C}$, Vtilp is localized to Golgi and pre-vacuolar membrane as punctate structures both in WT and in the mutant, but in the mutant some staining around the ER could also be seen (Fig.12a). Protein synthesis was arrested by addition of $100 \mu \mathrm{g} / \mathrm{ml}$ Cycloheximide, to check whether the newly synthesized protein is accumulated in the ER or the localization of the mutant Vtilp itself is in the ER. Cycloheximide was added to the pre-incubated cells at $24^{\circ} \mathrm{C}$, further incubated for $30 \mathrm{~min}$ and then fixed at the respective temperatures. 
At $24^{\circ} \mathrm{C}$ with cycloheximide, vtiQ29RW79Rp was still localized to the punctate structures. When the cells were shifted to $37^{\circ} \mathrm{C}$ for $30 \mathrm{~min}$, a clear relocalization of vtiQ29RW79Rp to ER was observed, even after the treatment of cycloheximide (Fig.12b). The effect was not altered by deleting ENT3, an interacting partner for the Nterminus of Vtilp, in the background of vtiQ29RW79R. But the 2 AA mutant was expressed from a $C E N$ plasmid which led to mild over expression of the protein. When the mutation was integrated into the genomic locus, the ER staining had disappeared and normal punctate staining pattern was observed as shown in the Fig.12b (lower panel). Thus, vti1Q29RW49Rp was localized to ER under slightly over expressing conditions. This delocalization is due to the mutation because over expression of wild type VTII using a $2 \mu$ plasmid does not result in ER localization.
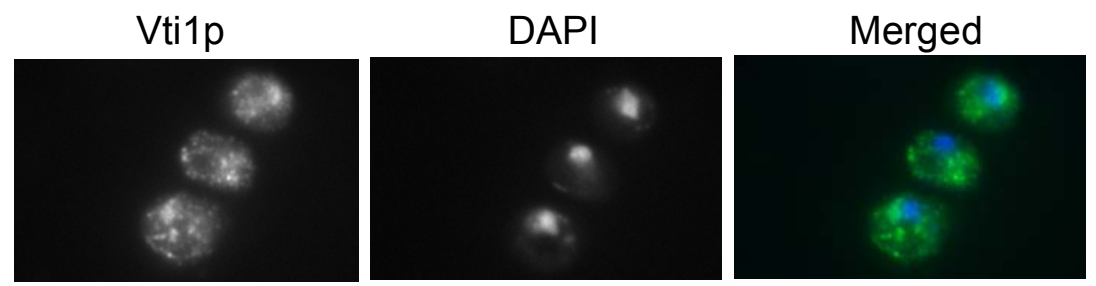

SEY6210
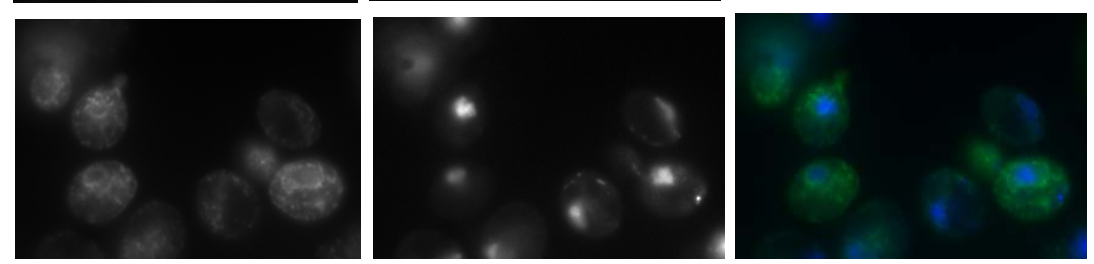

vti1Q29R

W79R $24^{\circ} \mathrm{C}$
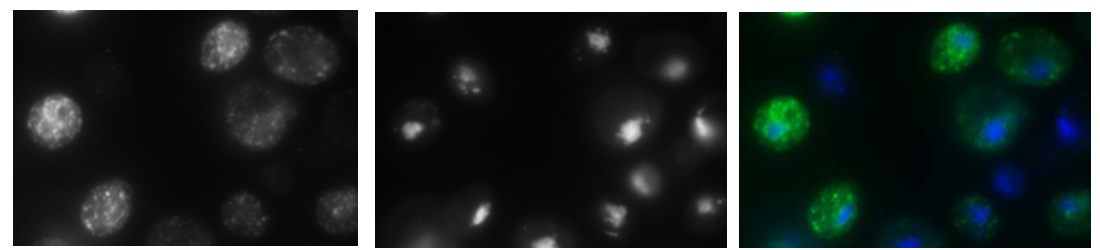

vti1Q29R

W79R $24^{\circ} \mathrm{C}+$ Cycloheximide $(100 \mu \mathrm{g} / \mathrm{ml})$

Fig.12a. Localization of vti1Q29RW79Rp at $24^{\circ} \mathrm{C}$ : The 2 AA mutant was pre-incubated at $24^{\circ} \mathrm{C}$ for $30 \mathrm{~min}$, treated with cycloheximide $(100 \mu \mathrm{g} / \mathrm{ml})$ for $30 \mathrm{~min}$ and fixed at the same temperature. By Indirect immuno-fluorescence, the 2 AA mutant was detected using the antibody against Vtilp. DAPI staining was done to localize nucleus. 

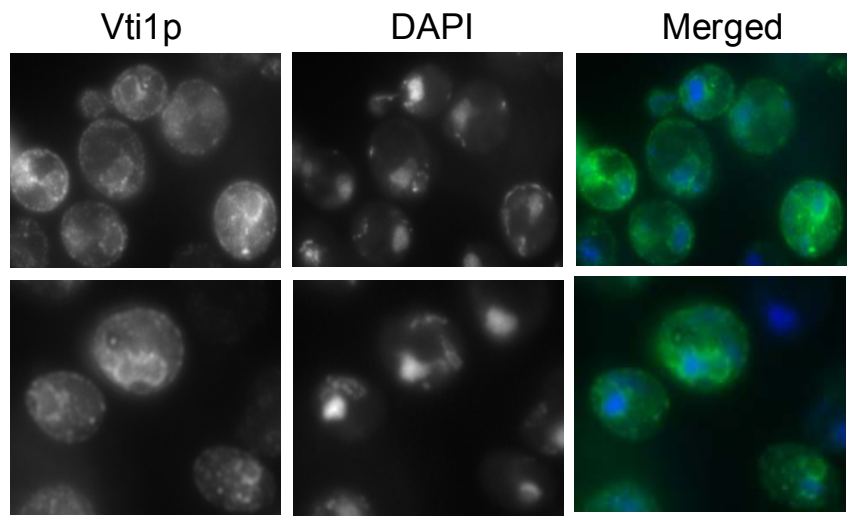

vti1Q29R

$W 79 R$ at $24^{\circ} \mathrm{C}+$

shift $37^{\circ} \mathrm{C}, 15 \mathrm{~min}$
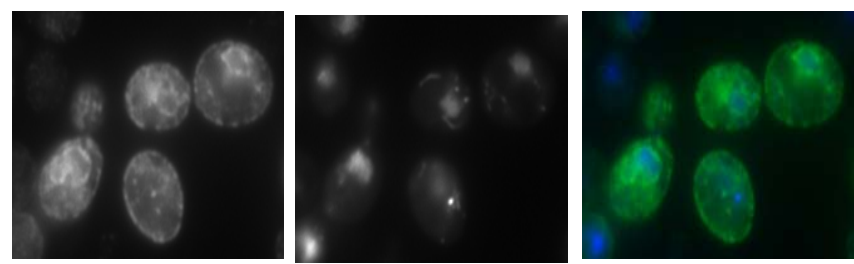

vti1Q29R

$W 79 R$ at $24^{\circ} \mathrm{C}+$

Cycloheximide,

shift $37^{\circ} \mathrm{C}, 15 \mathrm{~min}$
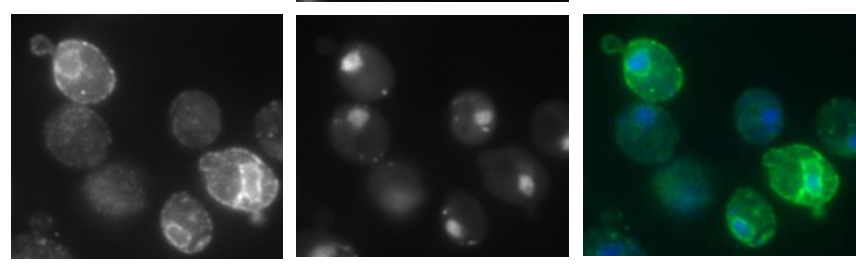

vti1Q29R

$W 79 R+$

cycloheximide

$37^{\circ} \mathrm{C}, 30 \mathrm{~min}$
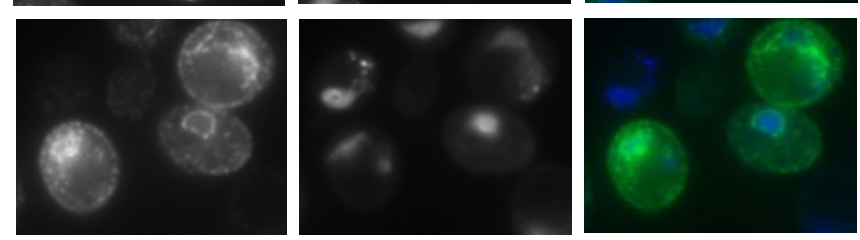

vti1Q29R

W79R ent $3 \triangle 37^{\circ} \mathrm{C}$,

30min
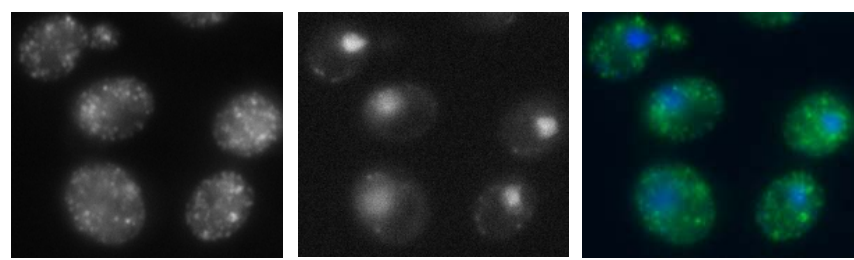

vti1Q29R

W79R (SCY14)

$37^{\circ} \mathrm{C}, 30 \mathrm{~min}$

Fig.12b. Localization of vti1Q29RW79Rp at $37^{\circ} \mathrm{C}$ : The $2 \mathrm{AA}$ mutant (CEN and SCY14) and the 2 AA mutant with the ENT3 deletion was pre-incubated at $24^{\circ} \mathrm{C}$ for $30 \mathrm{~min}$, treated with cycloheximide $(100 \mu \mathrm{g} / \mathrm{ml})$ for $30 \mathrm{~min}$ and shifted to $37^{\circ} \mathrm{C}$ for $15 \mathrm{~min}$ or $30 \mathrm{~min}$ and fixed at the same temperatures. By Indirect immuno-fluorescence, the 2 AA mutant was detected using the antibody against Vtilp. DAPI staining was done to localize nucleus. The 2 AA mutant was expressed from $C E N$ plasmid except in the lower panel (SCY14).

The localization of 1 AA mutants were strikingly different from the 2 AA mutants which was also slightly over expressed from the $C E N$ plasmids. Both the 1 AA mutants were found on vacuolar membranes and on internal small structures (Fig.12c). 


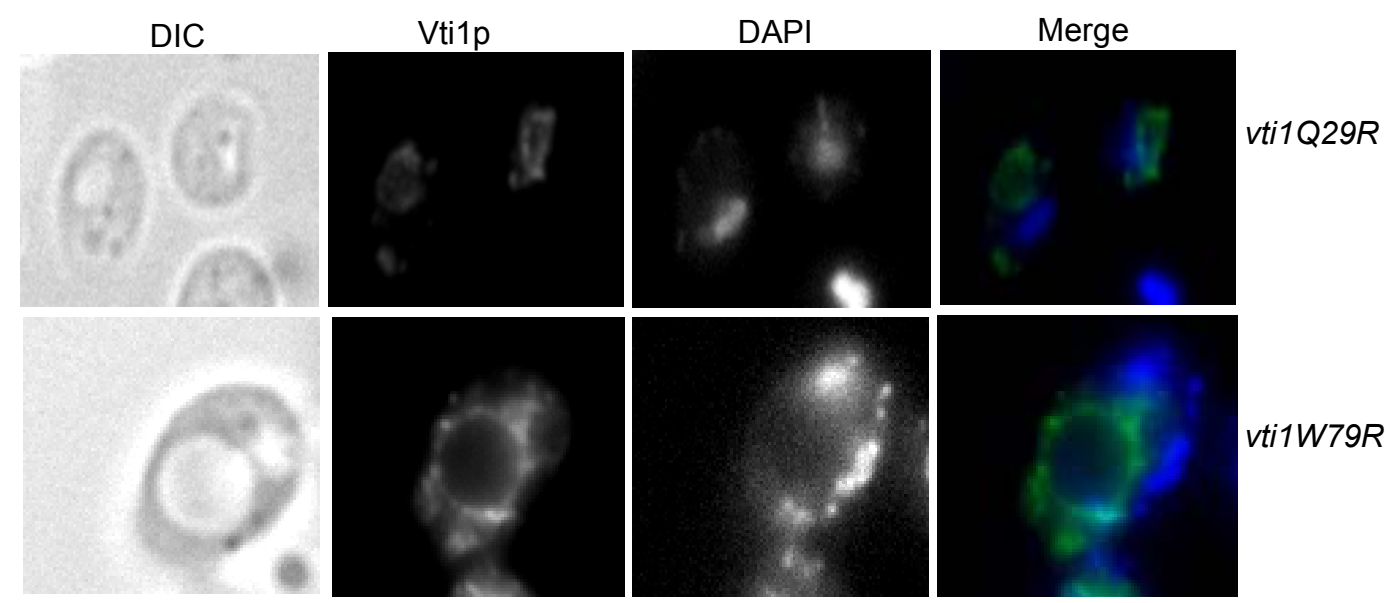

Fig.12c. Localization of 1 AA mutants at $37^{\circ} \mathbf{C}$ : The 1 AA mutants $v t i l Q 29 R$ and $v t i l W 79 R$ were fixed at $37^{\circ} \mathrm{C}$ and by Indirect immunoflurescence, the $1 \mathrm{AA}$ mutatnt Vti1p was detected. The DIC pictures were made to clearly localize the vacuoles. DIC: Differential Interference Contrast.

\subsubsection{CPY sorting by mutant Vti1p}

Carboxypeptidase Y traffics from the ER to the vacuole via the pre-vacuolar compartment and exists in three different forms. When there is a block in the traffic step, the corresponding form of the CPY accumulates intracellular or the Golgi form is secreted into the medium which can be analyzed by SDS gel. The CPY pathway was analyzed in the 2 AA mutants by pulse chase immunoprecipitation at $24^{\circ} \mathrm{C}$ and $37^{\circ} \mathrm{C}$ and for $1 \mathrm{AA}$ mutants at $37^{\circ} \mathrm{C}$ (Fig.13). IP was done both from the cell pellet (I) and the extracellular medium (E). In $2 \mathrm{AA}$ mutants $(C E N)$ at $37^{\circ} \mathrm{C}$, only $33.5 \%$ of $\mathrm{CPY}$ was processed to the mature form (I) and p2CPY was secreted out into the medium (E) whereas this defect was not observed at $24^{\circ} \mathrm{C}$. So, the 2 AA mutation is temperature sensitive. But in the case of 1 AA mutants, the CPY pathway was not affected. When the 2 AA mutation was integrated into the genome, the biosynthetic defect was even stronger and the percentage of mCPY was drastically reduced from 33.5 to 5 (Fig.14). Also, more p2CPY was present in the cell pellet $(24 \%)$ with slightly increased levels of p1CPY. To check, whether the 2 AA mutation has a dominant negative effect, the mutation was over expressed from a $2 \mu$ plasmid in the wild type cells and the CPY pathway was analyzed by pulse chase immuno-precipitation. But the mutation did not show any dominant negative effect (Fig.14). 


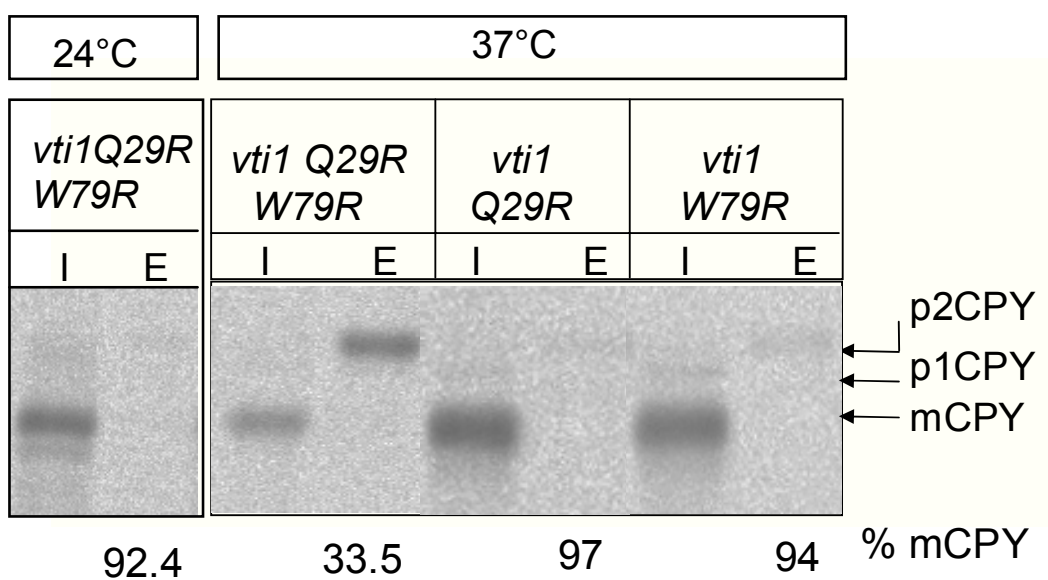

Fig.13. CPY pulse chase immuno-precipitation in 2AA and 1AA Vti1p mutants: Cells grown at $24^{\circ} \mathrm{C}$ were labeled with ${ }^{35} \mathrm{~S}$ at $24^{\circ} \mathrm{C}$ or preincubated at $37^{\circ} \mathrm{C}$ for $15 \mathrm{~min}$ before labeling with ${ }^{35} \mathrm{~S}$ for $10 \mathrm{~min}$, chased for $30 \mathrm{~min}$ at $24^{\circ} \mathrm{C}$ or $37^{\circ} \mathrm{C}$ and immunoprecipitation was done from the cell pellet (I) and from the medium (E), using antibody against CPY. The three forms of CPY, p1CPY (from ER, $67 \mathrm{kDa}$ ), p2CPY (from Golgi, $69 \mathrm{kDa}$ ) and mCPY (from Vacuole, $61 \mathrm{kDa}$ ) were separated on a SDS gel. The percentage of mCPY was calculated.

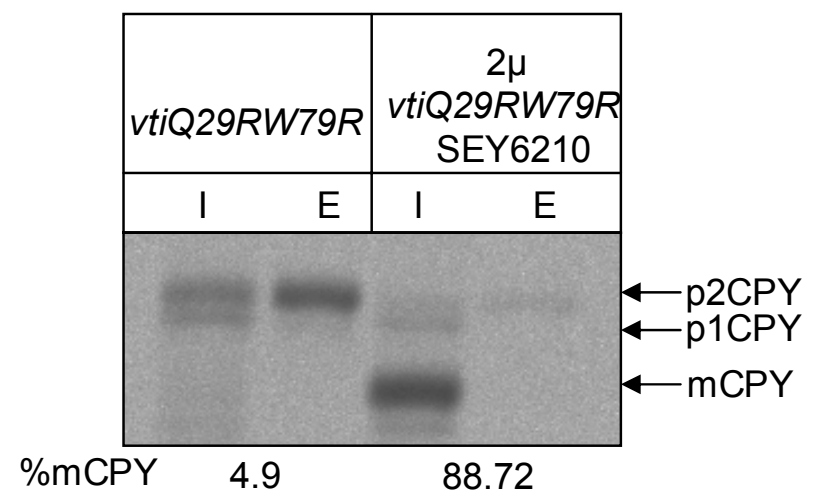

Fig.14. Pulse chase immunoprecipitation of CPY from overexpressed 2 AA mutant cells: The 2 AA mutant (SCY14) and the wildtype cells over expressing the 2 AA mutant from a $2 \mu$ plasmid were used for pulse chase labeling at $37^{\circ} \mathrm{C}$ and immunoprecipitaion of $\mathrm{CPY}$. The percentage of mCPY was calculated.

Further, the onset of the defect in the CPY pathway was analyzed with and without preincubation at $37^{\circ} \mathrm{C}$ (Fig.15). The WT and the 2 AA mutant cells were labeled without preincubation (0'), with $5 \mathrm{~min}$ pre-incubation (5') and with $10 \mathrm{~min}$ pre-incubation (10') at 
$37^{\circ} \mathrm{C}$. There was no time dependent change in the sensitivity of the defect. This indicates that the onset of the defect is extremely rapid.

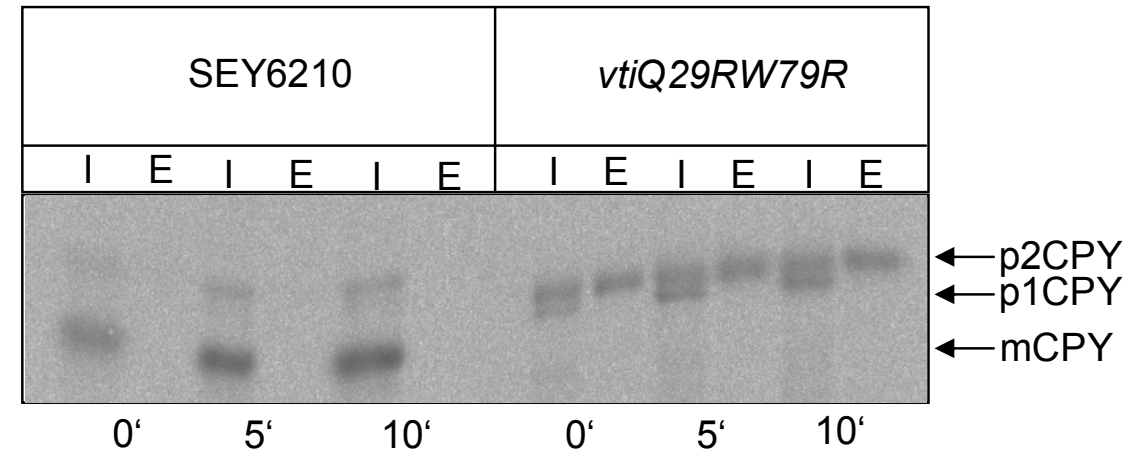

Fig.15. CPY-IP with and without pre-incubation in the 2 AA mutant.

\subsubsection{Stability of N-terminal mutants}

The stability of 1 AA and 2 AA Vtilp mutants (all from $C E N$ plasmid) was analyzed by pulse chase immunoprecipitation of Vtilp at different chase points namely, $10 \mathrm{~min}, 2 \mathrm{~h}$ and $5 \mathrm{~h}$ at $37^{\circ} \mathrm{C}$. The $2 \mathrm{AA}$ mutant was very unstable, compared with $1 \mathrm{AA}$ mutants (Fig.16). After $5 \mathrm{~h}$ of chase, only 33\% of the Vtilp was present in the 2 AA mutant (on an average of 3 experiments) whereas in the wild type cells $85 \%$ of Vtilp was present which showed that wildtype Vtilp is very stable. The 1 AA mutants didn't show significant instability of Vtilp (average of 2 experiments). The genomically integrated 2 AA mutant Vti1p (SCY14) was highly unstable, only $17 \%$ was present after $5 \mathrm{~h}$ chase (on an average of three experiments).

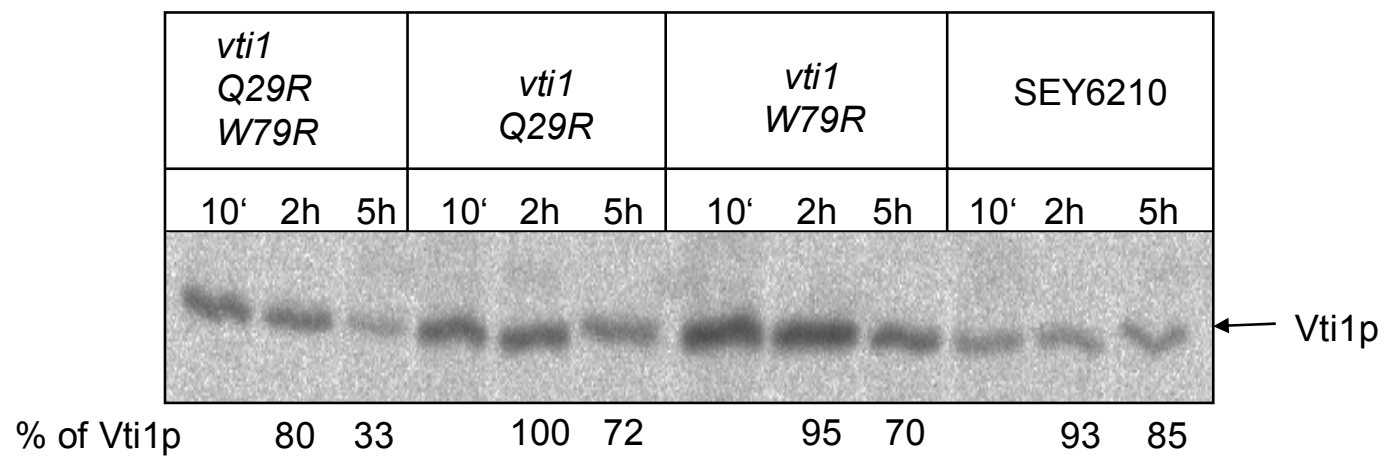

Fig.16. Stability of Vti1p in 1 AA and 2 AA mutants: The WT and the mutant cells were labeled with ${ }^{35} \mathrm{~S}$ for $25 \mathrm{~min}$, chased for $10^{\prime}, 2 \mathrm{~h}$ and $5 \mathrm{~h}$ at $37^{\circ} \mathrm{C}$ and Vtilp was immunoprecipitated. The percentage of Vtilp was calculated for each time point. 


\subsection{4 vtiQ29RW79Rp is not degraded by Vacuolar proteases}

Since the 2 AA mutant was highly unstable, it was very interesting to study how it would get degraded. Vacuolar proteinases are important for the vacuolar degradation of proteins, among which Proteinase A, coded by the PEP4 gene plays an important role since it activates all vacuolar proteases. The stability of Vtilp was studied in the wild type, 2 AA mutant and in the pep 4 deletion strains by pulse chase immunoprecipitation of Vtilp at 10 min and at $5 \mathrm{~h}$ chase points, at $37^{\circ} \mathrm{C}$ (Fig.17). Vtilp was degraded by the vacuolar degradation pathway, because the pep4 deletion in the wildtype cells stabilized Vtilp, increasing the percentage of Vtilp remaining after $5 \mathrm{~h}$, from 49 to $113 \%$. But in the 2 AA mutant, pep4 deletion did not have any effect which demonstrated that the 2 AA mutant Vtilp was not degraded by the vacuolar degradation pathway.

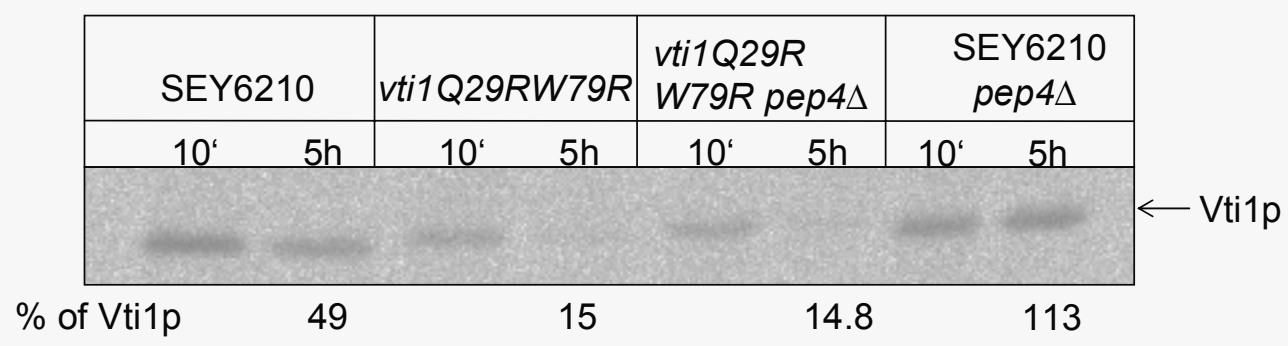

Fig.17. Stability of Vtilp in pep4 deletion strains: Pulse chase immunoprecipitation of Vtilp was done from the wildtype, 2 AA mutant (SCY14), 2 AA mutant with pep4 deletion (SCY18) and wildtype with pep4 deletion (BKY12) cells at $10 \mathrm{~min}$ and $5 \mathrm{~h}$ chase points at $37^{\circ} \mathrm{C}$. The percentage of Vtilp remaining after $5 \mathrm{~h}$ compared to the $10 \mathrm{~min}$ chase point was calculated.

\subsubsection{Polyubiquitination is required for $v t i Q 29 R W 79 R p$ degradation}

Proteasome mediated proteolysis is the major pathway for protein degradation in the cells apart from the vacuolar/lysosomal degradation. Proteasomes are multi-protein complexes found in the cytosol and the nucleus (reviewed in: Coux et al., 1996). The means of targeting proteins to proteasomes is by their modification with chains of ubiquitin. Ubiquitination is an essential cellular process effected by a multi-enzyme cascade involving classes of enzymes known as E1s (ubiquitin-activating enzymes), E2s (ubiquitin-conjugating enzymes or Ubcs), and E3s (ubiquitin-protein ligases) (reviewed in: Bonifacino and Weissman, 1998). Ubc7p is an ubiquitin conjugating enzyme, involved in the ER-associated protein degradation pathway which requires Cuelp for 
recruitment to the ER membrane. Cuelp can bind ubiquitin to facilitate intramolecular monoubiquitination. The Cuelp-Ubc7p complex is not only required for degradation of luminal ER protein but also for membrane proteins which are anchored with their tails in the cytosolic face of the ER membranes (like SNAREs). Ubiquitin is attached to lysine on a target protein or to another ubiquitin chain at K48 of ubiquitin, resulting in the generation of chains of ubiquitin which is referred to as either polyubiquitination or multiubiquitination. The formation of the K48 linked polyubiquitin chains on proteins constitutes a potent targeting signal for degradation in $26 \mathrm{~S}$ proteasomes.

To check whether the 2 AA mutant was degraded by the proteasomes, CUE1 and UBC7 genes were deleted in the 2 AA mutant background. Also, a plasmid expressing the mutant ubiquitin in which lysine 48 has been mutated to an arginine $(K 48 R)$ was transformed into the $2 \mathrm{AA}$ mutants. The $K 48 R$ mutation renders ubiquitin unable to form poly-ubiquitin chains, thus preventing the proteasomal degradation. The stability of mutant Vtilp was studied in these strains by pulse chase immunoprecipitation (Fig.18). Vtilp was not stabilized in the cuel and $u b c 7$ deletions. But the $u b K 48 R$ stabilized the mutant Vtilp from $16 \%$ to $63 \%$ at $3 \mathrm{~h}$ and from $10 \%$ to $41 \%$ at $5 \mathrm{~h}$. So, polyubiquitination was required for the degradation of the mutant Vtilp.

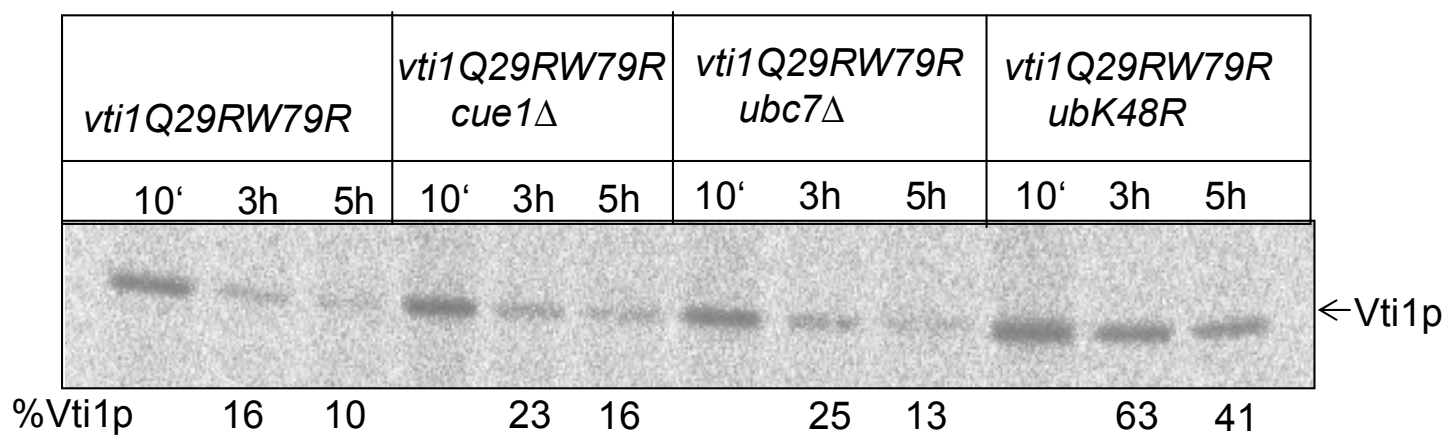

Fig.18. Vti1p stability in Proteasomal mutants: The 2 AA mutant (SCY14), 2 AA mutant with cue1s (SCY22), 2 AA mutant with $u b c 7 \Delta$ (SCY21) and 2 AA mutant with $u b K 48 R$ (SCY14pUB203) were used for the pulse chase immunoprecipitation of Vtilp at $10 \mathrm{~min}, 3 \mathrm{~h}$ and $5 \mathrm{~h}$, at $37^{\circ} \mathrm{C}$. 


\subsection{Characterization of Ent proteins in S.cerevisiae}

\subsubsection{Role of Ent proteins in the trafficking of CPY and ALP}

In several ent deletion mutants, CPY transport was analyzed by pulse chase labeling followed by immunoprecipitation at $37^{\circ} \mathrm{C}$ (Fig.19). No defects in CPY maturation were observed in ent $4 \Delta$ and ent $5 \Delta$ cells. Slightly elevated levels of p2CPY were secreted into the medium (E) by ent $3 \Delta(6.2 \%)$ and ent $3 \Delta$ ent $4 \Delta$ (4.6\%) cells even though most CPY reached the vacuole ( $\mathrm{mCPY}$ in the intracellular fraction I). $\mathrm{p} 2 \mathrm{CPY}$ is secreted from the cells if transport from the TGN to the vacuole is defective. ent $3 \Delta$ ent $5 \Delta$ and ent $3 \Delta$ ent $4 \Delta$ ent $5 \Delta$ cells secreted even more p2CPY (9.3\% and $8.1 \%$ respectively) and accumulated p2CPY within the cells. This slight transport defect indicates that Ent3p and Ent5p have a partially redundant function in CPY transport.

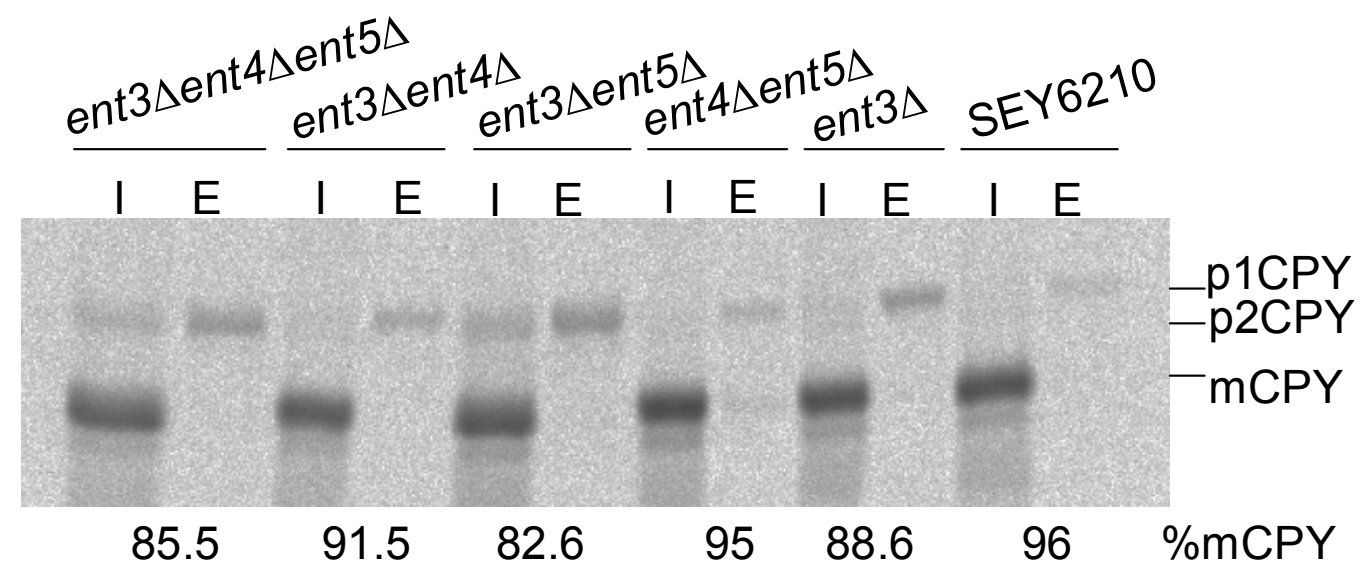

Fig.19. CPY transport in Ent mutants: CPY was immunoprecipitated from the cellular extracts (I) and the medium (E) after pulse-chase labeling at $37^{\circ} \mathrm{C}$. p1CPY: ER proCPY (carboxypeptidase Y); p2CPY: Golgi proCPY; mCPY: vacuolar mature CPY.

The ALP pathway, which bypasses the pre-vacuolar compartment to reach the vacuole, was also analyzed in the ent mutants by pulse chase labeling and immunoprecipitaiton of alkaline phosphatase at $37^{\circ} \mathrm{C}$ (Fig.20). ALP pathway was not significantly affected in the ent mutants. 


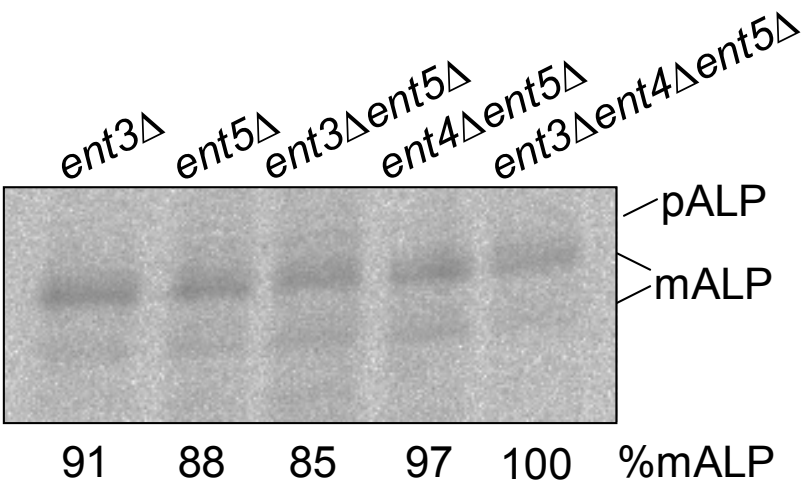

Fig.20. ALP transport in ent mutants: Pulse chase labeling and immunoprecipitation of ALP was done at $37^{\circ} \mathrm{C}$. pALP: proALP; mALP: mature ALP (vacuolar form).

\subsubsection{Ent3p binds phosphoinositides}

Ent3p binds the clathrin adaptor Gga2p and has been implicated in clathrin coated vesicle formation at the Golgi or endosome (Duncan et al., 2003). Different phosphoinositides are regulators of trafficking in these organelles in yeast (Simonsen et al., 2001). PI(4)P is implicated in secretory traffic from the Golgi to the plasma membrane, PI(3)P in traffic to the endosome and autophagocytosis. $\mathrm{PI}(3,5) \mathrm{P}_{2}$ is required for sorting into the internal vesicles in prevacuolar endosomes to form multivesicular bodies. To detect whether Ent3p has any specificity towards phosphoinositides, the strep-tagged ENTH domain of Ent3p was bacterially expressed, purified and incubated with liposomes containing phosphatidylcholine (PC) and phosphoinositol (PI) as controls along with the above mentioned phosphoinositides. Ent3p bound specifically to liposomes with PI(3)P and $\mathrm{PI}(3,5) \mathrm{P}_{2}$ (Fig.21).

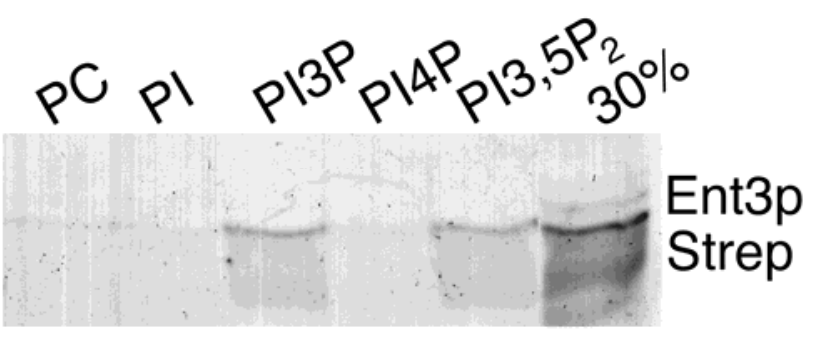

Fig.21. Ent3p binding to phosphoinositides: The ENTH domain of Ent3p with a C-terminal Strep tag was incubated with liposomes containing 70\% PC, 20\% PE and $10 \%$ of the indicated lipids. Liposomes were pelleted and recruitment of Ent3p was followed by separation of the pellet fraction by SDS-PAGE and Coomassie blue staining. 30\%: 30\% of the protein used in the assay was loaded for comparison. 


\subsubsection{Localization of Ent3p and Ent5p in wildtype and in mutant cell}

\subsubsection{Localization of endogenous Ent3p using antibody against Ent3p}

Initially, the localization of Ent3p was analyzed using Ent3p tagged with 3 copies of the HA epitope at the C-terminus which turned out to be non functional because it did not complement for the loss of Ent3p in Y24ent3 $\Delta$ cells in the growth test at $37^{\circ} \mathrm{C}$. Therefore we cannot rely on the Ent3p-HA data. Anti-Ent3p rabbit serum was raised against a StrepENTH domain of Ent3p which recognized specifically a protein with the expected molecular weight for Ent3p at around $50 \mathrm{kDa}$ in a whole-yeast wild-type cell extract, but not in an ent3s cell extract both in SEY6210 and BY4742 background, as shown in the Fig.22a. Subcellular fractionation of wild type cells showed that Ent3p was more cytosolic (S200) and less associated with the membrane fraction (P13), when the lysis was done very gently after spheroplasting by homogenization with lysis buffer containing $20 \mathrm{mM}$ HEPES (pH 6.8), 0.15 M potassium acetate, $10 \mathrm{mM} \mathrm{MgCl} 2$ and $0.25 \mathrm{M}$ Sorbitol with protease inhibitors (Fig.22b, SEY6210 cells). But when the lysis was done vigorously by glass beads with the same lysis buffer, Ent3p was more associated with membrane fractions (Fig.22b, SEY6210 cells). The P13 fraction contains vacuoles, mitochondrial and ER-membrane, the P200 fraction contains small vesicles and the Golgi and the S200 fraction derives all cyosolic proteins. Since, Ent3p and Vti1p are interacting partners, it was important to test whether Vtilp is required for the localization of Ent3p. Subcellular fractionation was done from several vtil mutants like SNARE motif mutants (vtil-1 and vtil-2), N-terminal 2AA mutant (vtiQ29RW79R) and the N-terminal truncations (vtilQ116-217 and vti1M55-217), to detect the localization of Ent3p, both by gentle (Fig.22b) and harsh (Fig.22c) methods of lysis. The N-terminal truncations express Vtilp amino acids from 55 to 217 [vtilM55-217 (FvmY6-pBK117)], from 116 to 217 [vti1Q116-217 (FvmY6-pBK117)] and an additional start 'methionine' under a constitutive promoter 789. These mutants exhibit slow growth, strong CPY sorting defects at all temperatures and lacks complete N-terminus involved in Ent3p interaction (amino acids 1-115). 


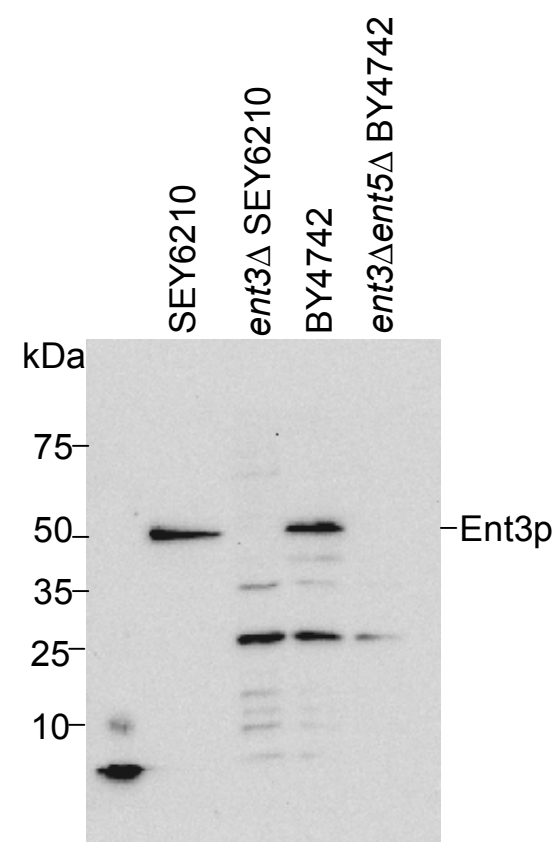

Fig.22a. Generation of anti-Ent3p rabbit serum: Serum from the terminal bleed of the strepEnt3p injected rabbit (ywop (t)) was diluted to 1:500 and used for probing the blot with protein

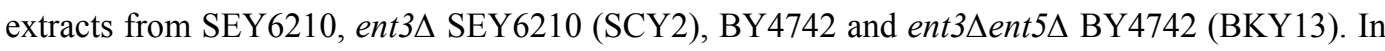
SEY6210 cells, a single band at $50 \mathrm{kDa}$, corresponding to Ent3p was detected. In other cells a mild cross reaction of anti-Ent3p was observed.

The cells were lysed in $1 \mathrm{ml}$ lysis buffer and fractionated. The pellet fractions were resuspended in $70 \mu \mathrm{l}$ of lysis buffer, protein concentration was quantified and equal amounts of protein were loaded on the gel. In wild type cells, around 1.3\% of Ent3p was present in the P13 fraction, 98\% in S200 and rest in the P200 by gentle lysis (Fig.22b). But, by harsh method of lysis, $65 \%$ of Ent $3 p$ was present in the P13, $8 \%$ in P200 and 27\% in S200 (Fig.22c). In vtil mutants, more or less, the same range of Ent3p was found by both the methods. Though, Ent3p was present more in the P13 fraction in the vtil mutants compared to wild type (Fig.22b), the consequent decrease in other fractions (S200) was not observed. On the other hand, fractionation done by the harsh lysis method (Fig.22b), showed that there was no apparent relocalization of Ent3p in the N-term truncations (since the N-term of Vtilp interacts with Ent3p, these mutants are the perfect tools to study the redistribution of Ent3p). The vacuolar ATPase, Vph1p was used as a control for the experiment (to check for rupture of vacuole during lysis). Vphlp is associated only with the P13 fraction but because of the glass beads, vacuoles might have got damaged, 
so it was seen in the P200 fraction also. These data showed that there was no redistribution of Ent3p in the vtil mutants.

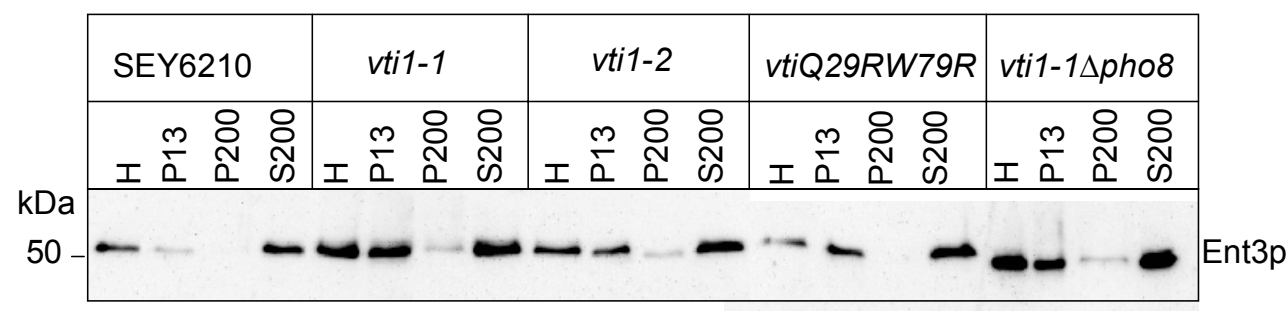

Fig.22b. Subcellular fractionation of Ent3p in vtil mutants by homogenization: Wild-type and the mutants vtil-1 (FvmY7), vtil-2 (FvmY24), vtiQ29RW79R (SCY14), vti1-1Apho8 (FvmY29) homogenates $(\mathrm{H})$ (from $10 \mathrm{OD}$ of cells) were fractionated (starting material $1 \mathrm{ml}$ ) into a $13000 \mathrm{~g}$ pellet (P13), a $200000 \mathrm{~g}$ pellet (P200) and a $200000 \mathrm{~g}$ supernatant (S200) by differential centrifugation. The pellet fractions P13 and P200 were resuspended in $70 \mu \mathrm{l}$ of lysis buffer. Fractions were analyzed by immunoblotting using antiserum against Ent3p. Equal amount of protein was loaded. Load: $6 \mu \mathrm{g}$ of the protein was loaded per well. In SEY6210 cells, total protein in H was $390 \mu \mathrm{g}$, in P13 (24.5 $\mu \mathrm{g})$, in P200 (24.5 $\mu \mathrm{g})$ and $200 \mu \mathrm{g}$ in S200. The percentage of Ent3p present in P13 was 1.3, in P200 was 0.33 and 98.38 in S200. In other cells also the same range of total protein was protein.

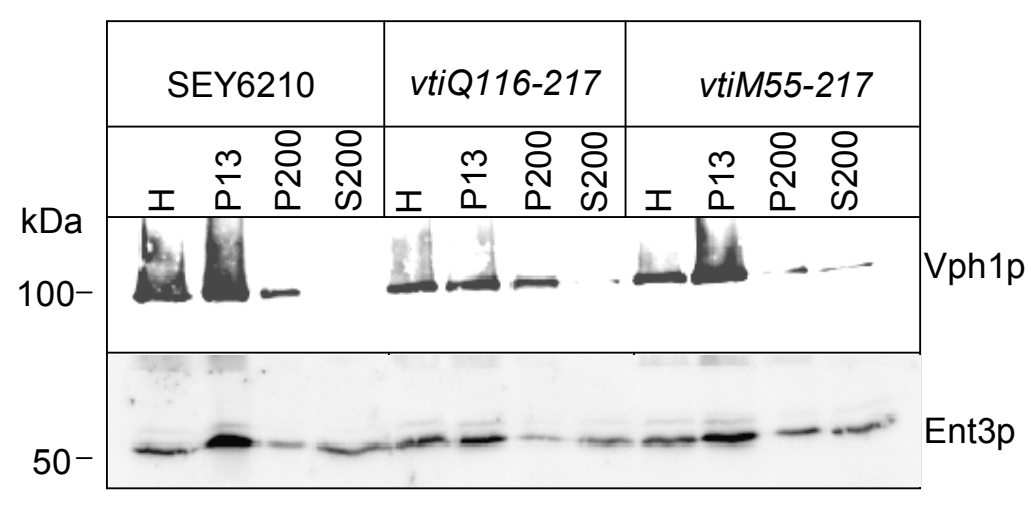

Fig.22c. Subcellular fractionation of Ent3p in vtil mutants by glass beads: Wild-type and the mutants vtilQ116-217 (FvmY6-pBK117) and vtilM55-217 (FvmY24-pBK119) homogenates (H) (from $25 \mathrm{OD}$ of cells) were fractionated (starting material $1 \mathrm{ml}$ ) and fractions were analyzed by immunoblotting using antisera against Vph1p (Vacuolar ATPase, 100kDa) and Ent3p. Equal amount of protein was loaded. Load: $70 \mu \mathrm{g}$ of protein per well. In SEY6210 cells, total protein in $\mathrm{H}$ was $2800 \mu \mathrm{g}$, in P13 $(710 \mu \mathrm{g})$, in P200 (720 $\mu \mathrm{g})$ and $945 \mu \mathrm{g}$ in S200. The percentage of Ent3p present in P13 was $65 \%$, in P200 was $8 \%$ and $27 \%$ in S200. 


\subsubsection{Fluorescence microscopy of Ent3p-GFP}

Since the antiserum against Ent3p was not suitable for the immunofluorescence studies, Ent3p with a C-terminal GFP (pSC22) was constructed. This construct was transformed into the wildtype cells and vtil mutants and imaged using a fluorescence microscope (Fig.23). Ent3p was localized into few punctate structures possibly corresponding to endosomes and mostly diffused in the cytoplasm irrespective of the temperature. In the vtil mutants, there was no marked difference in the localization of the Ent3p. But, sometimes, in the N-term truncation, vtilQ116-217 (Y6pBK117) (Fig.23b), a number of punctate structures were observed which was completely different from the wild type, although majority of the cells exhibited the same fluorescence pattern like the wild type (Fig.23a). Taking in account the subcellular fractionation and the fluorescence data, it was showed that Ent3p was not dependent on Vtilp for its localization.

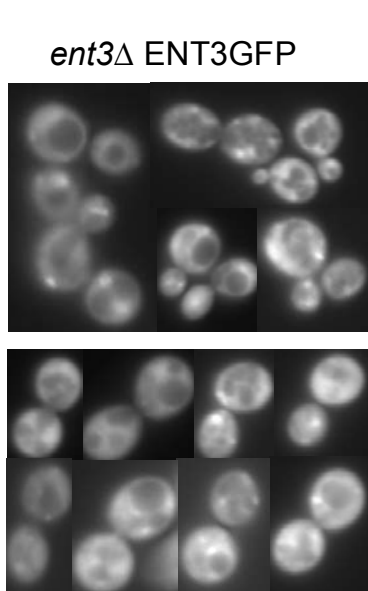

vti1M55-217 ENT3GFP

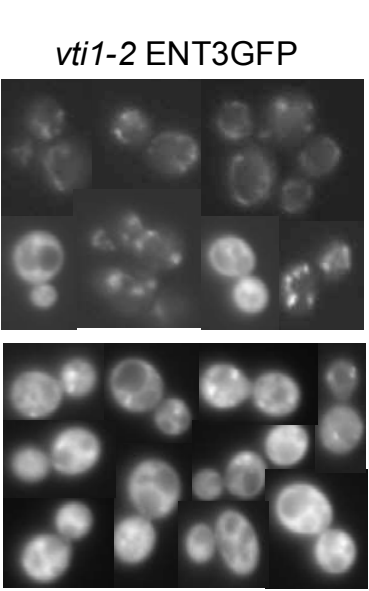

(a)
vti1Q29RW79R ENT3GFP
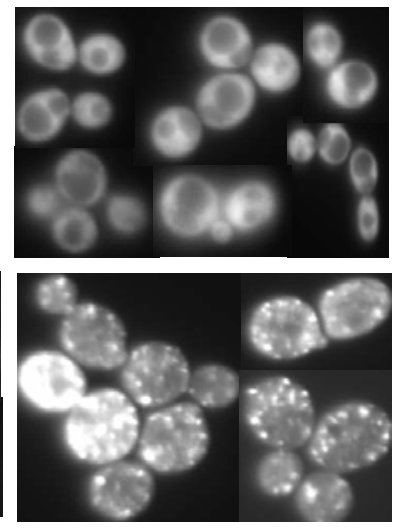

(b)

vti1Q116-217 ENT3GFP

Fig.23. Fluorescence microscopy of Ent3p-GFP: The strains ent3 $\mathrm{ENT} 3 \mathrm{GFP}$ (SCY2 pSC22), vtil-2 ENT3GFP (FvMY24 pSC22), vtilQ29RW79R ENT3GFP (SCY14 pSC22), vtilM55-217 ENT3GFP (Y6pBK119 pSC22), vtilQ116-217 ENT3GFP (Y6pBK117 pSC22) were grown overnight in the minimal medium at $30^{\circ} \mathrm{C}$ and were directly viewed (without fixation) under the microscope.

\subsubsection{Subcellular fractionation of Ent5p- GFP}

The C-terminal Ent5p-GFP construct was made to localize Ent5p in the wildtype and in the vtil mutants. The wildtype and the mutants harbouring the ENT5GFP plasmid (pSC24) were lysed gently by homogenization and fractionated (starting volume $1 \mathrm{ml}$ ). The P13 and P200 fractions were resuspended in $100 \mu l$ and $80 \mu 1$ respectively and equal 
volume was loaded on the gel. The blot was probed with antisera against GFP and Vph1p (Fig.24a). Ent5p-GFP was detected around $85 \mathrm{kDa}$ and present nearly $20 \%$ in the P200, $74 \%$ in S200 fraction and rest in the P13 fraction in wild type cells. Interestingly, the membrane associated Ent5p-GFP was found predominantly in P200 while Ent3p-GFP was more prominent in P13 even though both proteins were largely cytosolic. No change in the localization of Ent5p was observed in vtil mutants (Fig.24b).

A
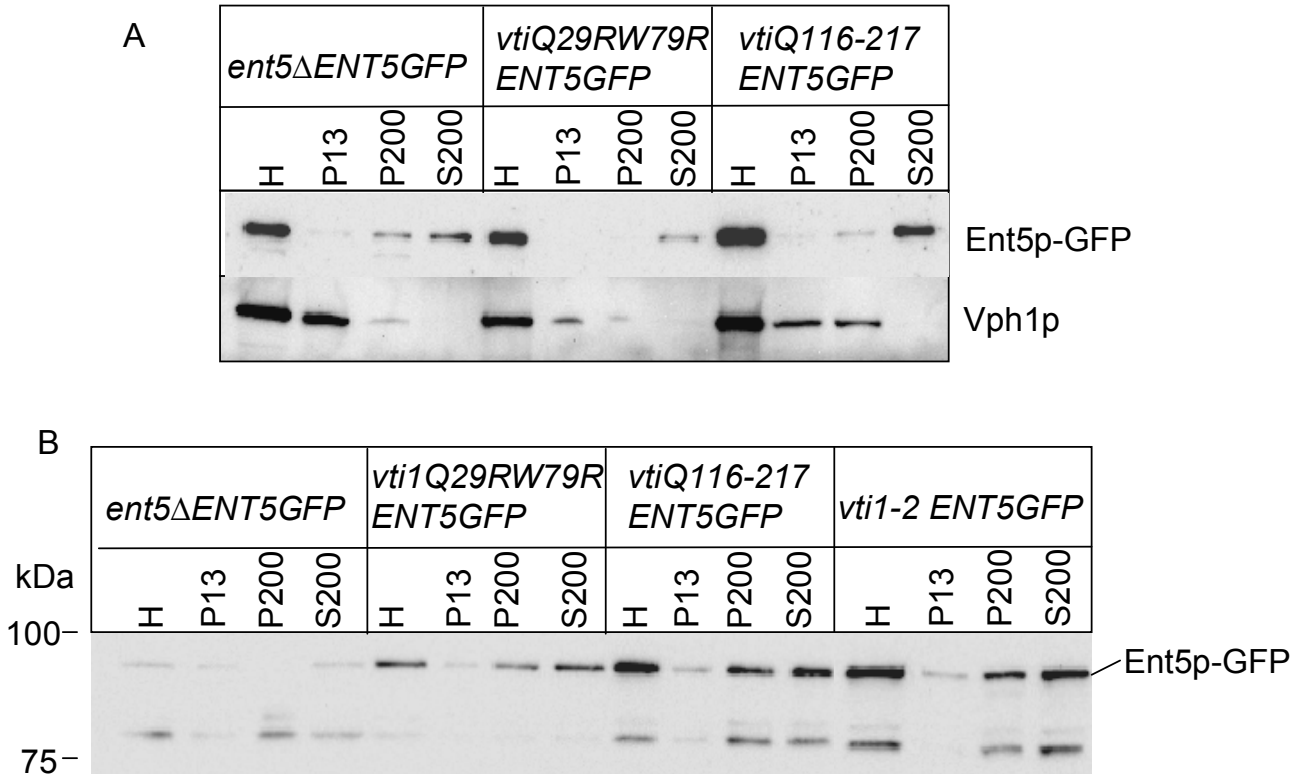

Fig.24. Subcellular fractionation of Ent5p-GFP: The strains (a) ent5 $\triangle \mathrm{ENT} 5 \mathrm{GFP}$ (SCY25 pSC24), vtilQ29RW79R ENT5GFP (SCY14 pSC24), vtilQ116-217 ENT5GFP (Y6pBK117 pSC24) and (b) vtil-2 ENT5GFP (FvMY24 pSC24), were gently lysed by homogenization and the homogenate (from $20 \mathrm{OD}$ of cells) fractionated (starting material $1 \mathrm{ml}$ ). The fractions were detected with antisera against GFP and Vph1p (vacuolar ATPase, as a control) (a). Equal volumes of the samples were loaded. Some nonspecific band around $80 \mathrm{kDa}$ with more or less same distribution pattern like Ent5p-GFP was observed in blot (b) which may be due to degradation.

\subsubsection{Ent5p-GFP localization}

Ent5p was localized to punctuate structures in wild-type cells as well as in vtil-2 cells (Fig.25i). vtilQ29RW79R cells were stained like wild-type but sometimes it showed many punctuate structures which could not be seen after few hours even from the same culture. Like Ent3p-GFP, in some vtilQ116-217 (N-terminal truncation) cells Ent5p was localized to many small punctuate structures and in some cells, it was localized to a few larger structure, sometimes close to vacuole possibly endosomes (Fig.25i (a)). Because of this 
strange staining pattern in the vtilQ116-217 cells, any change in the structure of the endosome and the vacuole was analyzed by uptake of FM4-64 dye (Fig.25ii). The uptake was delayed by $60 \mathrm{~min}$ when still some intermediate endosomal structures were also stained along with vacuoles. This indicates that transport from the endosomes to vacuoles was delayed in vtilQ116-217 cells. The vacuolar morphology of the vtilQ116-217 cells seems to be normal but the structure of the endosomes was not clear.

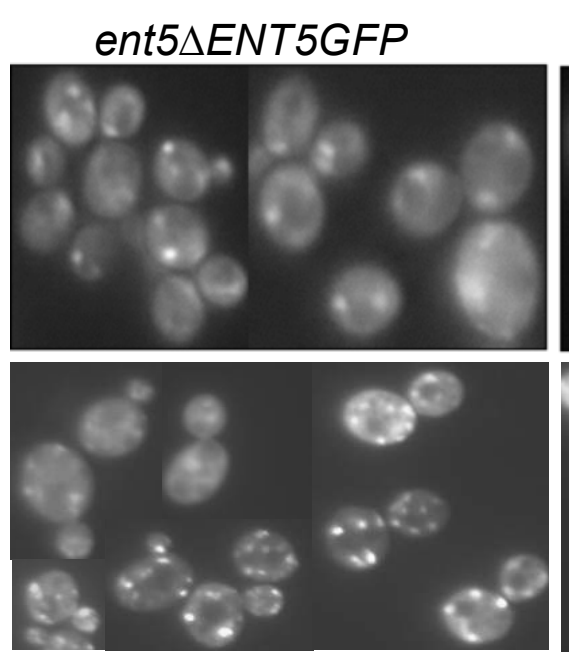

vti1Q29RW79R ENT5GFP
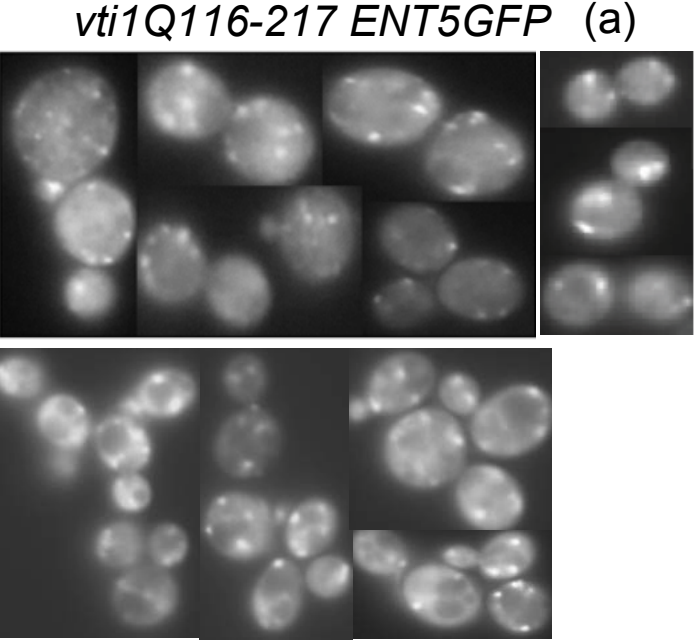

vti1-2 ENT5GFP

Fig.25(i). Fluorescence microscopy of Ent5p-GFP: The strains ent5 pSC24), vtilQ29RW79R ENT5GFP (SCY14 pSC24), vtilQ116-217 ENT5GFP (FvMY6pBK117 pSC24) and vtil-2 ENT5GFP (FvMY24 pSC24) were grown overnight at $30^{\circ} \mathrm{C}$ and the unfixed cells were imaged using a fluorescence microscope. 

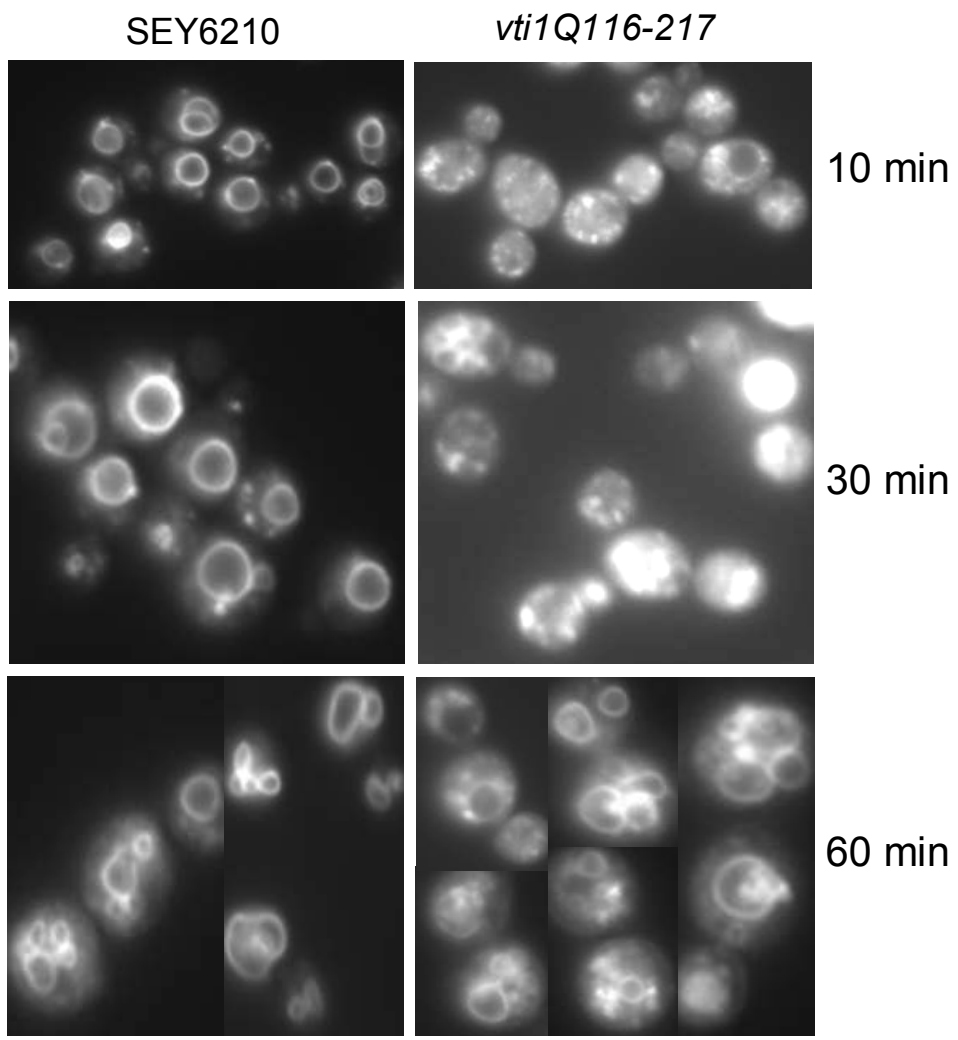

Fig.25(ii). Uptake of FM4-64 dye in N-terminal truncation: SEY6210 and vti1Q116-217 cells were incubated with FM4-64 dye at $24^{\circ} \mathrm{C}$ for $10 \mathrm{~min}$ (pulse) and the cells were viewed after an additional incubation (chase) of $10 \mathrm{~min}$ or $30 \mathrm{~min}$ or 60 under the microscope.

\subsubsection{Overexpression of Ent3p C-terminus and Ent3p in vtil mutants}

The over expression of the C-terminus of the ENTH domain protein Epsin1 has a dominant negative effect in mammalian cells (Itoh et al., 2001). A dominant negative effect can also be observed if a redundant protein is present. The C-terminus of Ent $3 p$ was over- expressed from a $2 \mu$ plasmid, to check whether it has a dominant negative effect on transport to the vacuole. Pulse chase immuno precipitation of CPY was done from SEY6210 and vtilQ29RW79R cells expressing the C-terminus of ENT3 (pSC2) (Fig.26a). There was no dominant negative effect from the C-terminus of Ent3p. Then the full length Ent3p (pSC4) was overexpressed in the vtil mutants, to check whether the full length protein is able to suppress CPY sorting defects in vtil mutants (Fig.26b). It did not improve the sorting and showed neither dominant negative defect nor suppression in the 2 AA mutant. 


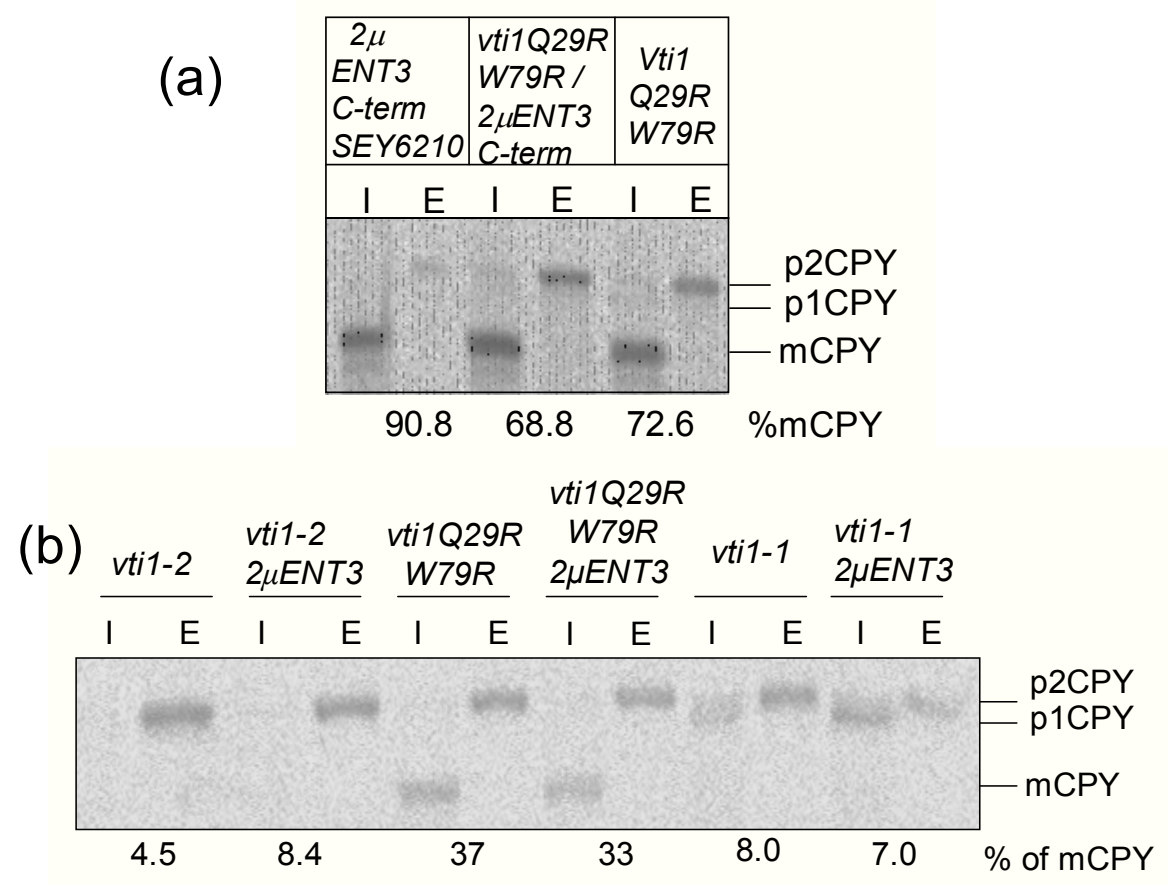

Fig.26. Overexpression of Ent3p in vtil mutants: Pulse chase immuno precipitation of CPY was done at $30^{\circ} \mathrm{C}$ (a) or at $37^{\circ} \mathrm{C}$ (b), from SEY6210 and vti1Q29RW79R (CEN) cells overexpressing the C-terminus of Ent3p (pSC2) (a) and from vtil-2 (FvMY24), vti1Q29RW79R (CEN), vtil-1 (FvMY7) cells overexpressing the full length Ent3p (pSC4) (b).

\subsubsection{Vacuolar morphology of ent mutants by FM4-64 staining}

The endocytosis and vacuolar morphology of ent mutants were studied by internalization of FM4-64 dye (Fig.27). The uptake was analyzed at different time points. There was no

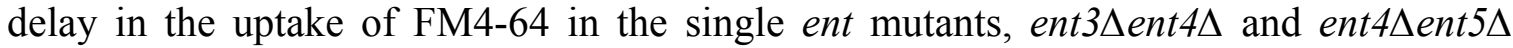
cells. In ent $3 \Delta$ ent $4 \Delta e n t 5 \Delta$ and ent $3 \Delta$ ent $5 \Delta$, except very few cells which looked abnormal, in other cells the uptake was normal. There was no defect in the vacuolar morphology of the mutants. 


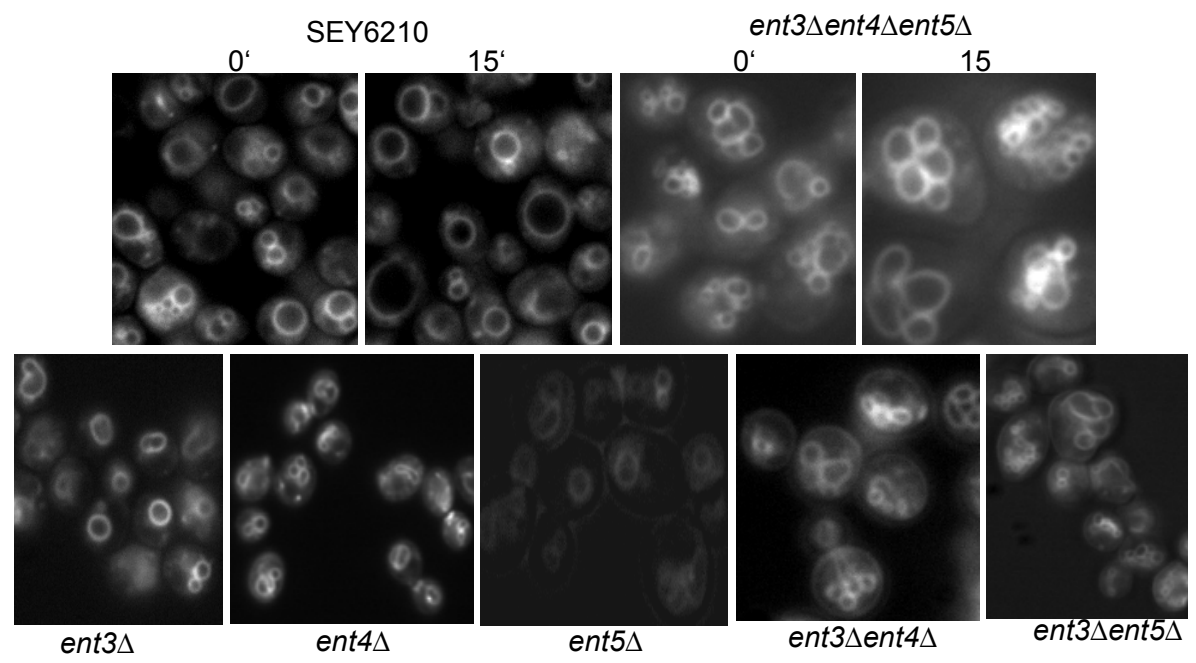

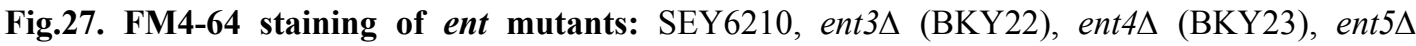

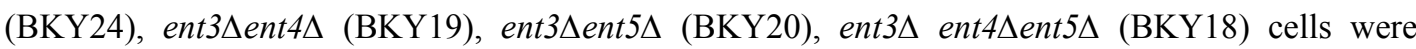
incubated with FM4-64 dye at $30^{\circ} \mathrm{C}$ for $15 \mathrm{~min}$ and viewed under microscope after an additional incubation of $0 \mathrm{~min}$ or $15 \mathrm{~min}$ for the top panel and $15 \mathrm{~min}$ for the lower panel.

\subsubsection{Genetic interaction of Ent proteins with Vti1p}

\subsubsection{CPY pathway in vtil mutants with ent deletion}

Different vtil mutant strains were used to investigate whether Ent3p or Ent5p have a functional connection with Vtilp and in which trafficking steps. ent 3 and ent 5 genes were deleted in the background of vtil mutants and pulse chase immuno precipitation was done (Fig.28). vtil-1 cells are only defective in transport from the Golgi to the prevacuole. The absence of Ent3p reduced mCPY levels in vtil-1 cells (SCY3) from 64.3\% (SD 12.0) to $11.9 \%($ SD $5.8, n=3)$ at a $33^{\circ} \mathrm{C}$ (Fig. 28a). Lack of Ent5p (BKY15) did not lead to a synthetic defect. vtil-2 cells are defective in transport from the Golgi to the prevacuole as well as in transport to the vacuole. The deletion of Ent3p in the vtil-2 cells (SCY1) reduced mCPY levels from $33 \%$ to $3.5 \%$. The 2 AA N-terminal mutant, vtilQ29RW79R has a defect and only $33.5 \%$ of $\mathrm{mCPY}$ was present at $37^{\circ} \mathrm{C}$ (Fig.28b). The biosynthetic defect was pronounced in vtilQ29RW79R when ent3 (SCY6) was deleted, in which only $13.5 \%$ of CPY was processed to the mature form at $37^{\circ} \mathrm{C}$. There was no synthetic defect by the absence of Ent3p in the 1 AA mutants vtilQ29R (SCY8) and vtil W79R (SCY9). 
(a)

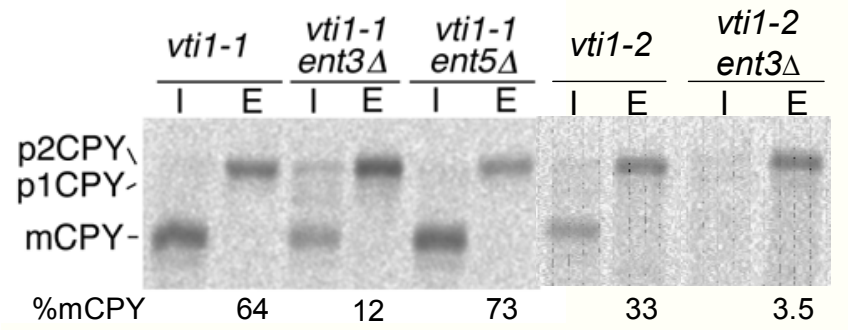

(b)
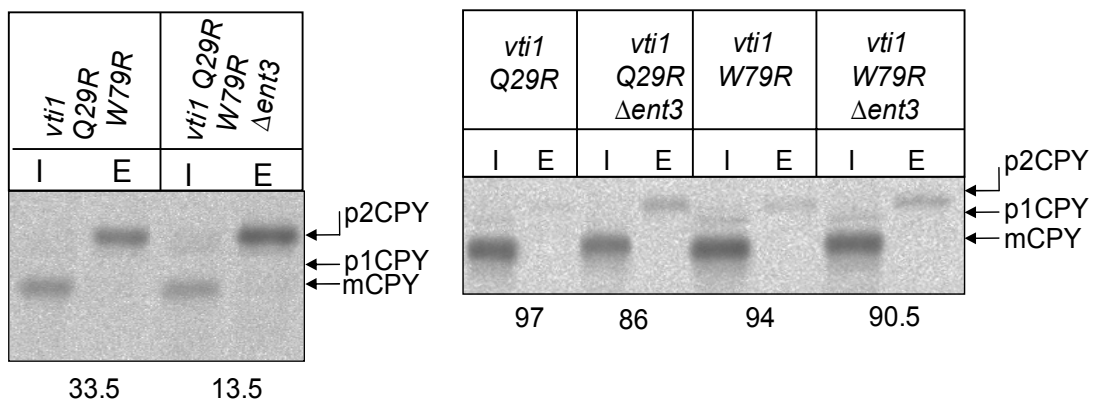

Fig.28. CPY pathway in vtil mutants with ent deletions: CPY was immuno precipitated from cellular extracts (I) and the medium (E) after pulse-chase labeling at $33^{\circ} \mathrm{C}$ for vtil-1 (FvMY7),

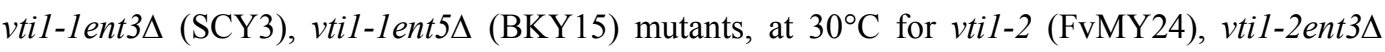
(SCY1), mutants (a) and at $37^{\circ} \mathrm{C}$ for vtilQ29RW79R (FvMY6pBK120), vtilQ29RW79R ent3山 (SCY6), vtilQ29R (FvMY6pBK123), vtilQ29R ent3A (SCY8), vtilW79R (FvMY6pBK128), vtil W79R ent $3 \Delta$ (SCY9) mutants (b).

\subsubsection{ALP pathway in vtil mutants with ent deletions}

Vacuolar maturation of the pro form of alkaline phosphatase (ALP) was used as an assay for fusion with the vacuole because the pALP travels from the Golgi to the vacuole without passage through the prevacuole. Pulse chase immuno precipitation of ALP was done in the mutants (Fig.29). A deletion of ent3 did not result in reduced appearance of vacuolar mALP in vtil-1 and vti1Q29RW79R cells at semi permissive temperature (Fig. 29a). Slightly less mALP was found in the absence of Ent5p in vtil-2 (BKY16) cells but not in the absence of Ent3p, after both a $5 \mathrm{~min}$ and a $30 \mathrm{~min}$ chase period (Fig.29b). After 30 min chase vtil-2 and vtil-2 ent $3 \Delta$ cells had 75.5\% (SD 1.5) and 73.9\% (SD 0.1) mALP respectively, but in the vti $1-2$ ent $5 \Delta$ had $60 \%(\mathrm{SD} 1.0, \mathrm{n}=2)$ of mALP. 
(A)

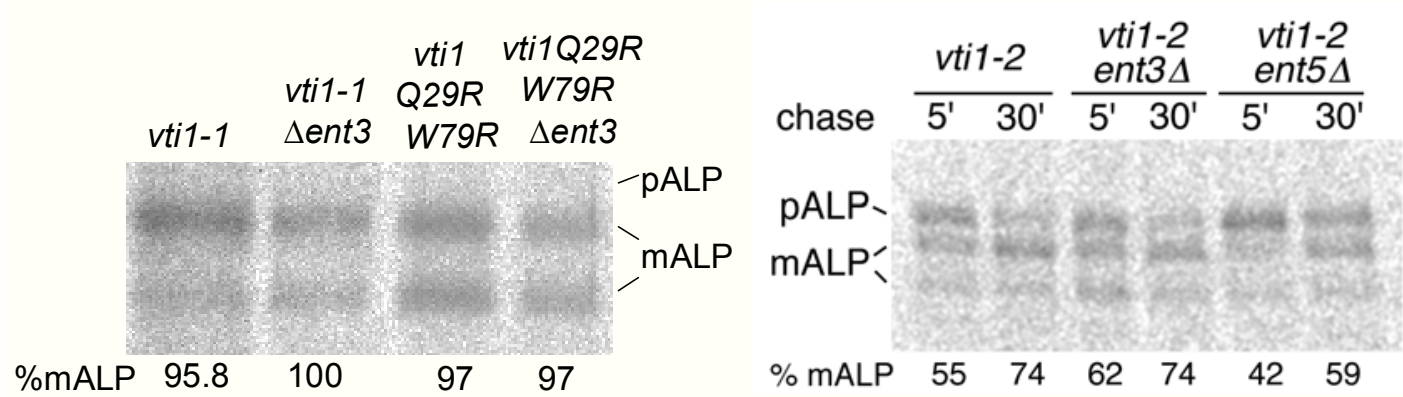

Fig.29. ALP pathway in vtil mutants with ent deletions: The cells were labeled at $30^{\circ} \mathrm{C}$ and chased for $30 \mathrm{~min}$ chase (a), for $5 \mathrm{~min}$ and $30 \mathrm{~min}$ (b) followed by immuno precipitation of ALP.

\subsubsection{Synthetic growth defects of ent deletions in vtil-2}

All the ent deletions in the background of vtil mutants were analyzed for their growth pattern to study the genetic interaction between the two proteins. There was no synthetic growth defect in the deletion mutants except in vtil-2 mutants. vtil-2 cells grow very slowly at $37^{\circ} \mathrm{C}$. Both vtil-2ent $3 \Delta$ and vtil-2ent $5 \Delta$ cells were unable to grow at $37^{\circ} \mathrm{C}$ (Fig.30). The synthetic growth defect in vtil-2ent3s cells is probably due to reduced trafficking through the prevacuole which was detected as synthetic defect in CPY maturation (Fig.28a). The small synthetic defects in ALP maturation may be the reason for the synthetic growth defect in vti1-2ent5s cells (Fig.29b).

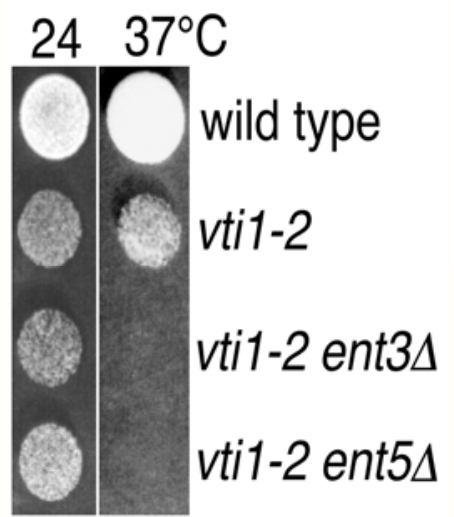

Fig.30. Synthetic growth defect in vtil-2 mutants: The strains were grown overnight at $24^{\circ} \mathrm{C}$ and diluted cells were spotted on a YEPD plated, incubated at $24^{\circ} \mathrm{C}$ and $37^{\circ} \mathrm{C}$ and the growth was observed. 


\subsubsection{Cell wall defects in ent $3 \Delta$ ent5 $\Delta$ mutants}

\subsubsection{Abnormal cell shapes in ent $3 \Delta$ ent $5 \Delta$}

In the transmission light ent $3 \Delta$ ent $5 \Delta$ cells looked abnormal. To study the cell morphology clearly, chitin present in the cell wall and in the bud scar was stained with calcofluor

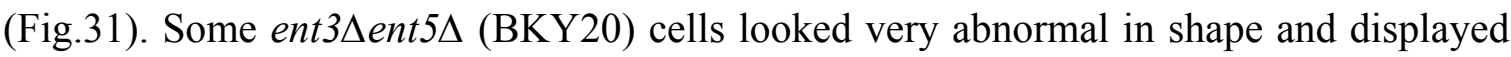
branched chain like budding pattern. They were larger than wild-type cells. The chitin ring was present in the bud neck of completely grown branched cells but the freshly budding cells lacked chitin in the bud neck (Fig.31, lower panel, $30^{\circ} \mathrm{C}$ ). The mutant cells might have delayed formation of the septum or may be defective in cell separation process. But this abnormality was not a homogenous defect. In ent $3 \Delta$ ent $5 \Delta$, the percentage of abnormal cells at $18^{\circ} \mathrm{C}$ was $20 \%$ and at $30^{\circ} \mathrm{C}$, it was $12.8 \%$. ent $3 \Delta$ ent $4 \Delta$ ent $5 \Delta$ (BKY18) cells displayed similar phenotypes as ent $3 \Delta$ ent $5 \Delta$ cells. The rest of the cells were normal and the size was comparable to wild-type.

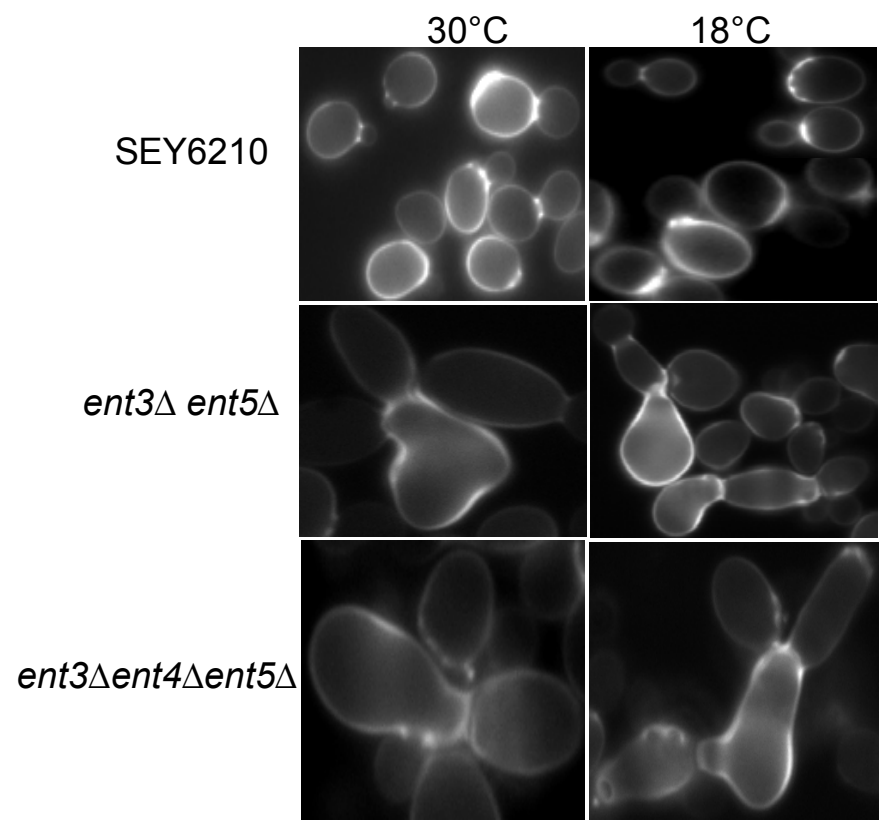

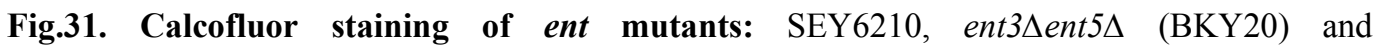
ent $3 \Delta$ ent $4 \Delta e n t 5 \Delta$ (BKY18) were grown at $24^{\circ} \mathrm{C}$ and shifted to $18^{\circ} \mathrm{C}$ or $30^{\circ} \mathrm{C}$ for $5 \mathrm{hrs}$ or $2 \mathrm{hrs}$ respectively. $10 \mu \mathrm{lof} 1 \mathrm{mg} / \mathrm{ml}$ calcofluor was added to the cells, incubated for $1 \mathrm{~h} 30 \mathrm{~min}$ and imaged using a microscope. 


\subsubsection{Irregular distribution of Chitin and Actin assembly in ent $3 \Delta e n t 5 \Delta$}

Since the cells were abnormal in shape, it was important to study the localization of actin assembly using phalloidin-fluorophor which binds polymerized actin, along with calcofluor (Fig.31). The yeast actin cytoskeleton is organized into atleast four biochemically and morphologically distinct structures, namely, cortical patches (discrete cytoskeletal bodies), actin cables (long bundles of actin filaments), the cap (polarized accumulation of cytoskeletal and regulatory proteins) and a cytokinetic ring (reviewed in: Pruyne and Bretscher, 2000). Cell polarity in budding yeast is established by a polarized actin cytoskeleton throughout the cell cycle. A cap (the bud site) of regulatory and cytoskeletal proteins establishes the polarity of actin cables and cortical patches (G1 phase). Actin cables then guide secretory vesicles to the cap, where they accumulate and fuse, thus polarizing growth. During isotropic growth (G2 and M phase), the proteins of the cap are more diffusely distributed, cortical patches are isotropically distributed and actin cables form a meshwork. A fourth cytoskeletal structure, a cytokinetic ring, mediates cell division when all the actin components reorient to the mother-bud junction.

The chitin and actin localization in some abnormal cells were shown in Fig.31a (Actin and chitin localization in the same cells). The actin filaments were absent in the abnormal cells from ent $3 \Delta$ ent5 $(\mathrm{BKY} 20)$. Also the number of actin patches was more in the abnormal cells. Chitin was deposited irregularly in the abnormal cells independent of the temperature. As shown in the middle panel of Fig.31a, all the cells were attached with each other but the cell having irregular chitin deposition lacks actin staining. The initial cells in the branch lost their actin staining as the branch grew. In the abnormal cells actin cap was formed properly even if the cells were not separated and elongated (Fig.31a, lower panel). Though the actin assembly was disorganized, the abnormal cells could form new buds, but could not get separated, resulting into branched cell morphology. These observations were restricted only to the $20 \%$ of the abnormal cells in the mutants whereas the rest of the cells exhibited wild-type phenotype. The cell cycle dependent actin localization in the normal cells of ent $3 \Delta$ ent $5 \Delta$ was shown in Fig.31b. 


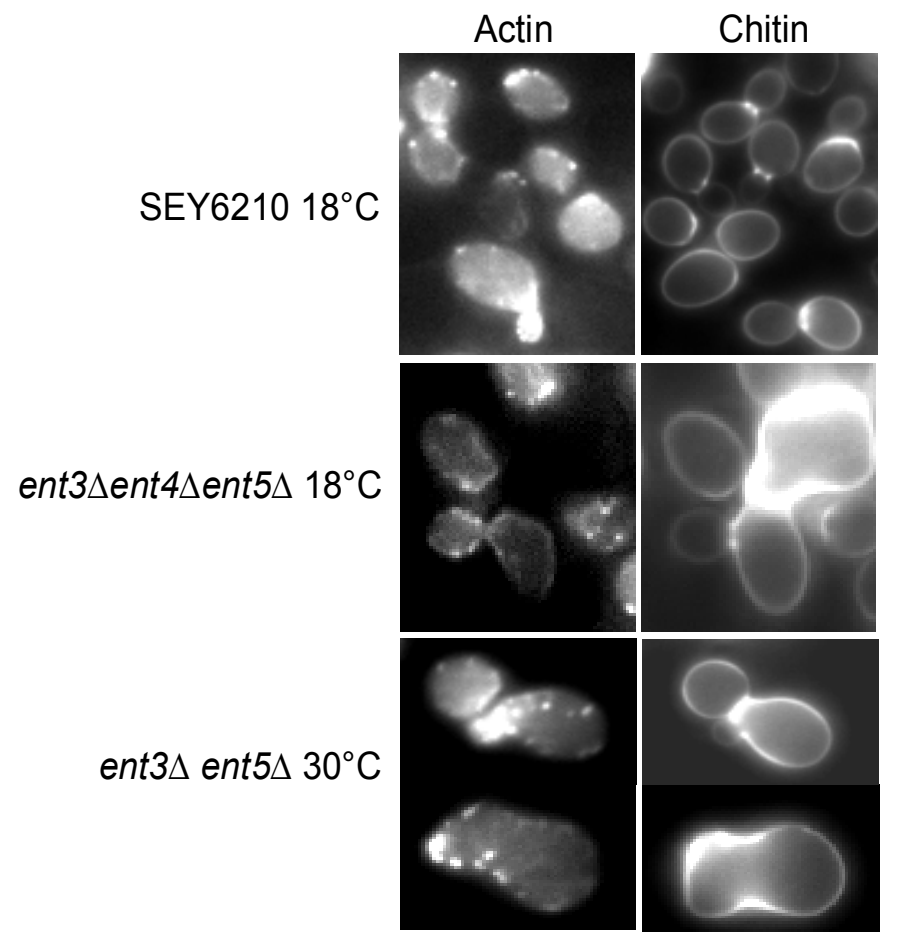

Fig.32a. Phalloidin and calcofluor staining of abnormal cells in ent mutants: SEY6210, ent $3 \Delta$ ent $4 \Delta e n t 5 \Delta$ (BKY18) and ent $3 \Delta$ ent $5 \Delta$ (BKY20) cells were grown at $24^{\circ} \mathrm{C}$, shifted to $18^{\circ} \mathrm{C}$ or $30^{\circ} \mathrm{C}$ for $5 \mathrm{~h}$ or $2 \mathrm{~h}$ respectively, incubated with phalloidin and calcofluor at the corresponding temperature for $1 \mathrm{~h} 30 \mathrm{~min}$ and imaged using a fluorescence microscope.

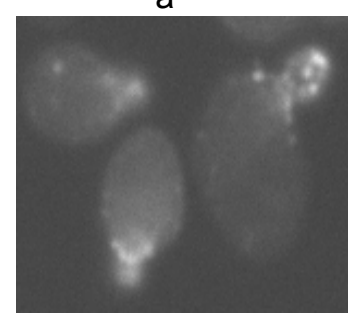

Actin cap

(phase $S-G_{2}$ )

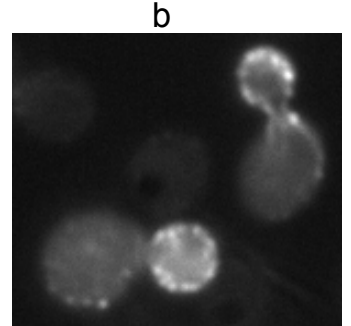

Polarized growth (phase $\mathrm{G}_{2}-\mathrm{M}$ )

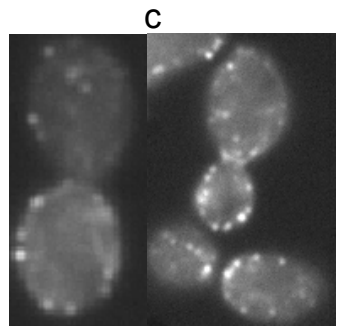

Isotropic growth (phase M)

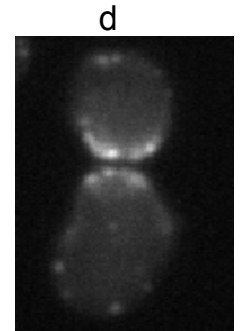

Cytokinetic ring (phase M-G ${ }_{1}$ )

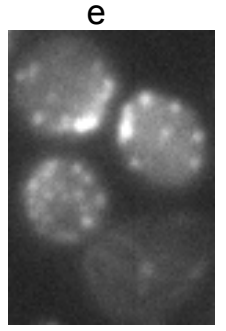

(Phase $\mathrm{G}_{1}$ )

Fig.32b. Actin staining of normal cells in ent $3 \Delta$ ent $5 \Delta$ cells: Nearly $80 \%$ of the cells displayed

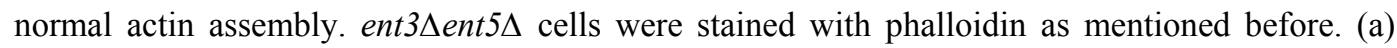
Formation of actin cap structure in the bud site during the cell cycle phase $S-G_{2}$. (b) Actin patches and actin cables start distributing from the polarized growth at the beginning of $M$ phase. (c) Isotropic distribution of actin patches and cables during $\mathrm{M}$ phase. (d) Actin structures are concentrated to form a cytokinetic ring in the beginning of $G_{1}$ phase. (e) After cytokinesis, actin patches are redistributed again isotropically. 


\subsubsection{Localization of Chs3p-GFP in ent mutants}

The three chitin synthases of Saccharomyces cerevisiae, Chs1p, Chs $2 p$, and Chs $3 p$, participate in septum and cell wall formation of vegetative cells and in cell wall morphogenesis of conjugating cells and spores. Since in the ent $3 \Delta$ ent $5 \Delta$ cells, chitin deposition was irregular and also bud scar was not clearly present in some cells which indicated that the septum might not have formed well. Chs3p is responsible for the chitin synthesis in the septum wall formation (Shaw et al., 1991) which is transported out of ER with the help of Chs $7 p$ and targeted to the plasma membrane via the Golgi with the help of Chs $5 \mathrm{p}$. Before being delivered to the bud neck, chs $3 p$ is recovered from the cell surface, stored in an endocytic structure and delivered to the bud neck by the vesicles that contain Tlg1p (Chuang and Schekman, 1996; Holthuis et al., 1998). The plasmids, CHS3GFP (RSB2310) and CHS7 (pSC23) were transformed into all the ent mutants and the localization of Chs3p was studied by GFP fluorescence (Fig.33). Chs3p-GFP was localized into the bud neck in small budded cells and in some internal compartments in wild-type. In some wild-type cells, ER localization was also observed. It could be because of the uneven expression of Chs7p which is needed for the exit of Chs $3 p$ from the ER. In all the mutant cells, Chs3p was present in the bud neck, in some internal compartments

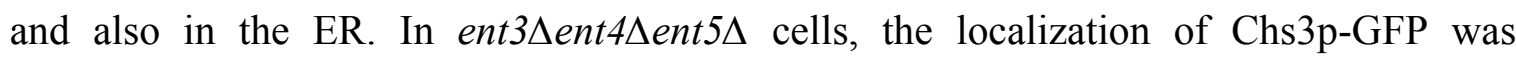
analyzed at $18^{\circ} \mathrm{C}, 30^{\circ} \mathrm{C}$ and $37^{\circ} \mathrm{C}$. This experiment showed that $\mathrm{Chs} 3 \mathrm{p}$ reached its destination in the mutants, for example, in the budding cells, Chs $3 p$ was present in the bud site and in the bud neck. The localization of Chs3p-GFP was very heterogeneous in different cells from wild type as well as in mutants. No differences in overall staining pattern were detected. 


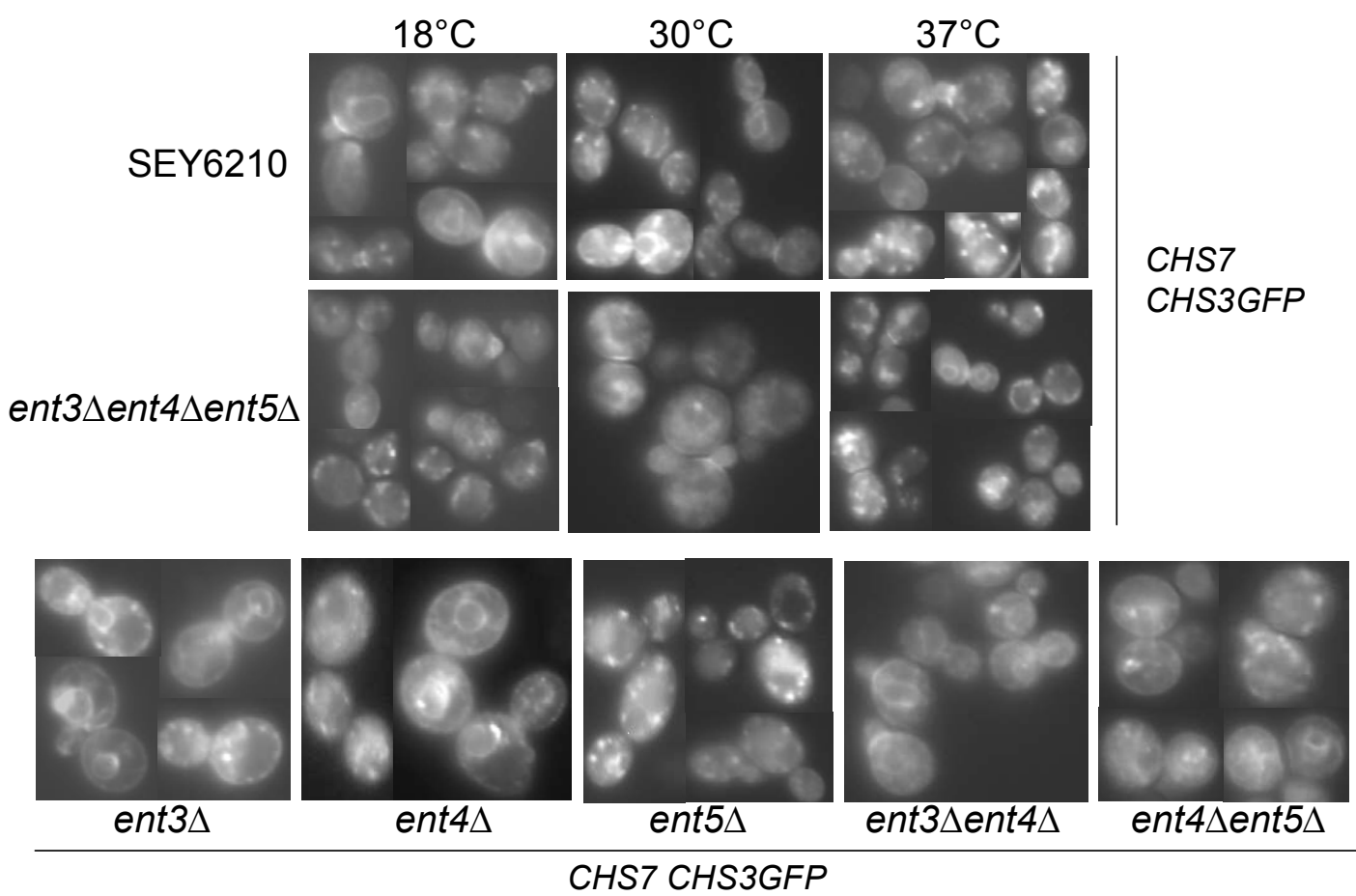

Fig.33. Chs3p localization in ent mutants (mixed background): SEY6210, ent3A (BKY22),

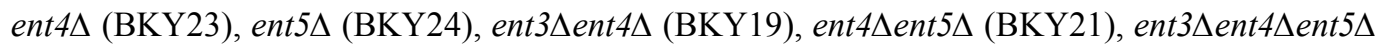
(BKY18) cells expressing Chs7p and Chs3p-GFP were grown overnight at $18^{\circ} \mathrm{C}$ or $30^{\circ} \mathrm{C}$ or $37^{\circ} \mathrm{C}$ and viewed under microscope. In the lower panel, cells from $30^{\circ} \mathrm{C}$ were shown.

\subsubsection{Aniline blue staining of ent mutants}

The yeast cell wall represents a complex structure of cross linked chitin, 1, 3- $\beta$-Glucan, 1 , $6-\beta$-Glucan and mannoproteins. Since chitin deposition was not regular in ent mutants, it was interesting to check whether 1, 3- $\beta$-glucan deposition was normal. Aniline blue (also called as Methyl blue) specifically stains the 1,3- $\beta$-glucan layer in the cell wall. All the ent mutants were stained with aniline blue (Fig.34). No defect in the 1,3- $\beta$-glucan layer of ent mutants was observed. 


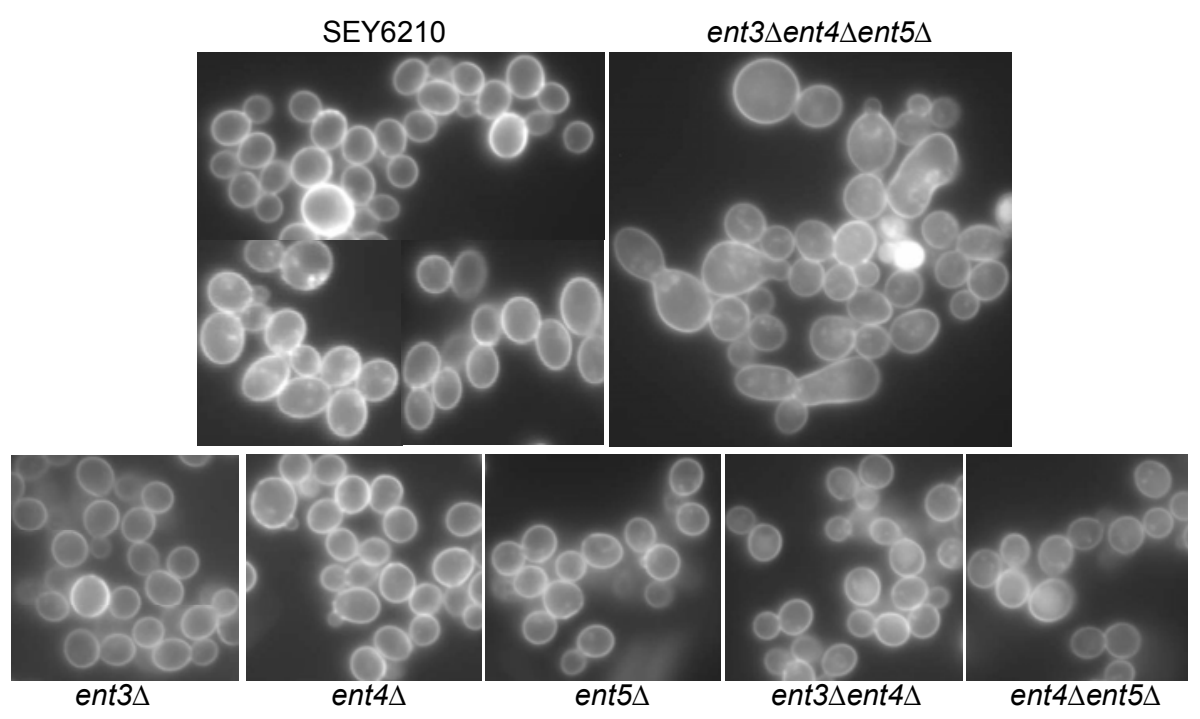

Fig.34. Aniline blue staining of ent mutants (mixed background): SEY6210, ent $3 \Delta$ (BKY22),

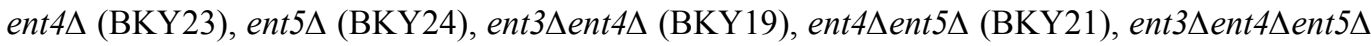
(BKY18) cells were grown overnight at $30^{\circ} \mathrm{C}$ and viewed under microscope.

\subsubsection{Growth defects caused by cell wall perturbing agents}

The growth pattern of ent mutants were analyzed on $1 \mathrm{M} \mathrm{NaCl}, 1.4 \mathrm{M} \mathrm{NaCl}, 50 \mu \mathrm{g} / \mathrm{ml}$ calcofluor and on $0.05 \%$ SDS (Fig.35). These agents are generally used to screen cell wall mutants. Yeast cell have a rigid cell wall and higher internal turgor pressure. If the cell wall is defective, the cells can not grow on high osmotic or salt stress $(\mathrm{NaCl})$ because of the loss of the turgor pressure. SDS, as a detergent, will solubilize protein and disrupt the architecture of the cell wall. Calcofluor white is a negatively charged fluorescent dye that binds to nascent chains of chitin and, to a lesser extent, glucan through hydrogen bonding and dipole interactions and, by preventing microfibril assembly, interferes directly with the supramolecular organization of the cell wall (Elorza et al., 1983; Murgui et al., 1985; Ram et al., 1994). A disturbed or weakened cell wall is not able to withstand drug

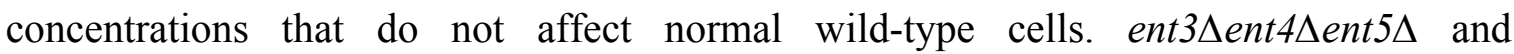
ent $3 \Delta$ ent $5 \Delta$ cells were sensitive to all the tested cell wall perturbing agents except that ent $3 \Delta$ ent $5 \Delta$ was not sensitive to $1 \mathrm{M} \mathrm{NaCl}$. ent3 3 was sensitive to SDS and calcofluor. This shows that ent deletions have a defective cell wall. 


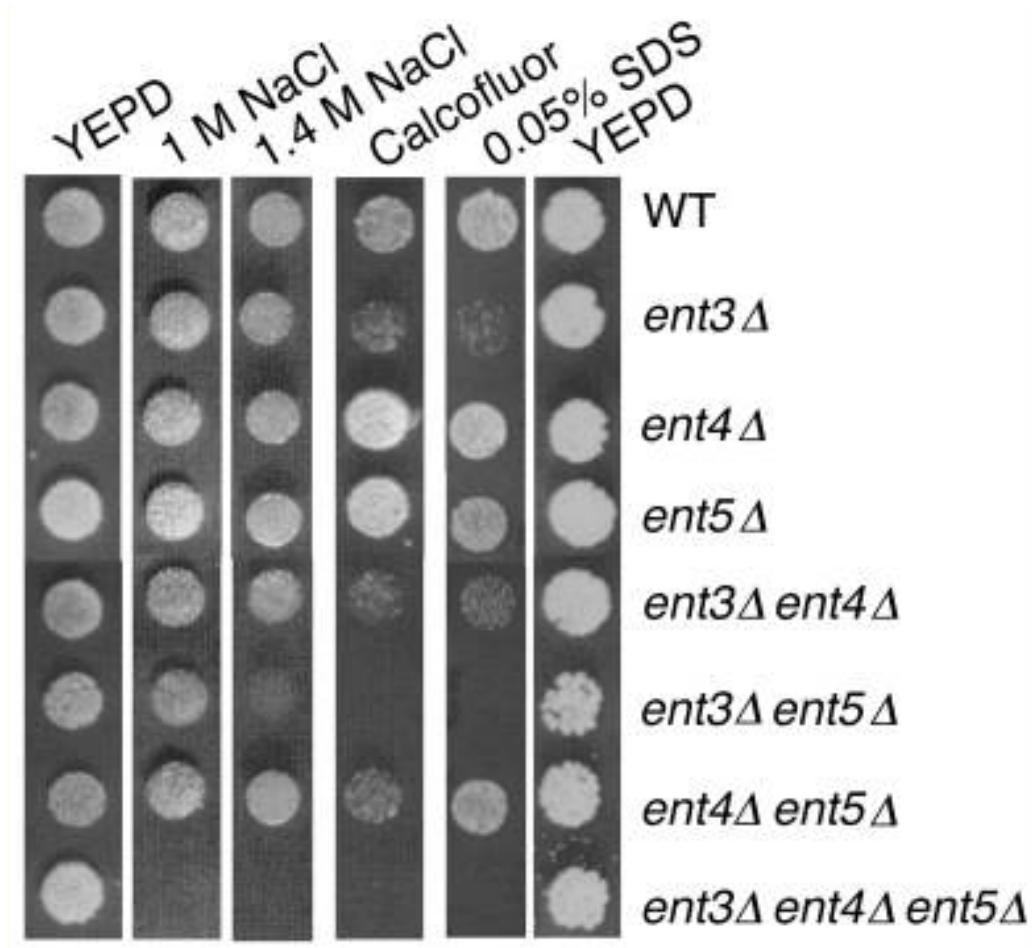

Fig.35. Growth defects of ent mutants by cell wall perturbing agent: BY4742, ent $3 \Delta$, ent $4 \Delta$,

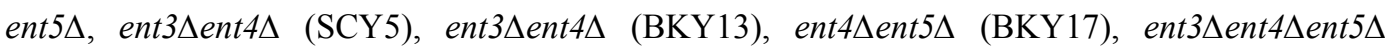
(BKY18). Cells were grown at $24^{\circ} \mathrm{C}$ and different dilutions were spotted on YEPD plate and YEPD containing $1 \mathrm{M} \mathrm{NaCl}, 1.4 \mathrm{M} \mathrm{NaCl}, 50 \mu \mathrm{g} / \mathrm{ml}$ calcofluor, $0.05 \%$ SDS and incubated at $30^{\circ} \mathrm{C}$.

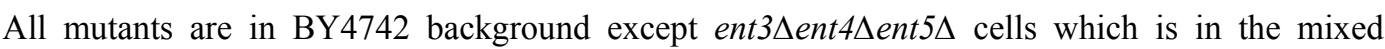
BY4742 x SEY6210 background.

\subsubsection{Zymolyase sensitivity curve}

Zymolyase is a $\beta-1,3$ - Glucanase enzyme which cleaves the $\beta-1,3$-glucosidic linkages. Cells would show altered sensitivity to zymolyase, if the cell wall composition was altered. Sensitivity to zymolyase may reflect changes in the $\beta$-1, 3-glucan layer (Ovalle et $a l ., 1998)$ or changes in the external mannoprotein layer that result in altered permeability to cell wall degrading enzymes (De Nobel et al., 1991). ent mutants were incubated with zymolyase and every one hour the optical densitiy was measured (Fig.36). Dent3 cells behaved like the wild type cells whereas $\Delta e n t 5$ and $\Delta e n t 3 \Delta e n t 5$ were more resistant to zymolyase which showed that the cell wall composition was altered in $\Delta e n t 3 \Delta e n t 5$ and $\Delta e n t 5$ mutants. 


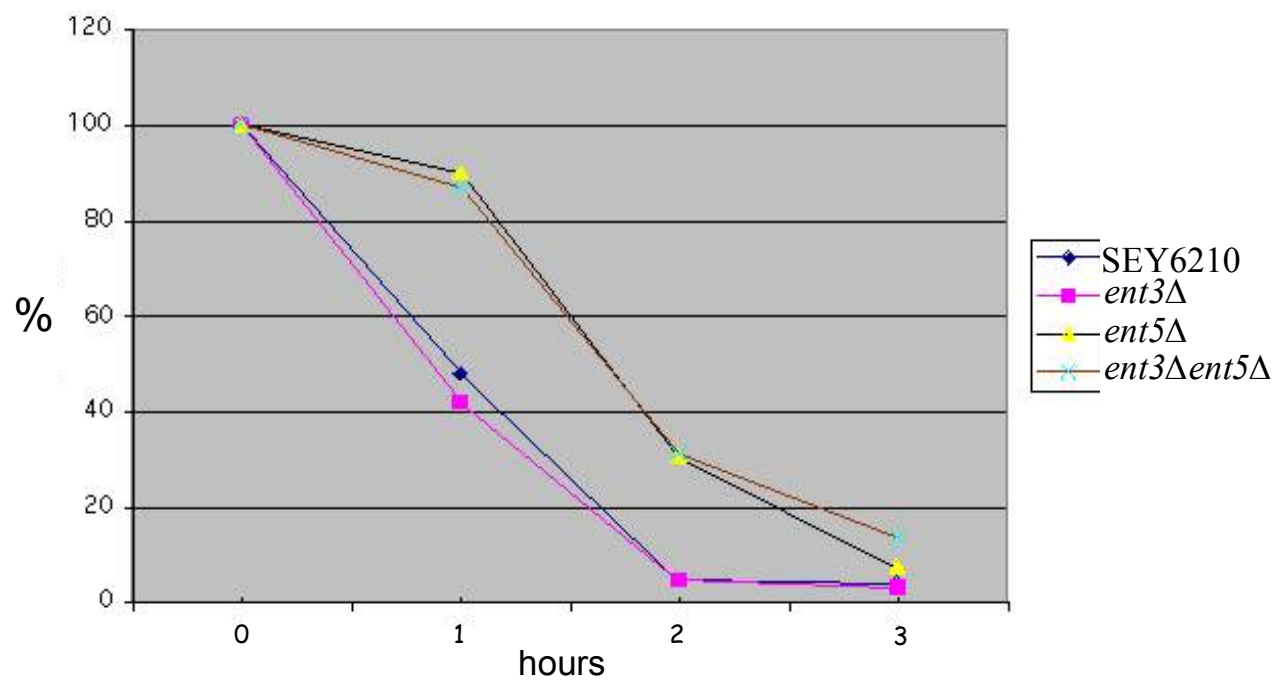

Fig.36. Zymolyase sensitivity curve: SEY6210, $\Delta e n t 3$ (SCY2), $\Delta e n t 5$ (SCY25) and $\Delta e n t 3 \Delta e n t 5$ (SCY26) cells were grown overnight at $24^{\circ} \mathrm{C}$ and incubated with zymolyase $(5 \mu \mathrm{g} / \mathrm{ml})$ at $37^{\circ} \mathrm{C}$. Every one hour the $\mathrm{OD}_{600}$ was measured for $3 \mathrm{~h}$ and the percentage of the final OD was calculated. OD: optical density.

\subsubsection{Interaction of Ent3p with Pep12p and Syn8p}

\subsubsection{Two hybrid interactions of Ent3p}

A two hybrid assay was done in the group to find out whether Ent3p interacts with other SNARE proteins apart from Vti1p (Fig.37a). Interestingly, Ent3p interacted with the Nterminal domains of Syn8p and Pep12p which are present in the endosomal SNARE complex with Vtilp and didn't interact with Tlg1p. EpsinR was used as a control. This two hybrid interaction was confirmed further by an in vitro pull down assay using His tagged Vti1p, Pep12p, Tlg1p and Syn8p with Strep tagged Ent3p (Fig.37b). 


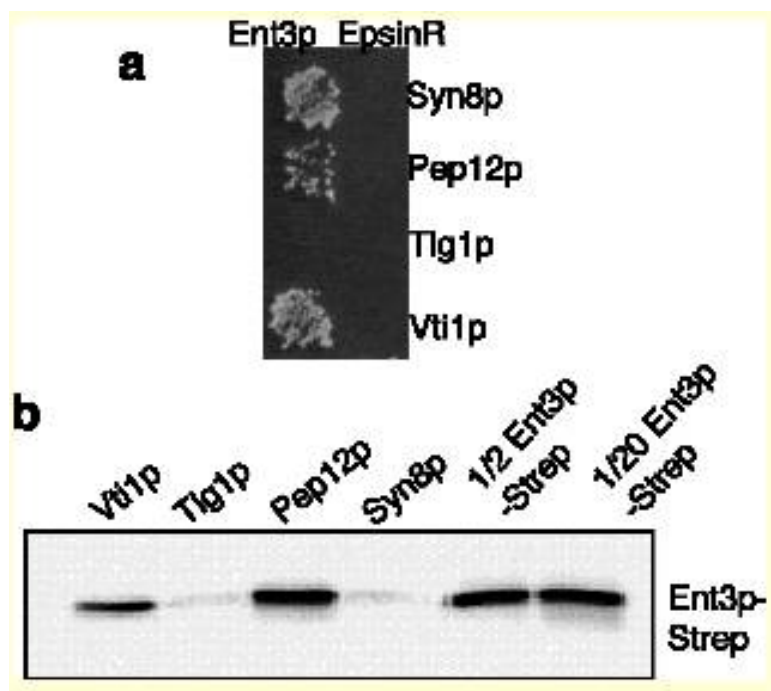

Fig.37. (a) Two hybrid interactions were detected between Ent3p and Syn8p and Pep12p. No interaction was found with Tlg1p. The interactions with EpsinR were used as a negative control. (b) In vitro binding assay was done as mentioned before with slight changes in the binding buffer. 1/20 Ent3p-Strep: 1/20 of the protein used in the assay.

\subsubsection{Pep12p and vti1-2p are stabilized in ent $3 \Delta$ cells}

The stability of Pep12p and vti1-2p were studied in the ent mutants by pulse chase immuno precipitation of Pep12p and Vti1p (Fig.38). vti1-2p was more stable when ent3 was deleted (Fig.38a) and the same was true for Pep12p (SCY2) (Fig.38b). The amount of vti1-2p after $2 \mathrm{~h}$ chase in vtil-2 was $81.37 \%$ (SD 41, $\mathrm{n}=3$ ), in vtil-2ent $3 \Delta 116.4 \%$ (SD 26) and in SEY6210 $97 \%$ (SD 5.7). Absence of Ent5p (SCY25) did not lead to stabilization of Pep12p. In $\Delta e n t 3 \Delta e n t 5$ (SCY26), a slight stabilization of Pep12p could be observed. After $3 \mathrm{~h}$ of chase, $26.9 \%$ [SD 0.2, n=3] Pep12p was present in the wild type, $28.25 \%$ (SD 8.13) in ent $5 \Delta$ cells whereas in ent $3 \Delta, 56.5 \%$ [SD 10.6, $\mathrm{n}=3$ ] was present. In $\Delta e n t 3 \Delta e n t 5$ cells, $34.7 \%$ (SD 5.6) Pep12p was found. After $5 \mathrm{~h}$ of chase, the amount of Pep12p in wild type was $13 \%(\mathrm{n}=1)$, in ent $3 \Delta 33.6 \%$, in ent5 $10.5 \%$ and in $\Delta e n t 3 \Delta e n t 525.6 \%$. The epistatic effect of ENT5 might have masked the effect of ENT3, resulting in less stabilization of Pep12p in $\Delta e n t 3 \Delta e n t 5$. Three experiments were done which were reproducible both for vti $1-2 p$ and Pep12p. Ent3p might be required for the anterograde transport of Pep $12 p$ and vti1-2p. 


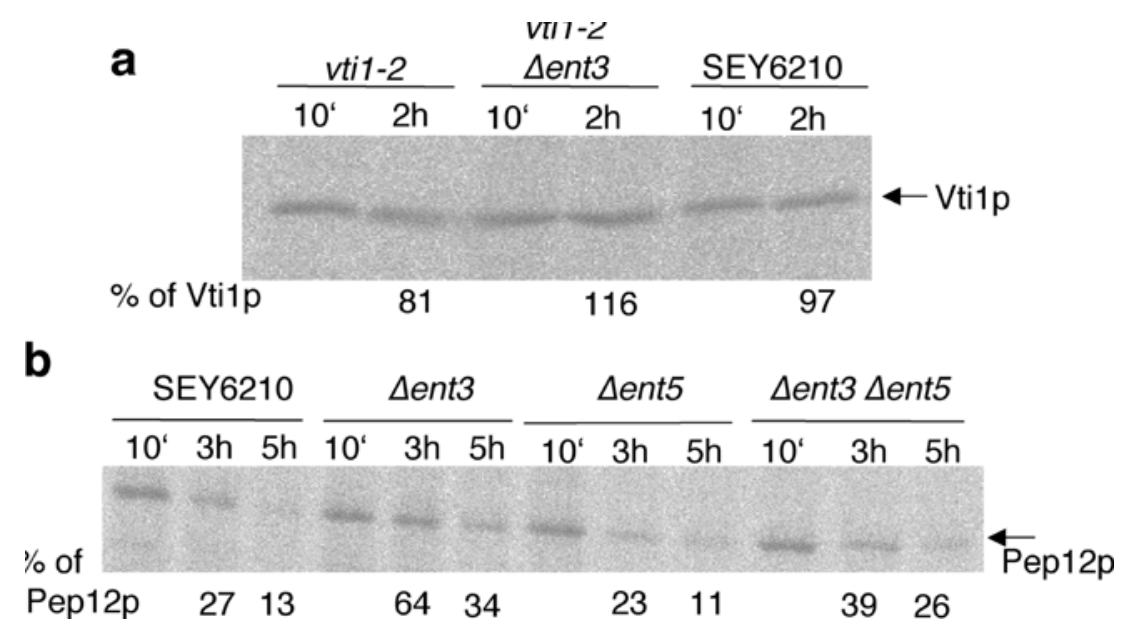

Fig.38. Stability of Pep12p and vti1-2p in ent mutants: Cells grown at $24^{\circ} \mathrm{C}$ were labeled with radioactive methionine for $30 \mathrm{~min}$ and chased for $10 \mathrm{~min}$ or $2 \mathrm{~h}$ or $3 \mathrm{~h}$ or for $5 \mathrm{~h}$ at $37^{\circ} \mathrm{C}$. Vtilp (a) and Pep12p (b) were immunoprecipitated from cellular extracts, separated by SDS-PAGE and quantified by phospho imager.

\subsubsection{Localization of Pep12p in ent deletion cells}

Indirect immuno fluorescence of Pep12p was done in the ent mutants to study the localization of Pep12p (Fig.39). Both in wildtype and mutant cells, Pep12p was localized to punctuate structures corresponding to prevacuolar endosomes. Pep12p localization was not affected in the ent mutants. This should be further confirmed by sucellular fractionation of the ent mutants.
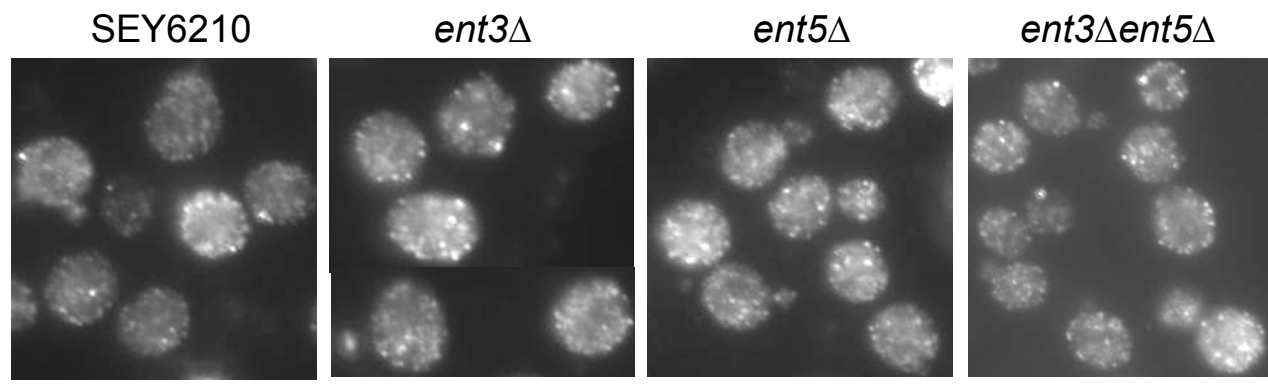

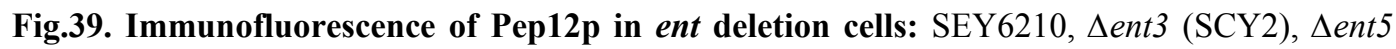
(SCY25), sent3dent5 (SCY26) cells were fixed, treated with monoclonal antibody against Pep12p and using a fluorescing secondary antibody, Pep12p was localized. 


\subsubsection{Synthetic growth defect of pep12 deletion in ent mutants}

To study the genetic interaction between PEP12 and ENT, the mutants were scored for growth at $37^{\circ} \mathrm{C}$ (Fig.40). ent $3 \Delta$ pep $12 \Delta$ and ent $3 \Delta$ ent $5 \Delta$ pep $12 \Delta$ cells could not grow at $37^{\circ} \mathrm{C}$. When cells were grown on plates containing $1 \mathrm{M} \mathrm{NaCl}$ and $1.4 \mathrm{M} \mathrm{NaCl}$ at $30^{\circ} \mathrm{C}$, ent $3 \Delta$ pep $12 \Delta$ and ent $3 \Delta$ ent $5 \Delta$ pep $12 \Delta$ showed a synthetic growth defect. The cells did not grow on plates containing calcofluor and SDS (even the SEY6210 wild type). Only cells from the BY4742 background could grow on calcofluor and SDS.

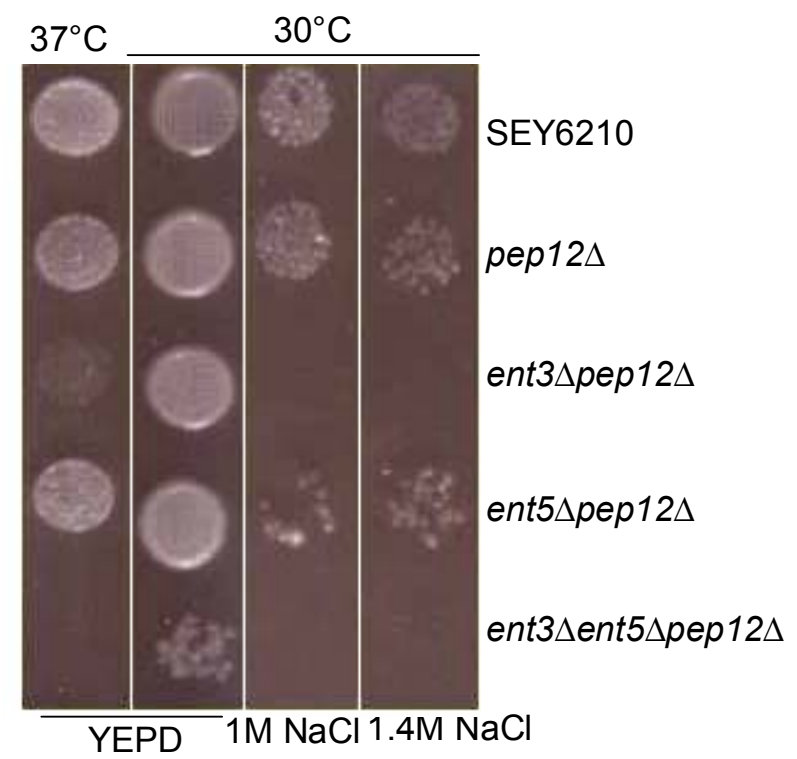

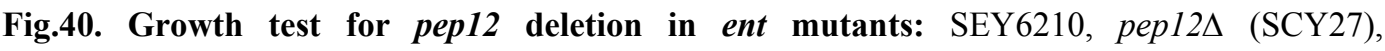

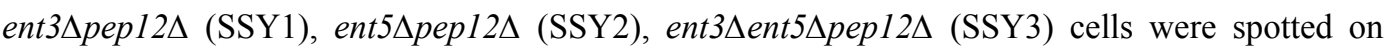
YEPD and plates containing 1 and $1.4 \mathrm{M} \mathrm{NaCl}$ and incubated at $37^{\circ} \mathrm{C}$ or $30^{\circ} \mathrm{C}$. All the mutants are in SEY6210/6211 background.

\subsubsection{5 vti1-2p was destabilized in ent5 $\Delta$}

The vti1-2p was stabilized in the absence of Ent3p but destabilized by the absence of Ent5p (SCY25), shown by pulse chase immuno precipitation of Vti1p at $37^{\circ} \mathrm{C}$ (Fig.41a). After $5 \mathrm{~h}$ of chase the amount of vti1-2p in vtil-2 cells was, $71 \%$ [SD $4.2(\mathrm{n}=3)$ ], which

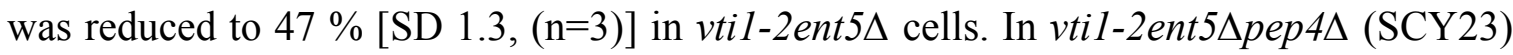
cells, similar amounts of vti1-2p remained after $3 \mathrm{~h}$ and $5 \mathrm{~h}$ compared to vtil-2pep $4 \Delta$ (MDY7). This indicated that the vti1-2p was degraded by the vacuolar degradation pathway. But this effect was temperature dependent. At $30^{\circ} \mathrm{C}$, vti1-2p was neither destabilized in the absence of Ent5p nor stabilized in the absence of Ent3p (Fig.41b). 
(A)
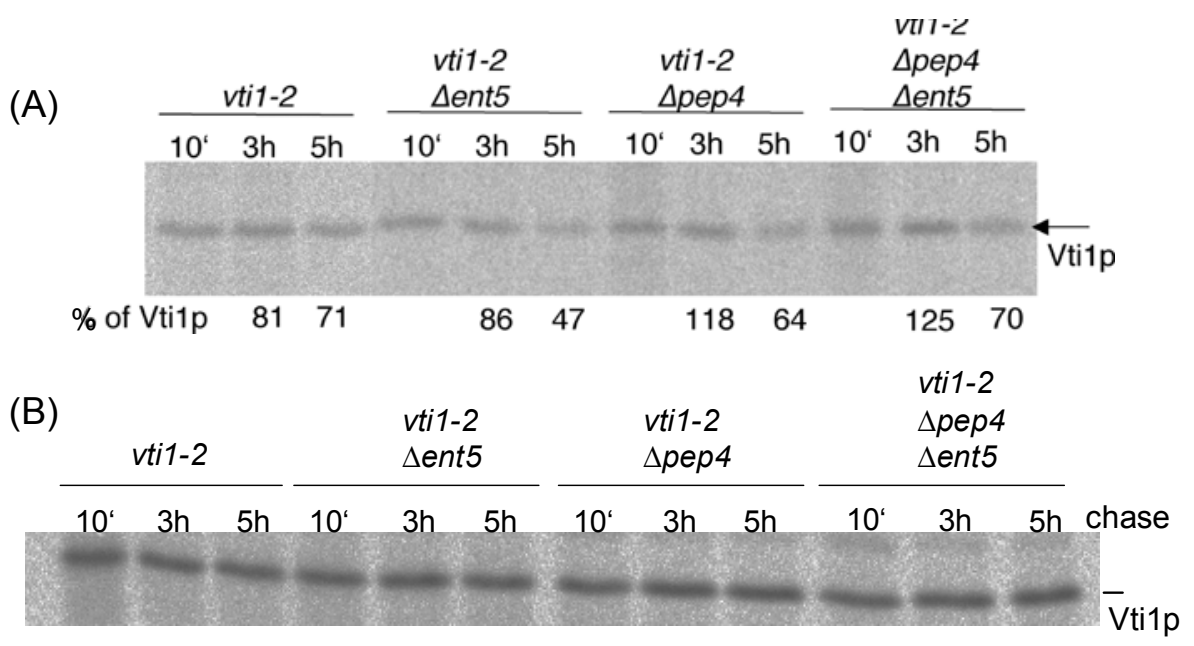

Fig.41.Stability of vti1-2p in ent mutants: cells were labeled at $37^{\circ} \mathrm{C}(\mathrm{A})$ or $30^{\circ} \mathrm{C}$ (B), chased for 10 min or $3 \mathrm{~h}$ or $5 \mathrm{~h}$ and Vtilp was immuno precipitated.

\subsubsection{Stability of Vti1p in ent mutants}

The vti1-2p showed temperature dependent stability which did not give a clear idea of whether absence of Ent5p leads to destabilization of Vtilp. Pulse chase immuno precipitation of Vtilp was done at $37^{\circ} \mathrm{C}$ from the ent mutants (Fig.42). There was no

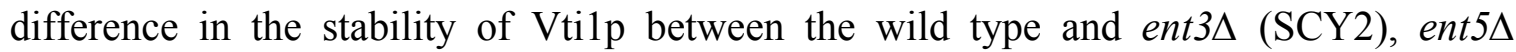

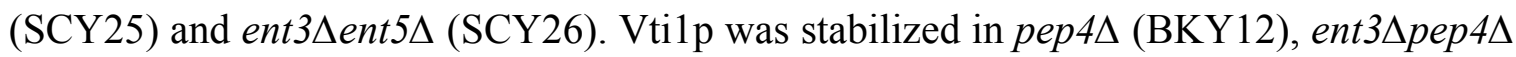

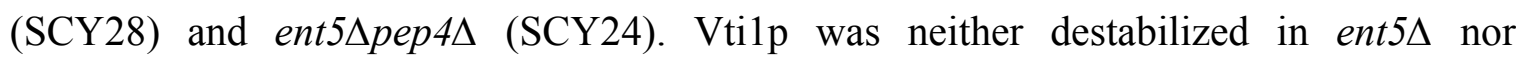
stabilized in ent $3 \Delta$.

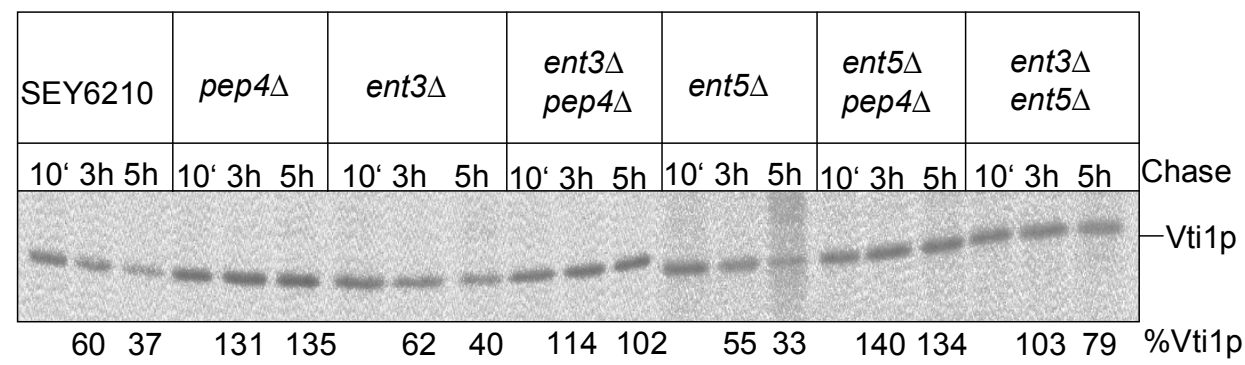

Fig.42. Stability of Vti1p in ent mutants: Cells were labeled at $37^{\circ} \mathrm{C}$ and chased for 10 min or 3 $\mathrm{h}$ or $5 \mathrm{~h}$ and Vtilp was immunoprecipitated. 


\subsubsection{Subcellular distribution of Vti1p in ent mutants}

Subcellular fractionation of wild type and ent mutants were done to study the redistribution of Vtilp in ent mutants (Fig.43). Both in the wild type and in the mutants, Vti1p was present in the P13 and P200 (in pre vacuolar membrane and in Golgi). Vph1p, vacuolar ATPase and PGK, a soluble protein were used as controls. There was no redistribution of Vtilp in the ent mutants. But it is difficult to differentiate subtle changes by subcellular fractionation.

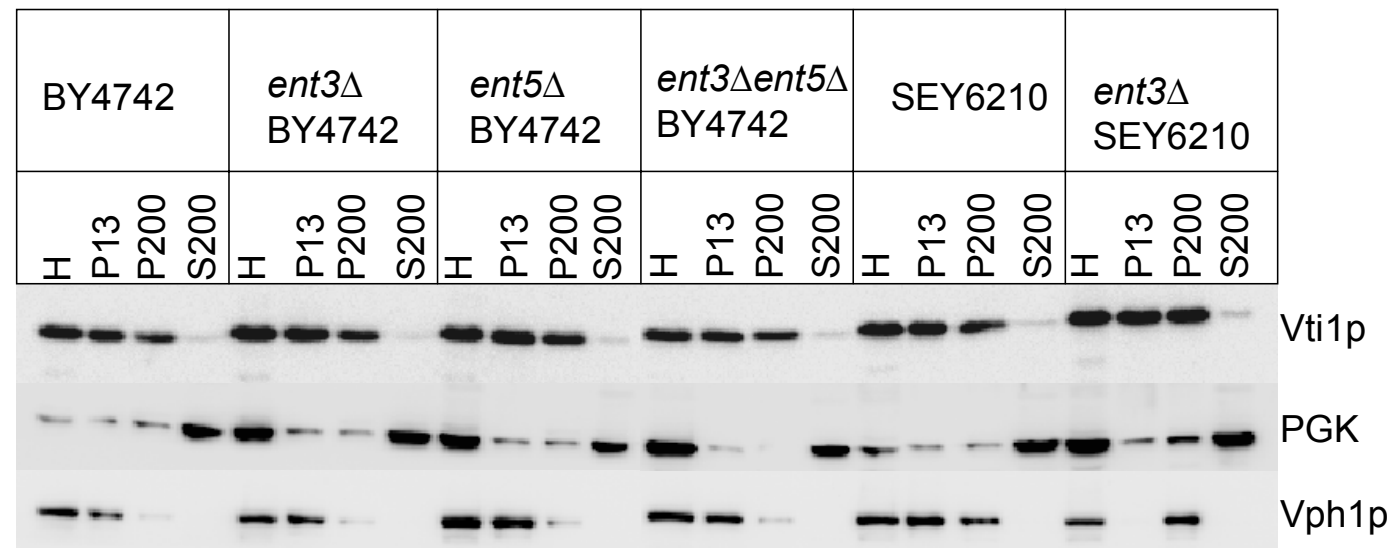

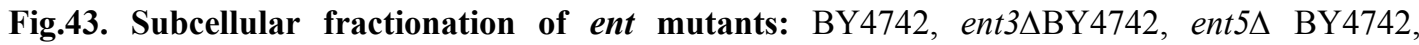

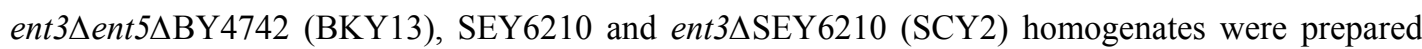
by gentle lysis method, fractionated and the blot was probed with antisera against Vtilp, PGK and Vph1p. Starting volume was $1 \mathrm{ml}$ and equal volume was loaded.

\subsubsection{Vti1p Immunofluorescence in ent mutants}

Vtilp was localized to the punctuate structures of Golgi and PVC, both in the wild type and ent mutants studied by indirect immuno fluorescence of Vtilp (Fig.44). No change in the localization of Vtilp in ent mutants was observed. 


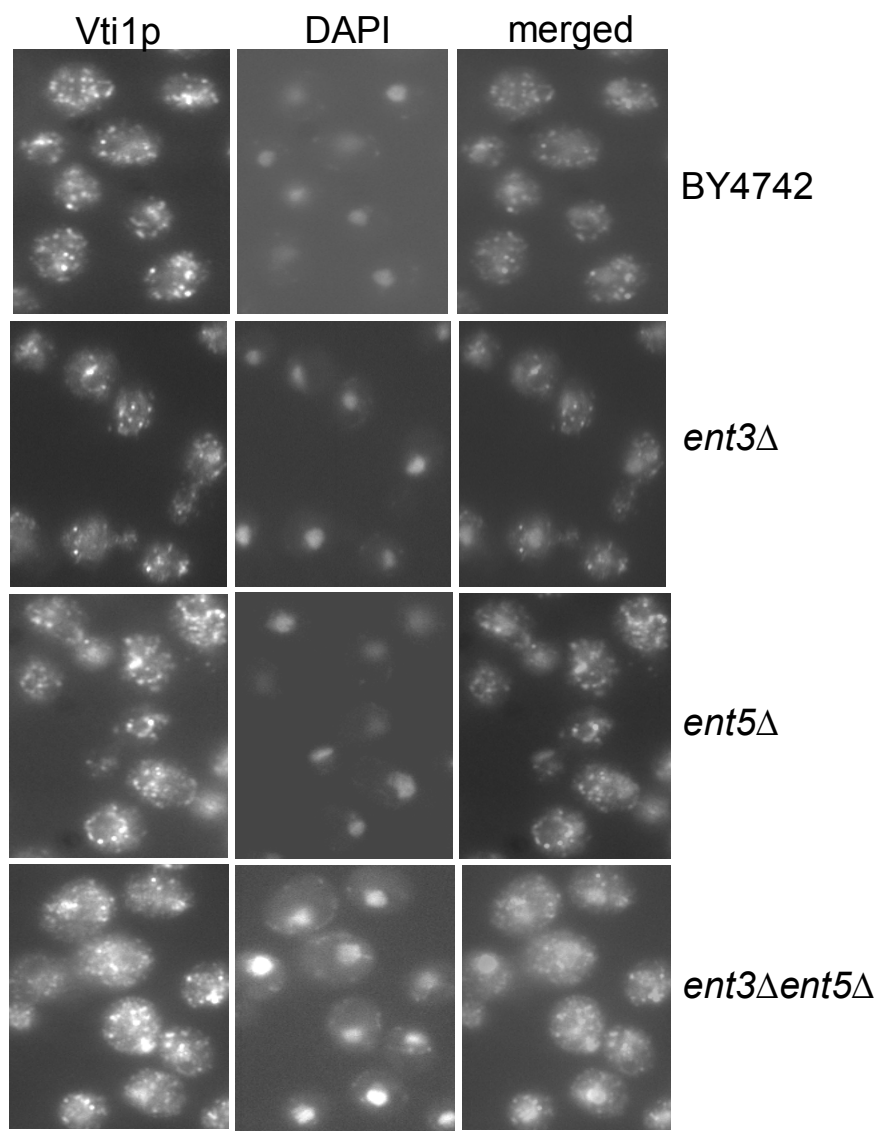

Fig.44. Immunofluorescence of Vti1p in ent mutants: Vti1p was localized in BY4742, ent3山, ent5 $\Delta$ and ent $3 \Delta e n t 5 \Delta$ (BKY13). DAPI staining was done to localize nucleus.

\subsubsection{The composition of endosomal SNARE complex in ent3 $\Delta e n t 5 \Delta$}

Since Ent3p interacted with Vtilp, Pep12p and Syn8p from the endosomal SNARE complex, it might be possible that Ent3p interacts with the whole SNARE complex and regulate the formation and dissociation of the complex. To check whether deletion of ent 3 or ent 5 affected the amounts of SNAREs present in the complex, immunoprecipitaion was

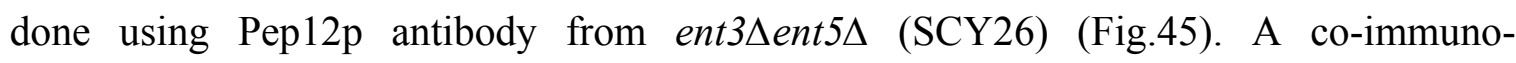
precipitation of Vtilp was observed. There was no change in the amounts of Vtilp which co-immnuoprecipitated with Pep12p in the ent mutant. 


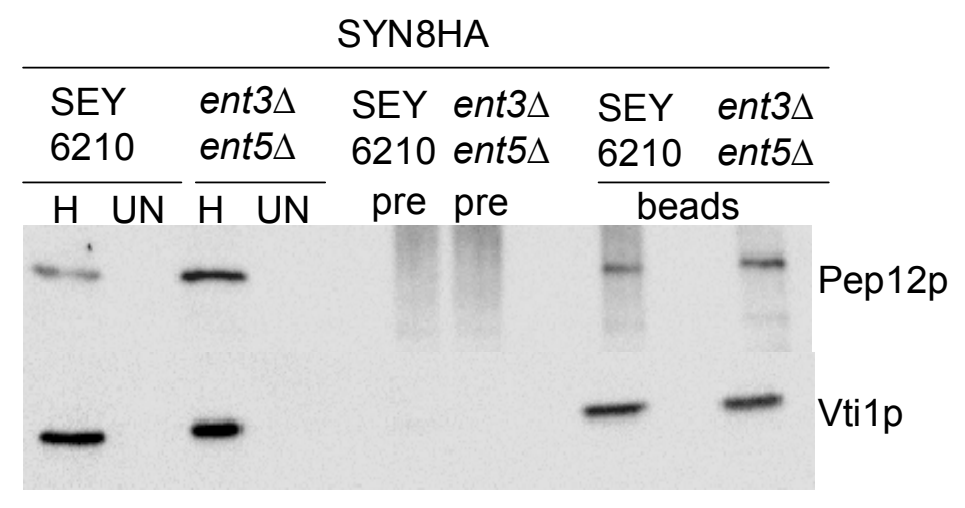

Fig.45. Immunoprecipitation of SNARE complex in ent3 $\Delta e n t 5 \Delta$ : SEY 6210 and ent $3 \Delta e n t 5 \Delta$ (SCY26) cells expressing Syn8pHA (pSC19) were used to precipitate SNARE complex using beads crosslinked with antisera against Pep12p. H: homogenate; UN: unbound; pre: preimmune.

\subsubsection{Retrograde transport of A-ALP and Vps10p}

To study if Ent5p or Ent3p were involved in the retrograde transport, the stability of AALP and Vps10p which recycle between TGN and endosome, was analyzed (Fig.46). Vps10p is a receptor that sorts several different vacuolar proteins by cycling between a late Golgi compartment and the endosome. Vps10p is the receptor for CPY. A-ALP consists of the cytosolic domain of dipeptidyl aminopeptidase A [DPAP A] fused to the transmembrane and lumenal domains of the alkaline phosphatase [ALP]), which localizes to the yeast TGN. The cytosolic tail of DPAP A confers recycling between the TGN and the endosome. The delivery of this protein to the vacuole can be monitored by proteolytic maturation of proALP. Pulse chase immuno precipitation of A-ALP was done from ent deletions in pho8 (which codes for ALP) deleted cells, transformed with the A-ALP plasmid (Fig.46a). After $120 \mathrm{~min}$ of chase, $59.4 \%(\mathrm{n}=1) \mathrm{mALP}$ was present in pho8s

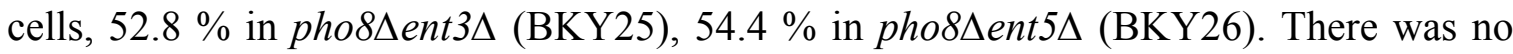
destabilization of A-ALP in the mutants. The amount of Vps10p in wild type cells was

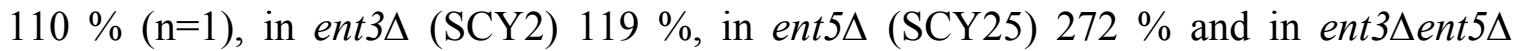
(SCY26) $115 \%$ (Fig.46b). The high value in ent5s cells might be due to technical problems since the $3 \mathrm{~h}$ band was optically comparable with other strains. Vps10p was also not affected in the ent mutants. 

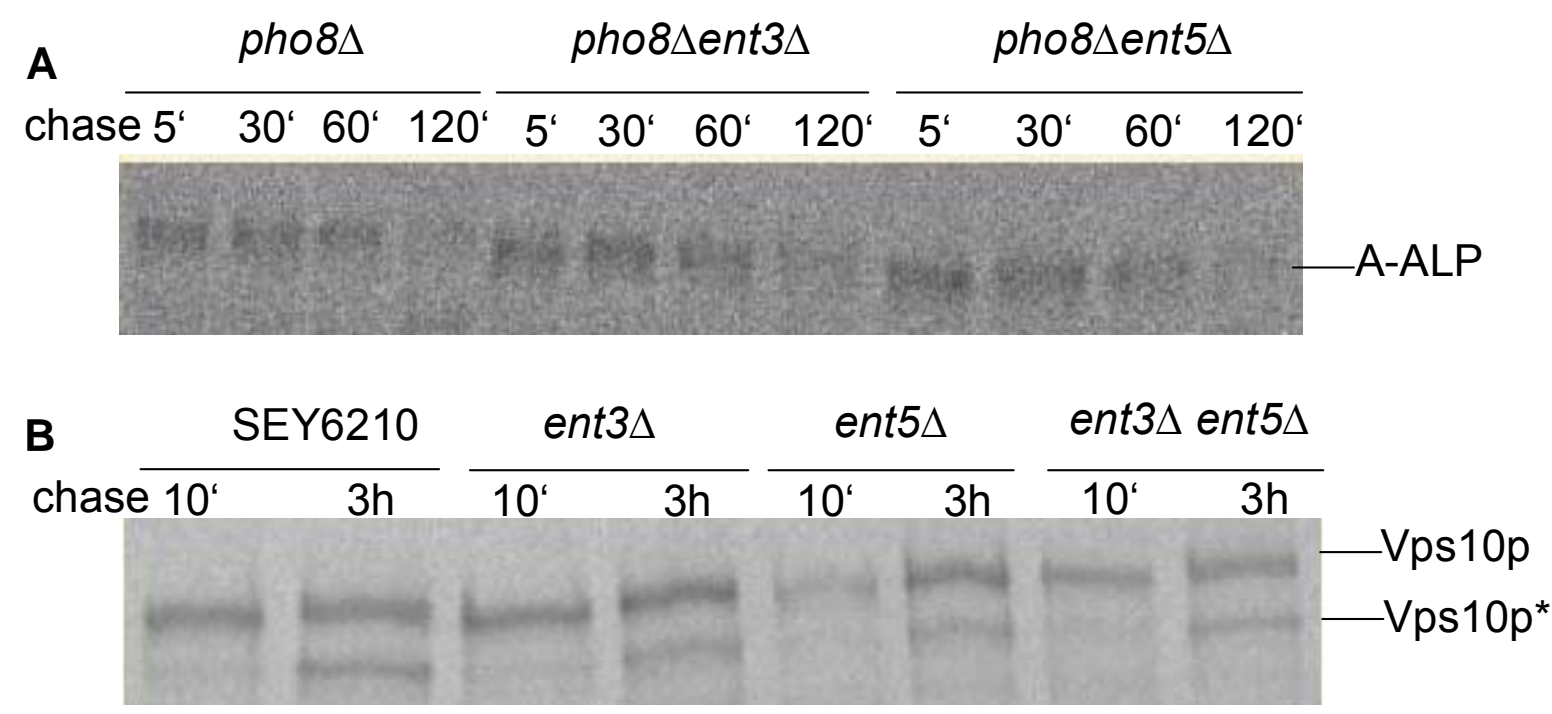

Fig.46. Pulse chase immunoprecipitation of A-ALP (a) and Vps10p (b): Cells were labeled at $37^{\circ} \mathrm{C}$ and chased for $5 \mathrm{~min}$ or $30 \mathrm{~min}$ or $60 \mathrm{~min}$ or $120 \mathrm{~min}$ for A-ALP and $10 \mathrm{~min}$ and $3 \mathrm{~h}$ for Vps10p. Vps10p*: degraded Vps10p.

\subsubsection{Role of Ent proteins in pApe1p processing}

Amino peptidase I reach the vacuole through the CVT pathway in logarithmically growing cells and in early stationary cells and through autophagy in stationary and starved cells. These pathways were analyzed in the ent mutants to investigate the involvement of Ent proteins in this transport route (Fig.47). pApe1p would appear if the CVT pathway or the autophagy was blocked. In ent $3 \Delta$, pApelp was present more in the $\log$ phase cells. But, the ent $3 \Delta$ ent $5 \Delta$ cells did not have pApe1p in both the phases. There may be some factors in ent $3 \Delta$ ent $5 \Delta$ cells which rescued the effect of ent $3 \Delta$ or the

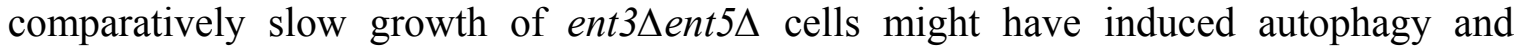
pApelp was processed. In the nitrogen starved cells, Apelp was processed properly showing that autophagy was not affected by Ent proteins. 


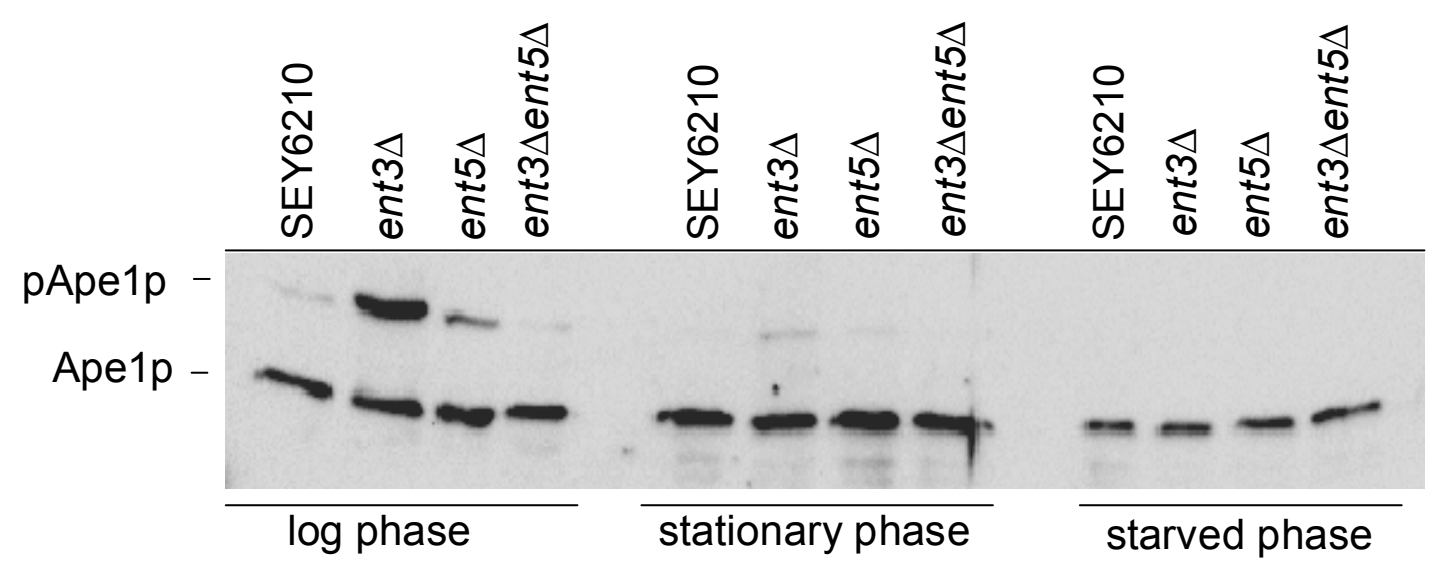

Fig.47. Ape1p processing in ent mutants: protein extracts were prepared from SEY6210, ent3A

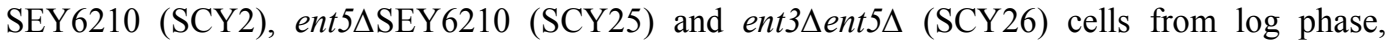
stationary phase and nitrogen starved condition. pApe1p:proApelp. log phase: till $\mathrm{OD}_{600} 1.2$; stationary phase: around $24 \mathrm{~h}$ growth, $\mathrm{OD}_{600} 3$ to 8 . 


\section{Discussion}

The main aim of this study was to identify and characterize the interaction partners of Vtilp and to unravel the function of the N-terminus of Vtilp. In the first part, the importance of the N-terminus of Vti1p is discussed and in the second part the interaction between Vtilp and Ent3p is elaborated with comments on the characterization of the ent mutants.

\subsection{Function of the N-terminus of Vti1p}

The N-terminal domains of all syntaxins have overall similar structures. The N-terminal domain of neuronal syntaxin 1 and its yeast plasma membrane homologue Sso1p consists of a three-helix bundle which interacts with its own SNARE motif resulting into closed conformation and can down regulate the capability to form SNARE complexes (Dulubova et al., 1999; Munson et al., 2000). But when the N-terminal domain of Sso1p was removed, formation of the SNARE complex assembly was accelerated (Nicholson et al., 1998). The SNAREs classified in the group of Qb and Qc are more divergent, and only few structures are known. Vtilp is a Qb SNARE and the function of the N-terminal domain is completely unknown. The identification of structurally related regions in Tlg1p and Vtilp argue that the N-terminal regions of these nonsyntaxin SNAREs are likely to mediate equal inhibitory intramolecular interactions that regulate fusion. The $\mathrm{N}$-terminus of vtilb forms 3-helix bundles resembling syntaxin1, Sso1p and Vam3p but do not bind with the SNARE motif and has no influence on the assembly kinetics (Antonin et al., 2002a). In vitro liposome fusion assays of N-terminal truncated Pep12p/Tlg1p and Vti1p (111-216) with all of the potential v-SNAREs in yeast showed that the specificity of fusion is fully conserved in the absence of any of the N-terminal domains (Paumet et al., 2004). The removal of the N-terminal domains of Vtilp (1-118) and Tlg1p increases the fusion kinetics of the early endocytic/TGN complex and late endocytic complex in, in vitro liposome fusion assays (Paumet et al., 2005). In this study, vtilQ29RW79R, a mutant having two amino acid replacements in the amino terminal region ( 2 AA mutant) has been employed to study the function of the N-terminus of Vtilp. Vtilp has high content of $\alpha$-helices, $82.95 \%$ determined by PROF predictions of secondary structure of 
proteins. In vtiQ29RW79Rp, the predicted $\alpha$-helix content is $83.4 \%$, the increase in the $\alpha$ helix content is provided by the replacement of tryptophan at 79 with arginine which also created a phosphorylation site for cAMP- and cGMP-dependent protein kinase in the mutant Vtilp. vtilQ29RW79R is not a dominant negative mutation indicating that it does not sequester binding partners which are rate limiting.

A portion of the slightly overexpressed vti1Q29RW79Rp is localized to the ER. The fraction of ER localized vtilQ29RW79Rp increased upon shift to $37^{\circ} \mathrm{C}$. The $1 \mathrm{AA}$ mutants, vti1Q29Rp and vti1W79Rp are partially localized to the vacuole whereas the genomically integrated 2 AA mutant did not show a strong ER localization. But, when Vtilp-HA was slightly overexpressed, it did not localize to the ER. This gives a hint that the N-terminal domain might contain some signal for the localization of Vtilp. The $\mathrm{N}$ terminal extension of VAMP-4 contains a target signal for the TGN (Zeng et al., 2003). The N-terminal (longin) domain of rat Ykt6 is required for its sub-cellular particle localization (Hasegawa et al., 2003). The longin domain of the Vamp7p from Arabidopsis thaliana is necessary for its vacuolar and sub-cellular targeting (Uemura et al., 2005). However, further studies on the localization of the N-terminal truncations (which was difficult to analyze since the antiserum against Vtilp did not recognize the truncated versions) should give clear view of the role played by N-terminus in the localization of Vtilp. On the other hand, the stability of the proteins could give an indirect idea about their localization. The Vtilp is very stable and degraded by the vacuolar proteases whereas vtiQ29RW79Rp is highly unstable and requires polyubiquitination for its degradation. The N-terminus of the Vtilp might be responsible for the protein conformation or binding of the N-terminus with some stabilizing factor might have been disrupted, leading to instability of the mutant Vtilp. The N-terminal domain of Ykt6 forms a folded back conformation which is important for the stability of the protein (Tochio et al., 2001). The reason for the ER localization of CEN 2 AA mutant but not genomically integrated mutation, could be because of the slow exit kinetics of CEN 2AA mutant or there might be too much protein for the slow residual pathway. In other case, the degradation kinetics of the 2 AA mutant might have an effect on the localization. The $\mathrm{N}$-terminus of Vtilp might have signals for its localization and is required for the stability and proper degradation of Vtilp. 
The defect in the maturation of CPY but not ALP in vtilQ29RW79R cells demonstrates that the N-terminus of Vtilp is important for its function only in the traffic from the TGN to the prevacuole. Vtilp might interact with some regulatory proteins in the traffic from the TGN to the vacuole, which could be disturbed in the mutants, but this additional protein may not be needed in the ALP pathway. A comparable situation was found in vacuolar fusion, it was shown that the deletion of the $\mathrm{N}$-terminal domain of Vam3p resulted in significantly less vacuolar fusion because the $\mathrm{N}$-terminus was required to recruit the HOPS complex (an essential docking factor) and for coordinated docking (Laage and Ungermann, 2001). Since the N-terminal mutant Vtilp shows defects only in the CPY pathway, it again supports the fact that participation of additional proteins in vesicular targeting is necessary to provide the specificity for SNARE function and SNAREs do not have innate specificity (Dilcher et al., 2001; Fischer von Mollard et al., 1997; Lazar et al., 1997; Lupashin et al., 1997). The onset of the CPY sorting defect in $v t i 1 Q 29 R W 79 R$ cells is immediate upon shift to restrictive temperature. CPY transport to the vacuole is almost completely blocked in $10 \mathrm{~min}$ after shift to the restrictive temperature. Misfolding or mistargeting as fast mechanisms lower affinity with interaction partners. The half life of the mutant protein is longer than $2 \mathrm{~h}$ at $37^{\circ} \mathrm{C}$. This indicates that the CPY transport defect and the instability of vti1Q29RW79Rp are two different autonomous effects. Thus, the N-terminus of Vtilp may play multiple roles.

\subsection{Interaction of ENTH domain with SNARE proteins}

A full length ENTH domain protein called as enthoprotin or CLINT or epsinR (Hirst et al., 2003; Kalthoff et al., 2002; Mills et al., 2003; Wasiak et al., 2002) emerged as a potential interaction partner for vtilb. The N-terminus of vtilb interacted with ENTH domain of epsinR and also the interaction was specific that vtilb did not interact with other ENTH domains. So far, only two proteins binding to ENTH domains have been identified. The transcription factor PLZF interacts with ENTH domain of Epsin 1 which is present in the nucleus as an additional pool (Hyman et al., 2000). The cytoskeletal protein tubulin interacts with ENTH (epsin1 and epsinR) and ANTH (AP180, HIP1 and Hip1R) domains (Hussain et al., 2003). 


\subsubsection{Ent3p is a yeast ortholog of epsinR}

The further investigation showed that this interaction between a SNARE and an ENTH domain was conserved between mammals and yeast. The N-terminus of Vtilp interacted only with the ENTH domain of Ent3p among eight A/ENTH domain proteins in yeast. The following points indicate that Ent3p could be the yeast homolog of epsinR.

The BLAST searches of yeast protein sequences with ENTH domain of epsinR predicted that Ent3p is more related to it and only Ent3p shares sequence homologies with epsinR that extend even beyond the ENTH domain. Also, both proteins interact with AP-1 and the TGN adaptor proteins of the GGA family and colocalize with the clathrin-coated vesicles in the Golgi area and play a role in clathrin coated vesicle formation at the TGN or the endosomes (Duncan et al., 2003; Hirst et al., 2003; Kalthoff et al., 2002; Mills et al., 2003; Wasiak et al., 2002). ENTH domain of Ent3p is required for its membrane localization (Friant et al., 2003) like that of epsinR (Hirst et al., 2003). By liposome binding assay, I could demonstrate that Ent3p specifically binds PI3P and PI3,5P 2 which are regulators of the traffic from TGN to endosome and multivesicular body formation, respectively (Simonsen et al., 2001). But, Friant et al., showed that Ent3p binds only with $\mathrm{PI} 3,5 \mathrm{P}_{2}$ which could be because of the differences in the fusion protein. I used C-terminal Strep tagged ENTH domain which is better than the N-terminal GST tagged ENTH domain used by Friant group. The GST tag is large and since the tag is in the N-terminus, it might have blocked some binding sites in ENTH domain. The ENTH domain of epsinR interacted strongly with PI4P (Hirst et al., 2003; Kalthoff et al., 2002; Mills et al., 2003). But both PI3P and PI4P are present in the Golgi complex (De Matteis et al., 2002) which may substitute for each other to recruit Ent3p or epsinR to the same organelle. This difference in the phosphoinositide binding was predicted by the structural modeling of tertiary structure of the ENTH domains of Ent3p and epsinR with epsin1 ENTH. It showed that the phosphoinositide binding pocket of epsinR and Ent3p is different between each other (Duncan and Payne, 2003). From my study, it has been shown that Ent3p and Vti1p are involved in the TGN to endosome trafficking in yeast (Chidambaram et al., 2004). It is unclear in mammalian cells which SNAREs are involved in this pathway. The binding of vtilb with epsinR specifies that vtilb might be required for this route, supported by the finding that GGAs function in TGN to endosome traffic in mammalian cells (Hinners and Tooze, 2003) with which epsinR interacts. The deletion of 
ent3 in other mutant combinations leads to distorted vacuolar transport pathways, (Chidambaram et al., 2004; Duncan and Payne, 2003) parallel to the Cathepsin D processing phenotype observed in epsinR overexpressing mammalian cells (Mills et al., 2003).

\subsubsection{Role of Ent proteins in the TGN-endosome trafficking}

The overexpression of the C-terminus of the ENTH domain protein Epsin1 has a dominant negative effect on endocytosis in mammalian cells (Itoh et al., 2001). But overexpression of neither C-terminus of Ent3p nor the full length Ent3p demonstrated dominant negative effect in yeast cells. The defect in the CPY transport in ent $3 \Delta$, ent $3 \Delta e n t 4 \Delta$ and especially the synthetic defect in ent $3 \Delta e n t 5 \Delta$ cells showed that Ent $3 p$ is involved in CPY traffic and Ent3p and Ent5p are redundant proteins in this pathway. 83 $\%$ of CPY reached the vacuole even in ent $3 \Delta$ ent $5 \Delta$ cells indicating that other proteins can almost compensate for their loss. The synthetic defect of ENT3 in vtil-1 cells and of vtil2 cells demonstrates that VTII and ENT3 function together in TGN to endosome trafficking. This is in accord with the interaction between Gga2p and Ent3p (Black and Pelham, 2000) and the requirement for GGA proteins in traffic from the TGN to the prevacuole (Costaguta et al., 2001). Absence of Ent3p in vtilQ29RW79R cells also shows a synthetic defect in CPY pathway. ALP pathway is not affected in the single ent mutants

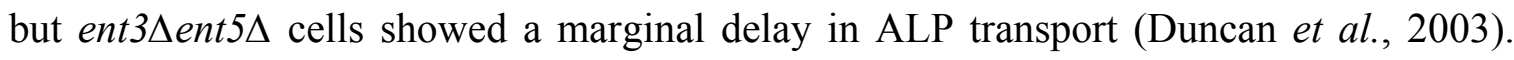
Slightly less mature ALP was found in the absence of Ent5p but not of Ent3p in vtil-2

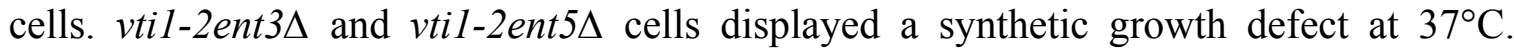
Temperature sensitive growth defects have been observed in the absence of proteins involved in different post Golgi transport steps. The synthetic defect in the CPY pathway may be the reason for the synthetic growth defect of $v$ til-2ent $3 \Delta$ cells. In $v$ til-2ent $5 \Delta$, the synthetic growth defect might be due to a small synthetic defect in the ALP pathway. ent $3 \Delta$ ent $5 \Delta$ cells secrete $\alpha$-factor precursor (Duncan et al., 2003). This processing of $\alpha$ factor precursor requires Kex $2 p$ in the TGN which might be lost in ent $3 \Delta$ ent $5 \Delta$ cells. The Kex $2 p$ recycles between the TGN and endosomes and the retrograde traffic to the TGN may be defective in ent $3 \Delta$ ent $5 \Delta$ cells. Hence it is likely that Ent5p might be required for the retrograde traffic to the TGN. This may be another reason for the growth defect in $v t i 1-2 e n t 5 \Delta$ cells. Recent study support this speculation by showing that epsinR is 
involved in the retrograde transport of exogenous Shiga toxin and two endogenous proteins TGN38/46 and mannose 6-phosphate receptors from early endosomes to the TGN (Saint-Pol et al., 2004). In contrary to this, the retrograde transport of A-ALP and Vps10p is not affected in ent $3 \Delta$, ent $5 \Delta$ and ent $3 \Delta$ ent $5 \Delta$ cells, stating that Ent proteins are not involved in the retrograde transport of at least these proteins in yeast. But still Ent5p might have cargo specificity for retrograde transport which has not been analyzed thoroughly or maybe Ent5p is involved in an unidentified pathway.

In addition to epsinR, there are a number of alternative adaptors on the AP-1 pathway whose role should be explored, like the $\gamma$ ear binding partners $\gamma$-synergin, p200 and aftiphilin which all form a complex and facilitate AP-1 function but additional roles await further investigation (Hirst et al., 2005). The same is true for the yeast AP-1 pathway adaptors Ent3p and especially Ent5p. Though Ent3p and Ent5p are redundant, different synthetic transport defects in vtil mutant backgrounds indicate that Ent3p and Ent5p have slightly different functions. The function of epsinR might be apportioned between Ent $3 p$ and Ent5p.

\subsubsection{Consequences of the interaction between ENTH domains and SNAREs}

The interaction between the ENTH domains of Ent3p/epsinR and SNAREs Vtilp/vtilb may be required for the sorting and recruitment of the SNAREs into budding vesicles. I could not substantiate this hypothesis by co-immunoprecipitating Ent3p with Vtilp or epsinR with vtilb, even after overexpressing the proteins. But it is common that interactions between adaptor proteins and cargo are often of low affinity and have to be very dynamic because the complexes have to dissociate after vesicle formation. Consequently, the binding between adaptor protein complexes and membrane receptors are hardly ever demonstrable by co-immunoprecipitations and have been studied almost exclusively using in vitro binding and yeast two-hybrid assays (Bonifacino and Dell'Angelica, 1999). An analogous adaptor-cargo interaction of UNC-11, a homolog of the ANTH protein AP180, with R-SNARE synaptobrevin was required for proper localization of synaptobrevin in Caenorhabditis elegans (Nonet et al., 1999). UNC-11 may directly recruit synaptobrevin into clathrin coated vesicles during endocytosis. It has been shown that SNAREs bind other components of the budding machinery like COPII coat proteins in ER to Golgi transport (Springer and Schekman, 1998) and adaptor 
complexes which couple cargo selection to clathrin recruitment. The mammalian RSNARE VAMP-4 interacts with AP-1 at the TGN (Peden et al., 2001). In yeast, the vacuolar syntaxin Vam3p binds AP-3 in transport from the TGN to the vacuole (Darsow et al., 1998). A complex of mammalian AP-3 and synaptobrevin mediates formation of synaptic vesicles from endosomes (Salem et al., 1998) indicating that incorporation of a SNARE can regulate vesicle budding. In ENTH proteins only the ubiquitin interaction motif has been implicated in cargo binding (Polo et al., 2002; Shih et al., 2002). This UIM motif is located outside of the ENTH domain in epsin family proteins and is absent from epsinR and Ent3p. From our data, we suggested that cargo sorting may be a novel function of the ENTH domain (Chidambaram et al., 2004). The findings are summarized in the Fig. 48 .

Recently, our hypothesis has been endorsed by the finding that epsinR is a cargo specific adaptor for vtilb (Hirst et al., 2004). Less vtilb was recruited into the clathrin coated vesicles isolated from epsinR (siRNA treated) depleted cells whereas vtila recruitment was unaffected. The depletion of epsinR caused redistribution of vtilb from the Golgi region to the cell periphery. Given the role of epsinR in the retrograde transport, it was proposed that epsinR might be required for the recycling of vtilb. But in my study, an alteration of the localization of Vti1p was not observed in the absence of Ent3p or Ent5p and the vice versa. In fact, it is certainly difficult to assess a small change in the distribution of Vti1p. In yeast, Golgi, TGN, early and late endosomal structures cannot be distinguished by their morphology. Vtilp is localized to all of these compartments. Vtilp uses the retrograde transport to achieve its proper steady-state localization. Loss of Pep12p should alter the localization of Vti1p but it could not be shown clearly because of the diffuse and punctuate localization of Vtilp (Gerrard et al., 2000a). Ent3p and Ent5p are shown to be important for ubiquitin dependent protein sorting into multivesicular body along with Vps27p (Eugster et al., 2004). This shows that Ent3p and Ent5p could do two different functions like transport from the TGN to the endosomes and sorting in the MVB. 


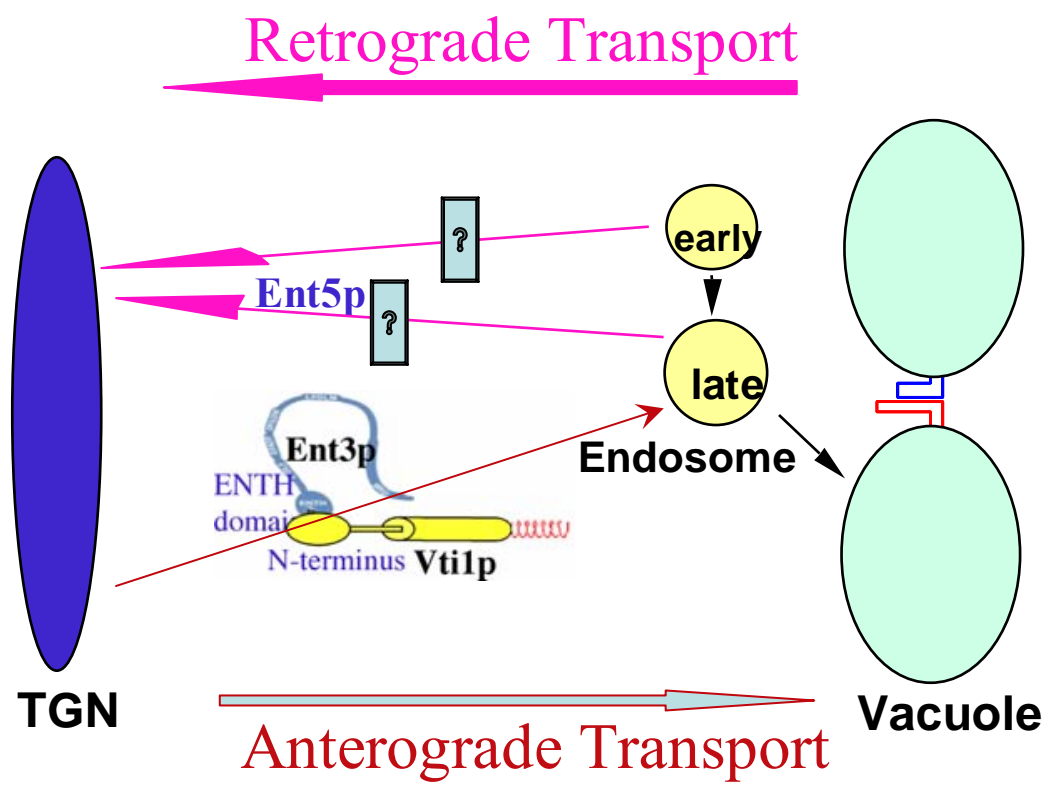

Fig.48. The ENTH domain of Ent3p and the N-terminus of Vtilp interact in the anterograde transport from the TGN to the late endosome. Ent5p may play a role in the retrograde transport from the endosome to the TGN.

\subsubsection{Characterization of ent mutants}

Subcellular fractionation and fluorescence microscopy studies in wt cells showed that Ent $3 p$ is a cytosolic protein with barely detectable association with small membrane structures and Ent5p is cytosolic with localization to punctuate structures, which was observed also by other groups (Eugster et al., 2004; Friant et al., 2003). The subcellular fractionation experiment underestimates the membrane pool and may dissociate during procedure. Interestingly, the membrane associated Ent5p was found predominantly in P200 while Ent3p was more prominent in P13 even though both proteins were largely cytosolic, indicating that Ent3p and Ent5p are localized to different compartments. The localization of Ent3p and Ent5p was not affected in vtil mutants. Vacuolar morphology and internalization of FM4-64 in ent $3 \Delta$, ent $5 \Delta$ and ent $3 \Delta e n t 5 \Delta$ cells are not affected. But

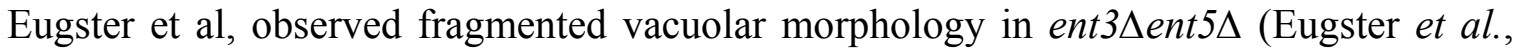
2004). This dissimilarity might be because of different yeast strain background.

The yeast cell wall consists of a complex structure of cross-linked chitin, $\beta-(1,3)-d-$ glucan, $\beta-(1,6)$-d-glucan and mannoproteins. Chitin and $\beta-(1,3)$-d-glucan are synthesiszed by enzymatic complexes at the cell membrane and extruded into the 
periplasmic space, mannoproteins are synthesized along the yeast secretory pathway and the site of $\beta$-(1, 6)-d-glucan synthesis is still unknown (Raclavsky, 1998). Among them, $\beta-(1,3)$-d-glucan is the main component responsible for the rigidity of yeast cells. $\beta-(1$, 3)-d-glucan synthase (GS) is responsible for synthesizing a major structural component of cell wall having Fks1p/Fks2p as its subunits and Rholp is required as an activator (Douglas et al., 1994; Drgonova et al., 1996). Chitin is mostly concentrated in the septal region although some is dispersed throughout the cell wall. Despite its small quantity, chitin is essential for yeast survival (Shaw et al., 1991). The primary and secondary septa are formed by the deposition of chitin on a chitin ring at the basis of an emerging bud. The daughter and the mother cells are separated by the action of a chitinase that partially hydrolyzes the primary septum. The three chitin synthases, CSI, CSII and CSIII have been identified in yeast (Cabib et al., 1996; Cid et al., 1995). Chs3p is the main player to synthesis chitin at the septum. Chs3p is synthesized at ER and Chs7p is required for its exit out from ER (Trilla et al., 1997). At the Golgi, Chs3p is associated with Chs5p (Santos et al., 1997). Chs5p and Chs6p (Ziman et al., 1998) are necessary for its transfer to the vesicles (chitosomes) that will carry Chs3p to the plasma membrane (Chuang and Schekman, 1996; Ziman et al., 1998). Chs3p may be retained in a ring like area at the base of an emerging bud with the putative activator Chs4p (DeMarini et al., 1997). The major chitin synthase, Chs3p clearly recycles through the TGN. It has been well established that this protein is recovered from the cell surface and dwells in an endocytic compartment before being delivered to the bud neck at the appropriate stage of the cell cycle (Chuang and Schekman, 1996; Ziman et al., 1998). The syntaxin SNARE, Tlg1p is necessary for the correct localization of Chs3p (Holthuis et al., 1998).

The ent $3 \Delta$ ent $5 \Delta$ cells showed abnormal cell shapes with branched cell morphology. But this effect was restricted only to $12.8 \%$ of cells at $30^{\circ} \mathrm{C}$ and $20 \%$ of cells at $18^{\circ} \mathrm{C}$. The abnormal cells have irregular chitin deposition and abnormal actin assembly, though nearly $80 \%$ of the cells are normal. But, the ent $3-1^{\text {ts }}$ mutant cells have an actin organization defect at the restrictive temperature and no defect at the permissive

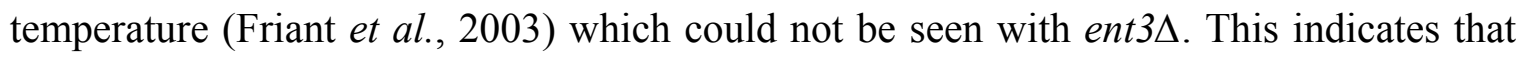
the ent $3-1^{\text {ts }}$ has a dominant negative defect. Since the SNARE Tlg1p is required for the transport of Chs3p, we suspected that Ent3p or Ent5p might interact with Tlg1p for the proper localization of Chs $3 p$ which might be distorted in the ent $3 \Delta$ ent $5 \Delta$ cells and so the 
septum might have not formed well, subsequently forming elongated and branched cell morphology. But no interaction was found in the two hybrid test between Ent3p and Ent5p with Tlg1p. Also, an effect on the localization of Chs3p was not observed in the mutants. This may be due to technical problems because the Chs3p-GFP localization was very heterogeneous. The $\beta-(1,3)$-d-glucan layer did not look different in the mutants stained with aniline blue. The defects in chitin and actin localization are interdependent. The actin cytoskeleton and polarity establishment proteins also participate in the organization of chitin in the cell wall. The mutants defective in actin display an altered pattern of chitin deposition in which chitin is present over the whole cell surface and is no longer restricted to the bud neck (Novick and Botstein, 1985). There is a correlation between actin delocalization and altered chitin deposition in polarity and bud emergence mutants like $c d c 24$ (Sloat et al., 1981), cdc42 and cdc43 (Adams et al., 1990). The heterogeneous aberration of cell shape in ent $3 \Delta$ ent $5 \Delta$ cells may not be a direct effect of loss of Ent proteins. The general defect by ent $3 \Delta e n t 5 \Delta$ in the intracellular transport may lead to loss of some components necessary for the biosynthesis of cell wall. For example, it has been shown that the loss of phosphatidic acid phosphatases in yeast caused abnormal cell shapes, aggregation and abnormal phenotypes in cell growth (Katagiri and Shinozaki, 1998). But a very clear defect in the cell wall of ent $3 \Delta e n t 5 \Delta$ cells is revealed by its sensitivity to many cell wall perturbing agents like $\mathrm{NaCl}$, SDS, calcofluor and zymolyase, demonstrating that the structure of the cell wall is altered. The combinations of ent $3 \Delta$ are very sensitive to $\mathrm{NaCl}, \mathrm{SDS}$ and calcofluor whereas ent $5 \Delta$ is more resistant to zymolyase, indicating that Ent proteins may have different roles on assembly of the cell wall. Although, Ent proteins show an obvious link with the defects in the organization of the cell wall, these observations are more difficult to explain.

\subsubsection{Ent3p is required for the anterograde transport of Pep12p and vti1-2p}

Apart from the interaction of Ent3p with Vtilp, it binds also with other endosomal QSNAREs Pep12p and Syn8p (to the N-terminus) which are present in the same SNARE complex. A two hybrid interaction was not observed between Ent3p and the R-SNARE Ykt6p in the complex. The N-terminus of Ykt6p is different from that of the other QSNAREs which explains for the absence of interaction. Crystal structure of the Nterminus of Ykt6p revealed five $\beta$-sheet strands, which are sandwiched by one $\alpha$-helix on 
one side and two $\alpha$-helices on the other side (Tochio et al., 2001). These interactions with three SNAREs of the same complex are very remarkable, suggesting that Ent3p may interact with individual SNAREs to recruit them into the vesicles or may help them in tethering. Otherwise, it may interact with the self assembled SNARE complex to regulate the core complex formation. The N-terminal domains of SNARE proteins are likely to be involved in controlling the rate of the complex formation and fusion (Antonin et al., 2002a; Dulubova et al., 2001; Misura et al., 2002; Tochio et al., 2001). In this respect, additional regulatory proteins may contribute to influence the effect of the $\mathrm{N}$-terminal domains of SNAREs (Paumet et al., 2004).

The degree of co-immunoprecipitation between the endosomal SNAREs Pep12p and Vti1p is not altered in ent $3 \Delta$ ent $5 \Delta$ cells. The localization of Pep12p is not changed in the ent mutants. The localization of Ent $3 p$ should be checked in pep12 $\Delta$ cells. By contrast to synthetic defects in vtil-2ent5 cells, a genetic interaction between PEP12 and ENT5 was

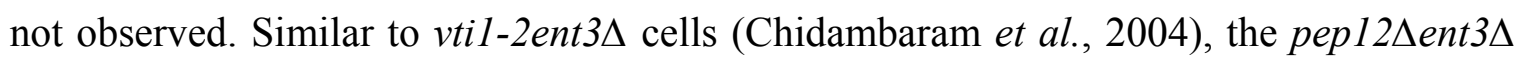
and pep $12 \Delta$ ent $3 \Delta$ ent $5 \Delta$ cells show synthetic growth defect at $37^{\circ} \mathrm{C}$, establishing the genetic interaction between ENT3 and PEP12. In addition, these cells were sensitive to high salt, relating them to the cell wall defects. Intriguingly, Pep12p is stabilized in the absence of Ent3p. In the absence of Ent3p and Ent5p, the stabilization is moderate, may be because of the epistatic effect of Ent5p. Ent3p might be required for the forward transport of Pep12p from the TGN to the endosome. In the absence of Ent3p, the anterograde transport of Pep12p might be blocked and it may get accumulated in the TGN which causes the increased stability (Fig.49).

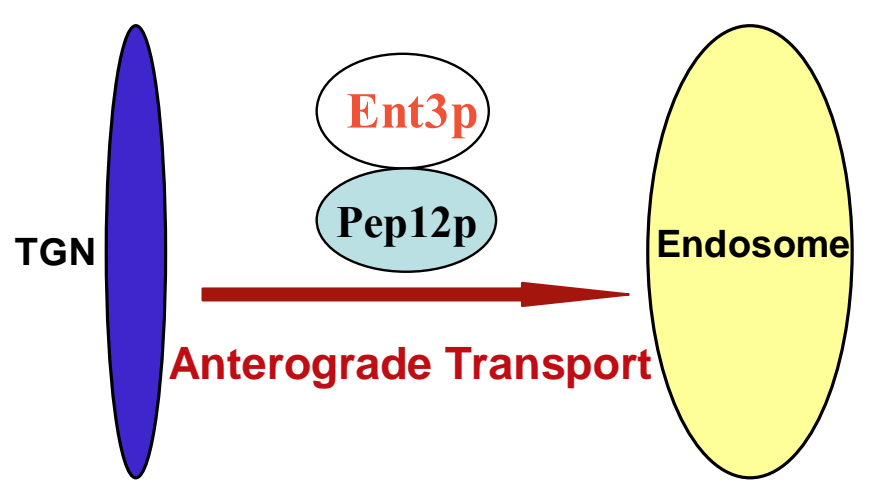

Fig.49. Ent $3 p$ is required for the anterograde transport of Pep12p from the TGN to the endosome. 
The same effect was observed for vti1-2p in the absence of Ent $3 p$ and in turn, vti1-2p was destabilized in the lack of Ent5p. This gives rise to a model that Ent3p may be important for the anterograde transport of vti1-2p and a block in this transport caused increased stability of vti1-2p by accumulating it in the TGN. When the retrograde transport of vti1$2 \mathrm{p}$ mediated by Ent5p is interrupted, it is destabilized by degradatative vacuolar proteases when it gets accumulated in the endosome. As the stability of Vtilp was not altered by the Ent proteins, this hypothesis could not be proved for Vtilp. In vtil-2 cells, general protein transport is impaired which might exert some secondary effects on the stability of vti1-2p. But still the stability and the instability of vti1-2p are very specific to the loss of Ent $3 p$ and Ent5p respectively. Unless there is some role played by the Ent proteins, this effect could not be so specific. It may be that it is a complex or combined effect and could not be observed only in the absence of Ent proteins, but needs to down regulate the function of Vtilp also. Ent3p and Ent5p are not essential for the transport of Vtilp. On the other hand, the Ent proteins may be involved in the transport of Vtilp but the loss can be compensated by other proteins. But in the case of vti1-2p, it may not be able to bind the compensatory proteins in the absence of Ent proteins.

\subsubsection{Role of Ent proteins in processing of pApe1p}

The ent3s cells are defective in CVT pathway which accumulated more pro aminopeptidase I in the $\log$ phase whereas ent $3 \Delta$ ent5 5 cells show a rescue effect. Autophagy is not affected in ent mutants. It could be that the absence of Ent $3 p$ may prevent the fusion of Cvt vesicles with vacuoles through Vtilp. An indirect effect due to a delay or defect in vacuolar processing may also show a defect in the maturation of Ape1p. Some vps mutants are essentially wild type for Apelp processing while others are strongly blocked showing a secondary effect (Klionsky et al., 1992; Scott and Klionsky, 1995). One more possibility is that a putative lipase Cvt17/Aut5p is essential for intravacuolar lysis of autophagic bodies. The transport of Aut5p from the TGN to the endosome could be affected in the ent $3 \Delta$ cells. Aut5p is targeted via the multivesicular body pathway to intravacuolar MVB vesicles by ubiquitin independent manner (Epple et al., 2003). Ent3p is required for the ubiquitin dependent internalization of cargo into MVB, though it could not interact directly with ubiquitin (Friant et al., 2003). Ent3p might be required for the internalization of Aut5p to process the pApe1p inside the 
vacuole. Ape $1 \mathrm{p}$ is recruited onto Cvt membrane and the Cvt vesicle is formed by homotypic membrane fusion which depends on the SNARE Tlg2p and Vps45p (Abeliovich et al., 1999). Ent3p could be needed for this step.

\subsection{Outlook}

The 2 AA mutations and the N-terminal truncations of Vtilp are helpful tools to study the function of N-terminus. Further studies should be done to find out whether the kinetics of assembly and the amounts of the SNARE complex are altered in vivo by the N-terminus of Vtilp and its mammalian homologs. It should be thoroughly investigated if the Nterminus contains some targeting signal. The ALP pathway in the truncations and their localization should be studied. It would be interesting to study if ERAD (ER associated degradation) machinery is involved in the degradation of vtiQ29RW79Rp.

It would be exciting to study whether the ENTH domain binding to the phophoinositides or Vtilp is competitive, cooperative or independent of each other by BIACORE analysis. The budding pattern and the localization of Bud proteins in the ent $3 \Delta$ ent $5 \Delta$ cells could be analyzed. It would be interesting to study the rescue factors for Apelp processing in ent $3 \Delta$ ent $5 \Delta$ cells. The presence of Ent $3 p$ on autophagosomes could be checked to show if the defect is a direct or a secondary effect. 



\section{Summary}

The main aim of the study was to elucidate the function and to find out the interaction partners of the N-terminus of Vtilp.

Immunofluorescence studies localized the mutant Vtilp to the ER pointing out that the Nterminus might have some targeting signal. Pulse chase immunoprecipitations showed that the N-terminus was required for the function of Vtilp in the traffic from the TGN to the endosome and was essential for the stability of the protein as well. The mutant Vtilp was not degraded by the vacuolar proteases. Degradation of mutant Vtilp necessitates the addition of polyubiquitin whereas the wild type Vtilp was degraded by the vacuolar degradation pathway. All these data indicate that the $\mathrm{N}$-terminus could play multiple roles in the targeting, stability and the function of Vtilp.

A yeast two-hybrid screen was done to discover interaction partners of the $\mathrm{N}$-terminus of vtilb. The N-terminus of vtilb interacted specifically with the ENTH domain of enthoprotin/CLINT/epsinR. Further analysis showed that this interaction between a SNARE and an ENTH domain was conserved between mammals and yeast. Yeast Vtilp interacted with the ENTH domain of Ent3p. The studies demonstrated that Ent3p could be the yeast homolog of epsinR. Liposome binding assays showed that the ENTH domain of Ent3p specifically binds with PI3P and PI3,5P 2 . Ent3p was involved in the CPY transport and was redundant with Ent5p. The Genetic interactions between VTI1 and ENT3 were investigated by pulse chase analyses. Synthetic defects suggested that Vtilp and Ent3p cooperate in transport from the TGN to the prevacuolar endosome.

Subcellular localization and fluorescence studies showed that Ent3p was more cytosolic and less associated with small membranes and Ent5p was localized to the cytosol and to small membranes. The localization of Ent proteins were not affected in the vtil mutants and vice versa. The overexpression of Ent3p did not show a dominant negative effect.

About $20 \%$ of the ent $3 \Delta$ ent $5 \Delta$ cells showed abnormal cell shape, disturbed actin assembly and irregular distribution of chitin. A mislocalization of chitin synthase III was not observed. Staining of the $\beta-(1,3)$-glucan layer was also not altered in the mutants. The ent $3 \Delta$ and ent $5 \Delta$ mutants exhibited different cell wall defects demonstrating that Ent3p and Ent5p may have different role on the assembly of the cell wall. 
The study was extended to identify Pep12p and Syn8p as further SNARE partners of Ent3p. Synthetic growth defects demonstrated the genetic interaction between Ent3p and Pep12p. Studies on stability of Pep12p inferred that Ent3p is required for the anterograde transport of Pep12p from the TGN to the endosome. For the recycling of vti1-2p, Ent $3 p$ and Ent5p were required. The retrograde transport of Vps10p and A-ALP from the endosomes to the TGN was not affected in the ent deletions. Also the amount of Pep12p

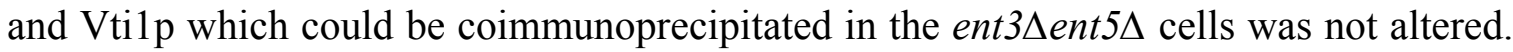
Further analysis showed that Ent3p may have a role in the CVT pathway.

This study identified the first cytoplasmic protein binding to a specific ENTH domain. The results revealed a novel function of the ENTH domain and a connection between proteins which function either in vesicle formation or in vesicle fusion. 


\section{Bibliography}

Abeliovich, H., T. Darsow and S. D. Emr (1999). "Cytoplasm to vacuole trafficking of aminopeptidase I requires a t-SNARE-Sec1p complex composed of Tlg2p and Vps45p.” EMBO J. 18(21): 6005-6016.

Adams, A. E., D. I. Johnson, R. M. Longnecker, B. F. Sloat and J. R. Pringle (1990). "CDC42 and CDC43, two additional genes involved in budding and the establishment of cell polarity in the yeast Saccharomyces cerevisiae.” J Cell Biol 111(1): 131-42.

Aguilar, R. C., H. A. Watson and B. Wendland (2003). "The yeast Epsin Ent1 is recruited to membranes through multiple independent interactions.” J Biol Chem 278(12): 10737-43.

Antonin, W., I. Dulubova, D. Arac, S. Pabst, J. Plitzner, J. Rizo and R. Jahn (2002a). "The N-terminal Domains of Syntaxin 7 and vtilb Form Three-helix Bundles That Differ in Their Ability to Regulate SNARE Complex Assembly.” J. Biol. Chem. 277(39): 36449-36456.

Antonin, W., D. Fasshauer, S. Becker, R. Jahn and T. R. Schneider (2002b). "Crystal structure of the endosomal SNARE complex reveals common structural principles of all SNAREs." Nat Struct Biol 9(2): 107-11.

Antonin, W., C. Holroyd, D. Fasshauer, S. Pabst, G. F. Von Mollard and R. Jahn (2000a). "A SNARE complex mediating fusion of late endosomes defines conserved properties of SNARE structure and function.” Embo J 19(23): 6453-64. 
Antonin, W., C. Holroyd, R. Tikkanen, S. Honing and R. Jahn (2000b). "The RSNARE endobrevin/VAMP-8 mediates homotypic fusion of early endosomes and late endosomes." Mol Biol Cell 11(10): 3289-98.

Antonin, W., D. Riedel and G. F. von Mollard (2000c). "The SNARE Vtila-beta is localized to small synaptic vesicles and participates in a novel SNARE complex." J Neurosci 20(15): 5724-32.

Atlashkin, V., V. Kreykenbohm, E. L. Eskelinen, D. Wenzel, A. Fayyazi and G. Fischer von Mollard (2003). "Deletion of the SNARE vtilb in mice results in the loss of a single SNARE partner, syntaxin 8." Mol Cell Biol 23(15): 5198-207.

Baba, M., M. Osumi, S. V. Scott, D. J. Klionsky and Y. Ohsumi (1997). "Two distinct pathways for targeting proteins from the cytoplasm to the vacuole/lysosome.” $\underline{J}$ Cell Biol 139(7): 1687-95.

Barlowe, C. (1997). “Coupled ER to Golgi transport reconstituted with purified cytosolic proteins.” J Cell Biol 139(5): 1097-108.

\section{Barlowe, C., L. Orci, T. Yeung, M. Hosobuchi, S. Hamamoto, N. Salama, M. F.} Rexach, M. Ravazzola, M. Amherdt and R. Schekman (1994). "COPII: a membrane coat formed by Sec proteins that drive vesicle budding from the endoplasmic reticulum.” Cell 77(6): 895-907.

Becherer, K. A., S. E. Rieder, S. D. Emr and E. W. Jones (1996). "Novel syntaxin homologue, Pep12p, required for the sorting of lumenal hydrolases to the lysosome-like vacuole in yeast." Mol Biol Cell 7(4): 579-94.

Black, M. W. and H. R. Pelham (2000). "A selective transport route from Golgi to late endosomes that requires the yeast GGA proteins." J Cell Biol 151(3): 587-600.

Blobel, G. (1980). “Intracellular protein topogenesis.” Proc Natl Acad Sci U S A 77(3): 1496-500. 
Bock, J. B., H. T. Matern, A. A. Peden and R. H. Scheller (2001). "A genomic perspective on membrane compartment organization." Nature 409(6822): 839-41.

Boehm, M. and J. S. Bonifacino (2001). “Adaptins: the final recount.” $\underline{\text { Mol Biol Cell }}$ 12(10): 2907-20.

Boehm, M. and J. S. Bonifacino (2002). "Genetic analyses of adaptin function from yeast to mammals." Gene 286(2): 175-86.

Boman, A. L., C. Zhang, X. Zhu and R. A. Kahn (2000). "A family of ADPribosylation factor effectors that can alter membrane transport through the transGolgi." Mol Biol Cell 11(4): 1241-55.

Bonifacino, J. S. and E. C. Dell'Angelica (1999). "Molecular bases for the recognition of tyrosine-based sorting signals.” J Cell Biol 145(5): 923-6.

Bonifacino, J. S. and A. M. Weissman (1998). "Ubiquitin and the control of protein fate in the secretory and endocytic pathways.” Annu Rev Cell Dev Biol 14: 19-57.

Brickner, J. H., J. M. Blanchette, G. Sipos and R. S. Fuller (2001). "The Tlg SNARE complex is required for TGN homotypic fusion.” J. Cell Biol. 155(6): 969-978.

Bryant, N. J. and T. H. Stevens (1998). "Vacuole biogenesis in Saccharomyces cerevisiae: protein transport pathways to the yeast vacuole." Microbiol Mol Biol Rev 62(1): 230-47.

Burri, L. and T. Lithgow (2004). "A complete set of SNAREs in yeast." Traffic 5(1): 45-52.

Cabib, E., J. A. Shaw, P. C. Mol, B. Bowers and W. Choi (1996). The mycota Vol III: 243-267. 
Cao, X., N. Ballew and C. Barlowe (1998). "Initial docking of ER-derived vesicles requires Usolp and Yptlp but is independent of SNARE proteins." Embo J 17(8): 2156-65.

Cereghino, J. L., E. G. Marcusson and S. D. Emr (1995). “The cytoplasmic tail domain of the vacuolar protein sorting receptor Vps10p and a subset of VPS gene products regulate receptor stability, function, and localization." Mol Biol Cell 6(9): 1089102.

Chapman, E. R., S. An, N. Barton and R. Jahn (1994). "SNAP-25, a t-SNARE which binds to both syntaxin and synaptobrevin via domains that may form coiled coils." J Biol Chem 269(44): 27427-32.

Cheever, M. L., T. K. Sato, T. de Beer, T. G. Kutateladze, S. D. Emr and M. Overduin (2001). "Phox domain interaction with PtdIns(3)P targets the Vam7 tSNARE to vacuole membranes." Nat Cell Biol 3(7): 613-8.

Chen, H., S. Fre, V. I. Slepnev, M. R. Capua, K. Takei, M. H. Butler, P. P. Di Fiore and P. De Camilli (1998). "Epsin is an EH-domain-binding protein implicated in clathrin-mediated endocytosis.” Nature 394(6695): 793-7.

Chen, Y. A. and R. H. Scheller (2001). "SNARE-mediated membrane fusion.” Nat Rev Mol Cell Biol 2(2): 98-106.

\section{Chidambaram, S., N. Mullers, K. Wiederhold, V. Haucke and G. F. von Mollard} (2004). "Specific interaction between SNAREs and epsin N-terminal homology $(\mathrm{ENTH})$ domains of epsin-related proteins in trans-Golgi network to endosome transport." J Biol Chem 279(6): 4175-9.

Chuang, J. S. and R. W. Schekman (1996). "Differential trafficking and timed localization of two chitin synthase proteins, Chs $2 p$ and Chs3p." J Cell Biol 135(3): 597-610. 
Cid, V., A. Duran, d. R. F., M. Snyder, C. Nombela and M. Sanchez (1995).

"Molecular basis of cell integrity and morphogenesis in Saccharomyces cerevisiae." Microbiol Rev. 59(3): 345-86.

Clague, M. J. (1999). “Membrane transport: Take your fusion partners.” Curr Biol 9(7): R258-60.

Conibear, E. and T. H. Stevens (1998). "Multiple sorting pathways between the late Golgi and the vacuole in yeast." Biochim Biophys Acta 1404(1-2): 211-30.

Cooper, A. A. and T. H. Stevens (1996). "Vps10p cycles between the late-Golgi and prevacuolar compartments in its function as the sorting receptor for multiple yeast vacuolar hydrolases." J Cell Biol 133(3): 529-41.

Costaguta, G., C. J. Stefan, E. S. Bensen, S. D. Emr and G. S. Payne (2001). "Yeast Gga coat proteins function with clathrin in Golgi to endosome transport." $\mathrm{Mol}$ Biol Cell 12(6): 1885-96.

Coux, O., K. Tanaka and A. L. Goldberg (1996). "Structure and functions of the 20S and 26S proteasomes.” Annu Rev Biochem 65: 801-47.

Cowles, C. R., G. Odorizzi, G. S. Payne and S. D. Emr (1997a). "The AP-3 adaptor complex is essential for cargo-selective transport to the yeast vacuole." Cell 91(1): 109-18.

Cowles, C. R., W. B. Snyder, C. G. Burd and S. D. Emr (1997b). "Novel Golgi to vacuole delivery pathway in yeast: identification of a sorting determinant and required transport component." Embo J 16(10): 2769-82.

Cremona (1999). "Essential role of phosphoinositide metabolism in synaptic vesicle recycling." Cell 99(2): 179-88. 
Darsow, T., C. G. Burd and S. D. Emr (1998). "Acidic di-leucine motif essential for AP-3-dependent sorting and restriction of the functional specificity of the Vam3p vacuolar t-SNARE.” J Cell Biol 142(4): 913-22.

Darsow, T., S. E. Rieder and S. D. Emr (1997). “A multispecificity syntaxin homologue, Vam3p, essential for autophagic and biosynthetic protein transport to the vacuole." J Cell Biol 138(3): 517-29.

de Camili, P., H. Chen, J. Hyman, E. Panepucci, A. Bateman and A. Brunger (2002). “The ENTH domain.” FEBS Lett 513(1): 11-8.

De Matteis, M., A. Godi and D. Corda (2002). "Phosphoinositides and the Golgi complex." Curr Opin Cell Biol 14(4): 434-47.

De Nobel, J. G., F. M. Klis, A. Ram, H. Van Unen, J. Priem, T. Munnik and H. Van Den Ende (1991). "Cyclic variations in the permeability of the cell wall of Saccharomyces cerevisiae." Yeast 7(6): 589-98.

Dell'Angelica, E. C., J. Klumperman, W. Stoorvogel and J. S. Bonifacino (1998). “Association of the AP-3 adaptor complex with clathrin." Science 280(5362): 4314.

Dell'Angelica, E. C., C. Mullins and J. S. Bonifacino (1999). “AP-4, a novel protein complex related to clathrin adaptors." J Biol Chem 274(11): 7278-85.

Dell'Angelica, E. C., R. Puertollano, C. Mullins, R. C. Aguilar, J. D. Vargas, L. M. Hartnell and J. S. Bonifacino (2000). "GGAs: a family of ADP ribosylation factor-binding proteins related to adaptors and associated with the Golgi complex." J Cell Biol 149(1): 81-94. 
DeMarini, D. J., A. E. Adams, H. Fares, C. De Virgilio, G. Valle, J. S. Chuang and J. R. Pringle (1997). "A septin-based hierarchy of proteins required for localized deposition of chitin in the Saccharomyces cerevisiae cell wall." J Cell Biol 139(1): 75-93.

Dilcher, M., B. Kohler and G. F. von Mollard (2001). "Genetic interactions with the yeast Q-SNARE VTI1 reveal novel functions for the R-SNARE YKT6.” J Biol Chem 276(37): 34537-44.

Douglas, C. M., F. Foor, J. A. Marrinan, N. Morin, J. B. Nielsen, A. M. Dahl, P. Mazur, W. Baginsky, W. Li, M. el-Sherbeini and et al. (1994). "The Saccharomyces cerevisiae FKS1 (ETG1) gene encodes an integral membrane protein which is a subunit of 1,3-beta-D-glucan synthase." Proc Natl Acad Sci U S A 91(26): 12907-11.

Drake, M. T. and L. M. Traub (2001). "Interaction of two structurally distinct sequence types with the clathrin terminal domain beta-propeller." J Biol Chem 276(31): 28700-9.

Drgonova, J., T. Drgon, K. Tanaka, R. Kollar, G. C. Chen, R. A. Ford, C. S. Chan, Y. Takai and E. Cabib (1996). "Rholp, a yeast protein at the interface between cell polarization and morphogenesis." Science 272(5259): 277-9.

\section{Dulubova, I., S. Sugita, S. Hill, M. Hosaka, I. Fernandez, T. C. Sudhof and J. Rizo} (1999). "A conformational switch in syntaxin during exocytosis: role of munc18." Embo J 18(16): 4372-82.

Dulubova, I., T. Yamaguchi, Y. Wang, T. C. Sudhof and J. Rizo (2001). "Vam3p structure reveals conserved and divergent properties of syntaxins." Nat Struct Biol 8(3): 258-64. 
Dumas, J. J., E. Merithew, E. Sudharshan, D. Rajamani, S. Hayes, D. Lawe, S. Corvera and D. G. Lambright (2001). "Multivalent endosome targeting by homodimeric EEA1.” Mol Cell 8(5): 947-58.

Duncan, M. C., G. Costaguta and G. S. Payne (2003). "Yeast epsin-related proteins required for Golgi-endosome traffic define a gamma-adaptin ear-binding motif.” Nat Cell Biol 5(1): 77-81.

Duncan, M. C. and G. S. Payne (2003). "ENTH/ANTH domains expand to the Golgi." Trends Cell Biol 13(5): 211-5.

Elorza, M. V., H. Rico and R. Sentandreu (1983). "Calcofluor white alters the assembly of chitin fibrils in Saccharomyces cerevisiae and Candida albicans cells.” J Gen Microbiol 129(5): 1577-82.

Epple, U. D., E. L. Eskelinen and M. Thumm (2003). "Intravacuolar membrane lysis in Saccharomyces cerevisiae. Does vacuolar targeting of Cvt17/Aut5p affect its function?" J Biol Chem 278(10): 7810-21.

Eugster, A., E. I. Pecheur, F. Michel, B. Winsor, F. Letourneur and S. Friant (2004). "Ent5p is required with Ent3p and Vps27p for ubiquitin-dependent protein sorting into the multivesicular body." Mol Biol Cell 15(7): 3031-41.

Fasshauer, D., W. Antonin, M. Margittai, S. Pabst and R. Jahn (1999). "Mixed and non-cognate SNARE complexes. Characterization of assembly and biophysical properties." J Biol Chem 274(22): 15440-6.

Fasshauer, D., R. B. Sutton, A. T. Brunger and R. Jahn (1998). "Conserved structural features of the synaptic fusion complex: SNARE proteins reclassified as Q- and RSNAREs.” Proc Natl Acad Sci U S A 95(26): 15781-6. 
Fischer von Mollard, G., S. F. Nothwehr and T. H. Stevens (1997). "The yeast vSNARE Vtilp mediates two vesicle transport pathways through interactions with the t-SNAREs Sed5p and Pep12p.” Journal of Cell Biology 137(7): 1511-1524.

Fischer von Mollard, G. and T. H. Stevens (1998). "A human homolog can functionally replace the yeast vesicle-associated SNARE Vtilp in two vesicle transport pathways." J Biol Chem 273(5): 2624-30.

Fischer von Mollard, G. and T. H. Stevens (1999). "The Saccharomyces cerevisiae vSNARE Vtilp is required for multiple membrane transport pathways to the vacuole." Mol Biol Cell 10(6): 1719-32.

Ford, M. G., I. G. Mills, B. J. Peter, Y. Vallis, G. J. Praefcke, P. R. Evans and H. T. McMahon (2002). "Curvature of clathrin-coated pits driven by epsin.” Nature 419(6905): 361-6.

Ford, M. G., B. M. Pearse, M. K. Higgins, Y. Vallis, D. J. Owen, A. Gibson, C. R. Hopkins, P. R. Evans and H. T. McMahon (2001). "Simultaneous binding of PtdIns(4,5)P2 and clathrin by AP180 in the nucleation of clathrin lattices on membranes." Science 291(5506): 1051-5.

Friant, S., E. I. Pecheur, A. Eugster, F. Michel, Y. Lefkir, D. Nourrisson and F. Letourneur (2003). "Ent3p Is a PtdIns(3,5)P2 effector required for protein sorting to the multivesicular body." Dev Cell 5(3): 499-511.

\section{Fukuda, R., J. A. McNew, T. Weber, F. Parlati, T. Engel, W. Nickel, J. E. Rothman} and T. H. Sollner (2000). "Functional architecture of an intracellular membrane tSNARE." Nature 407(6801): 198-202.

Gerrard, S. R., B. P. Levi and T. H. Stevens (2000a). "Pep12p is a multifunctional yeast syntaxin that controls entry of biosynthetic, endocytic and retrograde traffic into the prevacuolar compartment." Traffic 1(3): 259-69. 
Gerrard, S. R., A. B. Mecklem and T. H. Stevens (2000b). "The Yeast Endosomal tSNARE, Pep12p, Functions in the Absence of its Transmembrane Domain." Traffic 1(1): 45-55.

Gerst, J. E. (1997). "Conserved alpha-helical segments on yeast homologs of the synaptobrevin/VAMP family of v-SNAREs mediate exocytic function.” J Biol Chem 272(26): 16591-8.

Gonzalo, S., W. K. Greentree and M. E. Linder (1999). "SNAP-25 is targeted to the plasma membrane through a novel membrane-binding domain.” J Biol Chem 274(30): 21313-8.

Götte, M. and G. F. von Mollard (1998). “A new beat for the SNARE drum.” Trends Cell Biol 8(6): 215-8.

Gruenberg, J. and K. E. Howell (1989). "Membrane traffic in endocytosis: insights from cell-free assays." Annu Rev Cell Biol 5: 453-81.

Hanson, P. I., R. Roth, H. Morisaki, R. Jahn and J. E. Heuser (1997). "Structure and conformational changes in NSF and its membrane receptor complexes visualized by quick-freeze/deep-etch electron microscopy." Cell 90(3): 523-35.

Hasegawa, H., S. Zinsser, Y. Rhee, E. O. Vik-Mo, S. Davanger and J. C. Hay (2003). "Mammalian ykt6 is a neuronal SNARE targeted to a specialized compartment by its profilin-like amino terminal domain.” Mol Biol Cell 14(2): 698-720.

Hess, D. T., T. M. Slater, M. C. Wilson and J. H. Skene (1992). "The $25 \mathrm{kDa}$ synaptosomal-associated protein SNAP-25 is the major methionine-rich polypeptide in rapid axonal transport and a major substrate for palmitoylation in adult CNS.” J Neurosci 12(12): 4634-41.

Hinners, I. and S. A. Tooze (2003). "Changing directions: clathrin-mediated transport between the Golgi and endosomes.” J Cell Sci 116(5): 763-771. 
Hinshaw, J. E. and S. L. Schmid (1995). "Dynamin self-assembles into rings suggesting a mechanism for coated vesicle budding." Nature 374(6518): 190-2.

Hirst, J., G. H. Borner, M. Harbour and M. S. Robinson (2005). “The Aftiphilin/p200/ \{gamma\}-Synergin Complex.” Mol Biol Cell 16(5): 2554-65.

Hirst, J., M. R. Lindsay and M. S. Robinson (2001). "GGAs: roles of the different domains and comparison with AP-1 and clathrin." Mol Biol Cell 12(11): 3573-88.

\section{Hirst, J., W. W. Lui, N. A. Bright, N. Totty, M. N. Seaman and M. S. Robinson} (2000). "A family of proteins with gamma-adaptin and VHS domains that facilitate trafficking between the trans-Golgi network and the vacuole/lysosome." J Cell Biol 149(1): 67-80.

Hirst, J., S. E. Miller, M. J. Taylor, G. F. von Mollard and M. S. Robinson (2004). "EpsinR is an adaptor for the SNARE protein Vtilb." Mol Biol Cell 15(12): 5593602.

Hirst, J., A. Motley, K. Harasaki, S. Y. Peak Chew and M. S. Robinson (2003). "EpsinR: an ENTH Domain-containing Protein that Interacts with AP-1.” Mol. Biol. Cell 14(2): 625-641.

Holthuis, J. C., B. J. Nichols, S. Dhruvakumar and H. R. Pelham (1998). "Two syntaxin homologues in the TGN/endosomal system of yeast." Embo J 17(1): 113 26.

Huang, W. P. and D. J. Klionsky (2002). "Autophagy in yeast: a review of the molecular machinery." Cell Struct Funct 27(6): 409-20.

Hughson, F. M. (1997). "Enveloped viruses: a common mode of membrane fusion?" Curr Biol 7(9): R565-9. 
Hurley, J. H. and B. Wendland (2002). "Endocytosis: driving membranes around the bend." Cell 111(2): 143-6.

Hussain, N. K., M. Yamabhai, A. L. Bhakar, M. Metzler, S. S. G. Ferguson, M. R. Hayden, P. S. McPherson and B. K. Kay (2003). “A Role for Epsin N-terminal Homology/AP180 N-terminal Homology (ENTH/ANTH) Domains in Tubulin Binding.” J. Biol. Chem. 278(31): 28823-28830.

Hussain, N. K., M. Yamabhai, A. R. Ramjaun, A. M. Guy, D. Baranes, J. P. O'Bryan, C. J. Der, B. K. Kay and P. S. McPherson (1999). "Splice variants of intersectin are components of the endocytic machinery in neurons and nonneuronal cells." J Biol Chem 274(22): 15671-7.

Hyman, J., H. Chen, P. P. Di Fiore, P. De Camilli and A. T. Brunger (2000). "Epsin 1 undergoes nucleocytosolic shuttling and its eps 15 interactor $\mathrm{NH}(2)$-terminal homology (ENTH) domain, structurally similar to Armadillo and HEAT repeats, interacts with the transcription factor promyelocytic leukemia $\mathrm{Zn}(2)+$ finger protein (PLZF).” J Cell Biol 149(3): 537-46.

Itoh, T., S. Koshiba, T. Kigawa, A. Kikuchi, S. Yokoyama and T. Takenawa (2001). "Role of the ENTH domain in phosphatidylinositol-4,5-bisphosphate binding and endocytosis." Science 291(5506): 1047-51.

Jahn, R., T. Lang and T. C. Sudhof (2003). “Membrane fusion.” Cell 112(4): 519-33.

Jahn, R. and H. Niemann (1994). "Molecular mechanisms of clostridial neurotoxins." Ann N Y Acad Sci 733: 245-55.

Jahn, R. and T. C. Sudhof (1999). "Membrane fusion and exocytosis.” $\underline{\text { Annu Rev }}$ Biochem 68: 863-911. 
Kalthoff, C., S. Groos, R. Kohl, S. Mahrhold and E. J. Ungewickell (2002). “Clint: a novel clathrin-binding ENTH-domain protein at the Golgi." Mol Biol Cell 13(11): 4060-73.

Kamada, Y., T. Funakoshi, T. Shintani, K. Nagano, M. Ohsumi and Y. Ohsumi (2000). "Tor-mediated induction of autophagy via an Apg1 protein kinase complex.” J Cell Biol 150(6): 1507-13.

Katagiri, T. and K. Shinozaki (1998). "Disruption of a gene encoding phosphatidic acid phosphatase causes abnormal phenotypes in cell growth and abnormal cytokinesis in Saccharomyces cerevisiae.” Biochem Biophys Res Commun 248(1): 87-92.

Kay, B. K., M. Yamabhai, B. Wendland and S. D. Emr (1999). "Identification of a novel domain shared by putative components of the endocytic and cytoskeletal machinery." Protein Sci 8(2): 435-8.

Kihara, A., T. Noda, N. Ishihara and Y. Ohsumi (2001). “Two distinct Vps34 phosphatidylinositol 3-kinase complexes function in autophagy and carboxypeptidase Y sorting in Saccharomyces cerevisiae." J Cell Biol 152(3): 519-30.

Kim, J., S. V. Scott, M. N. Oda and D. J. Klionsky (1997). “Transport of a large oligomeric protein by the cytoplasm to vacuole protein targeting pathway." J Cell Biol 137(3): 609-18.

Kirchhausen, T. (1999). “Adaptors for clathrin-mediated traffic.” Annu Rev Cell Dev Biol 15: 705-32.

Klionsky, D. J., R. Cueva and D. S. Yaver (1992). “Aminopeptidase I of Saccharomyces cerevisiae is localized to the vacuole independent of the secretory pathway." J Cell Biol 119(2): 287-99. 
Klionsky, D. J. and S. D. Emr (2000). “Autophagy as a regulated pathway of cellular degradation." Science 290(5497): 1717-21.

Kornfeld, S. and I. Mellman (1989). “The biogenesis of lysosomes.” Annu Rev Cell Biol 5: 483-525.

Kreykenbohm, V., D. Wenzel, W. Antonin, V. Atlachkine and G. F. von Mollard (2002). "The SNAREs vtila and vtilb have distinct localization and SNARE complex partners.” Eur J Cell Biol 81(5): 273-80.

Kucharczyk, R., S. Dupre, S. Avaro, R. Haguenauer-Tsapis, P. P. Slonimski and J. Rytka (2000). “The novel protein Cczlp required for vacuolar assembly in Saccharomyces cerevisiae functions in the same transport pathway as Ypt7p.” $\underline{J}$ Cell Sci 113 Pt 23: 4301-11.

Laage, R. and C. Ungermann (2001). "The N-terminal domain of the t-SNARE Vam3p coordinates priming and docking in yeast vacuole fusion." Mol Biol Cell 12(11): 3375-85.

Lazar, T., M. Gotte and D. Gallwitz (1997). "Vesicular transport: how many Ypt/RabGTPases make a eukaryotic cell?" Trends Biochem Sci 22(12): 468-72.

Le Borgne, R. and B. Hoflack (1998). "Protein transport from the secretory to the endocytic pathway in mammalian cells." Biochimica et Biophysica Acta 1404: 195-209.

Legendre-Guillemin, V., S. Wasiak, N. K. Hussain, A. Angers and P. S. McPherson (2004). "ENTH/ANTH proteins and clathrin-mediated membrane budding." J Cell Sci 117(1): 9-18.

Letourneur, F., E. C. Gaynor, S. Hennecke, C. Demolliere, R. Duden, S. D. Emr, H. Riezman and P. Cosson (1994). "Coatomer is essential for retrieval of dilysinetagged proteins to the endoplasmic reticulum.” Cell 79(7): 1199-207. 
Levine, B. and D. J. Klionsky (2004). "Development by self-digestion: molecular mechanisms and biological functions of autophagy." Dev Cell 6(4): 463-77.

Lewis, M. J. and H. R. B. Pelham (2002). “A New Yeast Endosomal SNARE Related to Mammalian Syntaxin 8." Traffic 3(12): 922-929.

Lin, R. C. and R. H. Scheller (1997). "Structural organization of the synaptic exocytosis core complex." Neuron 19(5): 1087-94.

Lippincott-Schwartz, J., T. H. Roberts and K. Hirschberg (2000). "Secretory protein trafficking and organelle dynamics in living cells.” Annu Rev Cell Dev Biol 16: 557-89.

Lohi, O., A. Poussu, Y. Mao, F. Quiocho and V. P. Lehto (2002). "VHS domain -- a longshoreman of vesicle lines." FEBS Lett 513(1): 19-23.

Loranger, S. S. and M. E. Linder (2002). "SNAP-25 traffics to the plasma membrane by a syntaxin-independent mechanism.” J Biol Chem 277(37): 34303-9.

Lu, J., J. Garcia, I. Dulubova, T. C. Sudhof and J. Rizo (2002). "Solution structure of the Vam7p PX domain.” Biochemistry 41(19): 5956-62.

Lupashin, V. V., I. D. Pokrovskaya, J. A. McNew and M. G. Waters (1997).

"Characterization of a novel yeast SNARE protein implicated in Golgi retrograde traffic.” Mol Biol Cell 8(12): 2659-76.

Mallard, F., B. L. Tang, T. Galli, D. Tenza, A. Saint-Pol, X. Yue, C. Antony, W. Hong, B. Goud and L. Johannes (2002). "Early/recycling endosomes-to-TGN transport involves two SNARE complexes and a Rab6 isoform.” J Cell Biol 156(4): 653-64. 
Marcusson, E. G., B. F. Horazdovsky, J. L. Cereghino, E. Gharakhanian and S. D. Emr (1994). "The sorting receptor for yeast vacuolar carboxypeptidase $Y$ is encoded by the VPS10 gene.” Cell 77(4): 579-86.

Mellman, I. (1996). “Endocytosis and molecular sorting." Annu Rev Cell Dev Biol 12: 575-625.

Miller, G. J., R. Mattera, J. S. Bonifacino and J. H. Hurley (2003). "Recognition of accessory protein motifs by the gamma-adaptin ear domain of GGA3." Nat Struct Biol 10(8): 599-606.

Mills, I. G., G. J. Praefcke, Y. Vallis, B. J. Peter, L. E. Olesen, J. L. Gallop, P. J. Butler, P. R. Evans and H. T. McMahon (2003). "EpsinR: an AP1/clathrin interacting protein involved in vesicle trafficking." J Cell Biol 160(2): 213-22.

Misura, K. M., J. B. Bock, L. C. Gonzalez, Jr., R. H. Scheller and W. I. Weis (2002). "Three-dimensional structure of the amino-terminal domain of syntaxin 6 , a SNAP-25 C homolog.” Proc Natl Acad Sci U S A 99(14): 9184-9.

Misura, K. M., R. H. Scheller and W. I. Weis (2000). "Three-dimensional structure of the neuronal-Sec1-syntaxin 1a complex." Nature 404(6776): 355-62.

Montecucco, C. and G. Schiavo (1995). "Structure and function of tetanus and botulinum neurotoxins." Q Rev Biophys 28(4): 423-72.

Morgan, J. R., K. Prasad, W. Hao, G. J. Augustine and E. M. Lafer (2000). “A Conserved Clathrin Assembly Motif Essential for Synaptic Vesicle Endocytosis.” J. Neurosci. 20(23): 8667-8676.

Mukherjee, S., R. N. Ghosh and F. R. Maxfield (1997). "Endocytosis." $\underline{\text { Physiol Rev }}$ 77(3): 759-803. 
Munson, M., X. Chen, A. E. Cocina, S. M. Schultz and F. M. Hughson (2000). "Interactions within the yeast t-SNARE Sso1p that control SNARE complex assembly." Nat Struct Biol 7(10): 894-902.

Murgui, A., M. V. Elorza and R. Sentandreu (1985). "Effect of papulacandin B and calcofluor white on the incorporation of mannoproteins in the wall of Candida albicans blastospores." Biochim Biophys Acta 841(2): 215-22.

Murray, R. Z., F. G. Wylie, T. Khromykh, D. A. Hume and J. L. Stow (2005). "Syntaxin 6 and Vtilb form a novel SNARE complex, which is up-regulated in activated macrophages to facilitate exocytosis of tumor necrosis Factor-alpha.” $\underline{J}$ Biol Chem 280(11): 10478-83.

Nice, D. C., T. K. Sato, P. E. Stromhaug, S. D. Emr and D. J. Klionsky (2002). "Cooperative binding of the cytoplasm to vacuole targeting pathway proteins, Cvt13 and Cvt20, to phosphatidylinositol 3-phosphate at the pre-autophagosomal structure is required for selective autophagy.” J Biol Chem 277(33): 30198-207.

Nichols, B. J. and H. R. Pelham (1998). "SNAREs and membrane fusion in the Golgi apparatus." Biochim Biophys Acta 1404(1-2): 9-31.

Nicholson, K. L., M. Munson, R. B. Miller, T. J. Filip, R. Fairman and F. M. Hughson (1998). "Regulation of SNARE complex assembly by an N-terminal domain of the t- SNARE Sso1p.” Nat Struct Biol 5(9): 793-802.

Noda, T., K. Suzuki and Y. Ohsumi (2002). "Yeast autophagosomes: de novo formation of a membrane structure.” Trends Cell Biol 12(5): 231-5.

Nonet, M. L., A. M. Holgado, F. Brewer, C. J. Serpe, B. A. Norbeck, J. Holleran, L. Wei, E. Hartwieg, E. M. Jorgensen and A. Alfonso (1999). "UNC-11, a Caenorhabditis elegans AP180 homologue, regulates the size and protein composition of synaptic vesicles.” Mol Biol Cell 10(7): 2343-60. 
Novick, P. and D. Botstein (1985). "Phenotypic analysis of temperature-sensitive yeast actin mutants." Cell 40(2): 405-16.

Novick, P., S. Ferro and R. Schekman (1981). "Order of events in the yeast secretory pathway." Cell 25(2): 461-9.

Orci, L., M. Stamnes, M. Ravazzola, M. Amherdt, A. Perrelet, T. H. Sollner and J. E. Rothman (1997). "Bidirectional transport by distinct populations of COPIcoated vesicles." Cell 90(2): 335-49.

Ovalle, R., S. T. Lim, B. Holder, C. K. Jue, C. W. Moore and P. N. Lipke (1998). “A spheroplast rate assay for determination of cell wall integrity in yeast." Yeast 14(13): 1159-66.

Overstreet, E., X. Chen, B. Wendland and J. A. Fischer (2003). "Either part of a Drosophila epsin protein, divided after the ENTH domain, functions in endocytosis of delta in the developing eye." Curr Biol 13(10): 854-60.

Owen, D. J. (1999). “A structrual explanation for the binding of multiple ligands by the alpha-adaptin appendage domain.” Cell 97(6): 805-15.

\section{Owen, D. J., P. Wigge, Y. Vallis, J. D. Moore, P. R. Evans and H. T. McMahon} (1998). "Crystal structure of the amphiphysin-2 SH3 domain and its role in the prevention of dynamin ring formation.” Embo J 17(18): 5273-85.

Palade, G. (1975). "Intracellular aspects of the process of protein synthesis." 189(4200): 347-58.

Paumet, F., V. Rahimian, M. Di Liberto and J. E. Rothman (2005). "Concerted autoregulation in yeast endosomal t-SNAREs." J Biol Chem. 
Paumet, F., V. Rahimian and J. E. Rothman (2004). "The specificity of SNAREdependent fusion is encoded in the SNARE motif." Proc Natl Acad Sci U S A 101(10): 3376-80.

Peden, A. A., G. Y. Park and R. H. Scheller (2001). "The Di-leucine Motif of Vesicleassociated Membrane Protein 4 Is Required for Its Localization and AP-1 Binding.” J. Biol. Chem. 276(52): 49183-49187.

Pelham, H. R. (2001). "SNAREs and the specificity of membrane fusion." Trends Cell Biol 11(3): 99-101.

Peters, C., P. D. Andrews, M. J. Stark, S. Cesaro-Tadic, A. Glatz, A. Podtelejnikov, M. Mann and A. Mayer (1999). "Control of the terminal step of intracellular membrane fusion by protein phosphatase 1." Science 285(5430): 1084-7.

Piper, R. C., N. J. Bryant and T. H. Stevens (1997). "The membrane protein alkaline phosphatase is delivered to the vacuole by a route that is distinct from the VPSdependent pathway." J Cell Biol 138(3): 531-45.

Piper, R. C., A. A. Cooper, H. Yang and T. H. Stevens (1995). "VPS27 controls vacuolar and endocytic traffic through a prevacuolar compartment in Saccharomyces cerevisiae.” J Cell Biol 131(3): 603-17.

Polo, S., S. Sigismund, M. Faretta, M. Guidi, M. R. Capua, G. Bossi, H. Chen, P. de Camili and P. P. Di Fiore (2002). "A single motif responsible for ubiquitin recognition and monoubiquitination in endocytic proteins." Nature 416: 451-55.

Pruyne, D. and A. Bretscher (2000). "Polarization of cell growth in yeast." J Cell Sci 113 ( Pt 4): 571-85.

Raclavsky, V. (1998). "Signalling towards cell wall synthesis in budding yeast." Acta Univ Palacki Olomuc Fac Med 141: 7-16. 
Ram, A. F., A. Wolters, R. Ten Hoopen and F. M. Klis (1994). "A new approach for isolating cell wall mutants in Saccharomyces cerevisiae by screening for hypersensitivity to calcofluor white." Yeast 10(8): 1019-30.

Reggiori, F., M. W. Black and H. R. Pelham (2000). "Polar transmembrane domains target proteins to the interior of the yeast vacuole." Mol Biol Cell 11(11): 3737-49.

Rice, L. M., P. Brennwald and A. T. Brunger (1997). "Formation of a yeast SNARE complex is accompanied by significant structural changes." FEBS Lett 415(1): 4955.

Rieder, S. E. and S. D. Emr (1997). “A novel RING finger protein complex essential for a late step in protein transport to the yeast vacuole.” Mol Biol Cell 8(11): 2307-27.

Riezman, H., P. G. Woodman, G. van Meer and M. Marsh (1997). "Molecular mechanisms of endocytosis." Cell 91(6): 731-8.

Robinson, J. S., D. J. Klionsky, L. M. Banta and S. D. Emr (1988). "Protein sorting in Saccharomyces cerevisiae: isolation of mutants defective in the delivery and processing of multiple vacuolar hydrolases." Mol Cell Biol 8(11): 4936-48.

Robinson, M. S. and J. S. Bonifacino (2001). “Adaptor-related proteins.” Curr Opin Cell Biol 13(4): 444-53.

Rosenthal, J. A., H. Chen, V. I. Slepnev, L. Pellegrini, A. E. Salcini, P. P. Di Fiore and P. De Camilli (1999). “The epsins define a family of proteins that interact with components of the clathrin coat and contain a new protein module.” $\mathrm{J}$ Biol Chem 274(48): 33959-65.

Rossi, G., A. Salminen, L. M. Rice, A. T. Brunger and P. Brennwald (1997). "Analysis of a yeast SNARE complex reveals remarkable similarity to the neuronal SNARE complex and a novel function for the $\mathrm{C}$ terminus of the SNAP25 homolog, Sec9.” J Biol Chem 272(26): 16610-7. 
Rothman, J. E. (1994). “Mechanisms of intracellular protein transport.” Nature 372(6501): 55-63.

Rothman, J. E. and L. Orci (1996). "Budding vesicles in living cells.” Sci Am 274(3): 70-5.

Rothman, J. E. and F. T. Wieland (1996). "Protein sorting by transport vesicles." Science 272(5259): 227-34.

Saint-Pol, A., B. Yelamos, M. Amessou, I. G. Mills, M. Dugast, D. Tenza, P. Schu, C. Antony, H. T. McMahon, C. Lamaze and L. Johannes (2004). "Clathrin adaptor epsinR is required for retrograde sorting on early endosomal membranes." Dev Cell 6(4): 525-38.

Sakamoto, C., C. Kawamoto, K. Takeuchi, I. Miyamoto and H. Shuntoh (2004). "Fission yeast epsin, Ent1p is required for endocytosis and involved in actin organization.” Kobe J Med Sci 50(1-2): 47-57.

Salem, N., V. Faundez, J. Horng and R. Kelly (1998). "A v-SNARE participates in synaptic vesicle formation mediated by the AP3 adaptor complex." Nat Neurosci. 1(7): 551-6.

Sanderfoot, A. A., F. F. Assaad and N. V. Raikhel (2000). "The Arabidopsis genome. An abundance of soluble N-ethylmaleimide- sensitive factor adaptor protein receptors." Plant Physiol 124(4): 1558-69.

Sanderfoot, A. A. and N. V. Raikhel (1999). "The Specificity of Vesicle Trafficking: Coat Proteins and SNAREs." Plant Cell 11(4): 629-642.

Santos, B., A. Duran and M. H. Valdivieso (1997). "CHS5, a gene involved in chitin synthesis and mating in Saccharomyces cerevisiae." Mol Cell Biol 17(5): 2485-96. 
Schekman, R. and L. Orci (1996). "Coat proteins and vesicle budding.” Science 271(5255): 1526-33.

Schmid, S. L. (1997). "Clathrin-coated vesicle formation and protein sorting: an integrated process.” Annu Rev Biochem 66: 511-48.

Scott, S. and D. Klionsky (1995). "In vitro reconstitution of cytoplasm to vacuole protein targeting in yeast." J. Cell Biol. 131(6): 1727-1735.

Segui-Real, B., M. Martinez and I. V. Sandoval (1995). "Yeast aminopeptidase I is post-translationally sorted from the cytosol to the vacuole by a mechanism mediated by its bipartite N-terminal extension.” Embo J 14(22): 5476-84.

Semenza, J., K. G. Hardwick, N. Dean and H. R. Pelham (1990). "ERD2, a yeast gene required for the receptor-mediated retrieval of luminal ER proteins from the secretory pathway." Cell 61(7): 1349-57.

Senetar, M., S. Foster and R. McCann (2004). "Intrasteric inhibition mediates the interactionof the I/LWEQ module proteins Talin1, Talin2, Hip1, and Hip12 with actin.” Biochemistry 43(49): 15418-28.

Shaw, J. A., P. C. Mol, B. Bowers, S. J. Silverman, M. H. Valdivieso, A. Duran and E. Cabib (1991). "The function of chitin synthases 2 and 3 in the Saccharomyces cerevisiae cell cycle." J Cell Biol 114(1): 111-23.

\section{Shih, S. C., D. J. Katzmann, J. D. Schnell, M. Sutanto, S. D. Emr and L. Hicke} (2002). "Epsins and Vps27p/Hrs contain ubiquitin-binding domains that function in receptor endocytosis." Nat Cell Biol 4(5): 389-93.

Simmen, T., S. Honing, A. Icking, R. Tikkanen and W. Hunziker (2002). "AP-4 binds basolateral signals and participates in basolateral sorting in epithelial MDCK cells.” Nat Cell Biol 4(2): 154-9. 
Simonsen, A., A. E. Wurmser, S. D. Emr and H. Stenmark (2001). "The role of phosphoinositides in membrane transport." Curr Opin Cell Biol 13(4): 485-92.

Skehel, J. J. and D. C. Wiley (1998). “Coiled coils in both intracellular vesicle and viral membrane fusion." Cell 95(7): 871-4.

Sloat, B. F., A. Adams and J. R. Pringle (1981). "Roles of the CDC24 gene product in cellular morphogenesis during the Saccharomyces cerevisiae cell cycle.” J Cell Biol 89(3): 395-405.

Söllner, T., S. W. Whiteheart, M. Brunner, H. Erdjument-Bromage, S. Geromanos, P. Tempst and J. E. Rothman (1993). "SNAP receptors implicated in vesicle targeting and fusion." Nature 362(6418): 318-24.

Springer, S. and R. Schekman (1998). "Nucleation of COPII vesicular coat complex by endoplasmic reticulum to Golgi vesicle SNAREs.” Science 281(5377): 698-700.

Stahelin, R. V., A. Burian, K. S. Bruzik, D. Murray and W. Cho (2003a). "Membrane binding mechanisms of the PX domains of NADPH oxidase p40phox and p47phox." J Biol Chem 278(16): 14469-79.

Stahelin, R. V., F. Long, K. Diraviyam, K. S. Bruzik, D. Murray and W. Cho (2002). "Phosphatidylinositol 3-phosphate induces the membrane penetration of the FYVE domains of Vps27p and Hrs.” J Biol Chem 277(29): 26379-88.

Stahelin, R. V., F. Long, B. J. Peter, D. Murray, P. De Camilli, H. T. McMahon and W. Cho (2003b). "Contrasting Membrane Interaction Mechanisms of AP180 Nterminal Homology (ANTH) and Epsin N-terminal Homology (ENTH) Domains.” J. Biol. Chem. 278(31): 28993-28999.

Stahl, B., J. H. Chou, C. Li, T. C. Sudhof and R. Jahn (1996). "Rab3 reversibly recruits rabphilin to synaptic vesicles by a mechanism analogous to raf recruitment by ras." Embo J 15(8): 1799-809. 


\section{Stepp, J. D., A. Pellicena-Palle, S. Hamilton, T. Kirchhausen and S. K. Lemmon} (1995). "A late Golgi sorting function for Saccharomyces cerevisiae Apm1p, but not for Apm2p, a second yeast clathrin AP medium chain-related protein.” Mol Biol Cell 6(1): 41-58.

Storrie, B., R. Pepperkok and T. Nilsson (2000). "Breaking the COPI monopoly on Golgi recycling." Trends Cell Biol 10(9): 385-91.

Sutton, R. B., D. Fasshauer, R. Jahn and A. T. Brunger (1998). "Crystal structure of a SNARE complex involved in synaptic exocytosis at 2.4 A resolution." Nature 395(6700): 347-53.

Sweet, D. J. and H. R. Pelham (1993). “The TIP1 gene of Saccharomyces cerevisiae encodes an $80 \mathrm{kDa}$ cytoplasmic protein that interacts with the cytoplasmic domain of Sec20p.” Embo J 12(7): 2831-40.

Terrian, D. M. and M. K. White (1997). "Phylogenetic analysis of membrane trafficking proteins: a family reunion and secondary structure predictions.” Eur J Cell Biol 73(3): 198-204.

Tochio, H., M. M. Tsui, D. K. Banfield and M. Zhang (2001). “An autoinhibitory mechanism for nonsyntaxin SNARE proteins revealed by the structure of Ykt6p." Science 293(5530): 698-702.

Traub, L. M., M. A. Downs, J. L. Westrich and D. H. Fremont (1999). "Crystal structure of the alpha appendage of AP-2 reveals a recruitment platform for clathrin-coat assembly." Proc Natl Acad Sci U S A 96(16): 8907-12.

Traub, L. M. and S. Kornfeld (1997). “The trans-Golgi network: a late secretory sorting station." Curr Opin Cell Biol 9(4): 527-33. 
Trilla, J., T. Cos, A. Duran and C. Roncero (1997). "Characterization of CHS4 (CAL2), a gene of Saccharomyces cerevisiae involved in chitin biosynthesis and allelic to SKT5 and CSD4." Yeast 13: 795-807.

Uemura, T., M. H. Sato and K. Takeyasu (2005). "The longin domain regulates subcellular targeting of VAMP7 in Arabidopsis thaliana.” FEBS Lett.

Ungermann, C., G. F. von Mollard, O. N. Jensen, N. Margolis, T. H. Stevens and W. Wickner (1999). "Three v-SNAREs and two t-SNAREs, present in a pentameric cis-SNARE complex on isolated vacuoles, are essential for homotypic fusion.” J Cell Biol 145(7): 1435-42.

Wasiak, S., A. Y. Denisov, Z. Han, P. A. Leventis, E. de Heuvel, G. L. Boulianne, B. K. Kay, K. Gehring and P. S. McPherson (2003). "Characterization of a gamma-adaptin ear-binding motif in enthoprotin." FEBS Lett 555(3): 437-42.

Wasiak, S., V. Legendre-Guillemin, R. Puertollano, F. Blondeau, M. Girard, E. de Heuvel, D. Boismenu, A. W. Bell, J. S. Bonifacino and P. S. McPherson (2002). "Enthoprotin: a novel clathrin-associated protein identified through subcellular proteomics.” J Cell Biol 158(5): 855-62.

Weimbs, T., S. H. Low, S. J. Chapin, K. E. Mostov, P. Bucher and K. Hofmann (1997). "A conserved domain is present in different families of vesicular fusion proteins: a new superfamily.” Proc Natl Acad Sci U S A 94(7): 3046-51.

Weimbs, T., K. Mostov, S. H. Low and K. Hofmann (1998). "A model for structural similarity between different SNARE complexes based on sequence relationships." Trends Cell Biol 8(7): 260-2.

Wendland, B., K. E. Steece and S. D. Emr (1999). "Yeast epsins contain an essential Nterminal ENTH domain, bind clathrin and are required for endocytosis.” Embo J 18(16): 4383-93. 
Whyte, J. R. C. and S. Munro (2002). "Vesicle tethering complexes in membrane traffic.” J Cell Sci 115(13): 2627-2637.

Yamaguchi, T., I. Dulubova, S. W. Min, X. Chen, J. Rizo and T. C. Sudhof (2002). "Sly1 binds to Golgi and ER syntaxins via a conserved N-terminal peptide motif." Dev Cell 2(3): 295-305.

Zeng, Q., T. T. Tran, H. X. Tan and W. Hong (2003). "The cytoplasmic domain of Vamp4 and Vamp5 is responsible for their correct subcellular targeting: the Nterminal extenSion of VAMP4 contains a dominant autonomous targeting signal for the trans-Golgi network." J Biol Chem 278(25): 23046-54.

Zheng, H., G. F. von Mollard, V. Kovaleva, T. H. Stevens and N. V. Raikhel (1999). "The plant vesicle-associated SNARE AtVTI1a likely mediates vesicle transport from the trans-Golgi network to the prevacuolar compartment." Mol Biol Cell 10(7): 2251-64.

Ziman, M., J. S. Chuang, M. Tsung, S. Hamamoto and R. Schekman (1998). "Chs6pdependent anterograde transport of Chs $3 p$ from the chitosome to the plasma membrane in Saccharomyces cerevisiae." Mol Biol Cell 9(6): 1565-76. 


\section{Publications}

Subbulakshmi Chidambaram, Nina Müllers, Katrin Wiederhold, Volker Haucke, and Gabriele Fischer von Mollard (2004). Specific interaction between SNAREs and epsin Nterminal homology $(\mathrm{ENTH})$ domains of epsin-related proteins in trans-Golgi network to endosome transport. J. Biol. Chem. 6;279(6):4175-9.

Meik Dilcher, Beate Veith, Subbulakshmi Chidambaram, Enno Hartmann, Hans Dieter Schmitt and Gabriele Fischer von Mollard (2003). Use1p is a yeast SNARE protein required for the traffic from the Golgi to the ER .EMBO J, 22:14, 3664-3674.

Meik Dilcher, Subbulakshmi Chidambaram, Beate Veith, Enno Hartmann, Hans Dieter Schmitt and Gabriele Fischer von Mollard (2003). Use1p is a yeast SNARE protein required for the traffic from the Golgi to the ER. Yeast, 20(S1), S34:1-19. 


\section{Acknowledgement}

I thank Prof. Dr. Dr. h. c. Kurt von Figura for being my main examiner.

I give my special thanks to PD Dr. Stefan Irniger for his critical reading of my thesis as a co-referee.

My sincere and warm thanks go to my supervisor Professor Dr. Gabriele Fischer von Mollard who kindly took me in as a part of her group and always provided me with excellent supervision and facilities to do my thesis work. I also want to thank her for training me to think and write scientifically.

I would like to thank Prof. Dr. Detlef Doenecke, the speaker of the Graduiertenkolleg 521 for arranging scientific meetings and motivating to attend the practical courses \& seminars.

I thank my 'Thesis Committee' members, Prof. Dr. Reinhard Jahn, Prof. Dr. Volker Hauke and Prof. Dr. Micheal Thumm for their constructive and helpful comments on my thesis.

My thanks to PD Dr. Peter Schu, Prof. Dr. Thomas Dierks, Prof. Dr. Stefan Höning and Dr. Jobst Landgrebe who were always helpful and provided detailed technical advice and reagents.

I greatly appreciate my colleagues Dr. Vadim Atlachkine, Dr. Meik Dilcher, Dr. Vera Kreykenbohm, Nina müllers, Beate Veith and Namitha Kanwar for their technical support and for creating a lovely and pleasant environment in the lab. I am indebted to Dr. Meik Dilcher, an affectionate and caring friend who is always empathetic and helped me in all possible ways. I extend my thanks to Dr. Constanze Riel and Dr. Anna Boulankina for their help and kind interactions in and outside of the lab.

I thank Prof. Thumm's group members and especially Dr. Ulrike Epple for fruitful discussions.

I should thank Dr. P.N. Rekha, Malaiyalam Mariappan, Karthikeyan Radhakrishnan, Premkumar Sinha and Santhoshlakshmi Kante for creating a home out of home feeling.

My warm thanks to one of my brothers Dr. T.E.V. Balaji, for his invaluable moral support. I would not fail to mention Sreedhar Kilaru, for his good friendship.

Finally, I owe my deepest and loving thanks to my fiancè Pandian Arunachalam. Without his continuous love and warm support the making of this thesis would have been much more difficult. It is my great pleasure to dedicate this thesis to him. 


\section{Curriculum Vitae}

I was born on 10th June 1978 as the first child of Chidambaram Kuthalampillai and Thangamani Chidambaram in Dharmapuri, Tamil Nadu, India. From 1983 till 1988, I had my elementary education in a Government school in Karimangalam, Dharmapuri, India. In 1988, I joined a high school in Karimangalam and successfully completed in 1993 with a secondary school-leaving certificate. In 1993, I started studying higher secondary in St.Annes Girl's Higher Secondary School, Trichy, India and successfully compeleted in 1995.

During 1995-1998, I studied Biochemistry in Annai Sandhya Women's College, Krishnagiri affiliated to Madras University, India, to obtain my Bachelor's degree.

At Madurai Kamaraj University, I specialized my Master’s degree in Integrated Biology with a dissertation entitled 'Diurnal variations in visual response from the retina of the bat Cynopterus sphinx 1791 (vahl) to white light pulses', during 1998-2000.

In 2001, I obtained a Summer Research Fellowship from Indian Academy of Sciences and joined the department of Microbiology and Cell biology in Indian Institute of Sciences, Bangalore, India and carried out a project entitled 'An unexpected absence of queuosine modification in the tRNAs of an E. coli B strain'.

In June 2002, I had started my Ph.D thesis presented here with the title 'Characterization of ENTH domain proteins and their interaction with SNAREs in S. cerevisiae' in the department of Biochemistry II, Georg-August Universität Göttingen, Germany under the guidance of Prof. Dr. Gabriele Fischer von Mollard. 